\title{
PERSPEKTIVEN FÜR WALDBEWIRTSCHAFTUNG UND NATURSCHUTZ IN AUWÄLDERN
}





\section{PERSPEKTIVEN FÜR}

WALDBEWIRTSCHAFTUNG

UND NATURSCHUTZ IN

AUWÄLDERN

Ljubljana, 2021 


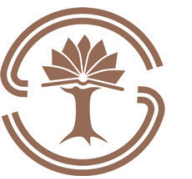

\section{Silva \\ Slovenica}

Verlag: Slovenian Forestry Institute, Silva Slovenica publishing centre, Ljubljana 2021

Titel: Perspektiven für Waldbewirtschaftung und Naturschutz in Auwäldern

Herausgeber: Markus Sallmannshofer, Silvio Schüler, Marjana Westergren

Technische Bearbeitung: Silvija Krajter Ostoić, Peter Železnik

Übersetzung und sprachliche Bearbeitung: Werner Ruhm, Viktoria Valenta, Markus Sallmannshofer, Silvio Schüler

Gestaltung und Druck: Klinger d.o.o.

1. Auflage

Preis: kostenlos

Druckauflage: 100

Elektronische Ausgabe: http://dx.doi.org/10.20315/SFS.176

Finanzierung: Resilient riparian forests as ecological corridors in the Mura-Drava-Danube Biosphere Reserve (DTP2044-2.3 - REFOCuS). The project was co-funded by European Union funds (ERDF, IPA).

Unterstützung: We would like to acknowledge the project Celebrating Biodiversity Governance (BIOGOV PGI04824) for guidance on participatory approaches used to draft this book.

Disclaimer: The contents and views presented in this handbook are the sole responsibility of the authors and not of the Interreg Danube Transnational Programme or European Commission.

\section{() (1) $\odot \odot$}

Perspectives for forest and conservation management in riparian forests is licensed under a Creative Commons Attribution 4.0 International License.

CIP - Kataložni zapis o publikaciji

Narodna in univerzitetna knjižnica, Ljubljana

$630 * 26(035)$

Perspektiven für Waldbewirtschaftung und Naturschutz in Auwäldern / [Herausgeber Marcus Sallmannshofer, Silvio Schüler, Marjana Westergren ; Übersetzung und sprachliche Bearbeitung Werner Ruhm ... et al.]. - 1. Aufl. - Ljubljana : Slovenian Forestry Institute, Silva Slovenica Publishing Centre, 2021. - (Studia Forestalia Slovenica, ISSN $0353-6025 ; 176$ )

ISBN 978-961-6993-60-9

COBISS.SI-ID 55644675 


\section{AUTOREN}

Kerstin Böck ${ }^{9}$

Gregor Božič²

Thomas L. Cech ${ }^{1}$

Debojyoti Chakraborty ${ }^{1}$

György Csóka ${ }^{7}$

Maarten de Groot ${ }^{2}$

László Demeter ${ }^{8}$

Andreas Fera ${ }^{4}$

Thomas Geburek ${ }^{1}$

Gernot Hoch $^{1}$

Thomas Kirisits ${ }^{4}$

Alen Kiš ${ }^{6}$

András Koltay ${ }^{1}$

Heino Konrad ${ }^{1}$

Marko Kovač ${ }^{2}$

Gyula Kovács ${ }^{7}$

Silvija Krajter Ostoić ${ }^{3}$

Katharina Lapin ${ }^{1}$

Aleksander Marinšek ${ }^{2}$

László $\mathrm{Nagy}^{7}$

Janine Oettel $^{1}$

Nikica Ogris ${ }^{2}$

Predrag Pap ${ }^{5}$

Werner Ruhm ${ }^{1}$

Markus Sallmannshofer ${ }^{1}$

Hannes Schönauer ${ }^{1}$

Silvio Schüler ${ }^{1}$

Katharina Schwanda ${ }^{1}$

Srdjan Stojnic ${ }^{5}$

Imola Tenorio-Baigorria ${ }^{7}$

Gregor M. Unger ${ }^{1}$

Viktoria Valenta ${ }^{1}$

Marjana Westergren ${ }^{2}$

Mirjana Zavodja ${ }^{5}$

Milica Zlatković ${ }^{5}$

\footnotetext{
${ }^{1}$ Austrian Research Centre for Forests BFW, Austria

${ }^{2}$ Slovenian Forestry Institute, Slovenia

${ }^{3}$ Croatian Forest Research Institute, Croatia

${ }^{4}$ Institute of Forest Entomology, Forest Pathology and Forest Protection, Department of Forest- and Soil Sciences, University of Natural Resources and Life Sciences, Vienna, Austria

${ }^{5}$ Institute of Lowland Forestry and Environment, University of Novi Sad, Serbia

${ }^{6}$ Institute for Nature Conservation of Vojvodina Province, Srbija

${ }^{7}$ University of Sopron, Forest Research Institute, Hungary

${ }^{8}$ Institute of Ecology and Botany, Centre for Ecological Research, Hungary

${ }^{9}$ WWF Austria, Austria
} 


\section{MITWIRKENDE}

Lajos Gyergyák ${ }^{1}$

Zoltán Puskás ${ }^{2}$

Herbert Tiefenbacher ${ }^{3}$

${ }^{1}$ Zalaerdő PLtd., Hungary

${ }^{2}$ SEFAG Forest Management and Wood Industry Share Co., Hungary

${ }^{3}$ Forest Estate Grafenegg, Austria

\section{FOTOS}

Wurden von Markus Sallmannhofer zur Verfügung gestellt, außer:

Gregor Božič (Abbildungen 3.1.1-1, 3.1.1-3 a, b, 3.1.3-2, Umschlag 3.3.2)

Thomas Cech (Abbildungen 3.3.1-3, 3.3.3-2, 3.3.3-3, 3.3.6-1, 3.3.6-2)

Jim Connel (Abbildung3.3.3-1)

György Csóka (Abbildung 3.3.1-1)

László Demeter (Abbildung 3.2.5-2

Andreja Ferreira (Abbildung 2.2-1)

Zoran Galić, (Abbildung 1.3-1)

Gernot Hoch (Abbildung 3.3.1-1)

Dušan Jurc (Abbildung 3.3.2-3)

András Koltay (Abbildungen 3.3.2-1, 3.3.2-5, 3.3.2-7)

Aleksander Marinšek (Abbildungen 3.1.1-2, 3.1.1-3 c)

Predrag Pap (Abbildung 3.3.2-4)

Janine Oettel (Abbildungen 3.2.7-1, 3.2.7-2)

Leopold Poljaković-Pajnik (Umschlag 2.5, Abbildung 3.3.1-2)

Werner Ruhm (Abbildungen 3.2.2-3, 3.2.6-2)

Gerald Schnabel (Abbildungen 2.3-1, 2.3-2, 3.1.5-1, 3.1.5-2, 3.2.2.-4)

Katharina Schwanda (Abbildungen 3.2.5-7, 3.3.4-1, 3.3.4-2)

Thomas Thalmayr (Abbildung 3.3.5-1)

Gregor M. Unger (Abbildung 3.3.5-2, 3.3.5-3)

Viktoria Valenta (Infographik Kapitel 4)

Mirjana Zavodja (Abbildung 1.3-2)

Milica Zlatković (Abbildungen 3.3.2-2, 3.3.2-6, 3.3.2-7) 


\section{INHALTSVERZEICHNIS}

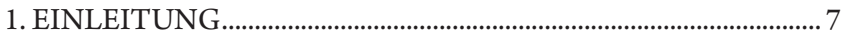

1.1 Ziel des Handbuchs ....................................................................... 7

1.2 Über das Projekt und den Biosphärenpark Mur-Drau-Donau .7

1.3 Fallstudie: Sicht von Interessensgruppen auf die

Bewirtschaftung und den Schutz von Auwäldern im

Biosphärenreservat Mur-Drau-Donau.................................................. 10

2. AUWÄLDER .......................................................................................... 17

2.1 Relevanz und Gefährdung von Auwäldern ................................17

2.2 Bewirtschaftung von Auwaldökosystemen...................................22

2.3 Struktur und Ökologie der Flussauenlandschaft........................26

2.4 Waldhabitattypen ............................................................................... 31

2.5 Gängige Waldbewirtschaftungsformen in Auwäldern ...............36

3. MANAGEMENTLEITLINIEN FÜR AUWÄLDER ........................39

3.1 Waldverjüngung und Genetik ..........................................................39

3.1.1 Entscheidung Für Natur- Oder Kunstverjüngung? .........39

3.1.2 Geeignetes forstliches Vermehrungsgut zur

Anpassung der Wälder an den Klimawandel................................49

3.1.3 Generhaltung in der Praxis .................................................55

3.1.4 Naturverjüngung und Saat von Stieleichenbeständen ...60

3.1.5 Künstliche Verjüngung der Stieleiche als Maßnahme zum Aufbau von Eichenwäldern, als Ergänzungspflanzung und zur Wiederherstellung von Auwaldökosystemen...............66

3.2. Wald- und Naturschutzmanagement ............................................ 71

3.2.1 Ziele des Biodiversitäts- und

Naturschutzmanagements ..................................................................71

3.2.2 Potentiale in der Laubwertholzproduktion ........................79

3.2.3 Herausforderungen im Klimawandel................................... 85

3.2.4 Wildeinfluss und Wildtiermanagement ..............................89

3.2.5 Management von nichtheimischen Pflanzen .....................96

3.2.6 Pappelwirtschaft und Diversität -

kein zwangsläufiger Widerspruch..................................................105

3.2.7 Integration von Totholz in die reguläre

Waldbewirtschaftung ....................................................................110

3.3 Gesundheit der Wälder....................................................................115

3.3.1 Forstschädlinge und Krankheiten in einer sich verändernden Welt: Die Bedeutung der Früherkennung......115

3.3.2 Krankheiten der Pappel und Pappelhybriden unter besonderer Berücksichtigung von Management- 
Empfehlungen

3.3.3 Eichensterben - Beispiel für ein Krankheitsphänomen ....... durch verschiedene interagierende kausale Faktoren

3.3.4 Eschen-Triebsterben - eine schwerwiegende

Bedrohung der Biodiversität in Auwäldern

3.3.5 "Esche in Not": Das österreichische Züchtungs-

und Erhaltungsprogramm für Fraxinus excelsior.

3.3.6 Maßnahmen gegen die Ausbreitung von

Phytophthora in Fluss begleitenden Wäldern

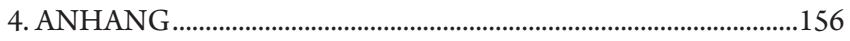

4.1 Baumartenvorkommen und Samentransfer ..............................156

4.1.1 Baumartenverbreitungsmodelle im Klimawandel..........156

4.1.2 Samentransferzonen ...........................................................156

4.2 Baumarten-Portraits ..................................................................... 158

4.2.2 Alternative Baumarten und Klone....................................168

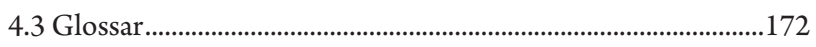

4.4 Referenzen pro Kapitel ................................................................174 


\section{EINLEITUNG}

Markus Sallmannshofer, Silvio Schüler, Marjana Westergren

\subsection{Ziel des Handbuchs}

Ziel des vorliegenden Handbuches ist es, gute Bewirtschaftungsverfahren für Auwälder darzustellen, um die vielfältigen Leistungen und Waldfunktionen dieser einzigartigen Ökosysteme zu erhalten, zu verbessern und ggf. wiederherzustellen. Die Empfehlungen dieses Handbuchs richten sich vorrangig an Praktiker aus der Forstwirtschaft und dem Naturschutz, darüber hinaus aber auch an Forstbaumschulen, Jagdausübende, regionale Initiativen, NGOs und auch Entscheidungsträger aus der Politik sowie an alle daran interessierten Personen.

Für die Ausarbeitung des Handbuchs wurden wichtige forst- und naturschutzfachliche Probleme in Auwäldern des grenzüberschreitenden Biosphärenparks Mur-Drau-Donau auf Basis von umfangreichen Erhebungen im Gelände erfasst, und in einem partizipativen Prozess von Experten aus der Forstwissenschaft, dem Naturschutz und der Forstwirtschaft bewertet. Darüber hinaus wurden Maßnahmen zum Umgang mit diesen Problemen vorgeschlagen und als Ausgangspunkt für das vorliegende Handbuch mit Stakeholdern aus dem Donauraum in einem Workshop diskutiert. In mehreren Begutachtungsrunden wurde Feedback eingeholt.

Das Handbuch ist in sechs Sprachen verfügbar und auch wenn die Ergebnisse und Bewirtschaftungsverfahren sich an den Herausforderungen im Biosphärenpark Mur-Drau-Donau orientieren, besitzen sie eine Gültigkeit für alle Auwälder in Mittel- und Südosteuropa und darüber hinaus.

\section{2 Über das Projekt und den Biosphärenpark Mur-Drau- Donau}

Das Projekt REFOCuS wurde im Rahmen des Interreg Danube Transnational Programmes unter der Priorität "Environment and culture responsible Danube region” gefördert. Das Programm beinhaltet u.a. Maßnahmen zur Wiederherstellung und zur Bewirtschaftung ökologischer Korridore. Ziel des Projektes REFOCuS ist die Stärkung der Resilienz von Auwäldern in dem neu etablierten länderübergreifenden Biosphärenpark Mur-Drau-Donau. Das Projektteam besteht aus fünf direkten Projektpartnern und sechs assoziierten Partnern aus Kroatien, Österreich, Serbien, Slowenien und Ungarn. Die Projektpartnerinstitutionen sind forstliche Forschungsinstitute und repräsentieren teilweise auch die nationalen Behörden. Die assoziierten Partner umfassen:

- Amt der Steiermärkischen Landesregierung, Baubezirksleitung Südoststeiermark, Österreich https://www.verwaltung.steiermark.at/cms/ziel/74835791/DE/ 
- Slovenian State Forests d.o.o., OE Murska Sobota, Slowenien www.sidg.si

- Ministry of Agriculture, Forestry and Food, Slovenia www.mkgp.gov.si

- Public Institution for Management of Protected Natural Areas in the Koprivnica Križevci County, Kroatien www.zastita-prirode-kckzz.hr

- Mecsek Forestry Co. Ltd., Ungarn www.mecsekerdo.hu

- Republic of Serbia, Ministry of Agriculture and Environmental Protection, Directorate of Forests, Serbien

http://www.minpoli.gov.rs 


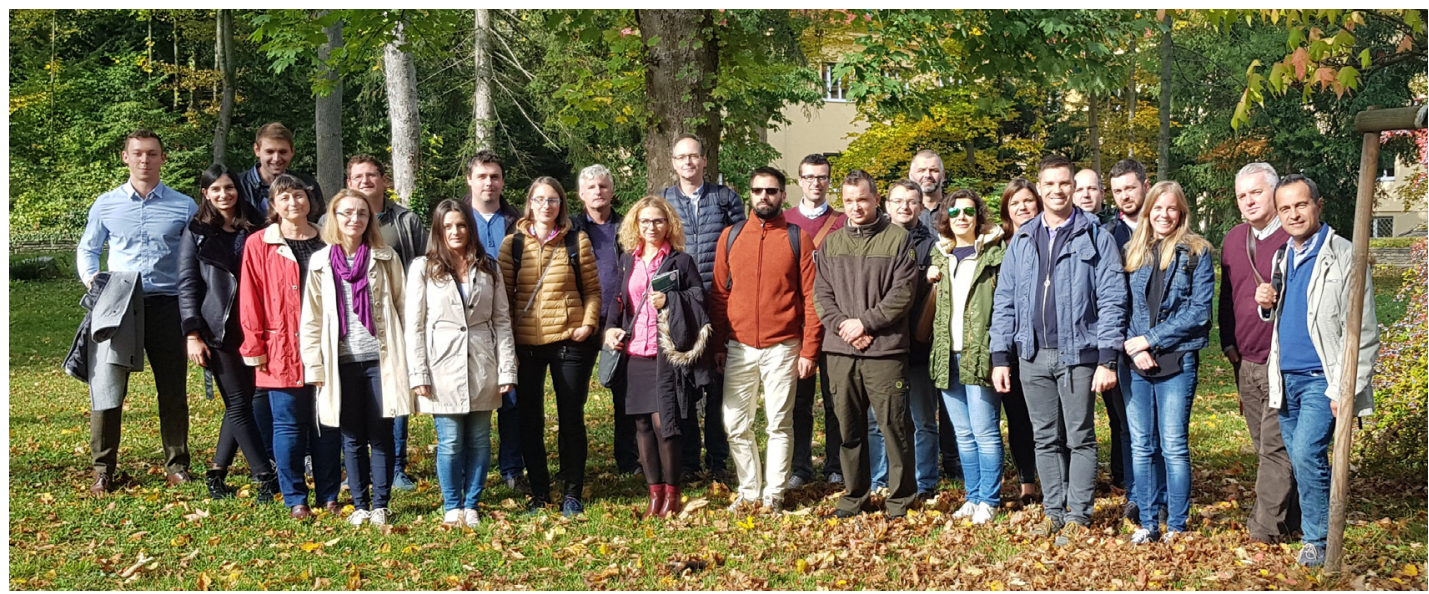

Abb. 1.2-1: Die Mehrheit der Autoren des vorliegenden Buches sind Mitarbeiter des REFOCuS Projektteams.

Der grenzüberschreitende Biosphärenpark Mur-Drau-Donau (Transboundary Biosphere Reserve, TBR MDD) umfasst eine Fläche von rund $8300 \mathrm{~km}^{2}$ in den Ländern Kroatien, Österreich, Serbien, Slowenien und Ungarn und besteht aus vier aneinander grenzenden Biosphärenparks (Abb 1.2-1). Neue Teile des TBR MDD sind erst kürzlich nominiert worden und sollen, nach ihrer Anerkennung durch die UNESCO (vorraussichtlich im Jahr 2021) als ein einziger grenzüberschreitender Biosphärenpark das größte Flussschutzgebiet Europas bilden. Die gesamte Kernzone, ein zusammenhängender Auwaldgürtel entlang der drei Flüsse, stellt einen wichtigen ökologischen Korridor dar, ist als Natura2000 Schutzgebiet ausgewiesen und beinhaltet weitere Schutzgebiete verschiedener Kategorien. Etwa 27\% (2 $\left.250 \mathrm{~km}^{2}\right)$ des TBR MDD sind bewaldet. Innerhalb der Kernzone steigt dieser Anteil auf $61 \%$ an.

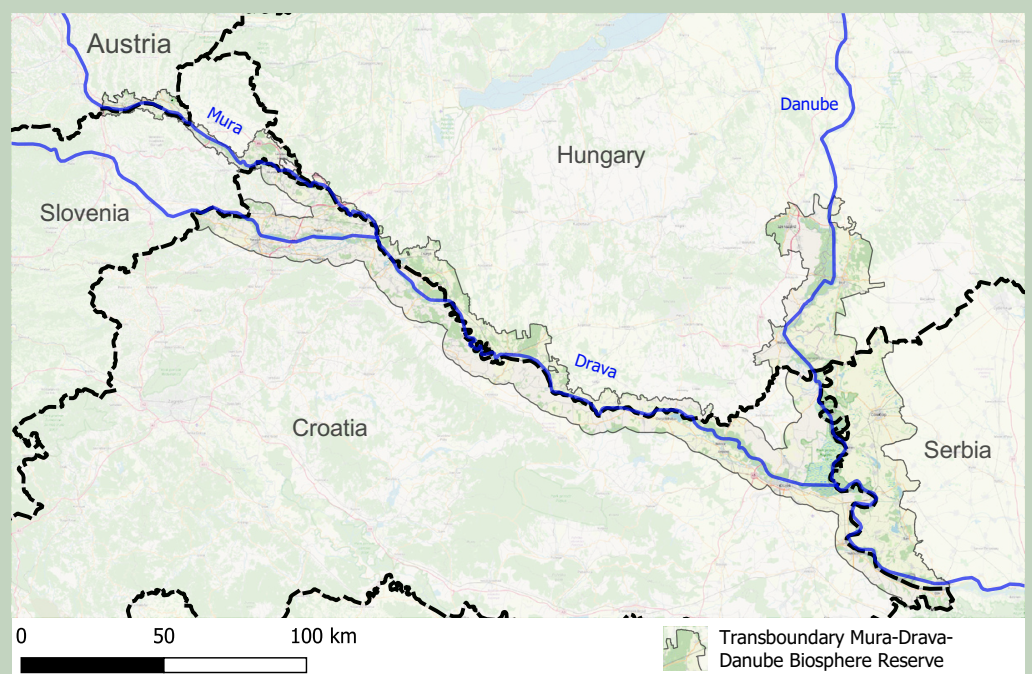

Abb. 1.2-2: Karte des grenzüberschreitenden Biosphärenparks Mur-Drau-Donau. 


\subsection{Fallstudie: Sicht von Interessensgruppen auf die Bewirtschaftung und den Schutz von Auwäldern im Biosphärenreservat Mur-Drau-Donau}

Srdjan Stojnić, Silvija Krajter Ostoić, Mirjana Zavodja

Verstärkter Natur- und Umweltschutz, Änderungen in der Landnutzung und die ländliche Entwicklung berühren vielfältige Interessen von Einwohnern, Touristen, Behörden, Naturschützern sowie den regionalen Landnutzern. Aus diesem Grund hat das Projekt REFOCuS von Beginn an danach gestrebt, verschiedene Interessensgruppen über das Projekt zu informieren und deren Meinung bei der Entwicklung zu berücksichtigen, um so letzlich einen Austausch zwischen Wissenschaft und Praxis in verschiedenen Workshops sicherzustellen. Die Ergebnisse dieser Stakeholder-Workshops werden im vorliegenden Kapitel zusammengefasst. An beiden Workshops waren Teilnehmer aus dem gesamten grenzüberschreitenden Biosphärenreservat Mur-Drau-Donau (TBR MDD) beteiligt und umfassten die Gruppen Naturschützer*innen, Waldbewirtschafter*innen, (Waldbesitzer*innen), Forstwissenschaftler*innen, Anwohner*innen und Landwirt*innen, im Folgenden einfach als Interessengruppen bezeichnet.

\section{Waldbezogene Politik}

Die UNESCO-Biosphärenreservate, einschließlich des TBR MDD, sollen sich als Modelle für Nachhaltigkeit entwickeln, die Landnutzung und Naturschutz integrieren. Aufgabe der nationalen Verwaltungsorganisationen der Biosphärenreservate ist es, entsprechende nationale Managementpläne zu entwickeln, um dieses Ziel voranzutreiben. Bestehende waldbezogene Politikfelder bieten einen Rahmen für Aktivitäten zum Schutz und der Bewirtschaftung von Auwäldern. Das Mosaik der verschiedenen und oft schwierigen Richtlinien führt in der Regel zu Verwirrung bei der Interpretation und Umsetzung. Daher kann es zu Konflikten zwischen den beteiligten Interessensgruppen kommen. Nichtsdestotrotz werden die Wälder in ihrer Bedeutung von allen beteiligten Akteuren anerkannt (Tab. 1.3-1).

Tab. 1.3-1: Gemeinsame Merkmale des grenzüberschreitenden Biosphärenreservats Mur-DrauDonau (TBR MDD), betrachtet durch das Prisma von Richtlinien, Rechtsakten und Verordnungen

\begin{tabular}{|c|c|c|c|}
\hline Land & $\begin{array}{c}\text { Fehlen einer } \\
\text { spezifischen } \\
\text { Regelung in } \\
\text { Bezug auf } \\
\text { (Wälder des) } \\
\text { TBR MDD }\end{array}$ & $\begin{array}{c}\text { Geringe Rolle } \\
\text { des TBR MDD } \\
\text { (Wälder) }\end{array}$ & $\begin{array}{c}\text { TBRMIDD Wälder/ } \\
\text { Reservatalsseltor- } \\
\text { übergrefender } \\
\text { Schwerpunkt }\end{array}$ \\
\hline Österreich & ++ & ++ & ++ \\
\hline Kroatien & ++ & ++ & ++ \\
\hline Ungarn & ++ & + & ++ \\
\hline Slowenien & ++ & ++ & ++ \\
\hline Serbien & ++ & + & ++ \\
\hline
\end{tabular}

Legende: $(++)$ trifft $\mathrm{zu},(+)$ trifft teilweise zu 


\section{Widersprüchliche Interessen verschiedener Gruppen}

Bei der Diskussion über die vorrangigen Ziele der Waldbewirtschaftung haben die Interessenvertreter der verschiedenen Sektoren unterschiedliche Einstellungen. Zum Beispiel wurde für den Forstsektor die Holzproduktion (Marktorientierung) als vorrangiges Ziel wahrgenommen, was oft mit der Priorität der Naturschutzsektoren kollidiert. Dies gilt insbesondere in dicht besiedelten Agrarlandschaften, die an Gebiete mit hoher Biodiversität angrenzen, wie z. B. Auwälder im Biosphärenreservat Mur-Drau-Donau. Wir werden diesen Konflikt am Beispiel von Koviljsko-Petrovaradinski Rit, das in der Provinz Vojvodina in Serbien liegt, illustrieren (Abb. 1.3-1).

Die Waldnutzer in dem Gebiet wurden eingeteilt in die folgenden Gruppen: Waldbesitzer (Staat/Provinz und privat), Forstangestellte, Unternehmen/Institutionen, und Bürger.

Die Analyse der Interessen der unterschiedlichen Waldnutzer verdeutlicht zwei Konfliktfelder (Abb. 1.3-2). Die erste Konfliktfeld liegt zwischen den sehr starken Interessen an der Waldnutzung, ausgedrückt durch Waldbesitzer und Forstwirtschaftsbetriebe, deren Hauptziel die profitable Holzernte ist, und den sehr starken Nutzerinteressen am Naturschutz, vertreten durch Unternehmen/Institutionen und Bürgern. Das zweite Konfliktfeld zeigt einen internen Konflikt des öffentlichen Unternehmens Vojvodinašume, welches als staatliches Forstwirtschaftsunternehmen für die Bewirtschaftung der Wälder in der Provinz Vojvodina zuständig ist und einerseits ein sehr starkes Interesse an profitabler Holzproduktion und andererseits am Naturschutz hat.

Um diese gegensätzlichen Interessen im Rahmen der gesetzlichen Vorgaben in Einklang zu bringen, hat das Unternehmen den Vorteil intern nach einer Lösung suchen zu können. Die derzeitigen Anteile der Schutzzonen (strenger Schutz 6\%, aktiver Schutz 29\% und rentable Holznutzung 65\%) spiegeln den aktuellen Kompromiss zwischen dem Eigentümer und den Interessen der übrigen Nutzer wider. Diese Lösung wird so lange Bestand haben, wie die Provinz in der Lage ist, sie mit den verfügbaren politischen Mitteln zu “verteidigen”. Mögliche Änderungen könnten Konflikte auslösen, z. B. mit der Holzindustrie, wenn der Anteil der strengen und aktiven Schutzzonen erhöht würde oder mit dem Naturschutz, wenn der Holzeinschlag intensiviert würde (Abb. 1.3-2).

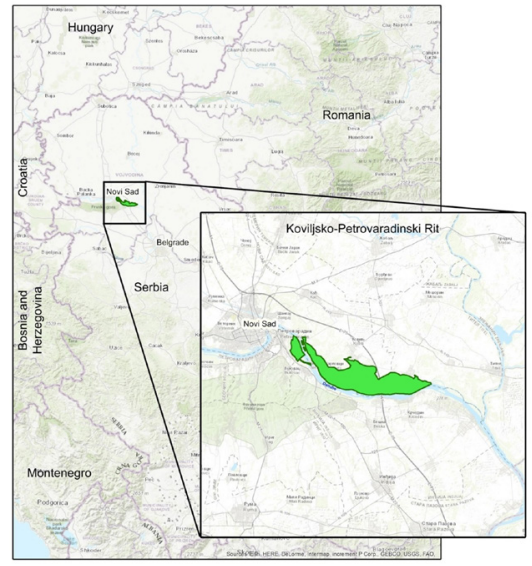

Abb. 1.3-1: Naturschutzgebiet Koviljsko-Petrovaradinski Rit in Serbien (Zoran Galić, ILFE). 


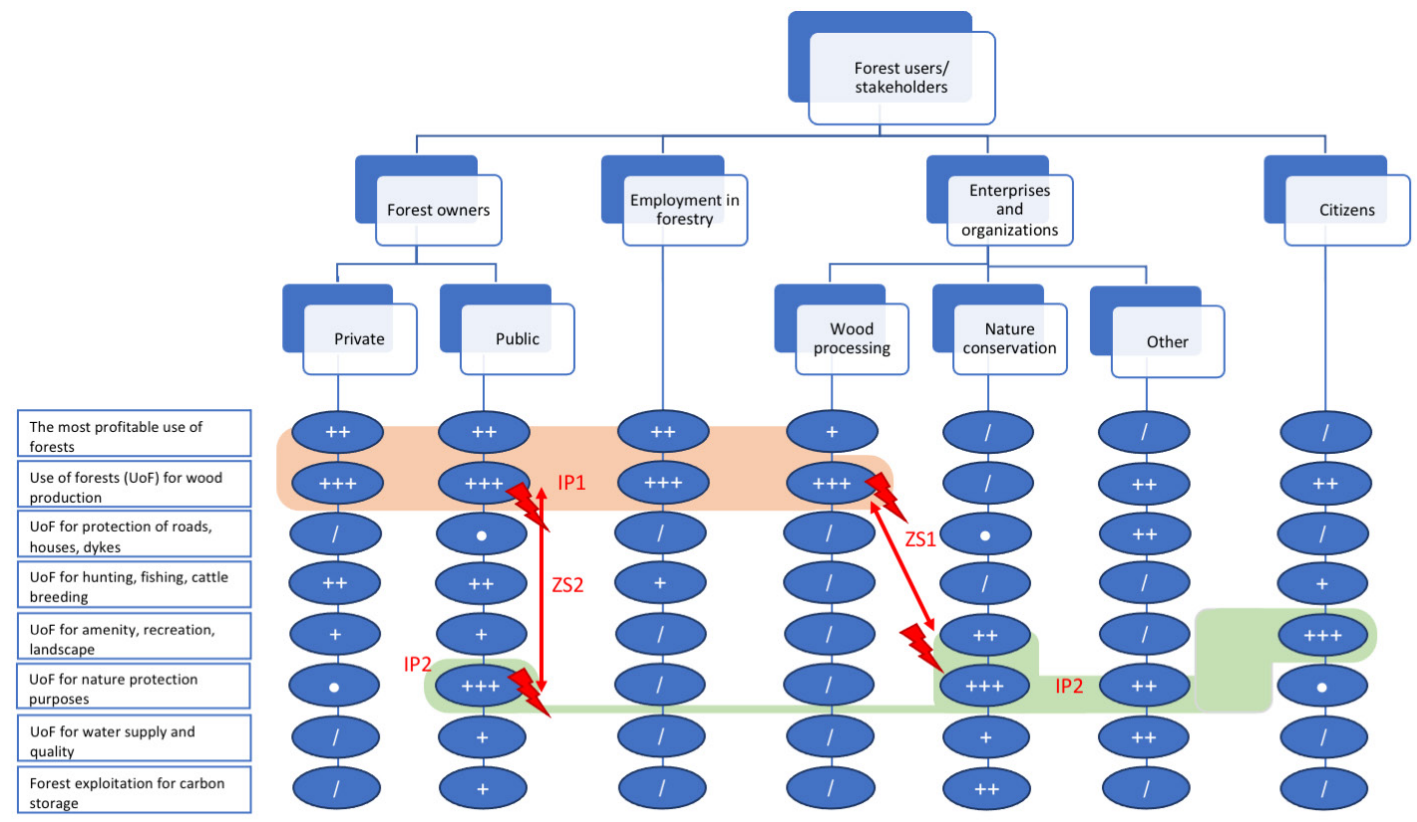

Legende: horizontal - Waldnutzer, vertikal - Nutzerinteressen, an deren Schnittpunkt (runde Felder) zeigt sich die geschätzte Intensität der Nutzerinteressen: sehr stark (+++), stark (++), mäßig (+), vorhanden (), nicht vorhanden (/); ZS - Konfliktzone (Zona Sukoba); IP - Interessenfeld (Interesno Polje)3

Abb. 1.3-2: Schematische Synthese der Waldnutzer, deren Nutzerinteressen, sowie Konfliktfeldern, dargestellt am Beispiel des Naturparks "KoviljskoPetrovaradinski Rit".

Der analytische Ansatz, wie er im Beispiel dargestellt ist, bietet eine gute Grundlage für eine aktivere Kommunikation zwischen Forstwirtschaft und Naturschutz, um einen Ausgleich zwischen den widerstreitenden Interessen und Zielen zu finden.

Einblicke der Interessensgruppen in die wichtigsten Probleme bei der Bewirtschaftung und Erhaltung von Auwäldern und Empfehlungen zur Lösung dieser Probleme

Die Stakeholder-Workshops lieferten wichtige Erkenntnisse zu den fünf "heißen Themen" des TBR MDD: Rückgang des Grundwassers, Schädlinge und Krankheiten, natürliche Verjüngung, Planung der Waldbewirtschaftung und Verfügbarkeit von forstlichem Vermehrungsgut (Abb. 1.3-2):

- $\quad$ Der Rückgang des Grundwassers ist in den Projektpartnerländern ein weit verbreitetes Problem, insbesondere für die Stieleiche. Das Absterben von Eichen im gesamten TBR MDD ist nicht nur in Altbeständen, sondern auch an Verjüngungsstandorten weit verbreitet und führt zu Misserfolgen bei der Wiederaufforstung. Darüber hinaus wird der Klimawandel als zusätzliches Problem identifiziert, da prognostiziert wird, dass er Stieleichen- 
ökosysteme und die nachhaltige Holzproduktion negativ beeinflussen wird.

- In Bezug auf Schädlinge und Krankheiten wurden neben den allgemein bekannten Problemen im TBR MDD, wie Eschensterben, Phytophthora sp., Windwurf und Windbruch, vom serbischen Vertreter das Problem der Eichennetzwanze (Corythucha arcuata) sowie das Auftreten einer komplexen Krankheit in Hybridpappelplantagen (d.h. die bakterielle Krebserkrankung, verursacht durch Lonsdalea populi) hervorgehoben.

- Die Verfügbarkeit von heimischem forstlichem Vermehrungsgut (FRM) stellt im Allgemeinen keinen begrenzenden Faktor für die Wiederaufforstung dar. In Slowenien zum Beispiel decken drei Baumschulen den Bedarf an FRM in der gesamten Region des TBR MDD. Die meisten Länder betonten jedoch, dass unregelmäßige Mastjahre der Stieleiche manchmal ein Problem darstellen können. Darüber hinaus betonten die Interessensvertreter aus Österreich, dass es wichtig ist, neue Handelsbeziehungen mit südosteuropäischen Ländern aufzubauen, da das aus Westeuropa importierte Saatgut anscheinend nicht gut an die erwarteten zukünftigen Bedingungen angepasst ist. In diesem Sinne schlugen Vertreter aus Slowenien vor, dass sich Baumschulproduzenten stärker am internationalen Handel orientieren sollten, um den Markt über die Grenzen des eigenen Landes hinaus zu erweitern, zum Beispiel durch die Etablierung eines regionalen Marktes.

- Hinsichtlich des FRM von nichtheimischen Baumarten werden Juglans nigra und Hybridpappeln als potenziell geeignet für Aufforstungen im TBR MDD angesehen, obwohl ihre Verwendung in einigen Ländern eingeschränkt ist. Es wurden Widersprüche in der Behandlung von nichtheimischen Baumarten zwischen verschiedenen Ländern beobachtet. In Serbien und Ungarn beispielsweise produzieren Baumschulen jährlich große Mengen an Hybridpappelstecklingen für die Anlage von Plantagen, während in Slowenien keine neuen Plantagen angelegt werden, außer zu Versuchszwecken.

- Alle Länder haben Waldbewirtschaftungspläne, die in unterschiedlichem Maße den Waldschutz, die Erhaltung und Bewirtschaftung der Wasserressourcen und andere Ziele berücksichtigen. Interessenvertreter aus Slowenien sind z. B. der Meinung, dass Pappel- und Weidenplantagen auf aufgelassenen Flächen angelegt werden sollten, anstatt sie von Privateigentümern auf kleinen Flächen anlegen zu lassen, da diese zu größeren Problemen führen könnten, wie z. B. der Hybridisierung mit autochthonen Baumarten. Ein Hauptmerkmal in Österreich ist nach Ansicht der Interessensvertreter die große Anzahl kleiner Waldgrundstücke und damit eine sehr unterschiedliche Bewirtschaftung, die häufig nur auf die Brennholzproduktion ausgerichtet ist. Vertreter aus Serbien, sowohl aus dem Bereich des Naturschutzes als auch 
der Waldbewirtschaftung, wiesen auf die Nichtexistenz einer Strategie zur klimafitten Waldbewirtschaftung hin, da die Holzproduktion für kommerzielle Zwecke im TBR MDD immer noch dominiert. Sie erklärten, dass der größte Teil der Wälder immer noch als Altersklassenwald bewirtschaftet wird und eine geringe Widerstandsfähigkeit gegenüber Störungen aufweist. Daher sollte die zukünftige Managementplanung in der Forstwirtschaft alle Aspekte der Forstwissenschaft berücksichtigen. Die Vertreter des Naturschutzsektors betonten, dass gesetzliche Änderungen erforderlich sind, um die negativen Auswirkungen des Klimawandels auf die Waldökosysteme zu mindern.

- Naturverjüngung im Allgemeinen gilt aufgrund der dichten Bodenvegetation als äußerst schwierig zu erreichen und erfordert daher aktive Bewirtschaftungsmaßnahmen. Die Bodenvegetation gilt als einer der einschränkendsten Faktoren für eine erfolgreiche Verjüngung. In Fällen, in denen die Bodenvegetation nicht $\mathrm{zu}$ dicht ist, werden Managementeingriffe vorgeschlagen, um die natürliche Verjüngung zu unterstützen.

- $\quad$ Es besteht die große Sorge, dass heimische Baumarten nicht mit den raschen klimatischen Veränderungen zurechtkommen. Es wurden mehrere Baumarten vorgeschlagen, die potenziell für die Wiederaufforstung gefördert werden könnten, darunter Traubeneiche und die nichtheimischen Baumarten Schwarznuss und Robinie, obwohl es Bedenken wegen der potenziellen Invasivität der letztgenannten gibt. Darüber hinaus sollten Risikovermeidungsstrategien im Hinblick auf die klimatischen Veränderungen und die damit verbundenen Änderungen der natürlichen Bedingungen und Risiken, die in den letzten Jahrzehnten deutlich zugenommen haben, in Betracht gezogen werden.

- Der Mangel an natürlicher Verjüngung wurde in Ungarn und Serbien als sehr stark empfunden, obwohl dokumentiert wurde, dass sich bestimmte Arten sogar auf marginalen Flächen erfolgreich spontan verjüngen (z. B. Stieleiche auf sandigen Dünen oder salzigen Böden). Daher sollten trotz der Probleme mit der Naturverjüngung die Möglichkeit der Naturverjüngung nicht vernachlässigt werden. Große Flächen mit extensiven Anpflanzungen von Hybridpappeln und Weiden in den genannten Ländern sowie der Druck des Wildes wurden als weiteres Hindernis für die Naturverjüngung im TBR MDD erkannt. 
Tab. 1.3-2: Hauptprobleme im Hinblick auf die Bewirtschaftung und den Schutz von Auwäldern im Biosphärenreservat Mur-Drau-Donau (TBR MDD), die während des Workshops in Novi Sad (April 2019) ermittelt und von den Ländervertretern während des Online-Workshops am 15. Oktober 2020 spezifiziert wurden.

\begin{tabular}{|c|c|c|c|c|c|c|}
\hline \multirow[b]{2}{*}{ Land } & \multirow{2}{*}{$\begin{array}{l}\text { Rückgang des } \\
\text { Grundwassers }\end{array}$} & \multirow[b]{2}{*}{$\begin{array}{l}\text { Schädlinge \& } \\
\text { Krankheiten }\end{array}$} & \multirow[b]{2}{*}{$\begin{array}{l}\text { Naturveriüngungsprobleme } \\
\text { (ind. Wildeinfluss) }\end{array}$} & \multirow[b]{2}{*}{$\begin{array}{l}\text { Planung derWald- } \\
\text { bewirtschaftung }\end{array}$} & \multicolumn{2}{|c|}{$\begin{array}{l}\text { Verfügbarkeit von forstlichem } \\
\text { Vermehrungsgut }\end{array}$} \\
\hline & & & & & heimisch & Nichtheimisch \\
\hline Kroatien & + & ++ & + & - & ++ & - \\
\hline Ungarn & ++ & ++ & ++ & - & + & - \\
\hline Slowenien & ++ & ++ & ++ & - & ++ & + \\
\hline Serbien & ++ & ++ & ++ & + & + & - \\
\hline
\end{tabular}

Legende: $(++)$ trifft $\mathrm{zu},(+)$ trifft teilweise $\mathrm{zu},(-)$ trifft nicht $\mathrm{zu}$ 


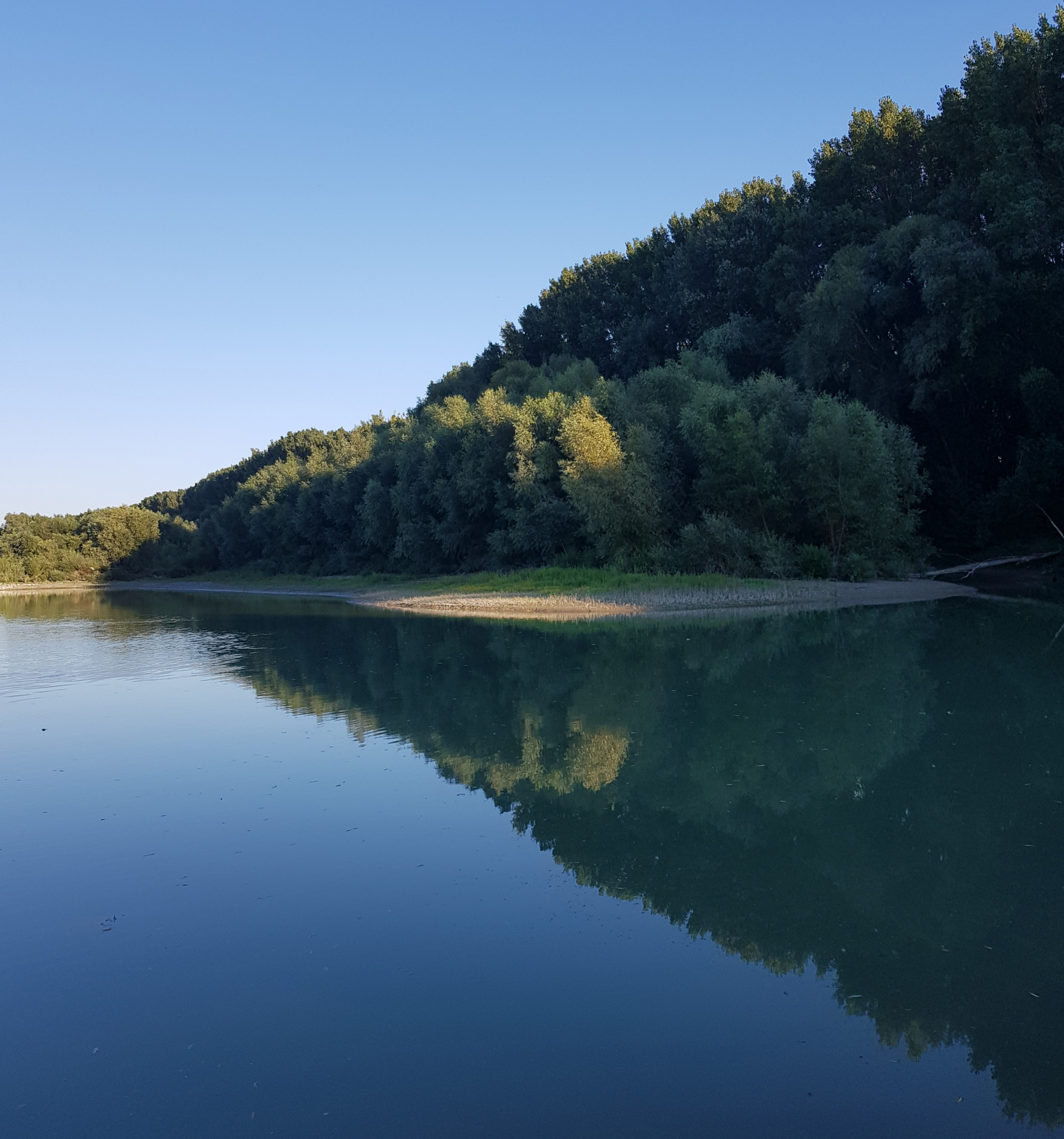




\section{AUWÄLDER}

Marko Kovač, Markus Sallmannshofer

\subsection{Relevanz und Gefährdung von Auwäldern}

Markus Sallmannshofer

Auwalder erfüllen wichtige Ökosystemleistungen. Sie dienen als natürliche Pufferräume entlang der Flüsse, schützen vor Überflutungen und tragen zum physikalischen, chemischen und biologischen Schutz des Bodens bei. Auwälder sind gekennzeichnet durch eine hohe Produktivität und ein hohes Level an Biodiversität. Daher spielen sie eine wichtige Rolle beim Erhalt der Artenvielfalt. Auch ihr Erhohlungs- und ästhetischer Wert wurde über die letzten Jahrzehnte zunehmend erkannt. Dennoch sind Auwälder durch historisches und gegenwärtiges, oft nicht-nachhaltiges Management, großräumige Umweltveränderungen sowie als Folge der Globalisierung unter Druck. Gleichzeitig steigt der Bedarf an gesunden Auwäldern, denn es wird erwartet, dass die Risiken durch den Klimawandel wie Stürme und Hochwässer in $\mathrm{Zu}$ kunft häufiger auftreten und dabei Auwälder als Überschwemmungsräume gefordert sind. Darüber hinaus können solche hochproduktiven Wälder durch Kohlenstoffspeicherung essentiell zur Abmilderung des Klimawandels beitragen können.

\section{Historische Veränderungen der Auwälder}

Die Besiedlung und Nutzung der flussnahen Gebiete entlang der zentraleuropäischen Flüsse reicht weit zurück. Die ersten bedeutenderen Eingriffe in die Auwälder erfolgten ab dem 7. Jahrhundert n. Chr., als die fortschreitende Besiedelung die Rodung und das kontrollierte $\mathrm{Ab}$ brennen großer Waldflächen zur Folge hatte, um genügend Ackerland für Nahrung und Weideflächen zu sichern. Bis zum 17. Jahrhundert wurden die flussnahen Wälder nur mäßig für Hausbau, Brennholz und Jagd genutzt. Die nächste Welle von Veränderungen, die um die Wende vom 17. zum 18. Jahrhundert einsetzte, führte zu umfangreichen Entwässerungen und Gewässerregulierungen in den Flussauenlandschaften. Diese Aktivitäten führten zu umgeleiteten Flüssen, eingetieften Gewässersohlen, veränderten Überflutungsregimen und Grundwasserspiegeln (die teils um mehrere Meter gesunken sind) und beeinträchtigten so die ökologischen Bedingungen der Auwälder erheblich, sie brachten diese Wälder teilweise nahe an ihren Untergang. Parallel zu den extensiven Landnutzungsaktivitäten erforderte die Waldbewirtschaftung zunehmende Baumaßnahmen zur Erschließung (z. B. Forststraßen und Schienen, Kanalisierung von Bachläufen, Überbrückung von Wasserläufen) und und brachte großflächige Kahlschläge in diese bis dahin nur mäßig genutzten Wälder (Abb. 2.1-1). In der zeitlichen Abfolge von Waldbewirtschaftungsmaßnahmen kam ab der Mitte des 


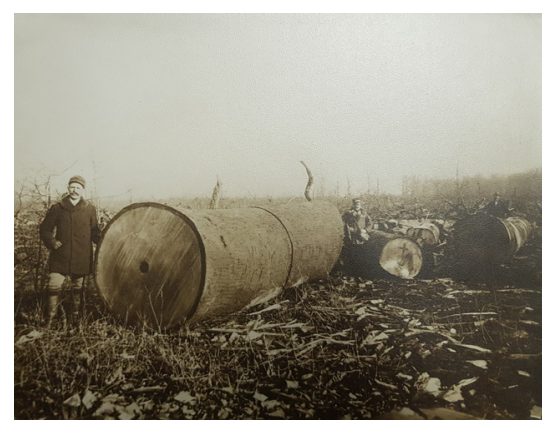

Abb. 2.1-1: Großflächige Kahlschläge veränderten die Waldlandschaft und es entstanden homogene Waldbewirtschaftungseinheiten.
20 Jahrhunderts der allmähliche Ersatz von heimischen Baumarten durch nichtheimische und teilweise auch standortsfremde Baumarten. Insbesondere schnell wachsende Hybridpappeln waren besonders beliebt und so entstanden vielerorts Plantagenwälder, die mit schnellwachsenden Arten und gut geformten und robusten Klonen bepflanzt wurden. Bis heute hat die landwirtschaftliche Bewirtschaftung 90 \% der europäischen Auwälder im letzten Jahrhundert zerstört. Auch wenn der Rückgang der Auwälder in Europa aufgehalten wurde, ist die Abholzung, Fragmentierung und Umwandlung von natürlichen Auwäldern weltweit immer noch ein großes Problem.

\section{Veränderte Flussdynamik}

An der Wende vom 17. zum 18. Jahrhundert wurde die nächste Welle von Veränderungen, mit umfangreichen Trockenlegungen und ersten Gewässerregulierungen, eingeleitet (Abb. 2.1-2). Bis heute wurden die Flusssysteme in großem Umfang verändert, um die Schifffahrt zu unterstützen und die Erzeugung von Wasserkraft zu ermöglichen. Diese Veränderungen regulierten die Flussläufe und Hand in Hand mit der Entwässerung der Auen traten schwerwiegende flussabwärts gerichtete Effekte, wie z. B. ein erhöhtes Risiko für Überschwemmungen, auf. Flussaufwärts sind die Folgen der veränderten Wasserdynamik vor allem ökologischer Natur. Zur Eindämmung der Hochwassergefahr wurden Schutzdeiche gebaut. Diese veränderten die Ökosysteme durch starke ökologische Fragmentierung und Entkopplung der wasserabhängigen Auenwälder von den Überschwemmungen zusätzlich. Die Flussregulierungen behindern die natürliche Auendynamik mit periodischen Überflutungen und unterbrechen die laterale Nährstoffversorgung. Dies beeinträchtigt den ökologischen Zustand erheblich, führt zum Rückgang der typischen Lebensräume der Weichholzau und reduziert somit drastisch die natürliche Verjüngung typischer Baumarten wie der Weiden und der Schwarzpappel (Abb. 2.1-3). Wasserkraftwerke in Kombination mit erhöhter Fließgeschwindigkeit und Unterbrechung des Sedimenttransports bewirken eine rasche Vertiefung des Flussbetts und die Absenkung der Wasserspiegel. Zusätzlich senkt die Grundwasserentnahme den Grundwasserspiegel. Diese veränderte Wasserverfügbarkeit macht Uferbaumarten anfällig für Dürreperio-

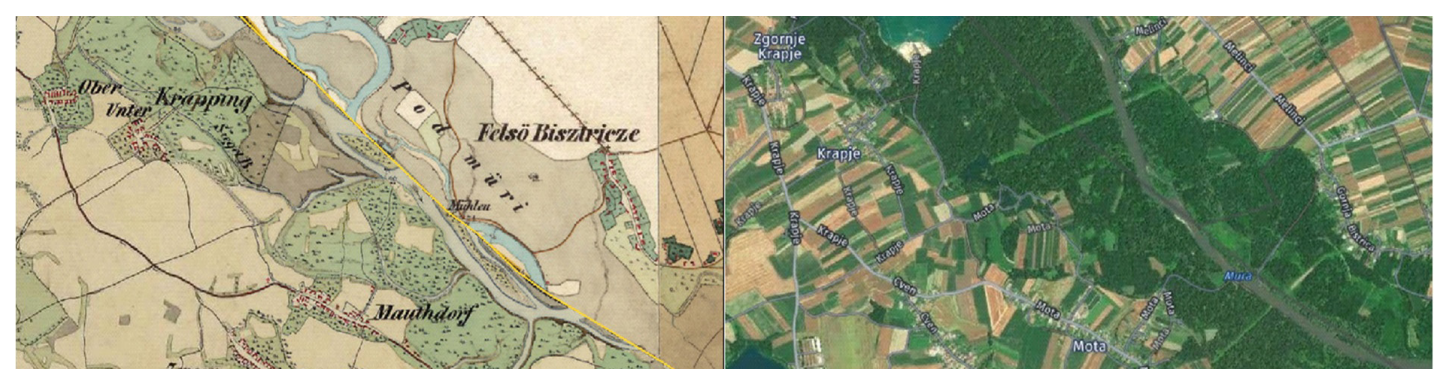

Abb. 2.1-2: Wasserlauf- und Landnutzungsänderungen entlang des Flusses Mur zwischen 1829 und 2020 (bei Bistrica, Prekmurje, Slowenien). 


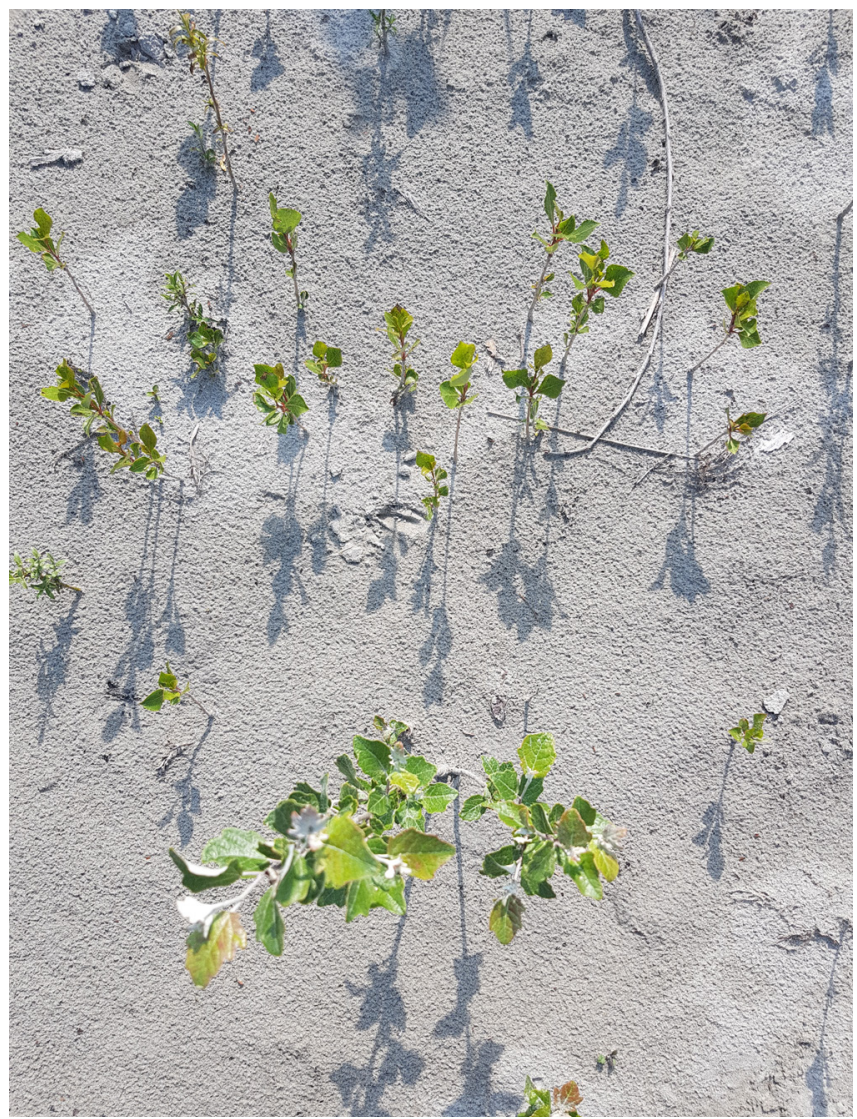

Abb. 2.1-3: Flussregulierungen haben zum Verlust geeigneter Lebensräume für Weichholzarten geführt und die natürliche Regeneration typischer Ufergehölze wie Weiden (Salix sp.) und Schwarzpappel (Populus nigra) drastisch reduziert.

den, die in einem sich verändernden Klima voraussichtlich häufiger auftreten werden.

\section{Klimawandel}

Störungen sind in Auwäldern mit ihren periodischen Überschwemmungen ein integraler Bestandteil des Waldökosystems und notwendig um die spezialisierte Artenzusammensetzung zu erhalten. Der Klimawandel bringt einen Temperaturanstieg, veränderte Niederschläge und eine veränderte Verteilung, Häufigkeit und ein unterschiedliches Ausmaß von Extremereignissen, das auch die Störungen im Auwaldsystem stark beeinträchtigen und bisher noch unbekannte Folgen für Auwälder haben kann. Schon jetzt verändert sich die Habitateignung und -Störungsanfälligkeit innerhalb des derzeitigen Verbreitungsgebiets lokaler Auwald-Pflanzengemeinschaften. Es wird erwartet, dass abioti- 
sche Störungen auch die Verbreitung von Schädlingen und Krankheitserregern verändern, was zu neuen, gefährlichen Übertragungen führen wird. Dazu kommt, dass die Anpassungsfähigkeit von Schädlingen und Krankheiten an neue Umweltbedingungen aufgrund der kürzeren Lebenszyklen höher ist, als die Anpassungsfähigkeit der Wirtsarten. Infolgedessen werden Wechselwirkungen zwischen abiotischen Stressoren und biotischen Schadfaktoren wahrscheinlich zu den Haupttreibern für Massenvermehrungen und den Ausbruch von Krankheiten. Ähnlich wie bei Krankheiten und Schädlingen kann auch die Verbreitung nichtheimischer Pflanzen zunehmen, was zu einem höheren Konkurrenzdruck auf heimische Pflanzengemeinschaften führt.

\section{Globalisierung}

Schon in der Jungsteinzeit, über größere Distanzen hinweg jedoch erst seit der Antike, hat eine aktive, vom Menschen geförderte Verbringung von Pflanzen und Tieren begonnen und ist in der Land- und Gartenwirtschaft sowie teilweise auch in der Forstwirtschaft auch heute noch üblich. Zusätzlich trägt die Globalisierung mit internationalem Handel und Reisen stark zu einer unbeabsichtigten Ausbreitung gebietsfremder Arten bei. Dies kann zu einem vermehrten Auftreten von gebietsfremden Schädlingen und Krankheiten, sowie von invasiv auftretenden Pflanzenarten in Wäldern führen. Insbesondere Auwälder sind aufgrund ihrer hohen Nährstoffverfügbarkeit, der wiederkehrenden Störungen, die zu günstigen Lichtverhältnissen führen, und der Flüsse als Transportvektoren für Samen und vegetatives Material sehr anfällig für die Invasion durch gebietsfremde Pflanzenarten.

Bei gebietsfremden Schädlingen und Krankheitserregern ist die Wahrscheinlichkeit, dass sie sich durch unbeabsichtigte Transfers verbreiten, aufgrund ihrer geringen Größe viel höher als bei Pflanzenmaterial. Da zwischen heimischen Pflanzen und den gebietsfremden Schädlingen und Krankheitserregern keine Koevolution stattgefunden hat, sind sie in der Regel anfälliger für deren Befall als die Baumarten im heimischen Verbreitungsgebiet dieser Schädlinge bzw. Krankheitserreger. Invasive gebietsfremde Pflanzen, Schädlinge und Krankheitserreger haben das Potential die Artenzusammensetzung und Struktur von Wäldern anhaltend zu verändern, was zu massiven ökologische Auswirkungen führen kann und damit die Ökosystemleistungen von Auenwäldern möglicherweise einschränkt.

\section{Aktuelle Wahrnehmung}

Aufgrund der Bedeutung und des ungünstigen Erhaltungszustandes (Abb. 2.1-4) haben Auwälder in jüngster Zeit nationale und internationale Anerkennung erfahren und wurden folglich in einer Reihe von Prozessen und Dokumenten explizit angesprochen. Erwähnenswert sind die Ramsar-Konvention, der Forest Europe-Prozess, die EU-Biodiversitätsstrategie und die FFH-Richtlinie. Auwälder werden dort als sensible Naturgüter wahrgenommen und es werden die verantwortli- 


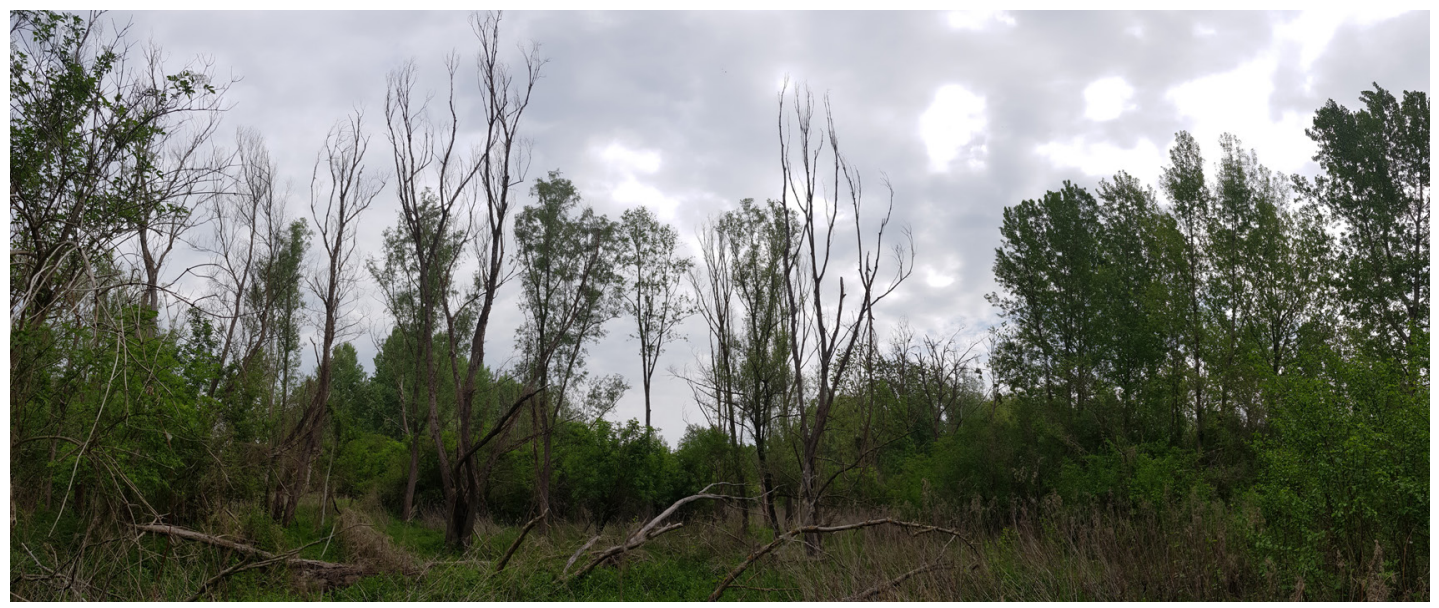

Abb. 2.1-4: Zurücksterben von Bäumen in Auwäldern an der Drau, Kroatien.

chen nationalen Behörden, Verwaltungen und Bewirtschafter aufgefordet, diese auf nachhaltige Weise zu bewirtschaften und die langfristige Entwicklung der Wälder mit der Bereitstellung aller ihrer Ökosystemleistungen in Einklang zu bringen. 


\subsection{Bewirtschaftung von Auwaldökosystemen}

Die langfristige Entwicklung von Auwäldern und der Erhalt ihrer vielfältigen Ökosystemleistungen erfordert die Berücksichtigung neuer Ansätze der nachhaltigen Waldbewirtschaftung. Zwei geeignete Ansätze sind die Landschaftsperspektive (wesentlich im Ökosystemmanagement) und das Konzept der ökologischen Integrität. Für die Zwecke dieses Beitrags ist der erstgenannte Ansatz als eine integrierte, ganzheitliche Waldbewirtschaftung auf Landschaftsebene zu verstehen. Das Konzept der ökologischen Integrität beschreibt darüber hinaus die Fähigkeit eines Auwaldes, seine flächenmäßigen, strukturellen und funktionellen Komponenten zu erhalten.

Aus landschaftsplanerischer Sicht kann ein Auwald als eine Waldmatrix betrachtet werden, die sich aus unterschiedlich geformten Waldteilen (Komplexen) und Korridoren zusammensetzt. In den meisten Fällen sind beide Landschaftselemente hinsichtlich ihrer Struktur heterogen, denn sie beherbergen eine Vielzahl von Lebensraumuntertypen mit unterschiedlich großen Kern- und Randflächen. Wenn man einige der Isolationseffekte berücksichtigt, wie z. B. i) dass ein Waldlebensraumtyp, der weit über sein ursprüngliches Verbreitungsgebiet verteilt ist, beständiger ist als ein Lebensraum, der auf kleine Teile beschränkt ist, ii) dass ein größerer Waldlebensraumtyp mit größeren Kerngebieten dem kleineren in seiner Dominanz überlegen ist und iii) dass ein zusammenhängender Waldlebensraumtyp robuster gegenüber Einwirkungen von außen ist als der fragmentierte, wird deutlich, dass die ökologische Integrität von Waldlebensraumtypen mit der Größe und Kompaktheit von Waldlebensraumtypkomplexen zunimmt.

Ein solches Verständnis eines Auwaldes hat Vorteile gegenüber der häufig vorgefundenen Bewirtschaftungspraxis; es betrachtet einen Auwald als Ganzes, anstatt ihn als Summe von Managementeinheiten zu sehen, ermöglicht neue Waldbewirtschaftungsperpektiven (z. B. Förderung von Femelhieben vs. Schirmschlag, Niederwald, Kahlschlag) und macht die Bewirtschaftung für den Erhalt auwaldtypischer Strukturen effizienter, indem es die Integrität des Waldlebensraumtyps fördert.

Die aktuelle Verteilung der Auwälder (Abb. 2.2-1) zeigt häufig, dass größere Komplexe in der forstlichen Raumplanung oft eine sehr homogene Verteilung von Altersklassen bzw. Entwicklungsphasen aufweisen. Die flussbegleitenden Lebensraum-Subtypen entlang der Fließgewässer, deren Längsgeometrien (Abb. 2.3-1) oft keine eigenen Kernflächen aufweisen, sind davon weniger betroffen. Dennoch sollten alle Lebensraum(sub)typen effektiv überwacht und bewirtschaftet werden, um sie langfristig funktionell zu erhalten. Plantagenartig bewirtschaftete Wälder, Plantagen und ähnliche Landnutzungen (z. B. Baumschulen) sollten dagegen von den Kern- und Randlebensraumtypen weg verlagert werden, um ein potenzielles Eindringen invasiver Arten und unerwünschte Auswirkungen (z. B. eventuelle Bestäubung, 
Nährstoffflüsse) zu vermeiden.

Zusätzlich zu beiden Ansätzen sind weitere Anstrengungen notwendig, um ein besseres Verständnis der Biodiversität, der Störungsereignisse und ihrer Auswirkungen auf die Waldbewirtschaftung zu erlangen. Un-

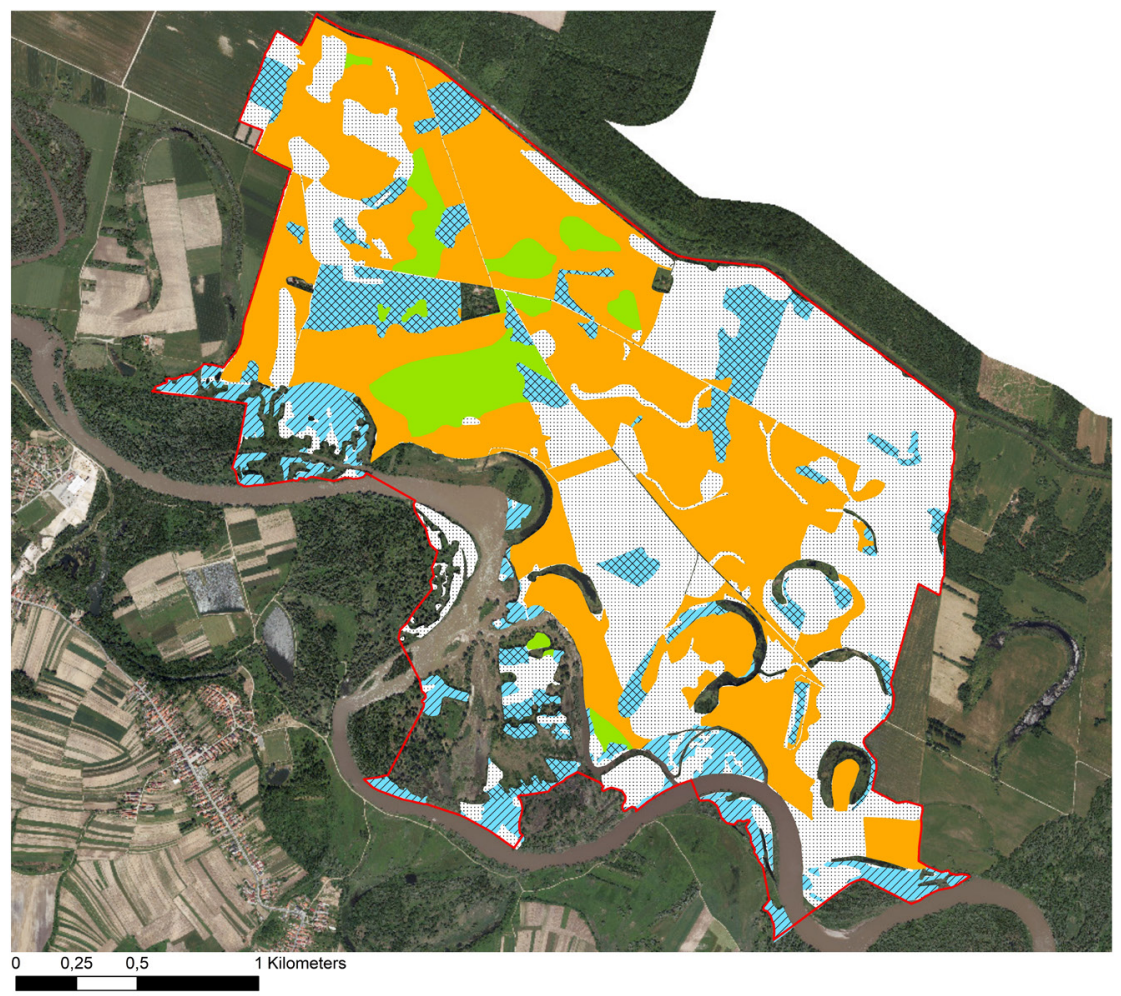

FOREST HABITAT TYPES

$91 \mathrm{FO}$

$\checkmark$ 91E0 - Salicetum subtype

Q1E0 - Alnetum subtype

$91 \mathrm{LO}$

forest - other

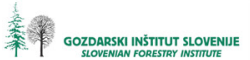

Data source: DOF025, 2014, GURS

Abb. 2.2-1: Kompartimentbasiertes Management (Habitattypen von Murska Šuma).

ter den Störungshypothesen sind insbesondere die intermediäre Störungshypothese und die Versicherungshypothese hervorzuheben. Erstere besagt, dass die Biodiversität zwischen zwei aufeinanderfolgenden Störungen am höchsten ist, solange der Zeitraum zwischen den beiden aufeinanderfolgenden Störungen ausreichend (aber nicht zu) lang ist. Diese Hypothese scheint in Auwäldern zuzutreffen, und lässt sich vom Wasserlauf zur äußeren Grenze der Aue gut veranschaulichen (Kapitel: „Struktur und Ökologie der Flussauenlandschaft"). In diesem Transekt finden sich die struktur-, kompositions- und nährstoffreichen Pioniersukzessionsstadien in der Nähe des Gewässers, wo die Störungen am häufigsten und stärksten sind. Im Gegensatz dazu finden sich die am weitesten entwickelten Sukzessionsstadien der Auwälder, die Stieleichenwälder meist in größerer Distanz vom Gewässer. Dort sind sie weiterhin vom Wasserregime abhängig, werden aber seltener gestört.

Die Versicherungshypothese befasst sich mit der bestehenden, funktio- 
nellen Baumartenzusammensetzung. Sie besagt, dass Arten, die derzeit in der Funktion des Waldlebensraums überflüssig sind, zu einem bestimmten Zeitpunkt, z. B. nach einer Störung, einige Funktionen übernehmen können, die zuvor von zurückgegangenen oder verschwundenen Arten erfüllt wurden. Diese Tatsache ist für das Verständnis der Baumartenzusammensetzung von Waldlebensraumtypen und -subtypen von Bedeutung, die nicht als dauerhaft und statisch, sondern als in Zeit und Raum dynamisch verstanden werden sollten. Die Versicherungshypothese hat insbesondere in Auwäldern eine wichtige Rolle. Der Grund dafür ist, dass viele der dominanten Baumarten der heutigen Waldgesellschaften unter einer Vielzahl von Krankheiten und Umwelteinflüssen leiden und dadurch (lokal) verschwinden könnten (Kapitel „Geeignetes forstliches Vermehrungsgut zur Anpassung der Wälder an den Klimawandel", und Kapitel "Gesundheit der Wälder”).

Auwälder sind komplexe ökologische Systeme, die einer Vielzahl von natürlichen und vom Menschen verursachten Störungen ausgesetzt und von diesen abhängig sind. Aufgrund ihrer Fragilität und der hohen Wahrscheinlichkeit, dass sich die Auswirkungen massiv auf die Flussauenlandschaft auswirken, sollen diese Wälder in verschiedenen räumlichen Maßstäben und in Anbetracht aktueller ökologischer Kenntnisse bewirtschaftet werden. Die Bewirtschafter von Auwäldern werden ermutigt, geeignete forstliche Bewirtschaftungsansätze einschließlich einer angemessenen räumlichen Anordnung von Lebensraumtypen im Bewusstsein der Risiken durch veränderte Flussdynamik, Klimawandel, Schädlinge und Krankheiten sowie invasive Arten umzusetzen, um das wirtschaftliche Potenzial und den ökologischen Wert dieser Wälder für künftige Generationen zu erhalten. 


\section{As \\ ate}

A.

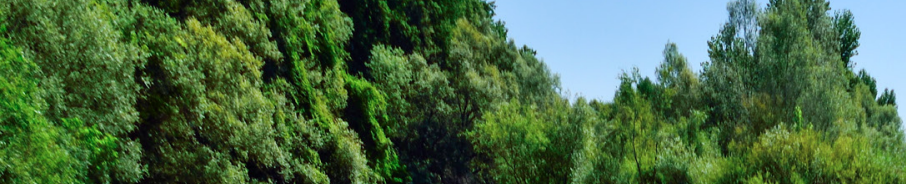

casur 100.

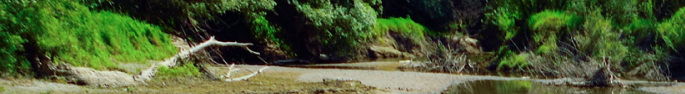

*.

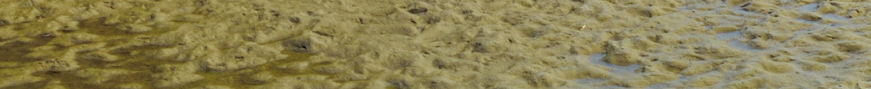

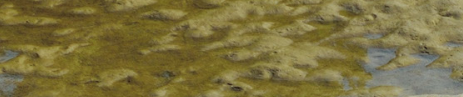

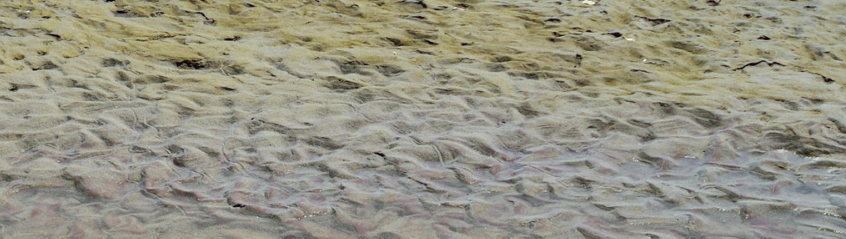

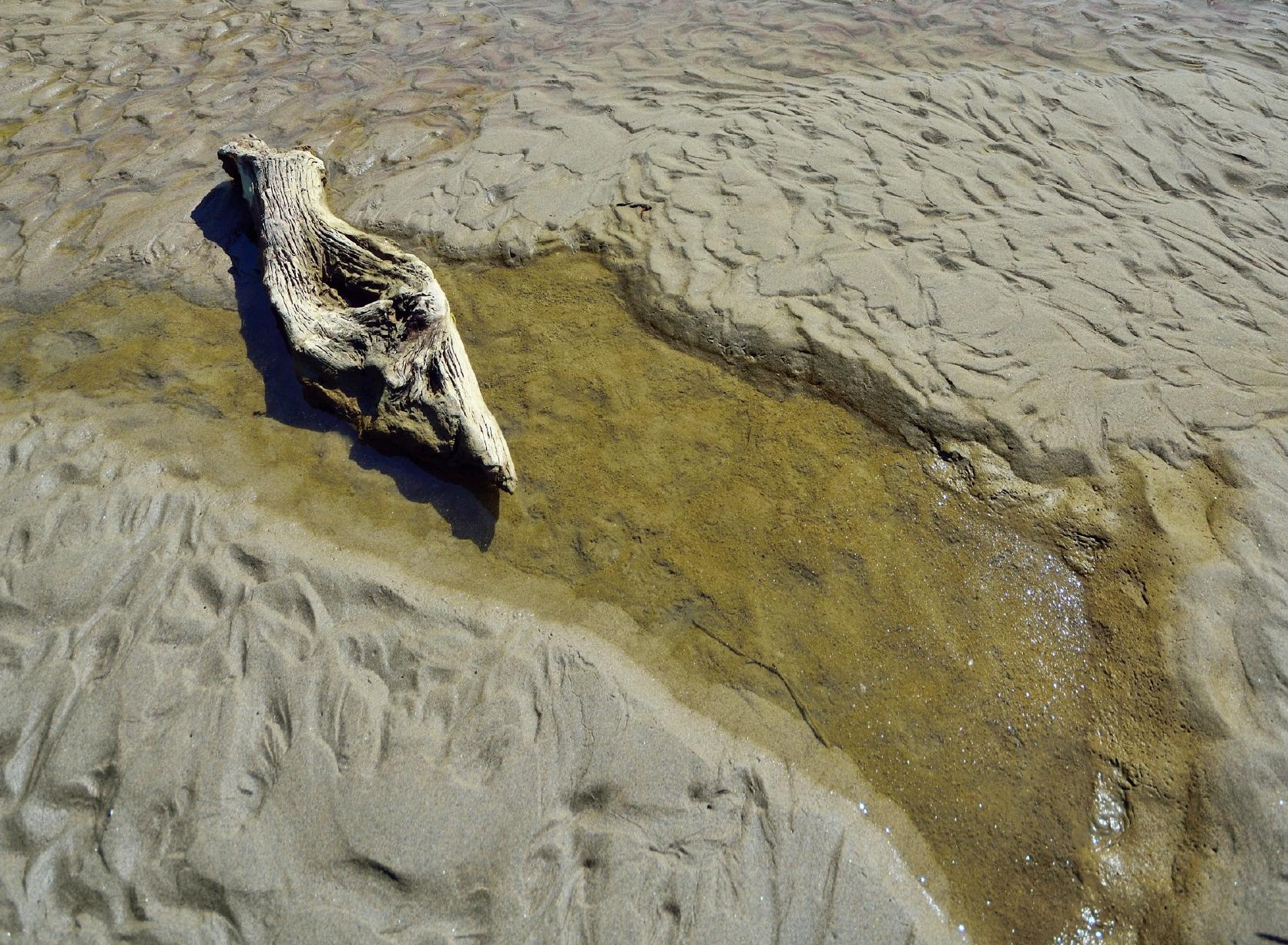




\subsection{Struktur und Ökologie der Flussauenlandschaft}

Das dynamische Zusammenspiel von Wasser und Land ist der wesentliche Prozess, der verschiedene Typen von Flussauenlandschaften hervorbringt und erhält (Kasten 1) und eine Vielzahl von Lebensräumen schafft.

- Initiale (Gebirgs-)Auen: z. B. Gebirgsauwald, der in engen Schluchten unter starkem Wasser- und Geschiebeeinfluss kontinuierlich unter hohem Störungseinfluss überformt wird

- Gleichgewichtsaue: Wasser mäandriert hier in ebeneren Landschaftsformen durch nicht-kohäsives Sedimentmaterial wodurch kontinuierliche, mäßige Landschaftsveränderungen auftreten

- Niedriggradiente Aue: Wasser mäandriert durch ebenes Tiefland-Relief mit bindigem Sedimentmaterial, mit langsamen, vergleichweise geringen Landschaftsveränderungen

Eine Flussauenlandschaft umfasst vier verschiedene Landschaftselementgruppen, die weiter in Ökotope und Ökoelemente unterteilt sind. Die erste und bedeutendste Gruppe umfasst die stehenden und fließenden Gewässer. Verbunden durch das Netzwerk von Gerinnen wird die Etablierung von autypischen Pioniergehölzen insbesondere durch Überflutungen und die Ablagerung von grob- und feinkörnigem Material und Nährstoffen unterstützt.

Die zweite Gruppe von Elementen stellt das Grundwasser dar, das Teil eines komplexeren Systems ist, das als unterirdischer Wasserleiter bezeichnet wird. Neben dem fließenden Wasser ist das Grundwasser die zweite Feuchtigkeitsquelle für Auwälder und wird in Trockenperioden zu einem kritischen Faktor. Ein hoher Grundwasserspiegel schafft und erhält auch seine eigenen Lebensräume, die sogenannten Sumpfwälder.

Die dritte Elementgruppe der Auenlandschaft, die für die Pflanzengesellschaften am Flussufer wesentlich ist, ist die Gruppe der geomorphologischen Merkmale. Die Vernetzung der Wasserströme in der Flussauenlandschaft schafft mäandrierende, verzweigte und anastomosierte Gerinne, die eingeschnittene Ufer, Stege, Inseln, Deiche und hügelige, überschwemmungsgefährdete Ebenen bilden, die reich an Senken und Erhebungen sind, die allesamt potenzielle Lebensräume für einzelne Waldpflanzen und kleine und große Flächen von Waldgesellschaften sind (Abb. 2.3-1). 


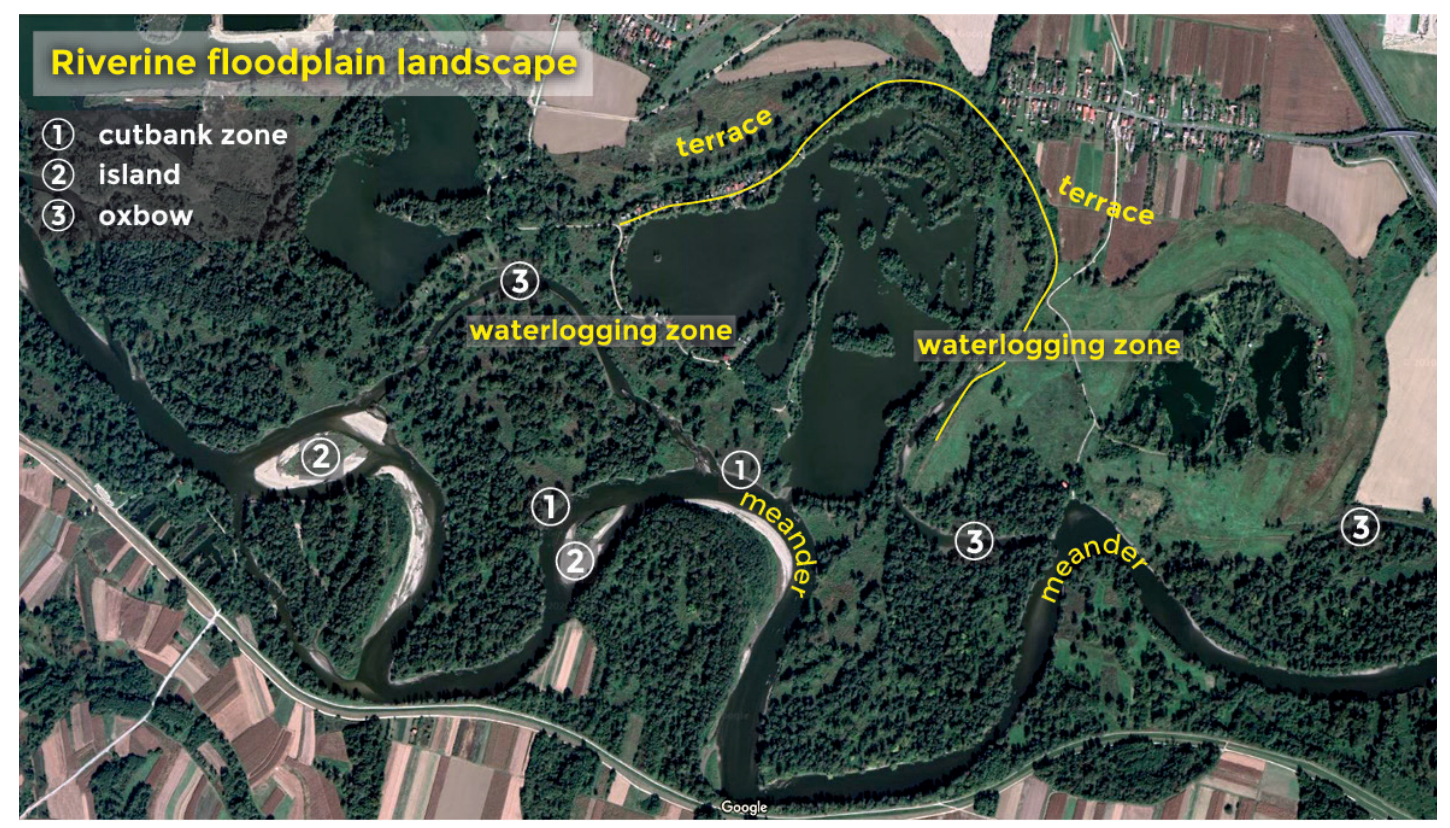

Abb. 2.3-1: Schema potenzieller Flusslebensräume mit Altarmen, Inseln, Terrassen, Stegen und Uferbänken.

Die letzte Elementgruppe der Flussauenlandschaften stellt die Vegetationsbedeckung durch Auwald-Pflanzengesellschaften dar. Obwohl die ökologischen Faktoren, die die Waldpflanzengemeinschaften in Flussauenlandschaften bestimmen, meist weniger deutlich erkennbar sind als in Landschaften mit abrupteren ökologischen Gradienten (z. B. Gebirgslandschaften), sind die Auwaldgesellschaften stark von ihnen abhängig. Besonders kritisch für ihre Existenz sind zweifellos Standort-Hydroperioden, makro- und mikromorphologische Gradienten (z. B. relative Höhenlage), Niederschläge und Bodentypen. Die vorgestellten Faktoren ermöglichen die Unterscheidung von drei HauptAuwaldgesellschaften entlang des Überschwemmungsgradienten hin zur äußeren Grenze der Aue, nämlich Fluss-, Auen- und Sumpfwälder (Abb. 2.3-2). 


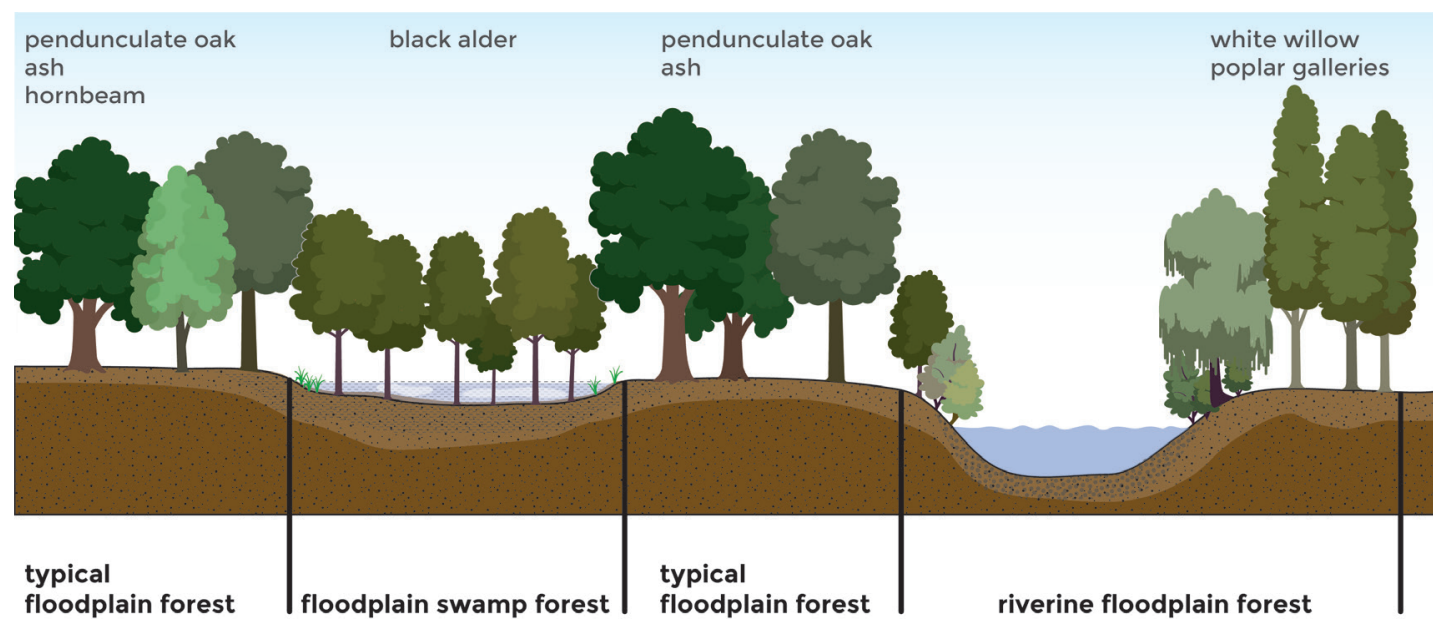

Abb. 2.3-2: Lateraler Transekt mit typischen Auenwaldtypen.

Die niedrigsten und an den Wasserlauf direkt angrenzenden Lebensräume, wie z. B. Steilufer und Inseln sowie die anderen von den Wasserstandsänderungen betroffenen Ufer, Dämme und Ebenen (Terrassen) sind typische Auwaldstandorte. Während letztere Lebensräume in der Lage sind, ständigen Wasserstandsänderungen, langanhaltender Staunässe und Wasserströmungen standzuhalten, sind die direkt an die Wasserläufe angrenzenden oft instabil. Der Gewässereinfluss lässt unbefestigte natürliche und naturnahe Flussufer erodieren, transportiert das abgeschwemmte Material in den Flussbetten, schwemmt Pflanzengruppen weg und fördert somit auch die Besiedlung neuer Lebensräume. Die Bodenfruchtbarkeit dieser Standorte ist aufgrund der langanhaltenden Sättigung mit Wasser und der stark unterentwickelten Böden gering. Pappel (Populus sp.), Eschen (Fraxinus sp.), Ulmen (Ulmus sp.) und manche Weiden (Salix sp.) siedeln auf gut drainierten, stabilisierten Standorten. Im Gegensatz dazu kommen besonders die pionierartigen Weidenarten (Salix eleagnos, S. purpurea, S. caprea, S. cinerea, S. alba) sowie Grau- und Schwarzerle (Alnus incana, A. glutinosa) auf den an das Wasser angrenzenden Standorten (d.h. Ufer, Stege, Inseln) vor.
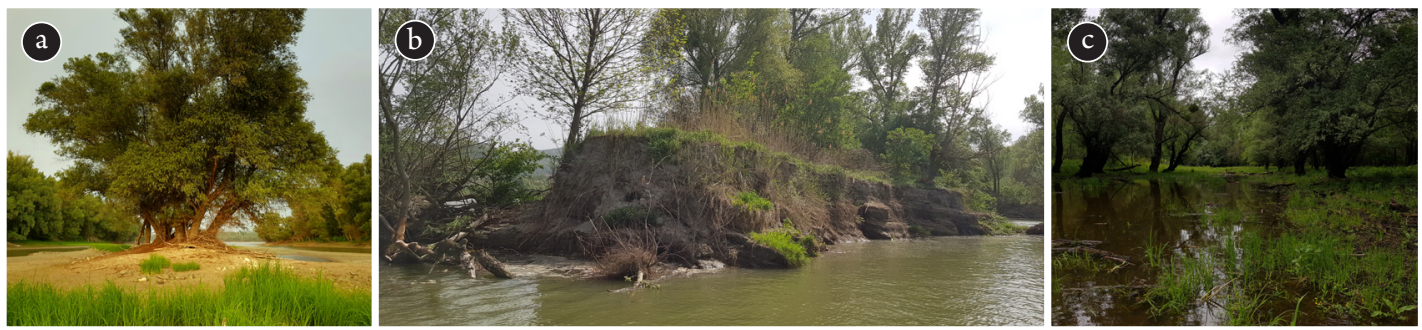

Abb. 2.3-3: a) Die Besiedlung neuer Lebensräume auf Flussinseln b) Stabilisierte Standorte sind in der Lage, ständigen Wasserstandsänderungen standzuhalten, aber auch die Erosion von Flussufern ist ein wesentlicher Bestandteil des Systems c) Von Salix-Arten besiedelte Überwschwemmungsfläche. 
Der zweite Standorttyp sind höher gelegene Auenflächen, die außerhalb der Reichweite der Abflussänderungen liegen, aber immer noch innerhalb der Grenzen der regelmäßig überfluteten Gebiete (Überschwemmungsgebiete). Auf diesen Standorten finden sich meist typische Auwälder mit den Baumarten Ulme (Ulmus laevis), Stieleiche (Quercus robur), Hainbuche (Carpinus betulus) und Esche (Fraxinus excelsior, F. angustifolia) sowie vereinzelt Bergahorn, Feldahorn, Linde und Kirsche (Acer pseudoplatanus, A. campestre, Tilia sp., Prunus avium), die gut drainierte Böden fordern und kurze Überschwemmungen ertragen. Die zuerst genannten Arten besiedeln regelmäßig überschwemmte Standorte, auch mit teilweise schlecht entwässerten Böden. Doch im Gegensatz zu den die Fließgewässer säumenden Galeriewäldern, die sehr tolerant gegenüber Feuchtigkeit und langanhaltender Staunässe sind, bevorzugen typische Auwälder regelmäßige saisonale Überflutungen. Da diese Wälder auch auf Standorten abseits der Wasserkanäle vorkommen, wo die Überflutungsperioden deutlich kürzer sind, sind sie dort stärker von Grundwasser und Niederschlägen abhängig. Niederschläge sind vor allem in den trockeneren Perioden vor dem Blattaustrieb der Bäume wichtig.

Der letzte hier den Auenwäldern zugeordnete Typ sind Sumpfwälder. Diese Wälder besiedeln Senken in den Auen, deren Böden aufgrund hoher Grundwasserspiegel und langanhaltender Staunässe schlecht entwässert sind (Gleysole). Im Gegensatz zu Fluss- und Auenwäldern im engeren Sinn sind diese Wälder in der Lage, auf Standorten mit häufigen anaeroben Bedingungen zu überleben, die durch stagnierende Gewässer verursacht werden. Die Hauptbaumart dieser Wälder ist die Schwarzerle (Alnus glutinosa). Aufgrund des hügeligen Geländes (oft im Bereich von einem Meter) werden weniger überschwemmte Standorte jedoch natürlicherweise oft auch von Ulme, Stieleiche und Esche (Ulmus laevis, Quercus robur, Fraxinus sp.) besiedelt.

Betrachtet man die Flussauenlandschaft als Ganzes, so sind die am häufigsten überschwemmten Waldflächen meist auch jene Orte, an denen die größte Menge an Nährstoffen produziert, gespeichert und zersetzt wird. Diese werden im Falle eines Hochwassers zu anderen, weniger fruchtbaren Standorten transportiert.

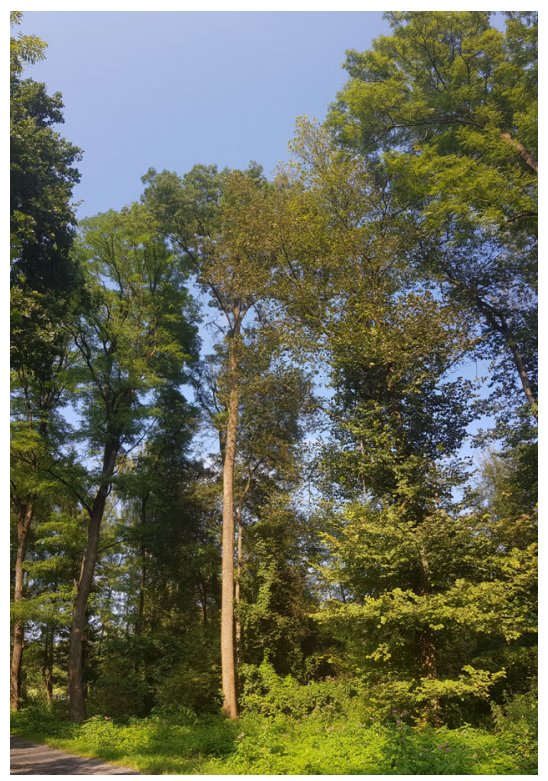

Abb. 2.3-4: Höher gelegener Auwald mit F. excelsior, U. laevis und Q. robur außerhalb der Reichweite der Strömungsänderungen, aber noch innerhalb der Grenzen der regelmäßig überschwemmten Gebiete.

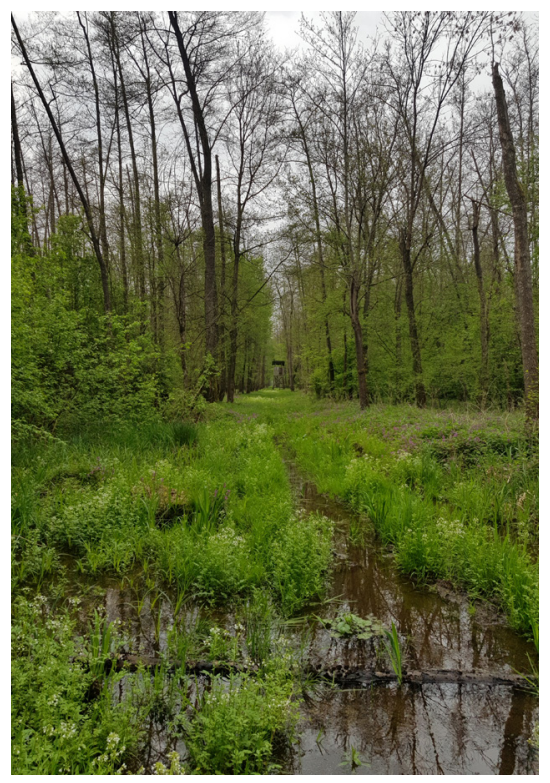

Abb. 2.3-5: Erlenbruchwald. 


\subsection{Waldhabitattypen}

\section{Einleitung}

Die Auen entlang der Flüsse Mur, Drau und Donau beherbergen viele Habitattypen und -subtypen. Um sie zu erhalten, wurden viele von ihnen offiziell ausgewiesen und in das Natura 2000-Netzwerk aufgenommen. Die am weitest verbreiteten, bekannten und aus ökologischer, ökonomischer und sozialer Sicht relevanten sind:

- *91E0 Auenwälder mit Alnus glutinosa und Fraxinus excelsior (Alno-Padion, Alnion incanae, Salicion albae),

- 91F0 Hartholzauenwälder mit Quercus robur, Ulmus laevis, Ulmus minor, Fraxinus excelsior oder Fraxinus angustifolia (Ulmenion minoris), entlang der großen Flüsse,

- $\quad$ 91L0 Illyrische Eichen-Hainbuchenwälder (Erythronio-Carpinion),

- 9160 Subatlantischer oder mitteleuropäischer Stieleichenwald oder Eichen-Hainbuchenwald (Carpinion betuli).

Diese vier Habitattypen unterscheiden sich in ihrer Ökologie. Der erste und heterogenste Habitattyp ( $\left.{ }^{*} 91 \mathrm{E} 0\right)$ umfasst verschiedene Habitatsubtypen, die häufig zu zwei größeren Gruppen gehören, die aus praktischen Gründen Weiden- bzw. Schwarzerlenwälder genannt werden. Der Weidenwald ist ein typischer Vertreter des Auwaldes, denn er besiedelt feuchte, oft überschwemmte, aber recht gut entwässerte Standorte in der Nähe des Wasserlaufs (Abb. 2.4-1). Der Lebensraumsubtyp Schwarzerlenwald besiedelt dagegen meist feuchte und schlecht entwässerte Standorte in der Aue und bildet die Sumpfwälder. Ihre Standorte sind oft durch die anaeroben Bedingungen gekennzeichnet, die durch die langanhaltenden Überschwemmungen und stagnierenden Gewässer sowie schwere Böden verursacht werden.

Die anderen Waldlebensraumtypen besiedeln die Auenkernbereiche und werden daher als typische Auwälder bezeichnet. Ihre dominierende Art ist die Stieleiche. Im Gegensatz zu den Schwarzerlen-Sumpfwäldern sind die Stieleichen-Waldgesellschaften jedoch stark von den regelmäßigen Überflutungen durch Fließgewässer, Grundwasser und Niederschläge abhängig. Die Unterschiede in der Baumartenzusammensetzung zwischen diesen Lebensraumtypen sind oft kaum erkennbar und sind auf die subtilen Höhenunterschiede im nur leicht hügeligen Gelände zurückzuführen.

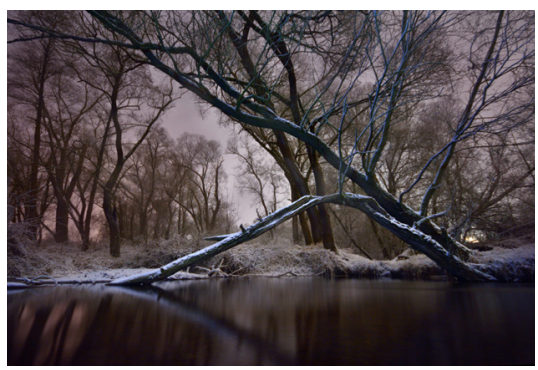

Abb. 2.4-1: Natürliche Weidenwälder in Bayern, Deutschland. 
Lebensraumtyp Wald: *91E0 Auenwälder mit Alnus glutinosa und Fraxinus excelsior (Alno-Padion, Alnion incanae, Salicion albae)

Der prioritäre Habitattyp *91E0 enthält drei Untertypen. Der erste Lebensraum-Subtyp, der zu den Weidenwäldern gehört, entwickelt im Allgemeinen zwei Sukzessionsbilder. Ein eher instabiles Pionierstadium herrscht an den an die Fließgewässer angrenzenden Standorten wie Steilufer, Stege und Inseln vor und besteht aus Büschen und kleinwüchsigen Weiden und Erlen (Salix sp., Alnus sp.). Im Gegensatz dazu besteht ein weiter entwickeltes Stadium aus großen Weiden (Salix sp.), Erlen (Alnus sp.), Ulmen (Ulmus sp.) und Eschen (Fraxinus sp.) und ist häufig auf den stabilisierten angrenzenden Flächen zu finden. Auch diese sind noch regelmäßigen Überschwemmungen ausgesetzt.

Die Bodenfruchtbarkeit beider Standorte ist aufgrund der sedimentären Böden, die aus grob- und feinkörnigem Kies, Sand und Schluff bestehen, gering. An stabilisierten Standorten sind hydromorphe Böden entwickelt.

Der zweite Lebensraum-Subtyp ist durch die Baumgalerien entlang der Fließgewässerufer gekennzeichnet, die meist aus großen Silberweiden (Salix alba) und Schwarzpappeln (Populus nigra) bestehen. Beide Arten bilden auch einzelne Bestände. Die Standorte sind gut bis mäßig entwässert und bestehen oft aus mäßig tiefen und tiefgründigen Lehmund Tonböden.

Der dritte und letzte Lebensraum-Subtyp wird durch die TieflandSchwarzerlen-Sumpfwälder (Alnus glutinosa) repräsentiert. Dieser Lebensraumsubtyp besiedelt die untersten Geländestufen in den Überschwemmungsgebieten, die aus reichhaltigen Humusschichten und Gleyen bestehen und die meiste Zeit des Jahres durch Niederschläge und Grundwasser mit stehendem Wasser überschwemmt sind. Die Schwarzerle bildet homogene und gemischte Bestände. Bei Mischwäldern wellt sich das Gelände und es entstehen sowohl sumpfige als auch frische Standorte, wobei die frischen oft von Stieleiche (Quercus robur), Ulme (Ulmus laevis), Esche (Fraxinus excelsior) und ähnlichen Arten besiedelt werden.

Dieser Habitattyp (*91E0) ist insgesamt reich an Weiden-, Pappel-, Ulmen-, Eschen- und Straucharten und umfasst viele Waldgesellschaften. Seine Verjüngung unterscheidet sich von Ort zu Ort. Die an die Fließgewässer angrenzenden Habitatstrukturen des Auwaldes, aktive und nicht aktive Altarme mit den Weidengalerien und kleinflächigen sumpfigen Schwarzerlenwäldern regenerieren sich natürlich. Umgekehrt können auch großflächige Weiden-, Pappel- und auch Schwarzerlenbestände künstlich regeneriert werden (Beispiel: der Schwarzerlenwald von Polana und Black Forest, zwischen den Dörfern Mala Polana und Mostje/Banuta, SLO). Der Hauptgrund ist die aggressive Bodenvegetation, die die Schösslinge erstickt und den Keimungsprozess erschwert (oder sogar hemmt).

Der *91E0 Habiattyp erfüllt eine wichtige ökologische Rolle. Da er 
eine Kombination aus terrestrischer und aquatischer Landschaft ist, beherbergt er zahlreiche Pflanzen- und Tierarten. Er hat auch eine große Schutzfunktion, denn er reguliert das Wasserregime und den Wasserkreislauf und trägt somit zur Sicherheit vor Überschwemmungen bei. Bemerkenswert ist auch seine Rolle aus der Sicht der Waldbewirtschaftung. Die Schwarzerlen-, Weißweiden- und Pappelbestände sind dafür bekannt, dass sie hochwertiges und schnell wachsendes Holz für die Holz- und Energieindustrie produzieren.

Die Subtypen dieses Habitattyps sind sehr gefährdet und anfällig für fatale Fehlentwicklungen. Die einflussreichsten Faktoren, die sich auf ihr weiteres Bestehen auswirken, sind ihre Seltenheit, die räumliche Verteilung und Gestalt ihrer Lebensräume, die Nachbarschaft zu kompakteren Waldtypen und menschliche Eingriffe. Die ersten beiden Faktoren sind rein ökologisch. Während der Seltenheit nur sehr schwer entgegengewirkt werden kann, können die bestehenden Flächen erhalten und verbessert werden, indem ihre Kerngebiete stabil und frei von konkurrenzstärkeren heimischen und exotischen Baumarten gehalten werden, die in sie eindringen. Menschliche Eingriffe, wie z. B. die Fragmentierung von Lebensräumen, die Entwässerung von landwirtschaftlichen Flächen und die Umwandlung von Landnutzungen, sollten sorgfältig geplant, überwacht und durch entsprechende Gesetze geregelt werden.

91F0 Hartholzauenwälder mit Quercus robur, Ulmus laevis, Ulmus minor, Fraxinus excelsior oder Fraxinus angustifolia (Ulmenion minoris), entlang der großen Flüsse, 91 Lo Illyrische Eichen-Hainbuchenwälder (Erythronio-Carpinion) und 9160 Subatlantischer oder mitteleuropäischer Stieleichenwald oder Eichen-Hainbuchenwald (Carpinion betuli)

Die Lebensraumtypen mit den Codes 91F0, 91L0 und 9160 haben eine ähnliche Ökologie und lassen sich oft nur in Bezug auf bestimmte Faktoren wie Standortentwässerung, Bodentyp, Feuchtigkeit, Niederschlag, Vorhandensein von Grundwasser und das Überschwemmungsregime unterscheiden. Aus Sicht der Sukzession gelten diese Auwald-Lebensraumtypen als die am weitesten entwickelten unter den Flussauenwäldern. In diesem Zusammenhang ist es erwähnenswert, dass der Habitattyp 9160 oft nur als ein anders klassifizierter Lebensraumtyp von $91 \mathrm{~F} 0$ angesehen wird.

Aufgrund der ungleichmäßig abgelagerten Böden sind Auflächen selten wirklich eben. Die vertikale Struktur im Mikrorelief schafft eine Vielzahl von Lebensräumen (es gilt: je tiefer desto feuchter und umgekehrt) für Bodenvegetation, Strauch- und Baumarten, die sich hinsichtlich ihrer Toleranz gegenüber Bodenfeuchte bzw. Trockenheit unterscheiden. Die Standorte sind meist schlecht entwässert und bestehen aus mäßig tiefen oder tiefen lehmigen, tonigen und sogar sedimentären Partikeln und Material. 
Die Unterschiede zwischen den Baumartenzusammensetzungen dieser drei Lebensraumtypen sind oft nicht greifbar. Alle drei werden von Stieleiche (Quercus robur) dominiert, die mit Ulme (Ulmus laevis), Esche (Fraxinus angustifolia, F. excelsior) und einigen anderen Begleitarten vermischt ist. Ist die Ebene jedoch ausreichend hoch gelegen und damit weniger langanhaltenden Überschwemmungen ausgesetzt, kann sie auch Hainbuche (Carpinus betulus), Bergahorn (Acer platanoides) und einige andere, weniger bodenfeuchte- und wasserverträgliche Arten beherbergen. Deutlich kürzere Überschwemmungen sowie weniger feuchtes Terrain sind also der Hauptunterschied zwischen den Habitattypen 91F0/9160 und 91L0. Dennoch beherbergen alle drei Lebensraumtypen viele Boden-, Strauch- und Baumpflanzenarten.

Die Entstehung dieser Auwald-Lebensraumtypen ist sehr unterschiedlich. Obwohl viele heute anzutreffende Bestände den natürlich entstandenen Wäldern sehr ähnlich sehen, wurden besonders große Komplexe oft durch Pflanzung oder Saat künstlich begründet. Die Naturverjüngung der Stieleiche ist anspruchsvoll und daher oft erfolglos. Die Hauptfaktoren sind der Lichtbedarf, Wildeinfluss, unzureichende Fruktifikation, aggressive Bodenvegetation und die abrasive Wirkung von Überschwemmungen (Kapitel "Naturverjüngung und Saat von Stieleichenbeständen").

Das forstwirtschaftliche Potenzial der Auwald-Habitattypen 91FO und 91E0 ist enorm. Wie alle Auwald-Habitattypen tragen sie zum spezifischen Wasserregime und zum Wasserkreislauf bei und beherbergen viele Pflanzen- und Tierarten. Darüber hinaus ist das Holz der Stieleiche und der beigemischten Arten wie Ulme oder Esche in der Holzindustrie wertvoll, wo es für die Produktion von Furnieren, Brettern, und anderen Produkten verwendet wird (Kapitel "Potentiale in der Laubwertholzproduktion").

Da alle drei Habitattypen ökologisch ähnliche Standorte bewohnen, leiden sie unter ähnlichen Beeinträchtigungen, d.h. Veränderung der Flussdynamik und Landentwässerung, Baumkrankheiten, dem Eindringen exotischer und konkurrenzstärkerer Baumarten sowie Fragmentierung der Lebensräume und Landnutzungsänderungen. Die bei weitem schädlichsten Faktoren scheinen Pflanzenkrankheiten zu sein, die einige der wichtigsten Baumarten des Habitats lokal zum Aussterben bringen sowie der abgesenkte Grundwasserspiegel aufgrund der Entwässerung angrenzender landwirtschaftlicher Flächen. 


\subsection{Gängige Waldbewirtschaftungsformen in Auwäldern}

Auwaldgesellschaften sind einer Vielzahl von Störungen ausgesetzt. Bestände, die direkt an Fließgewässer angrenzen, sind stärker der Überflutungsdynamik und gestaltenden Wirkung der Flüsse ausgesetzt. Das zeigt sich in abgebrochenen und umgestürzten Bäumen, Baumwunden, abgeschwemmten Böden und an- und abgetragenem organischem Material. Zudem wird über den Wasserlauf eine Vielzahl an Samen angeschwemmt, die sich zu Sämlingen und jungen Bäumen entwickeln können. Umgekehrt sind Bestände, die von den direkten Wassereinflüssen entfernt liegen, eher einer langanhaltenden Staunässe ausgesetzt und eignen sich besser für eine regelmäßige Waldbewirtschaftung. Generell sind Auwaldbaumarten besonders an jene ökologischen Nischen angepasst, die regelmäßig aber in unterschiedlicher Frequenz und Dauer durch Überschwemmungen gestört werden.

Die Anpassung an die ständig wechselnden Umweltbedingungen durch Baum- und Straucharten erfolgt durch zwei grundlegende Regenerations- und Reproduktionsmechanismen: die ungeschlechtliche vegetative und die sexuelle Vermehrung aus Samen. Beide Möglichkeiten werden von der Forstwirtschaft seit jeher genutzt: die natürliche vegetative Vermehrung, meist in Form von Stockausschlag, ist zum Beispiel bei der Bewirtschaftung von Niederwäldern die übliche Form der Verjüngung. Die Niederwaldbewirtschaftung diente vormals vor allem der Gewinnung von Brennholz, daher mussten die aus dem Stockaustrieb nachgewachsenen Stämme auch nur geringe Qualitäten aufweisen. Zur Produktion von hochwertigem Holz im Hochwald werden dagegen meist Kernwüchse aus Samen verwendet.

Als sehr traditionelle Bestandsform kommen Niederwälder auch in den typischen Auen abseits der Fließgewässer vor. Dennoch wurden aufgrund der veränderten Bedürfnisse und Prioritäten der Menschen vor etwa 200 Jahren große Teile der Niederwälder durch Hochwälder ersetzt, die zumeist mittels Saat und Pflanzung begründet wurden (Abb. 2.5-1). Der Hauptgrund für diese Veränderung war die Produktion von hochwertigem Holz für die Holzindustrie. Die häufigsten Baumarten von Hochwäldern in der Au sind Eiche, Esche, Ulme und damit vergesellschaftete Arten wie Hainbuche. Zusätzlich werden auch Silberweide, die in der Region heimische europäische Schwarzpappel und eine Vielzahl von Pappelklonen bei der Etablierung von großflächigen Hochwaldkomplexen eingesetzt.

Die letzte, ebenfalls sehr traditionelle Bestandsform, die aus den Auwäldern fast verschwunden ist, stellt der Mittelwald dar, bei dem es sich um eine Kombination aus Elementen des Hochwaldes und des Niederwaldes handelt. Die Oberschicht (Oberholz) besteht teilweise aus durchgewachsenen Stockausschlägen und Wurzelbrut aber auch aus Kernwüchsen. Die Unterschicht (Unterholz) besteht überwiegend aus Stockausschlägen und Wurzelbrut. Als Lassreitel werden im Mittelwald, bei der Nutzung des Unterholzes, stehengebliebene Jungbäume 
bezeichnet, die später ins Oberholz einwachsen sollen. Während das Unterholz in relativ kurzen Umtrieben (20-30 Jahre) in erster Linie auf Brennholz bewirtschaftet wird, verbleibt das Oberholz im Bestand und wird erst bei Erreichen der entsprechenden Durchmesser genutzt.

Alle drei Formen spielen eine wichtige Rolle bei der Erhaltung von Auenwäldern. Während das Potenzial von Hochwäldern, die sich besonders zur Laubwertholzproduktion eignen, recht gut erforscht ist, sind Studien, die sich mit Niederwäldern und Mittelwäldern befassen, noch selten. Neuere Untersuchungen in vielen verschiedenen Waldumgebungen zeigen, dass die Baumartenzusammensetzungen von Nieder- und Mittelwäldern im Allgemeinen vielfältiger sind als die der Hochwälder und dass sie wesentlich zur Erhaltung einiger lichtbedürftiger Arten beitragen können. Darüber hinaus handelt es sich um sehr alte Waldbewirtschaftungstechniken, die in den letzten Jahrhunderten in vielen europäischen Regionen wesentlich zur gesellschaftlichen Entwicklung beigetragen haben und daher als kulturelles Erbe erhalten werden sollten. Zudem sind sie auch sehr gut für kleine Waldbesitzer geeignet, da sie diese mit verschiedenen Holzsortimenten (z. B. Bauund Brennholz) und Nicht-Holzprodukten versorgen können.

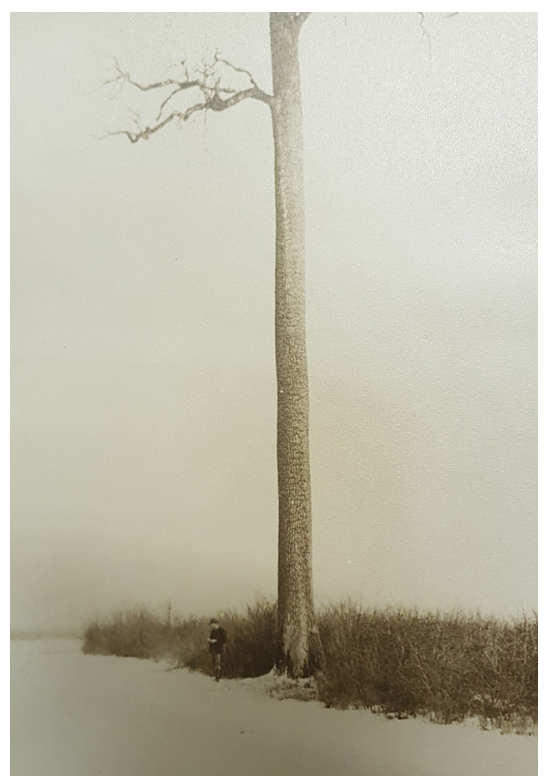

Abb. 2.5-1: Historische Aufnahme einer Esche vor einer großflächigen, gleichmäßig verjüngten Fläche in Vinkovci, Slawonien, Kroatien. 


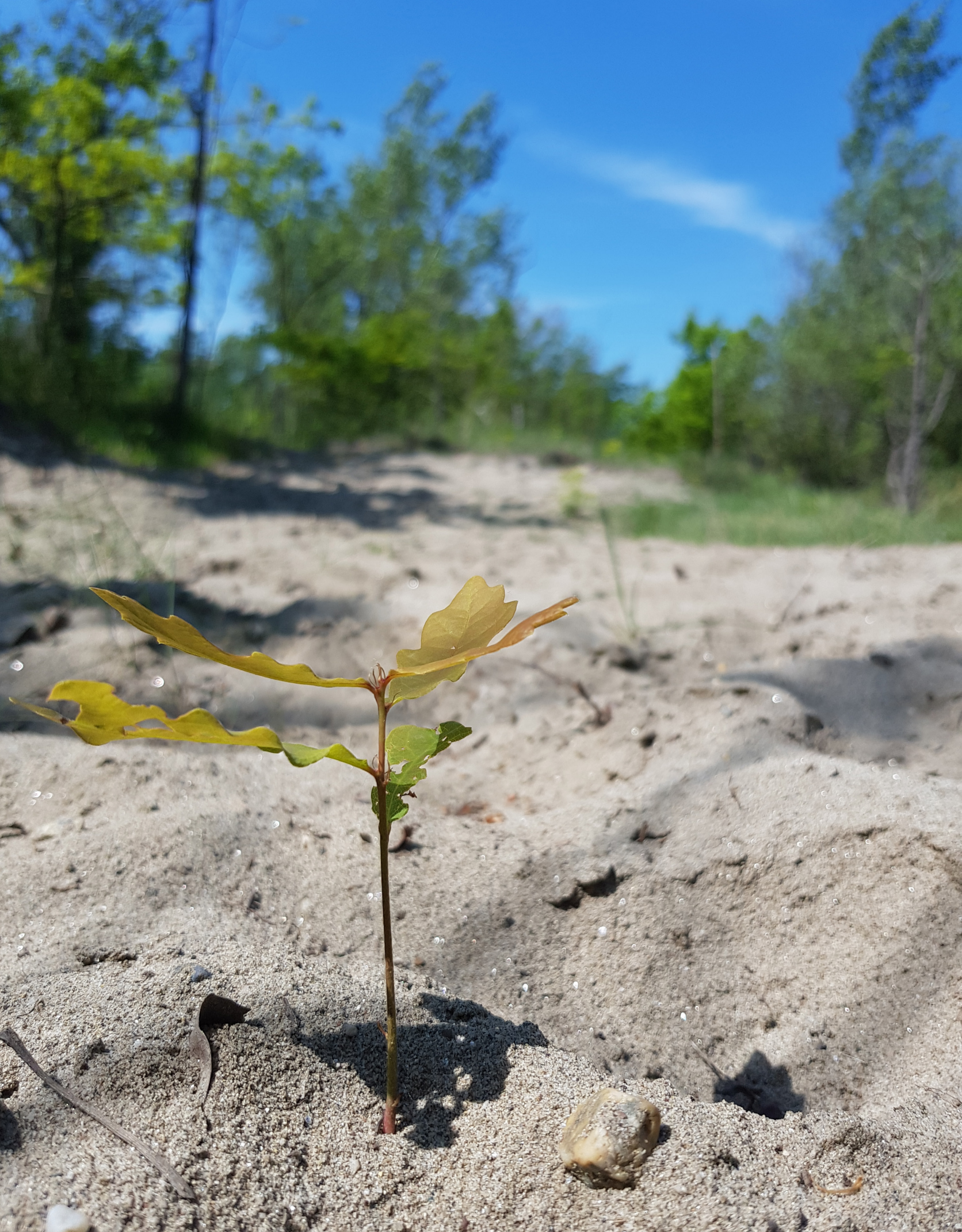




\section{MANAGEMENTLEIT- LINIEN FÜR AUWÄL- DER}

\subsection{Waldverjüngung und Genetik}

\subsubsection{Entscheidung für Natur- oder Kunstverjüngung?}

Marjana Westergren, Gregor Božič, László Nagy (Silvija Krajter Ostoić, Markus Sallmannshofer, Marko Kovac)

\section{Einleitung}

Die Verjüngung ist der wichtigste Teil des Lebenszyklus des Waldes. Es ist die Phase, durch die sich der Wald durch natürliche Selektion an veränderte Umweltbedingungen anpassen kann.

Sowohl die Naturverjüngung als auch die künstliche Verjüngung spielen eine wichtige Rolle bei der naturnahen nachhaltigen Bewirtschaftung von Auwäldern. Eine Förderung der Naturverjüngung ist aus den folgenden Gründen angebracht:

- da die natürliche Auslese bereits während der Keimung und der frühen Sämlingsentwicklung auf die Nachkommenschaft einwirkt und so die nachfolgende Baumgeneration an die jeweiligen lokalen Bedingungen gut angepasst ist,

- da die in der Naturverjüngungen auftretenden Baumarten vorwiegende das autochthone Baumartenspektrum umfassen,

- da Naturverjüngung bei der Begründung geringere Kosten verursacht.

Eine natürliche Verjüngung ist in Auwäldern jedoch oft nicht möglich, weil die Baumartenzusammensetzung zu stark verändert ist, die Bodenvegetation (die oft aus gebietsfremden Pflanzenarten besteht) sehr dicht ist und die zur Verjüngung erforderlichen Licht- und Feuchtigkeitsbedingungen verändert, die Flussdynamik zu stark verändert wurde, und der Wildeinfluss zu intensiv und großflächig auftritt. In derartigen Fällen bietet sich die künstliche Verjüngung als Alternative an. Bei der künstlichen Verjüngung kann der Waldbesitzer auch die Baumartenzusammensetzung und das erwartete Holzsortiment beeinflussen, z. B. um einen höheren Gewinn zu erzielen oder die Baumartenausstattung an die Veränderungen des Klimawandels und veränderte Standortsfaktoren (z. B. als Folge von Flussregulierungen) anzupassen. Die Anreicherungspflanzung ist eine Form der künstlichen Verjüngung, bei der die natürliche Verjüngung künstlich ergänzt wird, um die ökologischen, gesellschaftlichen oder wirtschaftlichen Waldfunktionen zu verbessern. 
In den Auwäldern des grenzüberschreitenden Biosphärenreservats Mur-Drau-Donau sind sowohl natürliche als auch künstliche Waldverjüngung von Bedeutung. Nach einer Expertenschätzung im Rahmen des Projekts REFOCuS überwiegt die natürliche Verjüngung in Serbien (64\%) und Kroatien (80 \%), während in Ungarn, Slowenien und Österreich die künstliche Verjüngung mit $80 \%, 75 \%$ und $60 \%$ der gesamten Waldverjüngung im Biosphärenreservat überwiegt. Diese Zahlen werden stark von den vorherrschenden Waldtypen und den entsprechenden Verjüngungstechniken bestimmt. Natürliche Verjüngung funktioniert am besten bei Eichen und Weiden, hat aber einen geringeren Erfolg bei anderen Auwaldgehölzen.
Grundsätzlich kann die künstliche Verjüngung durch Saat (z. B. Eiche) und durch die Pflanzung von Forstpflanzen in unterschiedlichen Größen bzw. von Stecklingen, die aus Spross- oder Wurzelteilen erzeugt wurden, erfolgen.

Die beste Option für die künstliche Verjüngung ist der Zugang zu hochwertigem forstlichem Vermehrungsgut mit erhöhter Toleranz gegenüber biotischem und abiotischem Stress. Die Produktion eines derartigen Materials setzt geeignete Saatgutbestände bzw. Stecklingsquartiere voraus, eine sachgemäße Saatgutgewinnung und -aufbereitung sowie geeignete Anzuchtbedingungen in der Baumschule, welche geeignet sind, die genetische Vielfalt des Materials zu erhalten und z. B. auch das Vorhandensein von Mykorrhiza fördern. Unter dem Gesichtspunkt der Erhaltung der genetischen Vielfalt bedeutet dies, dass das Saatgut in gleichen Mengen von einer ausreichenden Anzahl adulter Bäume gesammelt werden sollte, in der Regel mindestens 25, besser 50, nicht verwandte Bäume, die an aktuelle oder mögliche zukünftige Umweltbedingungen angepasst sind. Die Verwendung von qualifiziertem und geprüftem forstlichem Vermehrungsmaterial wird in der Regel die höchste genetische Qualität aufweisen und lässt den größten Mehrwert für die Forstwirtschaft erwarten.
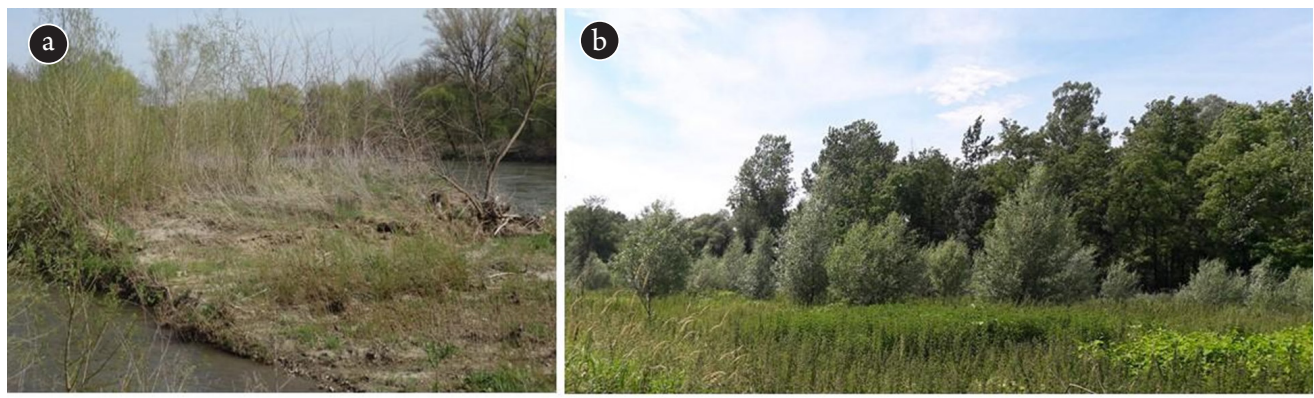

Abb. 3.1.1-1: Verjüngung von Weichholzwäldern entlang des Flusses Mur in Slowenien. A: Natürliche Verjüngung. B: Das Ergebnis der künstlichen Verjüngung von Silberweide auf Schwemmboden.

Sowohl die natürliche als auch die künstliche Verjüngung sollte den Leitprinzipien folgen, die auf den natürlichen Prozessen von Auwäldern basieren und die Biologie und Ökologie der Baumarten berücksichtigen. Diese Leitprinzipien sind:

- Die Wahl der Baumarten und Herkünfte sollte sich an den Standortbedingungen des Waldes orientieren. Dadurch wird sichergestellt, dass Arten und Herkünfte verwendet werden, die gut an die jeweiligen Standortbedingungen angepasst sind und daher biotischen und abiotischen Schadfaktoren widerstehen können und gleichzeitig hohe Wachstumsraten erzielen.

- Bisher wurde davon ausgegangen, dass heimische Baumarten und Samenherkünfte dieser Arten besser an die lokalen Standortbedingungen angepasst sind. Da heimische Baumarten mit anderen 
Pflanzen- und Tierarten in der jeweiligen Region koevolviert haben, stellen sie den besten Lebensraum für diese bereit. Diese Ansicht wird jedoch durch Umweltveränderungen (Klimawandel, Flussverbauungen) in Frage gestellt; daher kann die Beschaffung von forstlichem Vermehrungsgut aus benachbarten Regionen sinnvoller sein (Kapitel "Geeignetes forstliches Vermehrungsgut zur Anpassung der Wälder an den Klimawandel”).

- Nichtheimische Baumarten sollten nur gepflanzt werden, wenn sie nicht invasiv sind und in Situationen, in denen dies eine wirtschaftliche Notwendigkeit ist oder als Versicherung, wenn alle heimischen Baumarten ausfallen. Gesetzliche Beschränkungen für ihre Anpflanzung müssen beachtet werden. In jedem Fall sollten nichtheimische Baumarten einen kleineren Anteil des Waldes einnehmen.

- Die Einführung einer nicht-heimischen Art kann die Symbiose innerhalb eines Lebensraums stören und zu einer verminderten biologischen Vielfalt führen. Wenn das Vorhandensein nichtheimischen Arten nachteilige Auswirkungen hat, kann ihre Entfernung vor oder während der natürlichen oder künstlichen Verjüngung erforderlich sein.

- Der Schutz seltener und gefährdeter Baumarten und Samenherkünfte sollte in die Verjüngungsmaßnahmen einbezogen werden, indem man ihnen in Mischbeständen den Vorrang gibt.

- Die Dichte des Wildbestandes muss im Gleichgewicht mit der Tragfähigkeit des Standortes stehen.

\section{Natürliche Verjüngung}

Wenn möglich, sollte der Naturverjüngung der Vorrang gegeben werden. Damit die Naturverjüngung erfolgreich ist und die genetische Vielfalt erhalten werden kann, sollten mindestens 50 gesunde Samenbäume der Zielbaumart im Bestand vorhanden sein, die zudem mindestens $30 \mathrm{~m}$ voneinander entfernt stehen, um Verwandtschaft zu vermeiden. Gleichzeitig sollte die Bodenvegetation nicht zu dicht sein. Nach erfolgreicher Ansamung muss der Altbestand in Abhängigkeit der Lichtbedürfnisse der zu verjüngenden Baumart entweder durchforstet oder nach einigen Jahren vollständig abgetrieben werden, um geeignete Licht- und Feuchtigkeitsbedingungen für die Entwicklung der Sämlinge zu schaffen.

Natürliche Verjüngung funktioniert am besten für Eichen und Weiden und bis zu einem gewissen Grad auch für Pappeln. Eine erfolgreiche Naturverjüngung der Pappel erfordert das Vorhandensein geeigneter offener Habitate die durch die Flussdynamik geschaffen werden, zeitlich günstig fallende Niederschläge und einen leichten Zugang zu nährstoffreichem Grundwasser. Staunasse Flächen mit Sauerstoffmangel sind nicht geeignet. Die Naturverjüngung der europäischen Schwarzpappel kann jedoch aus Hybriden mit nichtheimischen Pap- 
peln bestehen. Aus diesem Grund wird die natürliche Verjüngung der Schwarzpappel in Ungarn nicht genutzt.

Wenn der Erfolg der natürlichen Verjüngung gering ist, kann die natürliche Verjüngung durch Anreicherungspflanzungen ergänzt werden, oder es sollte eine künstliche Verjüngung durchgeführt werden.

\section{Öffnung der Krone}

Um die natürliche Verjüngung zu fördern, kann durch die Entnahme einzelner Bäume oder eine kräftige Durchforstung die Kronenschicht geöffnet werden. Das fördert die Samenproduktion und sorgt für ausreichend Licht zur Keimung am Boden. Eine zu starke Öffnung der Kronenschicht kann jedoch zu einer üppigen Krautschicht führen, die eine natürliche Verjüngung verhindert. Es können unterschiedliche Lichtverhältnisse geschaffen werden, welche die richtigen Bedingungen für verschiedene Arten ermöglichen.

\section{Bodenvorbereitung}

Falls die natürlichen Störungen entlang des Flussbettes nicht ausreichen, muss zur Keimung von Schwarzpappel und Weidenarten der Boden vorher verwundet werden, um gute Keimbedingungen zu schaffen. Für andere Baumarten, muss ggf. ebenfalls die vorherrschende Krautund Strauchschicht entfernt oder reduziert werden bzw. sogar der Boden aufgelockert werden um geeignete Keimbedingungen zu schaffen.

Vor der Pflanzung oder Aussaat sollten die meisten Reste der Holzschlägerung wie Stümpfe oder Äste entfernt werden. Ein Teil des Altholzes kann jedoch im Bestand verbleiben, da es zahlreichen Tieren und Pilzen einen Lebensraum bietet. Wenn Unkräuter wie Rubus sp., Sträucher oder exotische Pflanzen vorhanden sind, sollten diese vor der Aussaat oder Pflanzung ebenfalls entfernt werden (Abb. 3.1.1-4).

Bei der Bodenvorbereitung auf empfindlichen Böden und in sensiblen Lebensräumen wie Sumpf- oder Moorgebieten, dem Vorkommen von Horstgräsern, kleinen Flussbetten usw. sollte der Einsatz schwerer Maschinen vermieden werden, da sie Bodenschäden und -verdichtungen verursachen.

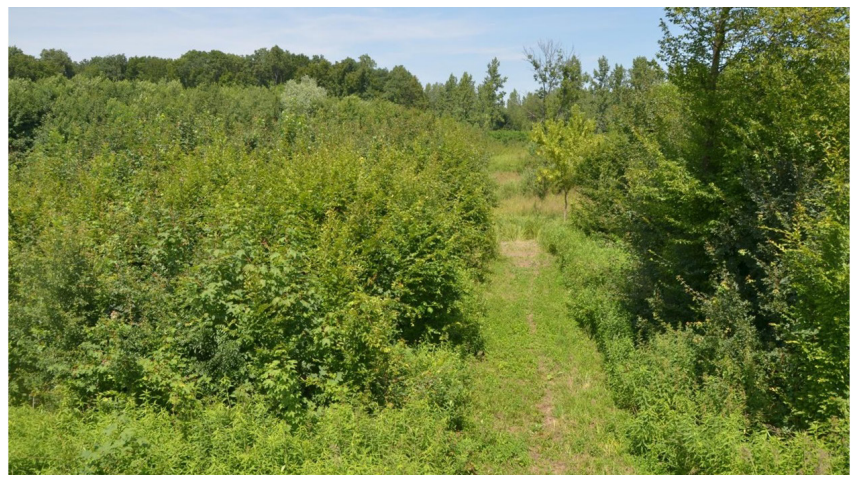

Abb. 3.1.1-3: Natürliche Verjüngung von Hartholzbaumarten. 


\section{Künstliche Verjüngung}

Künstliche Verjüngung wird dann eingesetzt, wenn eine natürliche Verjüngung nicht möglich oder nicht ausreichend vorhanden ist. Wichtige Gründe für den Einsatz künstlicher Verjüngung können sein: eine notwendige Änderung der Baumartenzusammensetzung; ungünstige Lichtverhältnisse aufgrund dichter Bodenvegetation (oft bestehend aus nichtheimischen Pflanzenarten); ein abgesenkter Grundwasserspiegel in der Aue, der eine natürliche Verjüngung verhindert; oder die zusätzliche Berücksichtigung bestimmte Ökosystemleistungen. Künstliche Verjüngung wird daher hauptsächlich eingesetzt, um alte Auwaldbestände zu regenerieren, durch Krankheiten, Schädlinge oder Windwurf gestörte Bestände wiederherzustellen, neue Auwälder auf kahlen Flächen zu etablieren (Plantagenumwandlungen, Neuaufforstungen) und um die genetische Vielfalt zu sichern und natürliche Prozesse zu unterstützen, die zu resilienten Wäldern führen.

\section{Auswahl von forstlichem Vermehrungsgut}

Es gibt vier Kategorien von forstlichem Vermehrungsgut: „quellengesichert", „ausgewählt“, „qualifiziert“ und „getestet“. Die genetische Qualität und die Kontrolle der Eigenschaften des künstlich verjüngten Bestandes steigen von der Kategorie „quellengesichert“ bis zur Kategorie „geprüft“ an. Im Allgemeinen stammt qualifiziertes und geprüftes Vermehrungsmaterial aus Samenplantagen, von Familieneltern, Klonen oder Klonmischungen, während quellengesichertes Vermehrungsmaterial aus Samenbäumen oder Samenbeständen kommt. Ausgewähltes Vermehrungsgut stammt dagegen immer aus Saatguterntebeständen, die aufgrund ihrer sichtbaren Überlegenheit in einer Reihe von wichtigen Merkmalen ausgewählt und zugelassen wurden.

Wenn möglich, sollte qualifiziertes oder geprüftes forstliches Vermehrungsgut verwendet werden. Wenn dies nicht möglich ist, ist ausgewähltes Material dem quellengesicherten vorzuziehen. Qualifiziertes und geprüftes forstliches Vermehrungsmaterial kann auch das Ergebnis von Züchtungsaktivitäten sein.

Die nationale Gesetzgebung zur Herkunft des zu verwendenden forstlichen Vermehrungsgutes ist zu beachten.

\section{Artenauswahl}

Für die künstliche Verjüngung in Auwäldern werden je nach Lebensraum verschiedene Arten empfohlen. (1) Das Fluss-Weidengebüsch ist eine Pioniervegetation, die sich speziell an Flussufern entwickelt; sie ist mit den größeren Flüssen verbunden und bildet oft einen schmalen Gürtel zwischen dem Flussbett und den Weichholzwäldern. Auch Weiden-Sumpfgebüsche, die meist Bereiche ohne Oberflächenentwässerung und Altarme besiedeln, werden hier erfasst. (2) Weichholz-Auwälder wachsen in den tiefer gelegenen Teilen der Auen, diese hygrophilen, von Weiden und Pappeln dominierten Wälder werden noch regelmäßig überflutet. (3) Hartholz-Auwälder kommen auf den höher gelegenen Teilen aktueller oder ehemaliger Überschwemmungsgebie- 
te im Tiefland sowie in den breiten Tälern der kollinen Regionen vor. (4) $\mathrm{Zu}$ den Übergangswäldern gehören stark umgewandelte, künstliche Wälder oder intensiv bewirtschaftete Plantagen.

Table 3.1.1-1: Empfohlene Baumarten für die künstliche Verjüngung in Abhängigkeit vom Auwaldtyp.

\begin{tabular}{|c|c|c|c|c|}
\hline Art & Weidengebüsch & Weichholzwälder & Hartholzwälder & Übergang \\
\hline Acer campestre & & & $\mathrm{X}$ & $\mathrm{X}$ \\
\hline Acer pseudoplatanus & & & $\mathrm{X}$ & $\mathrm{X}$ \\
\hline Alnus glutinosa & & $\mathrm{X}$ & $\mathrm{X}$ & $\mathrm{X}$ \\
\hline Alnus incana & & $\mathrm{X}$ & $\mathrm{X}$ & $\mathrm{X}$ \\
\hline Carpinus betulus & & & $\mathrm{X}$ & $\mathrm{X}$ \\
\hline Fraxinus angustifolia & & & $\mathrm{X}$ & $\mathrm{X}$ \\
\hline Fraxinus excelsior & & & $\mathrm{X}$ & $\mathrm{X}$ \\
\hline Juglans nigra & & & & $\mathrm{X}$ \\
\hline Malus sylvestris & & & $\mathrm{X}$ & $\mathrm{X}$ \\
\hline Prunus avium & & $\mathrm{X}$ & $\mathrm{X}$ & $\mathrm{X}$ \\
\hline Prunus padus & & $\mathrm{X}$ & $\mathrm{X}$ & $\mathrm{X}$ \\
\hline Populus alba & & $\mathrm{X}$ & $\mathrm{X}$ & $\mathrm{X}$ \\
\hline Populus hybrids & & & & $\mathrm{X}$ \\
\hline Populus nigra & $\mathrm{X}$ & $\mathrm{X}$ & $\mathrm{X}$ & $\mathrm{X}$ \\
\hline Populus $\mathrm{x}$ canescens & & $\mathrm{X}$ & & $\mathrm{X}$ \\
\hline Pyrus pyraster & & & $\mathrm{X}$ & $\mathrm{X}$ \\
\hline Quercus robur & & & $\mathrm{X}$ & $\mathrm{X}$ \\
\hline Salix alba & $\mathrm{X}$ & $\mathrm{X}$ & & $\mathrm{X}$ \\
\hline Salix fragilis & $\mathrm{X}$ & $\mathrm{X}$ & & $\mathrm{X}$ \\
\hline Andere Salix spp. ${ }^{*}$ & $\mathrm{X}$ & & & \\
\hline Tilia cordata & & & $\mathrm{X}$ & $\mathrm{X}$ \\
\hline Ulmus glabra & & & $\mathrm{X}$ & $\mathrm{X}$ \\
\hline Ulmus laevis & & & $\mathrm{X}$ & $\mathrm{X}$ \\
\hline Ulmus minor & & & $\mathrm{X}$ & $\mathrm{X}$ \\
\hline
\end{tabular}

*einschließlich S. cinerea, S. elaeagnos, S. purpurea, S. triandra, S. viminalis, S. daphnoides, S. fragilis, S. petandra 
Wenn die Verwendung nichtheimischer Baumarten gerechtfertigt und durch die einschlägigen forstlichen und naturschutzrechtlichen $\mathrm{Ge}$ setzgebung erlaubt ist, können nichtheimische Pappelarten und ihre Hybriden sowie Schwarznuss (Juglans nigra) verwendet werden. Jede Entscheidung sollte sorgfältig getroffen werden, gut geplant sein und die Maßnahmen sollten überwacht werden. Robinia pseudoacacia und Quercus rubra, zwei Arten, die in Auwäldern häufig vorkommen, sind manchmal konkurrenzstärker als heimische Arten und ihre unkontrollierte Ausbreitung kann zu einem Verlust der Artenvielfalt führen. Obwohl Robinie und Schwarznuss wichtige nichtheimische Baumarten mit vielen Vorteilen für den Waldbesitzer und andere Interessengruppen wie Imker sind, sollten intensive Pflanzungen in unmittelbarer Nähe von Waldschutzgebieten und gefährdeten Lebensräumen vermieden werden, um eine weitere Ausbreitung zu verhindern.

\section{Aussaat und Pflanzung}

In Auwäldern ist die Aussaat oder Pflanzung auf größeren offenen Flächen oft erfolgreicher. Auf kleineren Aufforstungen unter 1 ha kommt häufig einen dämmende teils invasive Bodenvegetation vor, die den Erfolg der Saat- bzw. Pflanzung einschränkt. In einigen Ländern begrenzt die aktuelle Gesetzgebung jedoch die maximale Größe von offenen Aufforstungen und diese kann u. U. zu klein für einen optimalen Aufforstungserfolg sein.

Pflanzungen sollten zwischen Oktober und März erfolgen, wenn die Sämlinge vollständig in der Ruhephase sind und den Stress, der durch das Ausheben, Hantieren, Lagern, Transportieren und die Pflanzung selbst entsteht, am besten vertragen.

Je nach Abstand zwischen den gepflanzten Setzlingen von 3 bis $2 \mathrm{~m}$ werden zwischen 1100 und 2500 Setzlinge für eine Fläche von 1 ha benötigt, für Eichenreihenkonzepte (siehe Kapitel Künstliche Verjüngung der Stieleiche als Maßnahme zum Aufbau von Eichenwäldern, als Ergänzungspflanzung und zur Wiederherstellung von Auwaldökosystemen) werden bis zu 5000 Pflanzen benötigt.

Für die meisten Auwaldarten ist das geeignetste Forstpflanzensortiment $1+2$, wenn die Sämlinge drei Jahre alt sind. Bei Eiche sollten die Setzlinge, die am besten mittels Lochpflanzung gesetzt werden 1,0 bis $1,3 \mathrm{~m}$ hoch sein. Die Setzlinge von Schwarzpappel und Weide sollten zwischen 2,0 und 4,0 $\mathrm{m}$ hoch sein und in 0,8 bis $1,0 \mathrm{~m}$ tiefe Löcher gepflanzt werden.

Manchmal kann die Aussaat von Eichen der Pflanzung vorgezogen werden, weil der Arbeitsaufwand geringer ist und vergleichbare Ergebnisse erzielt werden, wenn das Wild, insbesondere Wildschweine, aus dem Verjüngungsgebiet ausgeschlossen werden können (Zaun). Auf flachem Boden hat sich die Aussaat von Eicheln im Frühjahr mit einer speziellen Maschine bewährt, die den Boden bearbeitet und gleichzeitig die Eicheln aussät. In hügeligem Gelände hat sich die Aussaat von zwei bis vier Eicheln im Frühjahr in kleine Löcher nach manueller Bodenbearbeitung bewährt. 


\section{Pflegen}

Die manuelle Pflege von Sämlingen und Schösslingen (Entfernen von Unkraut rund um die Pflanze) ist mindestens einmal pro Vegetationsperiode erforderlich. Bei aggressiver Bodenvegetation sind mehrere Eingriffe üblich. Die Überlebensrate der Sämlinge steigt jedoch mit jeder zusätzlichen Pflegemaßnahme. Zwei bis vier Pflegeeingriffe pro Vegetationsperiode sind optimal.

Die Pflege sollte mindestens so lange durchgeführt werden, bis der Setzling größer ist als das umliegende Unkraut. Bei Pappeln sollte die Pflege einmal pro Jahr durchgeführt werden, und zwar zwei bis vier Jahre lang, nachdem die Setzlinge größer als die Bodenvegetation sind, um die Konkurrenz um Wasser und Nährstoffe zu beseitigen und ihr frühes Wachstum zu beschleunigen.

\section{Wildverbiss-Steuerung}

Die Umzäunung von großen Flächen zum Schutz von Sämlingen und jungen Bäumen ist die wirksamste Maßnahme gegen Wildverbiss. Der Zaun sollte mindestens $30 \mathrm{~cm}$ tief in den Boden eingelassen werden, um eine Zerstörung des Zaunes bzw. ein Untergraben durch Tiere zu verhindern. Auf kleineren Flächen können Setzlingen auch durch Einzelschutzmaßnahmen geschützt werden (Kapitel "Wildeinfluss und Wildtiermanagement").
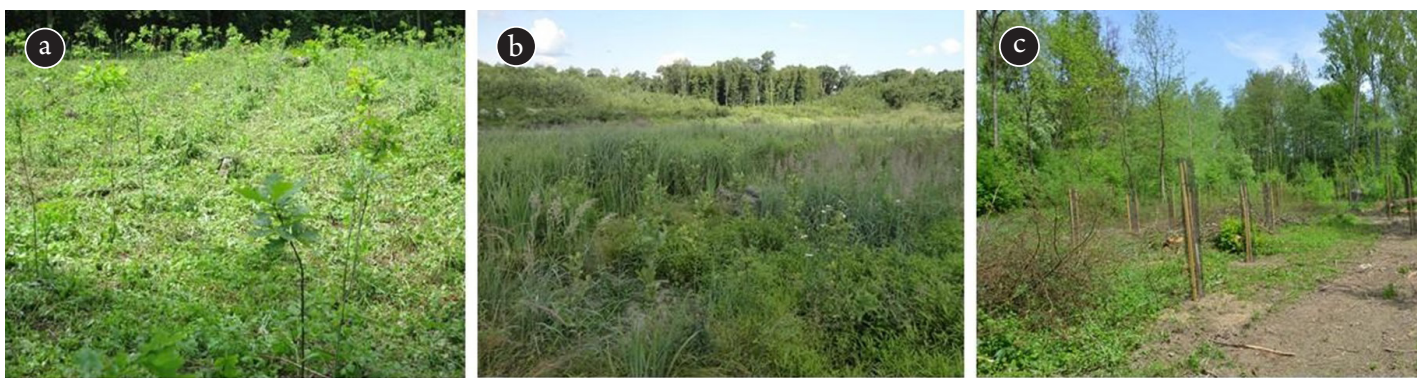

Abb. 3.1.1-2: Künstliche Verjüngung in Slowenien. A: Entwicklung von Stieleichensämlingen nach einer Wachstumsperiode. B: Pflegearbeiten sind notwendig, um die gepflanzten Sämlinge der Schwarzerle frei zu stellen. C: Einzelschutz der Schwarzpappel unmittelbar nach der Pflanzung ist eine notwendige Maßnahme, um die Sämlinge vor Verbiss zu schützen.

\section{Stockausschlag, Niederwald mit Standards}

Stockausschlag ist häufig in Auwäldern zu finden und funktioniert gut bei Pappel, Weide, Eiche, Esche und Erle. Nach dem Fällen der Bäume, regeneriert sich der Wald innerhalb weniger Jahre aus den verbliebenen Stöcken bzw. Wurzeln und bildet so einen Niederwald. Vorraussetzung dafür ist, dass genügend Licht zum Boden dringt, um eine kräftiges Regeneration zu fördern. Deshalb sollte ein ausreichend großer Teil des Niederwaldes, d.h. mindestens 0,1 bis 0,2 ha gleichzeitig geschnitten werden. Allerdings können die Bäume im Niederwald nicht kontinuierlich über mehrere Umtriebe hinaus vermehrt werden, da die Stockausschläge mit jedem Umtrieb wertloser werden (reduzierte Zuwachsleistung, schlechte Wuchsformen, Fäuleanfälligkeit). Zwei, manchmal 
drei Umtriebe machen bei Eichen, Eschen, und Erlen wirtschaftlich Sinn. Pappeln und Weiden, besonders auf schlechten Standorten, werden oft für eine höhere Anzahl an Umtrieben gepflanzt. Daher sollten derartige Bestände regelmäßig durch sexuell vermehrte Sämlinge ergänzt werden. Zur Verjüngung von Teilen des Niederwaldes können sowohl Naturverjüngung als auch Pflanzung nach den oben beschriebenen Überlegungen eingesetzt werden.

Der Niederwald kann als nützliches Instrument für Maßnahmen zur In-situ-Generhaltung oder, wenn eine Reduzierung der Bewirtschaftungsintensität angestrebt wird, für die Erhaltung der biologischen Vielfalt im Allgemeinen dienen.

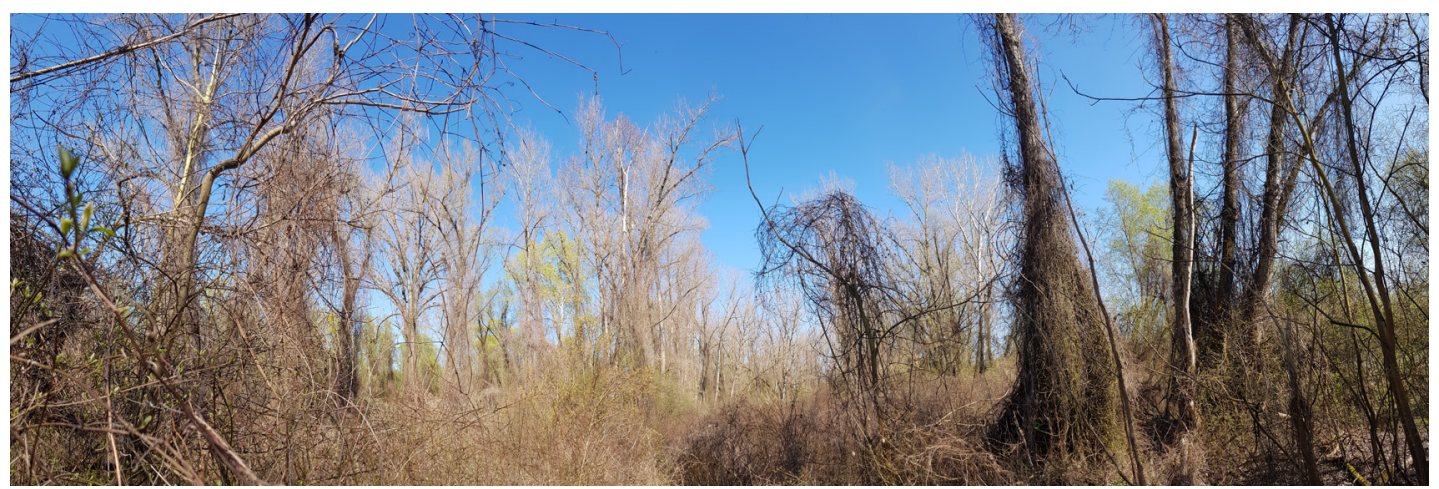

Abb. 3.1.1-4: Aggressive Waldrebe überwuchert die Verjüngung in einer Bestandes an der Drau, Ungarn.

\section{Ausblick und Zusammenfassung}

Durch Verjüngung kann sich der Wald an veränderte Umweltbedingungen anpassen. Sowohl die Naturverjüngung als auch die künstliche Verjüngung spielen eine wichtige Rolle bei der naturnahen, nachhaltigen Bewirtschaftung von Auwäldern. Ersterer sollte der Vorzug gegeben werden, da sie eine Anpassung durch natürliche Auslese ermöglicht und weniger kostspielig ist, aber in geschädigten und gestörten Wäldern und bei Fehlen geeigneter Samenquellen oft nicht möglich ist. Dann kommt die künstliche Verjüngung zum Einsatz, durch die auch eine Anpassung an veränderte Bedingungen möglich ist. Baumartenund Herkunftsauswahl, insbesondere unter Berücksichtigung des zukünftigen Klimas, sind ein entscheidender Schritt bei der künstlichen Verjüngung. In Auwäldern braucht die Naturverjüngung oft menschliche Eingriffe, durch Regulierung der Lichtmenge, Bodenvorbereitung, Pflege der Setzlinge und Schutz vor Tieren, ähnlich wie bei gepflanzten Setzlingen. 


\subsubsection{Geeignetes forstliches Vermehrungsgut zur Anpassung der Wälder an den Klimawandel}

Markus Sallmannshofer, Silvio Schüler

\section{Nationale Herkunftsgebiete schränken die Anpassung an den Klimawandel ein}

Waldökosysteme in Europa und die Verbreitungsgebiete europäischer Hauptbaumarten sind nicht durch nationale Grenzen und administrative Einheiten begrenzt, sondern von den vorherrschenden Klimabedingungen, welche oft von den topographischen Gegebenheiten (u.a. Gebirgszügen) und der geografischen Lage bestimmt werden. Auch die lokale Anpassung von Bäumen an ihre jeweiligen Standorte wird in größerem Ausmaß vom Klima und zu einem gewissem Anteil vom Boden bestimmt, aber keinesfalls von Landesgrenzen. Die bisherigen Regelungen zur Nutzung von forstlichem Vermehrungsgut (Saatgut, Pflanzgut, Stecklinge) auf nationaler Ebene berücksichtigen lokale Anpassungen in ihren Herkunftsgebietsgliederungen. Allerdings erschweren Sie die ökologische Vergleichbarkeit auf transnationaler Ebene und damit einen im Klimawandel wünschenswerten Austausch forstlichen Vermehrungsguts.

Auf nationaler Ebene der meisten europäischen Länder inklusive der Länder des TBR MDD machen Auwälder nur einen kleinen Teil der Waldökosysteme aus und sind damit auch in der Gliederung der Herkunftsgebiete unterrepräsentiert. Der geringe Anteil an Austandorten und damit auch der vergleichsweise geringe Bedarf von speziellem Saat- und Pflanzgut für Auwälder ist oft die Ursache für einen gravierenden Mangel an geeignetem, gut an Austandorte angepasstem Pflanzmaterial auf nationaler Ebene: da der Pflanzenbedarf so gering ist, lohnt es sich für viele Forstpflanzenproduzenten nicht, speziell für die Region des TBR MDD Forstpflanzen zu produzieren. Stattdessen werden größere Mengen Saat- und Pflanzgut für kolline und submontane Laubmischwälder der jeweiligen Region produziert und bei Bedarf auch im Auwald eingesetzt. Dieses Vermehrungsgut wird den ökologischen Bedingungen der Auwälder nur bedingt gerecht.

Es wird erwartet, dass der Klimawandel zu veränderten Standortsbedingungen für Wälder, einschließlich der Auwälder, führen wird. Der Klimawandel umfasst nicht nur einen Temperaturanstieg, sondern auch Veränderungen in der Häufigkeit und saisonalen Verteilung von Niederschlagsereignissen sowie eine Zunahme von klimatischen Extremereignissen (wie Stürme, Dürren und Überschwemmungen). Als Folge des Klimawandels verändern sich auch die lokalen Standortsbedingungen für Waldbäume und damit auch deren potentielle Verbreitungsgebiete; die wahrscheinliche Veränderung im Klimawandel kann durch geeignete Baumartenverbreitungsmodelle bei verschiedenen Klimaszenarien simuliert werden. 
Folgen und Wechselwirkungen zwischen Klimawandel und biotischen Stressfaktoren

Neben dem unmittelbaren Einfluss des Klimawandels auf Waldbäume hat sich gezeigt, dass vor allem biotische Störungen durch neu auftretenden Baumkrankheiten, neu einwandernde Schadinsekten und die verstärkte Vermehrung bereits bekannter Schädlinge das Überleben und zukünftige Vorkommen von Baumarten stark beeinflussen. Zudem ist zu erwarten, dass die Anpassungsfähigkeit von Schädlingen und Krankheiten aufgrund des schnelleren Generationswechsels höher ist als bei den Wirtsbaumarten. Weiterhin kann die Ausbreitung nichtheimischer Pflanzen zunehmen, was zu einem höheren Konkurrenzdruck auf heimische Pflanzengemeinschaften führen kann.

Gezielter Transfer von Vermehrungsgut als Maßnahme gegen verzögerte Anpassung

Im Vergleich zu anderen Organismen ist die Generationsdauer von Bäumen sehr lang. Daher ist die Anpassungsfähigkeit und Migrationsfähigkeit deutlich geringer als die Geschwindigkeit des Klimawandels. Diese verzögerte Anpassung wird viele Waldbeständen nachhaltig gefährden und damit auch die Ökosystemleistungen vieler Wälder bedrohen. Für die Verjüngung von Wäldern im Rahmen von Aufforstung und Naturverjüngung galt bisher die Regel, dass lokales Vermehrungsgut am besten ist. Dieses Paradigma muss im Klimawandel in Frage gestellt werden. Stattdessen sollte für heutige Verjüngungsmaßnahmen Vermehrungsgut ausgewählt werden, dass eine hohe Anpassungsfähigkeit an erwartete zukünftige Bedingungen besitzt, auch wenn diese aus anderen Teilen der natürlichen Verbreitungsgebiete unserer Waldbäume stammt. Der Transfer von Saat- und Pflanzgut, um eine schnellere Anpassung unserer Wälder zu gewährleisten, wird als „unterstützte Wanderung“ von Bäumen, bzw. als „unterstützter Genfluss“ bezeichnet. Mit der Auswahl besser für zukünftiges Klima geeigneten Pflanzmaterials könnte nicht nur die Überlebensrate potenziell gesteigert werden, es besteht auch die Chance auf Leistungssteigerungen sowohl im Wachstum als auch hinsichtlich der Widerstandsfähigkeit. Bei Aufforstungen stehen Waldbewirtschafter daher vor der Herausforderung, gut angepasstes Pflanzmaterial für Aufforstungen zu identifizieren.

Leitfaden zur Nutzung von Baumartenverbreitungsmodellen und Saatguttransferzonen im Klimawandel

Um die Herkunftswahl in Auwäldern zu unterstützen, wurden für die REFOCuS-Projektländer Baumartenverbreitungsmodelle und Saatguttransferzonen entwickelt (http://www.interreg-danube.eu/approved-projects/refocus/outputs). Mit dem fortschreitenden Klimawandel werden auch diese Zonen ihre räumliche Ausdehnung dynamisch verändern. Diese Werkzeuge können Waldbewirtschafter und Naturschützern allerdings schon heute dabei unterstützen, forstliches Vermehrungsgut auszuwählen, das für die zukünftigen Klimabedingungen eines bestimmten Gebietes geeignet ist. 
Die Ergebnisse der Baumartenverbreitungsmodelle und Saatguttransferzonen sind als grenzüberschreitende Karten (Beschreibungen und Web-Links im Anhang) für die sieben wichtigsten Auwaldbaumarten bereitgestellt. Zur Identifizierung von geeignetem forstlichem Vermehrungsgut werden zwei verschiedene Karten in drei Schritten verwendet:

1. Prüfung der zukünftigen Eignung der klimatischen Bedingungen am Pflanzort mit Baumartenverbreitungsmodellen.

2. Falls die gewählte Baumart für den betreffenden Standort auch in Zukunft noch geeignet ist, wird eine für die künftigen Bedingungen geeignete Samenherkunft ausgewählt. Um diese Samenherkunft auszuwählen, muss die betreffende Saatguttransferzone identifiziert werden, die für die Zukunft am Pflanzort prognostiziert wird.

3. Anschließend muss die Saatguttransferzone, die in Zukunft am Pflanzort auftreten wird, unter aktuellem Klima lokalisiert werden. Die Saatguttransferzone unter aktuellem Klima stellt den Teil des heutigen Verbreitungsgebietes einer Art dar, aus dem das forstliche Vermehrungsgut für die heutige Anpflanzung zu beziehen ist.

Es stehen Kartensätze sowohl für ein extremes (RCP 8.5) als auch für ein moderates Klimaszenario (RCP 4.5) zur Verfügung. 


\section{Beispiel (A)}

Die Leitung eines im westlichen Niederösterreich gelegenen Betriebes (rotes Kreuz in der Karte, Abb. 3.1.2-1) ist mit einem klimawandelbedingten Ausfall ihrer Hauptbaumart konfrontiert. Nach Prüfung der Eignung der Stieleiche (Quercus robur) unter zukünftigen Klimabedingungen mit sowohl RCP 4.5 als auch 8.5 (beide mit 0,8-1,0 klimatischer Eignung für die Art), entscheidet sich die Betriebsleitung für die Pflanzung von Stieleiche (Schritt I). Die gewählte Provenienz soll möglichst an die erwarteten klimatischen Bedingungen der Zukunft angepasst sein. Daher wird die Saatguttransferzone "CL4" um das Jahr 2100 am Standort des Unternehmens identifiziert (Schritt II). Schließlich wird forstliches Vermehrungsgut einer Herkunft der aktuellen Zone "CL4", die also bereits heute die gleichen klimatischen Bedingungen aufweist, zum Transfer ausgewählt (Schritt III).

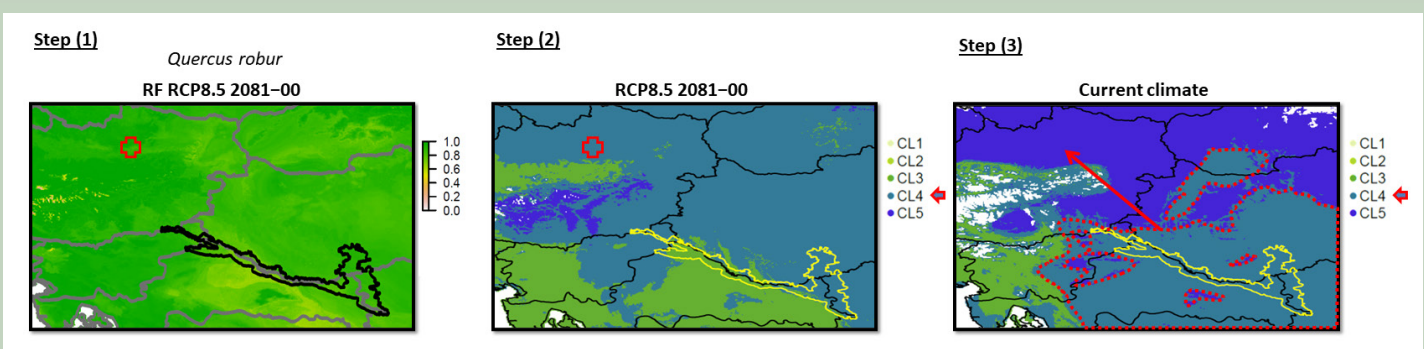

Abb. 3.1.2-1: Beispielhafter Transfer unter Anwendung der REFOCuS Baumartenverbreitungsmodelle (Step I) und der Saatguttransferzonen (Step II und III).

\section{Einschränkungen}

Die Karten sind eine zeitgemäße Hilfestellung und als ein Werkzeug für Praktiker zu sehen. Dennoch gibt es einige Einschränkungen, die bei der Verwendung zu beachten sind:

- Die Modelle beinhalten nur klimatische Variablen. Andere biotische und abiotische Faktoren müssen von den Waldbewirtschaftern auf der Grundlage ihrer Kenntnisse der lokalen Bedingungen berücksichtigt werden (z. B. Grundwasserversorgung und -level, Bodentyp, Stürme, Schädlinge und Krankheiten). Bei Berücksichtigung zusätzlicher Standortsfaktoren kann die regionale Eignung einer Baumart durchaus von den europaweit modellierten Baumartenverbreitungen abweichen.

- Die Fähigkeit von Baumarten, sich an veränderte Klimabedingungen anzupassen, ist sowohl auf Arten- als auch Populationsebene schwer zu quantifizieren. Daher kann das Ausmaß der "Anpassungsverzögerung” nicht exakt quantifiziert werden. Dennoch wird ein vorsichtiger Transfer von Vermehrungsgut unter Berücksichtigung möglicher negativer Effekte (z. B. zunehmende Frostempfindlichkeit) für einige Baumarten als eine der besten Optionen zur Überwindung der „Anpassungsverzögerung“ angesehen.

- Klimawandelszenarien enthalten große Unsicherheiten, so dass auch davon abgeleitete Veränderungen der Baumartenverbreitung und des Samentransfers unsicher sind.

- Interpolierte und herunterskalierte Klimadaten passen mög- 
licherweise nicht zu den lokalen Bedingungen des betreffenden (Mikro-)Standorts oder der zu transferierenden Provenienz.

- Aktuelle Baumvorkommen, die als Trainingsgrundlage der Modelle dienen, wurden stark vom Menschen beeinflusst.

\section{Beispiel (B)}

Ein Forstbetrieb im Biosphärenreservat Mur-Drau-Donau an der kroatisch-ungarischen Grenze (rotes Kreuz auf der Karte, Abb. 3.1.2-2) hat das Ziel, die derzeitige potenzielle Waldgesellschaft wiederherzustellen und zu erhalten. Die Flatterulme (Ulmus laevis) ist dabei von Interesse. Die aktuellen klimatischen Bedingungen sind ausgezeichnet (Vorkommenswahrscheinlichkeit von 0,8-1,0, in Abb. 3.1.2-2 nicht dargestellt), aber die Klimabedingungen sowohl unter RCP 4.5 als auch 8.5 sagen voraus, dass der Standort für die Zielbaumart in der Eignung abnimmt. Die prognostizierte Vorkommenswahrscheinlichkeit mit RCP 8,5 liegt unter 0,2 (Schritt I). Dennoch entscheidet sich der Forstbetrieb aus Gründen des Naturschutzes für die Pflanzung von Flatterulme und zählt dabei sowohl auf

- die natürliche Fähigkeit der Baumart, sich an die zukünftigen Bedingungen anzupassen und

- die Auswahl einer Herkunft aus Klimabedingungen, die in Zukunft wahrscheinlich auftreten werden.

Es wird festgestellt, dass die Saatguttransferzone “CL5” um 2100 am Standort vorhanden sein wird (Schritt II). Schließlich wird forstliches Vermehrungsgut einer Herkunft, die bereits heute dieselben klimatischen Bedingungen aufweist, also der aktuellen Zone "CL5", zum Transfer ausgewählt (Schritt III).

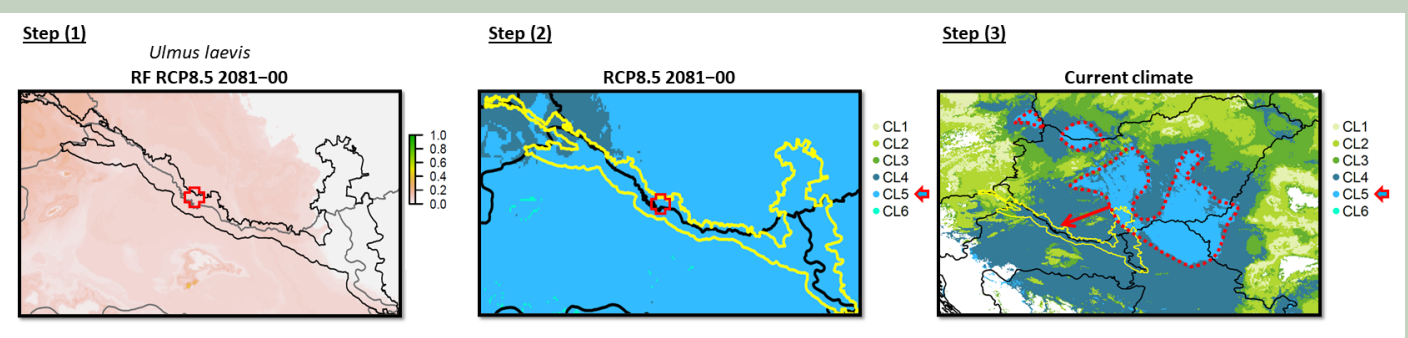

Abb. 3.1.2-2: Beispielhafter Transfer unter Anwendung der REFOCuS Baumartenverbreitungsmodelle (Step I) und der Saatguttransferzonen (Step II und III). 


\subsubsection{Generhaltung in der Praxis}

\section{Gregor Božič, Marjana Westergren, Marko Kovač}

Die langlebigen Waldbäume sind im Laufe ihres Lebens einer Vielzahl von abiotischen (z. B. Klima) und biotischen (z. B. Schädlinge, Konkurrenz) Stressfaktoren ausgesetzt und müssen daher eine entsprechende Anpassungsfähigkeit besitzen, um diesen Einflüssen zu trotzen. Eine nachhaltige Waldbewirtschaftung sollte daher auch das Prinzip der genetischen Nachhaltigkeit berücksichtigen. Nur so kann der gesamte gegenwärtige Nutzen des Waldes auch für die Zukunft gesichert werden. Waldbaumarten wachsen unter vielfältigen ökologischen Bedingungen, an die sie sich durch natürliche (und manchmal auch künstliche) Selektion angepasst haben. Im Durchschnitt haben Waldbaumarten eine hohe genetische Vielfalt innerhalb der Populationen. Diese hohe genetische Vielfalt innerhalb der Population macht Waldbestände widerstandsfähiger gegen verschiedene abiotische und biotische Stressfaktoren, da genetische Unterschiede zwischen den Bäumen es einigen ermöglicht, zu überleben und sich fortzupflanzen und so eine kontinuierliche Anpassung der Population an neue Umgebungen und sich verändernde Umweltbedingungen durch evolutionäre Veränderungen stattfindet.

Die genetische Vielfalt von Bäumen ist nicht einfach zu beobachten und $\mathrm{zu}$ quantifizieren. Normalerweise beobachten und untersuchen wir sie durch:

- phänologische Vielfalt,

- Unterschiede im Wachstum,

- Unterschiede in der Stammform,

- Grad der Resistenz gegen biotische und abiotische Beeinträchtigungen,

- Allel-Polymorphismus (molekulare Marker) innerhalb und zwischen Populationen.

Die genetische Vielfalt der Wälder zu erhalten und nachhaltig zu nutzen ist eine notwendige, aber nicht einfache Aufgabe. In der Vergangenheit (und in weiten Teilen der Welt auch heute noch) haben der Wald, die von ihm erbrachten Ökosystemleistungen und seine genetischen Ressourcen in der Praxis wenig Wert. Global gesehen sind die größten Bedrohungen für die genetischen Ressourcen der Wälder:

- industrielle Forstwirtschaft unter Verwendung von Vermehrungsgut mit einer schmalen genetischen Basis,

- Lebensraumverlust durch Abholzung, Fragmentierung, Urbanisierung und Feuer,

- Veränderungen von autochthonen Wäldern mit nichtheimischen Baumarten,

- $\quad$ unsachgemäße und unkontrollierte Verwendung von forstlichem Vermehrungsgut, 
- der Verlust von lokalen Rassen und autochthonen Populationen,

- invasive Arten,

- Klimawandel.

Die schnelle Geschwindigkeit des Klimawandels und seine unvorhersehbaren Auswirkungen auf lokaler Ebene erfordern jedoch als Vorsichtsmaßnahme die Erhaltung der genetischen Vielfalt einschließlich des Anpassungspotenzials der Wälder. Diese Themen werden zu einer der wichtigsten Aufgaben der Forstwissenschaft, -politik und -praxis.

Die Verjüngung von Wäldern ist die Schlüsselphase für die Weitergabe der genetischen Information des alten Bestandes an den neuen. Allerdings können die genetischen Ressourcen des Waldes trotz natürlicher Verjüngung bedroht sein, abhängig von den angewandten waldbaulichen Praktiken und der Anzahl der Bäume, die ihre Gene an die nächste Generation weitergeben. Manchmal ist eine künstliche Verjüngung erforderlich, um den Bestand mit neuen genetischen Varianten anzureichern. Bei der Auswahl von Herkünften für Aufforstungen muss die genetische Vielfalt sichergestellt werden. Forstliches Vermehrungsmaterial aus fortgeschrittenen Züchtungsprogrammen hat überlegene Wuchseigenschaften, kann aber unter Umständen eine geringere genetische Variabilität aufweisen. Andererseits ist die genetische Variabilität in Samenplantagen in der Regel deutlich höher, da hier Fremdbestäubung und der Austausch von Genen zwischen Bäumen gefördert wird. Ein Bereich mit zunehmender Bedeutung ist die Züchtung auf Resistenz gegen Krankheiten wie z. B. das Eschentriebsterben. Für derartige Programme muss ein Reservoir an genetischer Vielfalt vorhanden sein, um Züchtungsprogramme mit neuen genetischen Varianten anzureichern, falls neue Stressfaktoren auftauchen.

Genetische Ressourcen können durch statische und dynamische Erhaltung, Ex-situ oder In-situ, erhalten werden. Es besteht ein Konsens darüber, dass die dynamische In-situ-Erhaltung in so genannten Generhaltungswäldern am besten geeignet ist, die evolutionären Prozesse in Baumpopulationen und damit das Anpassungspotenzial von Waldbäumen zu erhalten. Generhaltungswälder sind Waldbestände, die sich an bestimmte Umweltbedingungen angepasst haben oder besondere Merkmale aufweisen. Sie befinden sich typischerweise in Wäldern, die für eine Mehrfachnutzung bewirtschaftet werden, können aber auch Schutzgebiete oder Saatgutbeständen umfassen. Ihr Management zielt jedenfalls darauf ab, das langfristige evolutionäre Potenzial dieser Baumpopulationen zu erhalten und zu verbessern. In der Regel werden sie auf natürliche Weise verjüngt, gelegentlich auch mit forstlichem Vermehrungsmaterial, das im selben Bestand oder in dessen Nähe gesammelt wurde, d. h. von derselben Population abstammt (Abb. 3.1.31).

Die statische Ex-situ-Erhaltung besteht hauptsächlich aus Sammlungen und lebenden Archiven, z. B. Klonsammlungen, Samenplantagen und Herkunfts- und Nachkommenschaftstests, die außerhalb von 
Wäldern angelegt werden. Solche Sammlungen und Archive sind oft gekennzeichnet und eingezäunt, um einen unbefugten Zugang zu verhindern (Abb. 3.1.3-2).

Die Ausweisung von Saatgutbeständen und die Produktion von forstlichem Vermehrungsgut (forest reproductive material, FRM) muss nicht nur wirtschaftliche Interessen verfolgen (z. B. zur Verbesserung der Holzqualität), sondern auch den Erhalt der genetischen Vielfalt und die Verbesserung der Widerstandsfähigkeit von Waldbaumpopulationen berücksichtigen. So müssen in den Samenbeständen genügend reproduzierende Bäume (dominante und co-dominante Bäume, die blühen und sich gegenseitig bestäuben) in ausreichendem Abstand vorhanden sein, um Familienstrukturen und damit Inzucht zu vermeiden. Zusätzlich zu einer ausreichenden Anzahl an reproduzierenden Bäumen sollte forstliches Vermehrungsgut von genügend Bäumen gesammelt werden, um eine hohe genetische Variabilität zu gewährleisten. Auch die Herkunft des Vermehrungsguts spielt eine Rolle. Die Verwendung von lokalem Vermehrungsgut wird nach wie vor oft als wünschenswert angesehen, wird im Klimawandel aber zunehmend hinterfragt (siehe aber auch Kapitel "Geeignetes forstliches Vermehrungsgut zur Anpassung der Wälder an den Klimawandel”).

Die Entwicklung von Auwäldern wird durch das Wasser reguliert. In unmittelbarer Nähe von Wasserläufen sind Auwälder den regelmäßigen Schwankungen des pulsierenden Wasserflusses, der kontinuierlichen Bewegung von Material und langanhaltenden Überschwemmungen ausgesetzt. Umgekehrt sind Wälder, die weiter vom Wasserlauf entfernt sind, weniger gestört; Überschwemmungen und die Bewegung von Material sind saisonal, und das Grundwasser hat einen viel größeren Einfluss. Abhängig von der Entfernung zum Wasserlauf haben die Bäume verschiedene Strategien der natürlichen Regeneration entwickelt. Wo tägliche Schwankungen auftreten, ist die vegetative Vermehrung (aus dem Baum selbst oder angeschwemmtem Pflanzenmaterial) aufgrund der hohen Störungen am effektivsten. Die sexuelle Vermehrung

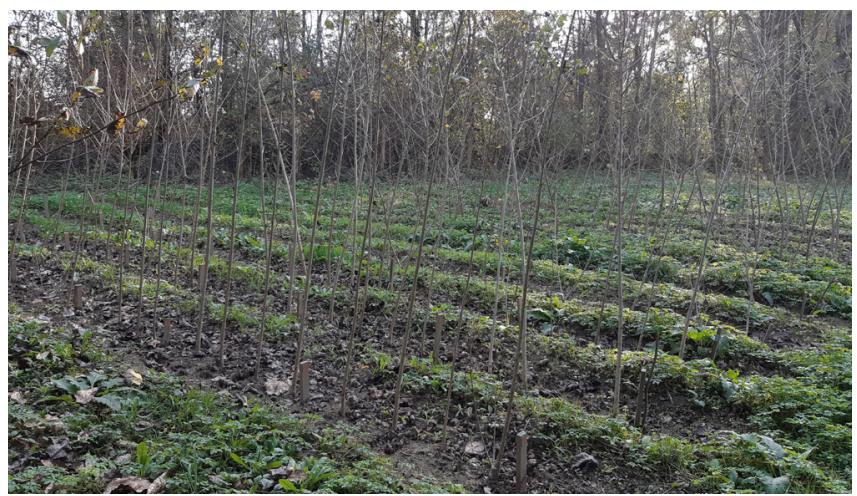

Abb. 3.1.3-2: Pflanzenproduktion mittels Saatgut zur Ex-situ Erhaltung der heimischen Schwarzpappel (Populus nigra) in Kroatien

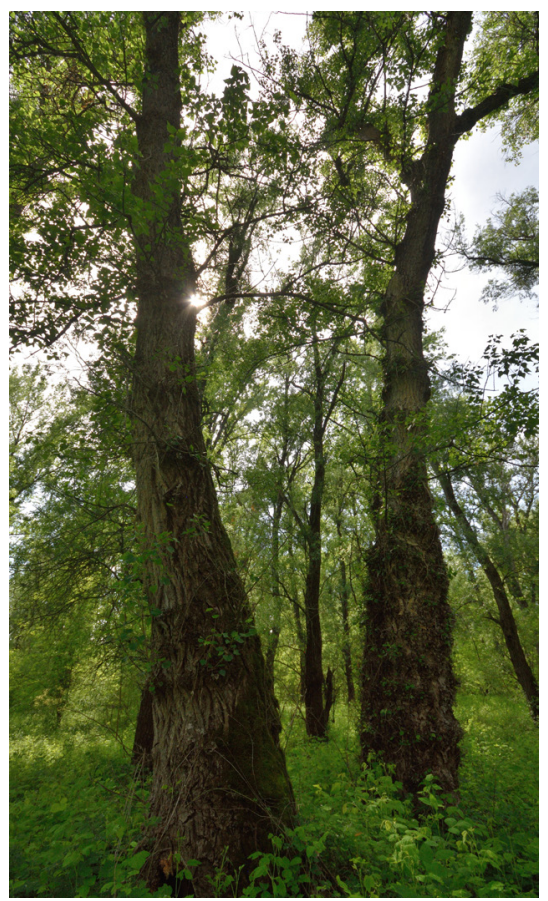

Abb. 3.1.3-1: Schwarzpappel (Populus nigra) In-situ Erhaltungseinheit und Samenbestand in Kroatien 
über Samen erfolgt normalerweise in Gebieten, die weniger ständigen Wasserschwankungen ausgesetzt sind. Aufgrund der Störungen in Auwäldern und der Schwierigkeit ihrer Regeneration werden folgende Maßnahmen zur Erhaltung der forstlichen Genressourcen empfohlen:

- Die Verjüngung von Niederwäldern aus Pionierbaumarten, die direkt an den Wasserläufen wachsen, sollte schrittweise erfolgen.

- Die Pflege der Bestände sollte die Entfernung von beschädigten und nicht vitalen Bäumen umfassen. Alle autochthonen Weiden(Salix sp. ), Pappel- (Populus sp. ) und Erlenarten (Alnus sp.) sollten gefördert werden.

- In Niederwäldern sollte das Fällen von Bäumen oberhalb einer bestimmten DBH-Schwelle vermieden werden, da dadurch die vitalsten und hochwertigsten Bäume und damit die genetische Variabilität dieser Bäume aus dem Bestand entfernt werden. Die schlechten und weniger vitalen Bäume sollten jedoch entfernt werden, während die qualitativ hochwertigen und vitalen Bäume belassen werden sollten, um deren Samenproduktion zu fördern und so den Bestand generative zu verjüngen.

- Wo Naturverjüngung möglich ist, sollte sie durch die Schaffung inhomogener Lichtverhältnisse im Zuge von Durchforstungseingriffen gefördert und durchgeführt werden. Lichtbedürftige Baumarten müssen durch entsprechende Freistellung gefördert werden, um plagiotropes Wachstum zu vermeiden (z. B. bei Eiche).

- In Bereichen, in denen die Naturverjüngung nicht möglich ist, sollten Ergänzungspflanzungen der gewünschten Zielbaumarten mit lokalen bzw. passenden Herkünften durchgeführt werden. Um die Fragmentierung von Auwäldern zu verhindern, sollte eine angemessene Mindestgröße bei Aufforstungen berücksichtigt werden.

- Um eine Naturverjüngung einzuleiten bzw. ihren Erfolg zu sichern, sollte die Beweidung durch Rinder und Schafe verhindert werden. Auch die Dichte des Wildbestandes sollte so reguliert werden, dass sich eine ausreichende Anzahl von Setzlingen pro Hektar etablieren kann. Wenn dies nicht gewährleistet werden kann, sollte die Verjüngung innerhalb eingezäunter Gebiete erfolgen.

- Bei der Durchführung von Verjüngungsmaßnahmen, wie auch bei anderen Eingriffen sollte die Etablierung von invasiven Pflanzen verhindert werden (siehe Kapitel "Management von nichtheimischen Pflanzen").

- Entlang der Fließgewässer sollten Sträucher und andere Pflanzen, die Lebensraum für Tiere darstellen, belassen werden. Wo Biber vorhanden sind, sollten Weichholzbaumarten (Salix sp., Populus sp., Alnus sp.) entlang des Wasserlaufs gepflanzt oder belassen werden, um Schäden zu vermeiden. 
Wann immer gepflanzt wird, sollte die geeignete Herkunft, eine hohe Pflanzenqualität und eine angemessene Handhabung des forstlichen Vermehrungsgutes sichergestellt werden. Denn wenn die gepflanzte Herkunft nicht in der Lage ist, in ihrer gepflanzten Umgebung zu überleben, gut zu wachsen bzw. sich an zukünftige Bedingungen anzupassen, kann trotz hoher finanzieller Aufwendungen für die Bodenvorbereitung, das Pflanzen, den Schutz und die Pflege der Jungbäume die geleistete Arbeit umsonst gewesen sein.

\section{Zusammenfassung und Ausblick}

Die Erhaltung und der Schutz der forstlichen Genressourcen schließt die Waldbewirtschaftung nicht aus; es bedeutet nur, dass jede Maßnahme im Hinblick auf ihre Auswirkungen auf die genetische Vielfalt und die Struktur der Population betrachtet werden muss. Wird dies nicht getan, kann die Bewirtschaftung langanhaltende negative Folgen für die genetischen Ressourcen haben.

Website-Empfehlung

EUFORGEN: www.euforgen.org

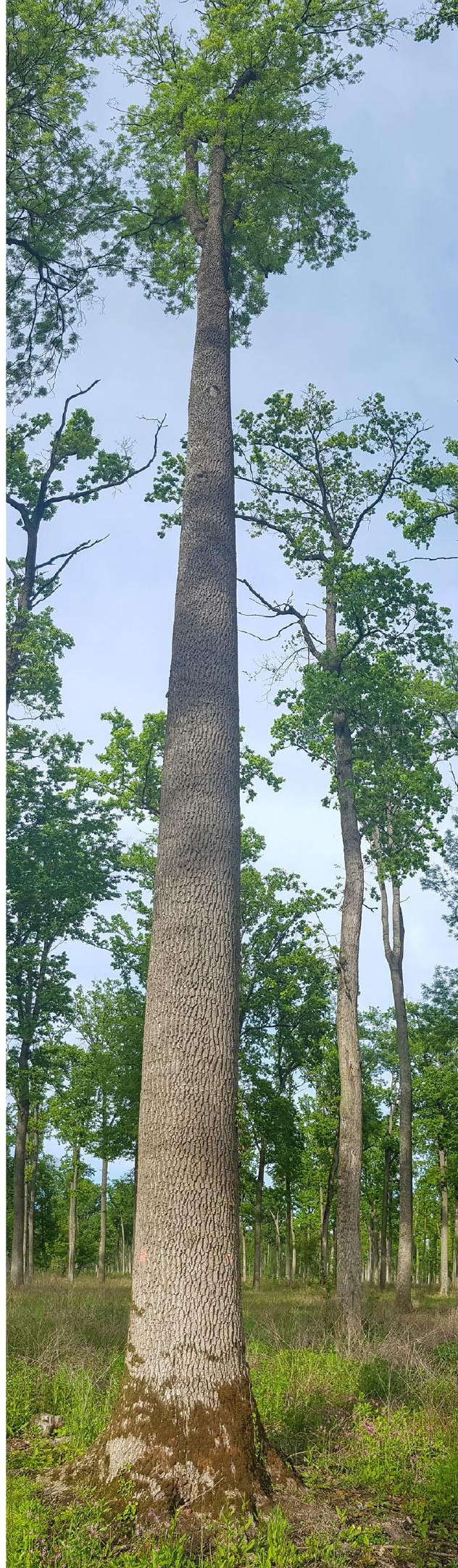




\subsubsection{Naturverjüngung und Saat von Stieleichenbeständen}

Gyula Kovács, Markus Sallmannshofer

(Lajos Gyergyák, Zoltán Puskás)

\section{Einleitung}

Die Naturverjüngung von Eich ist aus ökologischer und naturschutzfachlicher Sicht eine sehr günstige Lösung. Der wirtschaftliche Vorteil dieser Methode ist, dass lokales Vermehrungsgut verwendet wird, das kostengünstig vor Ort verfügbar ist. Der Nachteil ist, dass die Eichen nicht jedes Jahr ausreichend fruktifizieren und dass die Unsicherheit der Samenproduktion sich durch den Klimawandels und die daraus resultierenden häufigeren und intensiveren Dürreperioden noch verschärft hat. Im Falle der Stieleiche ist ein noch wichtigerer Faktor der Rückgang des Grundwasserspiegels. Eine wichtige Voraussetzung für eine gute Eichelernte ist auch die Kronengröße des Baumes, um eine ausreichende Samenmenge zu produzieren. Bei überwiegend kleinkronigen Individuen machen Naturverjüngungsvorbereitungen wenig Sinn, da mit mit einem ungenügenden Samenfall gerechnet werden muss. Dies muss bei der Bewirtschaftung und Verjüngungsplanung berücksichtigt werden.

Darüber hinaus erschweren ein hoher Wildbestand, der Lichtbedarf der Stieleiche, die starke Unkrautkonkurrenz und die Konkurrenz durch invasive gebietsfremde Pflanzenarten (Acer negundo, Fraxinus pennsylvanica, Robinia pseudoacacia, Ailanthus altissima) die Naturverjüngung erheblich.

Eine ausbleibende Eichelmast kann durch die sogenannte "Untersaat" kompensiert werden, die die Naturverjüngung imitiert. Der Vorteil dieser Methode ist, dass Vermehrungsmaterial mit besseren genetischen Eigenschaften verwendet werden kann. Dies kann den Bestandeswert erhöhen, aber die künstliche Eichelsaat ist deutlich teurer als Naturverjüngung.

In Ungarn werden Auwaldeichenbestände fast ausschließlich künstlich mit Setzlingen oder mittels Eichelsaat verjüngt. Dabei wird die Saat in der forstwirtschaftlichen Praxis bevorzugt, denn so entfallen die Kosten für die Sämlingsproduktion und die negativen Auswirkungen von Pflanzschocks können vermieden werden. Auf der anderen Seite ist es schwierig, jedes Jahr eine ausreichende Menge und Qualität an Eicheln für die Saat zu erhalten. Zudem ist die Pflanzung mit Sämlingen einfacher zu planen. Heute ist das Bewusstsein für eine richtige Auswahl von forstlichem Vermehrungsgut, das den Bewirtschaftungszielen, insbesondere den zukünftigen Umweltbedingungen, entspricht, viel größer.

\section{Management der natürlichen Regeneration}

In Auwaldeichenbeständen ist die Naturverjüngung eine anspruchsvolle fachliche Herausforderung. Die Dauer der Verjüngungsperiode 
wird durch den hohen Lichtbedarf der jungen Stieleiche bestimmt. Natürlich verjüngte Sämlinge können daher für 1-2 (maximal 3) Jahre beschattet werden, allerdings nur bei einer deutlichen Reduzierung des Kronenschlusses, die ca. $50 \%$ betragen sollte. Es wird keinesfalls empfohlen, den endgültigen Abtrieb des verbleibenden Bestandes hinauszuzögern, da die Gefahr einer intensiven Entwicklung von Wasserreisern an den verbleibenden Bäumen besteht.

\section{Schritte zur Etablierung von Naturverjüngung (Kurzversion des traditionellen Schirmschlags)}

Vorbereitung der Waldbestände für die Eichelproduktion. Reduktion des Kronenschlusses: Entfernung von Individuen mit kleinen Kronen, mit schlechter Genetik, unterdrückten und missgebildeten Individuen, um deren Fortpflanzung zu verhindern. Aufgrund des Risikos der Entwicklung von Wasserreisern und der aufkommenden Unkrautkonkurrenz wird nur eine moderate Reduktion empfohlen. Wenn eine Unterholzschicht aus Bäumen oder Sträuchern vorhanden ist, muss diese teilweise entfernt werden, um die Etablierung der Verjüngung zu ermöglichen. Die wichtige Funktion der Stamm- und Bodenbeschattung muss erhalten bleiben.

Nach dem Einsetzen der Verjüngung - idealerweise nach einem Mastjahr - müssen die Rückegassen angelegt werden, gefolgt von einem endgültigen Abtrieb innerhalb von 1-2 (maximal 3) Jahren.

Ergänzungspflanzungen können in der Regel mit künstlich gezogenen Sämlingen aus Forstbaumschulen erfolgen. Hier ist es möglich, Mischbaumarten einzubringen, häufig treten sie aber auch von selbst auf und überwuchern die Eichen in der Anfangsphase. Die Wachstumsdynamik muss beobachtet und in die Planung der räumlichen Verteilung verschiedener Arten in einem Bestand einbezogen werden (Kapitel „Künstliche Verjüngung der Stieleiche als Maßnahme zum Aufbau von Eichenwäldern, als Ergänzungspflanzung und zur Wiederherstellung von Auwaldökosystemen" und "Potentiale in der Laubwertholzproduktion").

Die Unkrautbekämpfung ist für (3-)4 Jahre erforderlich. Dies geschieht in der Regel mechanisch, manchmal ist jedoch die chemische Regulierung die einzige Chance für eine erfolgreiche Bekämpfung von Unkraut und anderen nichtheimischen Arten. Solche Probleme entstehen vor allem auf feuchten Standorten und mit dem zunehmenden Auftreten von nichtheimischen Pflanzen (z. B. Impatiens glandulifera an Mur und Drau). Besonders wichtig ist es, gebietsfremde invasive Baumarten zu entfernen (z. B. Acer negundo, Fraxinus pennsylvanica, siehe Kapitel "Management von nichtheimischen Pflanzen”). Die Verjüngung dieser Baumarten tritt mancherorts in großer Zahl auf (z. B. Donau-Gemenc), wodurch eine natürliche Verjüngung von Eichen unmöglich oder nur mit großem Aufwand zu erreichen ist. 


\section{Natürliche Verjüngungsmethoden}

Einstufige (Kahlschlag-) Verjüngung: bei großem Eichelanfall mit Kahlschlag 2-3 Jahre nach Auftreten der Verjüngung.

Schrittweise Verjüngung (“Schirmschlag”): kontinuierliche mehrstufige Methode, anwendbar in homogenen Beständen, das häufigste Verfahren in großen Eichenbeständen, wie sie in Slawonien, Kroatien, zu finden sind.

Gruppenverjüngung (Femelschlag): Kann in heterogenen Beständen besonders gut eingesetzt werden und hat die längste Dauer. Daher ist es schwierig, die Lichtanforderungen der Stieleiche zu erfüllen. Diese Methode baut strukturelle Vielfalt auf und ermöglicht es den Bewirtschaftern, andere Baumarten einzubeziehen, indem sie die Vielfalt der Lichtbedingungen steuern.

Lückenhafte Verjüngung: Ähnlich wie die Gruppenverjüngung, aber in einem kleineren Maßstab bis zu einer Baumlänge. Sobald die Verjüngung innerhalb der Lücke 2-3 Jahre alt ist, werden die Lücken entsprechend dem Wachstum der Verjüngung verbreitert.
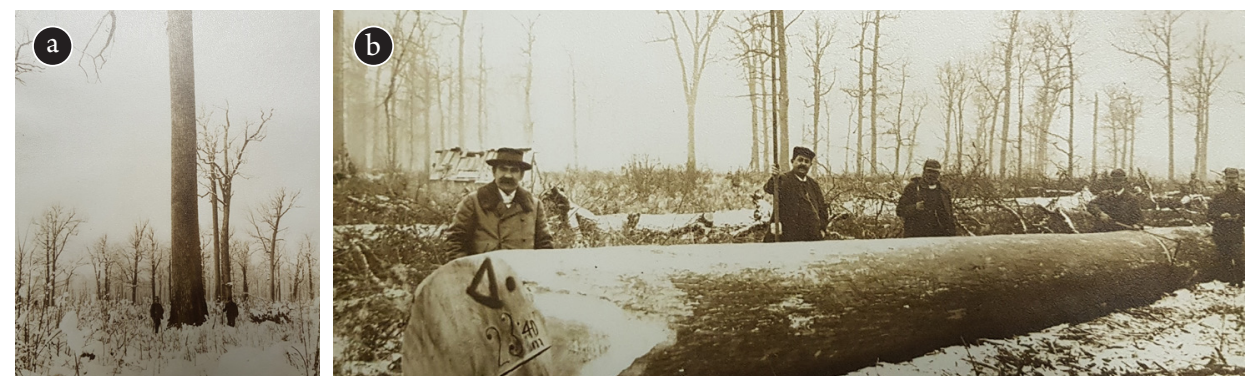

Abb. 3.1.4-1: a) Beim Schirmschlag sollen Eichen hervorragender Qualität bis zum letzten Hieb zur Eichelproduktion im Waldbestand bleiben. b) Ein lang-ausgeformter Eichenstamm von 23,4 m Länge vor einem Schirmschlag

\section{Praktische Anwendung}

Entlang der Drau auf ungarischer Seite ist der sogenannte "Eichelschlag" die bewährte Methode zur Verjüngung nach großen Eichelernten. Der Kahlschlag wird im Winter unmittelbar nach der Eichelmast durchgeführt. Dabei geht es darum, die große Menge an Verjüngung zu erfassen, die auf diese Weise nicht im Schatten der Mutterbäume steht.

Bei einer normalen Eichelmast wird eine 40-60\%ige Reduzierung des Kronenschlusses (schrittweise Verjüngung) vorgenommen. Gleichzeitig werden die schattentoleranten Arten, der Unterwuchs und die Strauchschicht entfernt, bevor der endgültige Abtrieb innerhalb von maximal 2 Jahren erfolgt. Die Mindestdichte der Nachkommenschaft für eine ausreichende Verjüngung beträgt 3-4 Pflanzen pro Quadratmeter. Falls nicht verboten, kann eine chemische Unkrautbekämpfung im Jahr der Eichelernte die Verjüngung deutlich unterstützen. 


\section{Untersaat}

Das Verfahren ist eine Mischform zwischen natürlicher und künstlicher Naturverjüngung. Geringe oder unzureichende Eichelmasten können durch bis zu $300 \mathrm{~kg} / \mathrm{ha}$ Eicheln ergänzt oder ersetzt werden. Der Vorteil dieser Methode ist, dass eine Verjüngung mit besserer genetischer Qualität als der bestehende Waldbestand möglich ist. Bei der Aussaat in Reihen kann die Unkrautbekämpfung mechanisiert werden. Die zu erwartende Dichte der Setzlinge beträgt ebenfalls 3-4 Pflanzen pro Quadratmeter.

\section{Künstliche Verjüngung mit Eichelsaat}

In Eichenbeständen an im Auwald ist die künstliche Verjüngung eine typische Praxis, bei der in großen Beständen Setzlinge gepflanzt oder Eicheln ausgesät werden. Die Aussaat wird bevorzugt, wenn genügend Eicheln zur Verfügung stehen; daher ist in Österreich die Pflanzung üblich. Für die künstliche Eichenverjüngung hat sich in Ungarn eine Menge von 300-400 kg/ha Eicheln, nach vollständiger oder teilweiser Bodenvorbereitung durch maschinelle oder manuelle Aussaat mit einem Reihenabstand von 1,5-1,8 m bewährt. Der Boden wird mit einem Pflug oder Mulcher vorbereitet, um die Etablierung der Jungpflanzen zu unterstützen.

\section{Weitere Probleme und Empfehlungen}

In den vergangenen Jahren stellten die klimatischen Bedingungen, z. B. trockene Winter gefolgt von Dürreperioden im Frühjahr und Som-

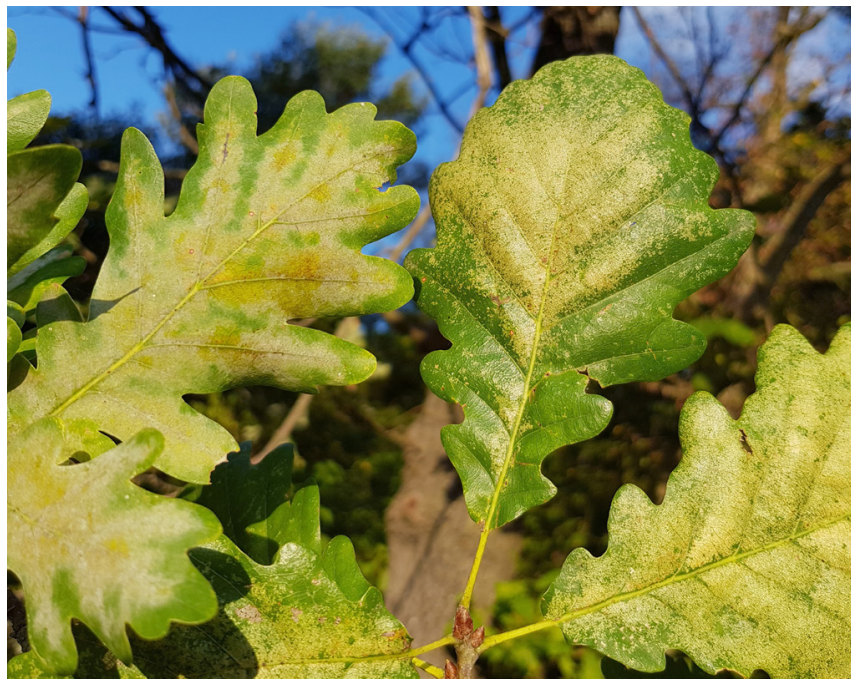

Abb. 3.1.4-3: Eichenmehltau (Erysipe, linke Blätter) und die nordamerikanische Eichenwanze (Corythucha arcuata, rechte Blätter) schädigen beide die Blätter und beeinträchtigen vermutlich die Eichenverjüngung 
mer oft ein signifikanten Hemmniss für die Eichenverjüngung dar. In den ersten Jahren nach der Keimung ist ein häufiges Problem der Echte Mehltau in vielen Eichenkulturen. Zudem kann regional auch der Fraß des Maikäfers die Verjüngung hemmen. Der Befall von Alteichen durch die nordamerikanische Eichennetzwanze (Corythucha arcuata) beeinflusst vermutlich die Samenproduktion (Abb. 3.1.4-3; Kapitel "Forstschädlinge und Krankheiten in einer sich verändernden Welt: Die Bedeutung der Früherkennung."). Die Schädlingsbekämpfung gegen den Maikäfer wird häufig im Zuge der künstlichen Verjüngung durchgeführt. Nach dem Entfernen der verbliebenen Stöcke des Altbestandes kann der Boden vollständig aufbereitet werden, und es kann eine chemische Bodendesinfektion (sofern erlaubt) durch Wenden der obersten $30-50 \mathrm{~cm}$ durchgeführt werden. Wenn bereits erkennbaren Schäden aufgetreten sind, kann auch eine Bodeninjektion, die allerdings im Normalfall weniger erfolgreich ist, angewendet werden. Der Einsatz von chemischen Bekämpfungsverfahren sollte grundsätzlich nur in absoluten Ausnahmefällen mit zugelassenen Mitteln und unter Anwendung der maximalen Vorsichtsmaßnehmen zum Schutz benachbarter Waldbestände, der vorhanden Fauna und der Anwender erwogen werden. Eines der wichtigsten Probleme ist der negative Einfluss von Wildtieren auf die Eichenverjüngung. Sowohl Nagetiere als auch Huftiere können eine ernsthafte Beeinträchtigung darstellen. Huftiere können derzeit meist nur durch den Bau von Wildzäunen wirksam abgewehrt werden (Kapitel "Wildeinfluss und Wildtiermanagement”). In den meisten Gebieten des TBR MDD und unabhängig von der angewandten Verjüngungstechnik sind Wildzäune für eine erfolgreiche Wiederaufforstung unbedingt erforderlich.

\section{Ausblick und Zusammenfassung}

Die Verjüngung von Eichen erfordert waldbauliches Wissen und Können. Sowohl bei der künstlichen als auch bei der natürlichen Verjüngung müssen oberirdische Unkrautkonkurrenz und invasive Baumarten (Acer negundo, Fraxinus pennsylvanica, Robinia pseudoacacia, Ailanthus altissima) kontinuierlich entfernt werden. Zudem ist ein Wildschutz notwendig, um die Verjüngung der Eichenbestände zu sichern. Bereits bekannte und neue durch den Klimawandel und die Globalisierung auftretende Probleme machen die Naturverjüngung noch aufwendiger und kostenintensiver. Nichtsdestotrotz gibt es in den Ländern des TBR MDD viel Wissen und Erfahrung, wie man die Stieleiche richtig verjüngen kann. 


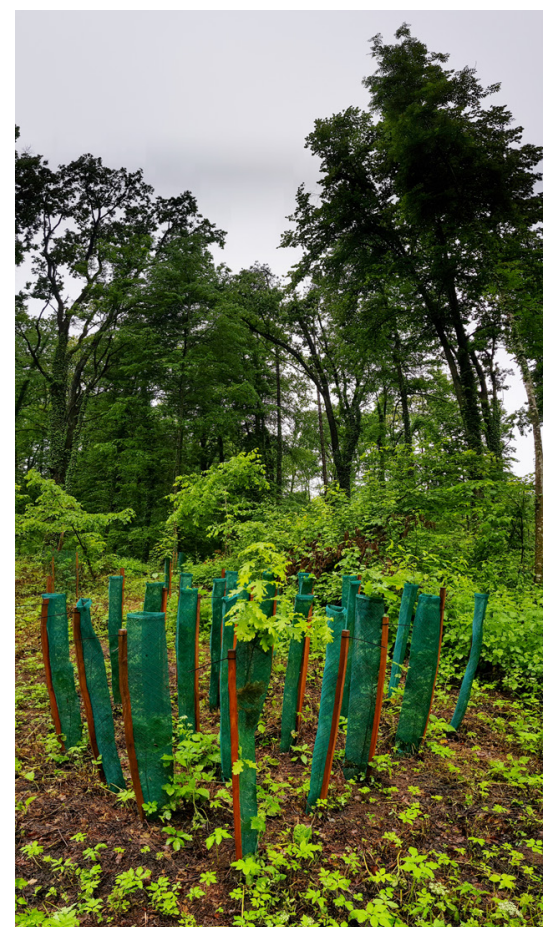

Fig. 3.1.5-1: Gruppenpflanzung von Stieleiche mit 18-25 Pflanzen und $1 \mathrm{~m}$ Abstand

\subsubsection{Künstliche Verjüngung der Stieleiche als Maßnahme zum Aufbau von Eichenwäldern, als Ergänzungspflanzung und zur Wiederherstellung von Auwaldökosystemen}

Silvio Schüler, Hannes Schönauer, Werner Ruhm, Gyula Kovács

Bewirtschaftete und unbewirtschaftete Auwälder befinden sich in einem andauernden Wandel. In naturbelassenen Flusslandschaften finden diese Veränderungen durch regelmäßige Überflutungen, Schwankungen der Wasserstände sowie klein- und großräumigen Verlagerungen der Flussläufe statt, in deren Folge Altarme vom Flussverlauf abgeschnitten werden können und frühere Wasserläufe verlanden. Damit entwickeln sich die Weichholzauen langsam zu Hartholzauen, denn die neuen Umweltbedingungen erschweren charakteristischen Pionierbaumarten die Regeneration und beeinträchtigen ihre Vitalität. Die in vielen Flüssen vorgenommenen Regulierungsmaßnahmen haben diese Veränderungen beschleunigt und viele Weichholzauwälder von den strömungsnahen Lebensräumen isoliert. Darüber hinaus stellen besonders konkurrenzfähige nichtheimische Pflanzen, Schädlinge und Krankheiten eine zusätzliche Herausforderung für Auwälder dar und gefährden die von diesen Wäldern erbrachten Ökosystemleistungen.

Die Stieleiche (Quercus robur), eine Charakterart europäischer Hartholzauwälder, zeigt bisher eine vergleichsweise hohe Resistenz gegenüber Schädlingen und Krankheiten und wäre daher eine der wichtigsten Baumarten, um Auwälder mit einem hohen ökologischen Wert und einem für den Bewirtschafter interessanten Deckungsbeitrag zu fördern. Allerdings gehört die Naturverjüngung der Eiche, insbesondere im Auwald zu den größten waldbaulichen Herausforderungen, denn ihr Gelingen hängt von verschiedenen Bedingungen ab, wie die Verfügbarkeit von nahegelegenen Samenbäumen, eine ausreichende Eichelmast, die Berücksichtigung einer meist konkurrenzfähigeren Begleitvegetation und nicht zuletzt einer angepassten Wildbewirtschaftung. Daher ist die künstliche Verjüngung von Eichenbeständen in vielen Fällen das am besten geeignete Verfahren, um Eichenwälder zur Produktion von Wertholz zu begründen, aber auch um Hartholzauwälder in Schutzgebieten wiederherzustellen. Die Anzahl an Z-Bäumen wird vom Zieldurchmesser und dem dafür benötigten Produktionszeitraum bestimmt. Es werden Z-Baumzahlen von 60-80 Stück pro Hektar empfohlen. Auf geeigneten Auwaldstandorten ist bei einer Umtriebszeit von 80-120 Jahren mit entsprechenden Durchforstungskonzepten, ein Zieldurchmesser von $60+\mathrm{cm}$ erreichbar. Die Produktion derartiger Stämme benötigt hohe Stammzahlen in der Begründung- und Jungwuchsphase, um durch natürliche Astreinigung einen ausreichenden astfreien Stamm mit der gewünschten Länge zu fördern.

Um eine derartige Bestandsentwicklung umzusetzen, kann die künstliche Verjüngung in zwei verschiedenen Aufforstungsvarianten umgesetzt werden: entweder durch Reihenpflanzung mit Pflanzenzahlen 
von mindestens 5000 Sämlingen pro ha oder durch Trupppflanzung bei welcher 60-80 Trupps pro ha mit Abständen von 10 bis $13 \mathrm{~m}$ voneinander gepflanzt werden und jeder Trupp aus 20-25 Sämlingen besteht. Dabei orientiert sich der Abstand zwischen den Trupps ungefähr am angestrebten Endbaumabstand und damit der Erfordernis einer optimalen Kronenentwicklung. Beide Aufforstungsvarianten haben Vor- und Nachteile und die Entscheidung für das jeweilige System ist abhängig von den jeweiligen Standortsbedingungen und den vorhandenen Bewirtschaftungsmöglichkeiten. Eine dritte Aufforstungsvariante ist die sogenannte Nesterpflanzung, bei welcher 20-30 Sämlinge auf kleiner Fläche (etwa $1 \mathrm{~m}^{2}$ ) im Abstand von etwa 0,2 m zueinander gesetzt werden. Zahlreiche Feldversuche in Österreich und anderen europäischen Ländern in den letzten Jahrzehnten haben jedoch gezeigt, dass die Nesterpflanzung zu höheren Ausfällen, geringerem Wachstum und schlechteren Stammqualitäten führt und daher nicht mehr empfohlen werden kann.

\section{Reihenpflanzung}

Reihenpflanzung ist die traditionelle Aufforstungsvariante. Dabei werden die Eichensämlinge in Reihen gesetzt, wobei der Abstand der Pflanzen innerhalb der Reihen ungefähr $1 \mathrm{~m}$ betragen sollte. In der Vergangenheit wurden als Abstände zwischen den Reihen ebenfalls rund 1 m gewählt, so dass pro ha 8000 bis 10000 Sämlinge nötig waren. Fortlaufende Untersuchungen der Eichenqualität in Feldversuchen haben jedoch gezeigt, dass Reihenabstände von $2 \mathrm{~m}$ ausreichen, um eine gute Qualitätsentwicklung der jungen Eichen zu garantieren und können deshalb als gut geeignet empfohlen werden. Bei Reihenpflanzungen kann die Eiche mit einer passenden dienenden Schattenbaumart wie zum Beispiel der Hainbuche (Carpinus betulus) kombiniert werden. Dazu sollten auf 3 Reihen Eiche 2 Reihen der jeweiligen Schattenbaumarten folgen: so wird eine gute Ausnutzung der überwiegend innerartlichen Konkurrenz zur Qualitätsentwicklung sichergestellt.
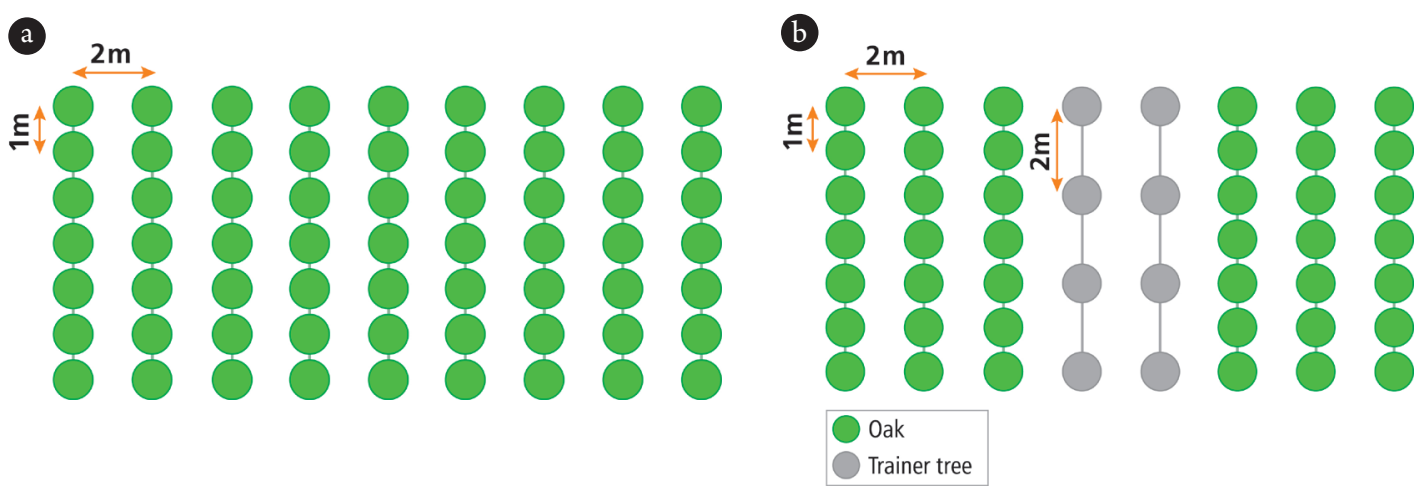

Abb. 3.1.5-1. Zwei gut geeignete Pflanzverbände bei der Reihenaufforstung mit Eiche. Links: reine Eichenaufforstung; Rechts: Mischung der Eiche mit einer schattentoleranten Begleitbaumart, die in Abhängigkeit des jeweiligen Standorts gewählt werden kann, die die Eiche aber nicht überwachsen sollte und ggf. reguliert werden muss. 
Die Reihenpflanzung hat vor allem dann Vorteile, wenn größere Flächen begründet werden sollen, denn die Reihenabstände von $2 \mathrm{~m}$ erlauben eine maschinelle Pflege zur Entfernung der Begleitvegetation und senken dadurch die Pflegekosten. Dieser Vorteil kann insbesondere in Auwälder wichtig sein, da hier die Begleitvegetation durch heimische und nichtheimische Pflanzen die lichtbedürftigen Eichenpflanzen leicht überwachsen. Bei der manuellen oder motormanuellen Pflege haben Reihenpflanzungen den Vorteil, dass die einzelnen Reihen leicht erkannt werden und Sämlingsverluste durch Pflegemaßnahmen gering gehalten werden können.

\section{Trupppflanzung}

Bei der Trupppflanzung werden Eichensämlinge nur an denjenigen Stellen der Aufforstungsfläche gesetzt, an denen ein Z-Baum erforderlich ist. Die räumliche Verteilung der Trupps hängt von den geplanten Zielbaumabständen ab und beträgt typischerweise 10-13 m. Jeder Trupp besteht aus 20-25 Setzlingen, die innerhalb des Trupps mit Abständen von $1 \mathrm{~m}$ gesetzt werden. Die Trupps können in einem Quadrat oder in 2-3 Kreisen mit zunehmendem Durchmesser angeordnet werden. Bei einem kreisförmigen Trupp wird ein zusätzlicher Kreis mit einer dienenden Baumart empfohlen, dieser kann auch bei quadratischen Trupps ergänzt werden.

Zwischen den Trupps kann eine schattentolerante dienende Baumart beigemischt werden. Im Idealfall existiert bereits Naturverjüngung von einer oder mehreren anderer Mischbaumarten, die die Formentwicklung am Rande der Trupps begünstigen können. Trupppflanzungen haben folgende Vorteile:

- Die Eichentrupps als potenzielle Z-Baumstandorte werden dort gepflanzt, wo sie gebraucht werden. Daher ist das Verfahrung auch in kleinen und mittelgroßen Beständen gut einsetzbar.

- Aufgrund der geringen Abstände zwischen den Sämlingen ist die Qualität und Wuchsentwicklung sowie das Überleben der jungen Eichen vergleichbar oder sogar besser als bei der Reihenpflanzung, wie eine Meta-Analyse in Mitteleuropa gezeigt hat.

- Aufgrund der geringeren Anzahl von Sämlingen (rund 1500 Pflanzen/ha) sowie der Notwendigkeit der Unkrautbekämpfung nur innerhalb und um die Trupps herum, sind die Kosten für die Begründung niedriger.

- Das Verfahren ist ideal für Ergänzungspflanzungen und trägt dazu bei die Baumartenvielfalt zu erhöhen und die natürliche Verjüngung ohne Produktivitätsverluste vollständig auszunutzen.

Die Nachteile der Gruppenpflanzung sind gering und umfassen:

- Trupppflanzungen erfordern entlang der Kontaktlinie zwischen Eichengruppen und der Naturverjüngung eine strenge Kontrolle der Konkurrenz durch die beigemischte Naturverjüngungen, 
um eine zu starke Kronenkonkurrenz durch schnell wachsende Pionierbaumarten oder die gepflanzte dienende Baumart zu vermeiden.

- Die Pflege der Verjüngung und die Reduktion der Begleitvegetation erfordern einen hohen Anteil manueller, bzw. motormanueller Pflege und setzen gut geschultes und motiviertes Personal voraus, um die Eichentrupps zu identifizieren und einen Verlust von Sämlingen während der Pflege zu vermeiden. Daher sollte jeder Sämling oder zumindest die äußere Reihe mit Pflanzstöcken markiert werden, um die Eichen während der Unkrautbekämpfung gut zu identifizieren.
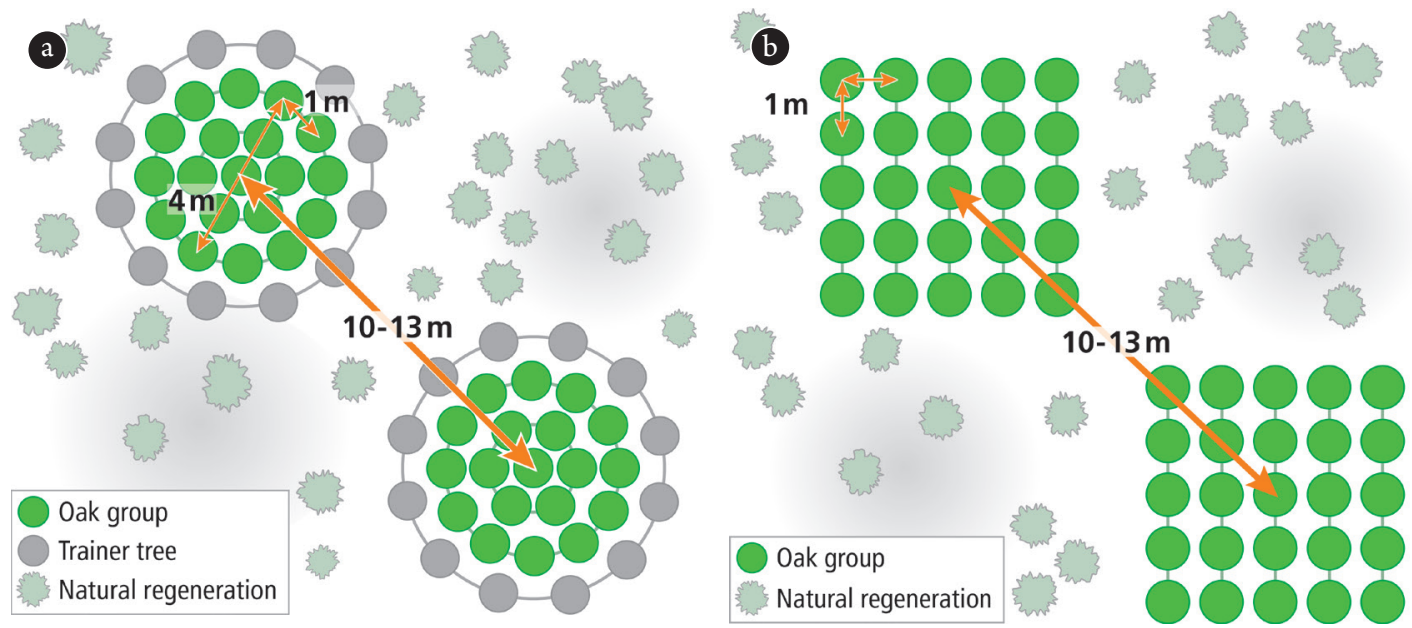

Abb. 3.1.5-2: Zwei mögliche Pflanzverbände für Trupppflanzungen entweder in quadratischer Form oder kreisförmig. Soweit vorhanden sollte Naturverjüngung für die Begründung der Fläche zwischen den Trupps genutzt werden. Falls nicht vorhanden, können statt Naturverjüngung andere, insbesondere dienende Baumarten gesetzt werden.

\section{Ausblick und Zusammenfassung}

Die künstliche Verjüngung von Eichen ist ein wichtiges Verfahren für die Wiederaufforstung und Begründung von Eichenwäldern im Rahmen der Wertholzproduktion und des Naturschutzes. Abhängig von den jeweiligen Standortbedingungen und Bewirtschaftungsmöglichkeiten können sowohl Reihenpflanzungen als auch Trupppflanzungen erfolgreich genutzt werden. Beide Pflanzkonzepte erfordern, ähnlich wie bei der natürlichen Eichenverjüngung, waldbauliche Kompetenz und eine kontinuierliche Pflege der Kultur, insbesondere die Entfernung der Begleitvegetation sowie den Schutz vor Wildverbiss. Zu den Vorteilen der Trupppflanzung gehören die geringeren Begründungskosten, eine wesentlich bessere Standraumökonomie durch die Orientierung der Trupps am optimalen Endbaumstandort und die mögliche Integration der vorhandenen Naturverjüngung, was langfristig zu einer höheren Baumartenvielfalt beiträgt. Daher ist die Trupppflanzung auch das bevorzugte Verfahren, um vorhandene Waldverjüngung mit Eichen oder potenziell anderen wertvollen Baumarten anzureichern. 


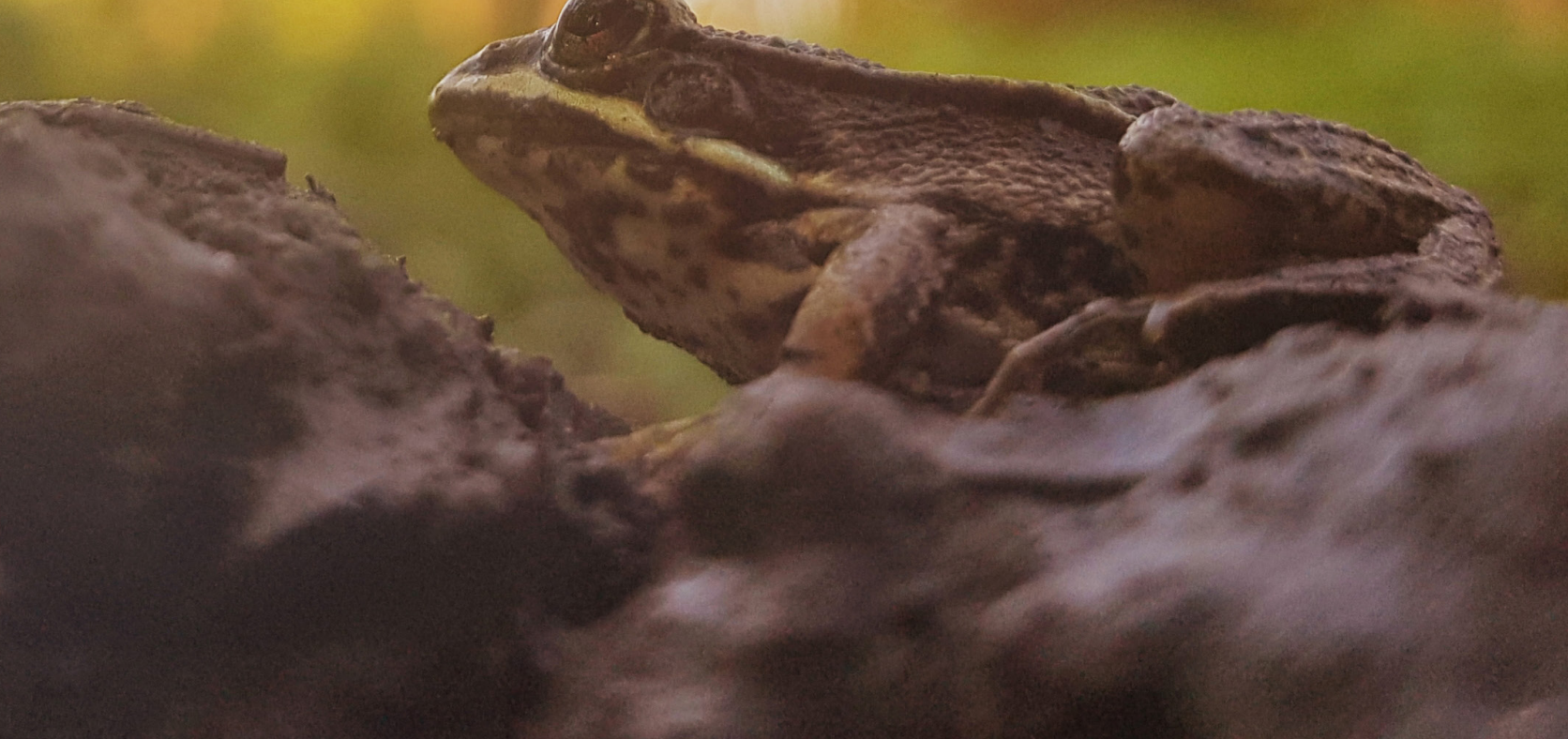




\subsection{Wald- und Naturschutzmanagement}

\subsubsection{Ziele des Biodiversitäts- und Naturschutzmanagements}

Katharina Lapin, Janine Oettel, Kerstin Böck, Maarten de Groot, Alen Kiš, Marjana Westergren

\section{Gefährdungen von Biodiversität in Auwäldern}

Biodiversität ist die Variabilität unter lebenden Organismen aus allen Bereichen, einschließlich terrestrischer, mariner und anderer aquatischer Ökosysteme und der ökologischen Komplexe, zu denen sie gehören; dies umfasst die Vielfalt innerhalb und zwischen Arten oder Ökosystemen. Auwälder erbringen vielfältige Ökosystemleistungen und beherbergen große Anteile der terrestrischen Biodiversität in Europa. Die biologische Vielfalt der Auwälder ist jedoch gefährdet. Die Hauptbedrohungen für Auwälder sind Lebensraumdegradierung, Klimawandel, Flussregulierung und invasive Arten (Kapitel "Relevanz und Gefährung der Auwälder").

Um die globale Biodiversitätskrise des 21. Jahrhunderts zu überwinden, wurde die biologische Vielfalt der Wälder zum Ziel internationaler, regionaler und lokaler Politik gemacht, um die Ziele zur Erhaltung der biologischen Vielfalt zu erreichen. So sieht der Strategieplan der Vereinten Nationen für Wälder 2030 unter dem globalen Waldziel vor, dass der Beitrag aller Arten von Wäldern zur Erhaltung der Biodiversität bis 2030 zunehmen soll. Eine nachhaltige Waldbewirtschaftung, die die genetische und die Artenvielfalt sowie alle Ökosystemleistungen berücksichtigt, ist das wichtigste Instrument zur Erreichung dieses Ziels. In diesem Kapitel diskutieren wir die Maßnahmen zum Erhalt und zur Förderung der Biodiversität in Auwäldern (Abb. 3.2.1-1).

\section{Indikatoren für Biodiversität}

Die Erhaltung der Biodiversität ist eines der Hauptziele der nachhaltigen Waldbewirtschaftung. Eine Voraussetzung für ihre Integration in die Managementplanung ist die Kenntnis des Zustands der Biodiversität, die durch ihr Monitoring gewonnen werden kann. Das Monitoring der Biodiversität ist äußerst anspruchsvoll und teuer, insbesondere für seltene Arten und Lebensräume. Im Rahmen des Forest-EuropeProzesses wird die Biodiversität im Rahmen der nachhaltigen Waldbewirtschaftung regelmäßig unter dem Kriterium Erhaltung, Schutz und angemessene Verbesserung der biologischen Vielfalt in Waldökosystemen überwacht. Dieses Kriterium umfasst 10 Indikatoren: Baumartenvielfalt, Verjüngung, Naturnähe, eingeführte Baumarten, Totholz, genetische Ressourcen, Waldfragmentierung, bedrohte Waldarten, Schutzgebiete und häufige Waldvogelarten. Diese Indikatoren werden (hauptsächlich) im Rahmen der nationalen Waldinventuren auf einem vordefinierten Raster von Dauerparzellen in standardisierter Weise gemessen. Da Auwälder flächenmäßig klein sind, erfassen nur wenige Punkte den Zustand der Biodiversität in Auwäldern.

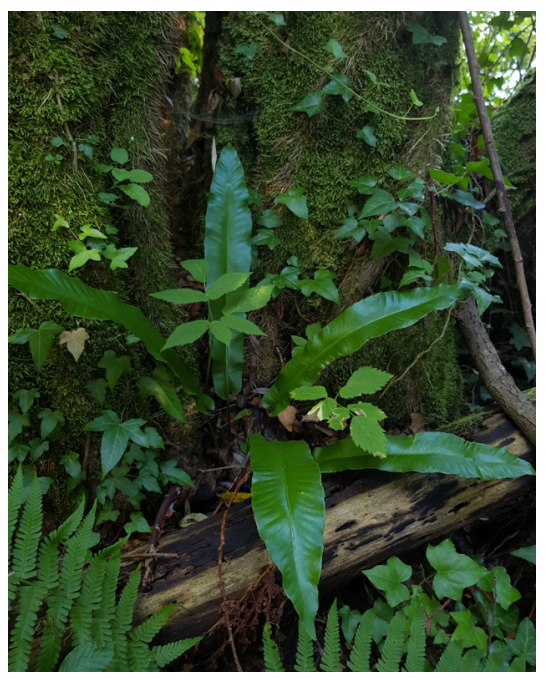

Abb. 3.2.1-1: Biodiversität kann als Artenreichtum, aber auch als Vielfalt von Lebensräumen und Landschaften oder genetische Vielfalt ausgedrückt werden. 
Risiken für die Biodiversität in Auwäldern im grenzüberschreitenden Mur-Drau-Donau Biosphärenreservat (TBRMDD)

Auwälder in Schutzgebieten innerhalb des TBR MDD bieten Lebensraum für mehrere geschützte und bedrohte Pflanzen- und Tierarten. Ökologisch nicht nachhaltige Waldbewirtschaftungspraktiken, invasive Arten, der Klimawandel, Baumaßnahmen und mangelnde Kooperation zwischen verschiedenen Interessensgruppen stellen hier eine Gefahr für die Biodiversität dar.

Intensive forstwirtschaftliche Praktiken wie reine Pappelplantagen verändern die Qualität der Lebensräume und die Artenvielfalt. Großflächige Kahlschläge führen zu einem raschen und erheblichen Verlust von Lebensräumen, Pflanzen und Tieren und haben somit einen erheblichen Einfluss auf die Biodiversität. Aus Sicht des Naturschutzes ist eine hohe Vielfalt an autochthonen Arten (Pflanzen und Tiere), deren Alter und natürliche Entwicklung wichtig und sollte auch durch die forstwirtschaftlichen Praktiken unterstützt werden.

\section{Anpassung des Managements}

Bewirtschaftungssysteme beeinflussen die Artenvielfalt erheblich. Die Einzelbaumentnahme sorgt für ein durchgehend geschlossenes Kronendach, das für viele schattenertragende Organismen im Wald wichtig ist, und führt zu einer ungleichmäßigen Altersstruktur auf Bestandsebene. Die Gruppenauswahl bietet die Möglichkeit, die Verfügbarkeit von Licht in den Lücken zu steuern und eine Vielzahl verschiedener Baum- und Krautarten einzubeziehen. Kahlschlag führt in der Regel zur Entwicklung gleichaltriger Wälder. Es werden großräumig Kronenflächen entfernt - mit Auswirkungen, die jenen von natürlichen Störungen, wie Waldbränden oder Windwürfen ähneln. Dies kann zu schnellen Habitatveränderungen, langfristig gleichmäßiger Habitatentwicklung, Nährstoffentzug und einer schnelleren Mineralisierung von Humus führen. Daher ist es wichtig, räumliche Rotationen und die Größe der Bewirtschaftungseinheit zu berücksichtigen, um ein Muster unterschiedlicher Altersstrukturen zu schaffen, das die Populationen gefährdeter Arten sichert.

Für Auwälder müssen sowohl ökonomisch als auch ökologisch rentable, nachhaltige Bewirtschaftungsformen gefunden werden. Eine Option könnte die Umwandlung bestehender Plantagen in naturnahe Wälder mit kontinuierlicher Waldbedeckung durch Anpflanzung heimischer und auch nichtheimischer, nicht invasiver Baumarten sein, die dem zukünftigen Klima entsprechen. Durch die Entwicklung neuer Techniken könnte der Einsatz von Pestiziden vermindert werden. Besonderes Augenmerk sollte auf faire Entschädigungsmaßnahmen für Waldbesitzer gelegt werden, wenn der Schutz der Biodiversität zu einem primären Managementziel wird. Dies könnte durch Verhandlungen zwischen Forstwirtschaft und Naturschutzbehörden in einem kontinuierlichen Prozess erreicht werden.

\section{Förderung der horizontalen und vertikalen Strukturvielfalt}

Die strukturelle Heterogenität bezieht sich auf eine Differenzierung in Brusthöhendurchmesser (BHD) und Baumhöhe. Sie sorgt für die Entwicklung von vielfältig strukturierten Wäldern mit Bäumen unter- 
schiedlicher Größe und unterschiedlichen Alters. Die Erhöhung der strukturellen Heterogenität ist ein wichtiges Instrument zur Förderung stabiler Wälder, die gegenüber Naturgefahren eine hohe Resilienz aufweisen. Heterogenität schafft Nischen mit unterschiedlichen biotischen und abiotischen Bedingungen und bietet Lebensraum für viele Arten. Dennoch kann die Bereitstellung solcher Bedingungen innerhalb ein und desselben Waldstücks die Artenvielfalt durch anhaltend geringe Lichtverfügbarkeit verringern.

\section{Anpassung der Baumartenzusammensetzung}

Die Baumartenzusammensetzung kann angepasst werden, indem einzelne oder eine Gruppe von Zielbaumarten bei Pflege- und Erntearbeiten gezielt gefördert werden. Auf diese Weise wird ihr Anteil im Waldbestand erhöht, und die Baumartenzusammensetzung kann in eine bestimmte Richtung gelenkt werden. Zusätzlich sollten bei der Holzernte Mischbaumarten im Bestand belassen werden, um deren natürliche Regeneration langfristig zu gewährleisten. Die Baumartenzusammensetzung kann auch durch die (Ergänzungs-) Pflanzung von artenmäßig und genetisch geeignetem forstlichem Vermehrungsgut angepasst werden (Kapitel "Entscheidung für Natur- oder Kunstverjüngung?” und “Geeignetes forstliches Vermehrungsgut zur Anpassung der Wälder an den Klimawandel”). Dennoch sollte, wenn geeignete Samenbäume vorhanden sind, der Naturverjüngung der Vorzug gegeben werden, um die genetische Vielfalt innerhalb der vorhandenen Arten zu erhalten. Außerdem gilt: Mehr ist nicht immer besser, denn je nach den herrschenden Störungsbedingungen kann weniger Vielfalt für einen bestimmten Waldstandort sogar von Vorteil sein. Eine funktionelle Vielfalt für aktuelle und zukünftige Bedingungen muss dennoch angestrebt werden.

Eine Vielfalt an geeigneten Baumarten zusammen mit struktureller und genetischer Heterogenität erhöht generell die Biodiversität eines Waldgebietes indem sie mehr Nischen für Vögel, Insekten, Pflanzen, Pilze und andere Artengruppen in Wäldern schafft.

Für die Wälder entlang der drei Flüsse Mur, Drau und Donau spielen das Eigentum an Waldflächen, das Nutzungsrecht, die Bestandsgröße und das Erbrecht eine zentrale Rolle. In den flussaufwärts gelegenen Teilen des TBR MDD gibt es viele Kleinwaldbesitzer, die Grundstücke mit nichtheimischen und teilweise nicht-uferbewohnenden Arten (wie Robinia pseudoaccacia oder Picea abies) geerbt haben. Für diese Landbesitzer kann es von Vorteil sein, eine alternative Artenzusammensetzung zu finden, die das Verlustrisiko verringert, ein angemessenes Einkommen ermöglicht und darüber hinaus zu einer standortgerechteren Ausstattung ihres Waldes führt.

Auf einer höheren Ebene sind andere Methoden erforderlich, um vielfältige und widerstandsfähige Wälder aufzubauen. Unterstützende Strukturen für die Weiterentwicklung der Waldbewirtschaftung sollten in einer gemeinsamen Anstrengung von Waldbesitzern, Behörden und Naturschutzakteuren aufgebaut werden. Dies könnte von Beratungsstrukturen bis hin zu Zuschüssen reichen. Zusätzlich sollte der Aufbau von spezialisierten Forstbaumschulen für heimische Baumarten (einschließlich ihrer lokalen/regionalen Anpassungen und eines vielfältigen Genpools) mit hohem Holzwert oder hohem ökologischen Wert angestrebt werden. 
Waldbewirtschaftung und Naturschutz sind unter Berücksichtigung und aktiver Förderung natürlicher Lebensräume und Zielarten durchzuführen (Abb. 3.2.1-2). Zu solchen Zielarten gehören auch Schirmarten, d.h. Arten, die regional für Erhaltungsentscheidungen ausgewählt werden, weil ihr Schutz den Schutz vieler anderer Arten impliziert, die die ökologische Gemeinschaft des jeweiligen Lebensraums bilden (z. B. können Dendrocopos medius, Ficedula albicollis, Felix sylvestris sowohl Tiefland- als auch Hochland-Waldhabitate im TBR MDD abdecken).

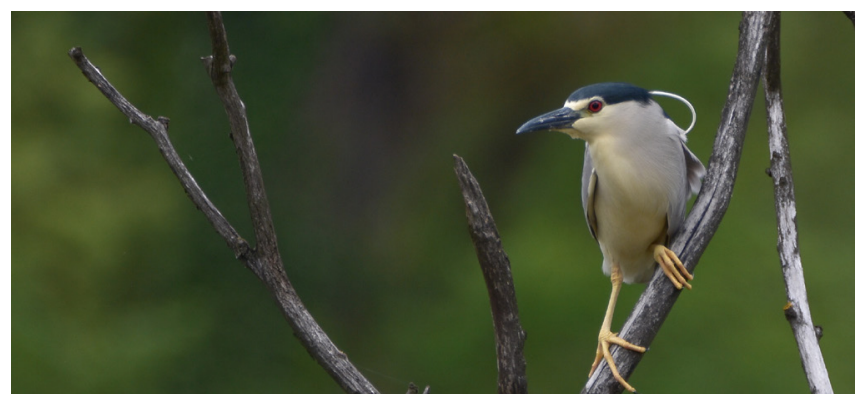

Abb. 3.2.1-2: Der Schwarzscheitel-Nachtreiher (Nycticorax nycticorax) ist eine typische Art, die in strukturreichen Auwäldern vorkommt.

Beispiele für gezielte Artenschutzmaßnahmen sind die Einschränkung von Forstarbeiten während der Hauptbrut-/Laichzeit wie etwa die Sperrung ausgewählter Forststraßen zur Laichzeit und während der Wanderung von Amphibien oder der Bau von Durchlässen unter Straßen.

\section{Förderung der Totholzmenge und-qualität}

Unter Totholzförderung versteht man die Erhöhung der Quantität und Qualität von Totholz. Die Qualität des Totholzes wird durch seine Anhäufung, Verteilung, Dimension, Zersetzung und den Typ (stehendes und liegendes Totholz, Stümpfe) definiert. Letztere sind häufig durch Holzerntemaßnahmen vorhanden. Auf diese Weise können viele totholzbewohnende Arten, wie Insekten und Vögel, in Auwäldern überleben (Kapitel "Integration von Totholz in die reguläre Waldbewirtschaftung”).

\section{Erhaltung von Habitat- und Veteranenbäumen}

Habitatbäume sind entweder lebende oder tote Bäume von hohem ökologischem Wert. Sie können verschiedene Arten von Löchern, morsche Teile, viele und grobe Äste, epiphytische Vegetation wie Moose oder Flechten aufweisen, oder eine seltene Baumart im umgebenden Wald sein. Veteranenbäume sind älter als der Rest des Bestandes (Abb. 3.2.1-3). Durch die Einbeziehung solcher Bäume bieten auch Bestände mit kurzen Umtriebszeiten potenziellen Lebensraum und werden der natürlichen Entwicklung überlassen. Der Erhalt von einzelnen oder Gruppen von Habitat- oder Veteranenbäumen erhöht die Artenvielfalt erheblich. 
Im Rahmen des vom WWF erstellten TBR MDD Aktionsplans wird ein Totholzartenprogramm in Verbindung mit Habitatverbesserungen in Wäldern vorgeschlagen. Das Ziel eines solchen Programms wäre es, die Quantität und Qualität von Totholzhabitaten (stehend oder liegend) zu erhöhen, um geeignete Lebensräume für Arten zu schaffen, die auf Totholz angewiesen sind (z. B. Flechten, Pilze, Spechte, Fledermäuse oder Insekten). Typische Schirmarten, die anvisiert und überwacht werden sollten, sind z. B. Osmoderma eremita(Eremit) oder Cucujus cinnaberinus (Scharlachkäfer). Die Erhöhung des Totholzanteils in den Wäldern der TBR MDD kann entweder durch die Erhöhung des Anteils an unbewirtschafteten Wäldern oder durch die Erhöhung des Anteils an Totholz, das nach Ernte- oder Pflegeeingriffen in den Wäldern verbleibt, erfolgen. Die Dokumentation dieser Maßnahmen sollte einen Hinweis darauf geben, wie viel Totholz in bewirtschafteten Wäldern belassen werden muss, um eine naturnahe Abundanz und Vielfalt an Totholzarten zu erreichen. Zusätzlich könnten, insbesondere bei großen Reinbeständen, Streifen mit Arten, die der natürlichen Sukzession zum Zeitpunkt der Neupflanzung entsprechen, eingebracht werden. Auf diesen Streifen sollte die forstliche Nutzung unterbleiben, so dass sich im Laufe der Zeit Totholz aus einer Vielzahl von Baumarten bilden kann, was sich positiv auf die Totholzartenvielfalt auswirkt.

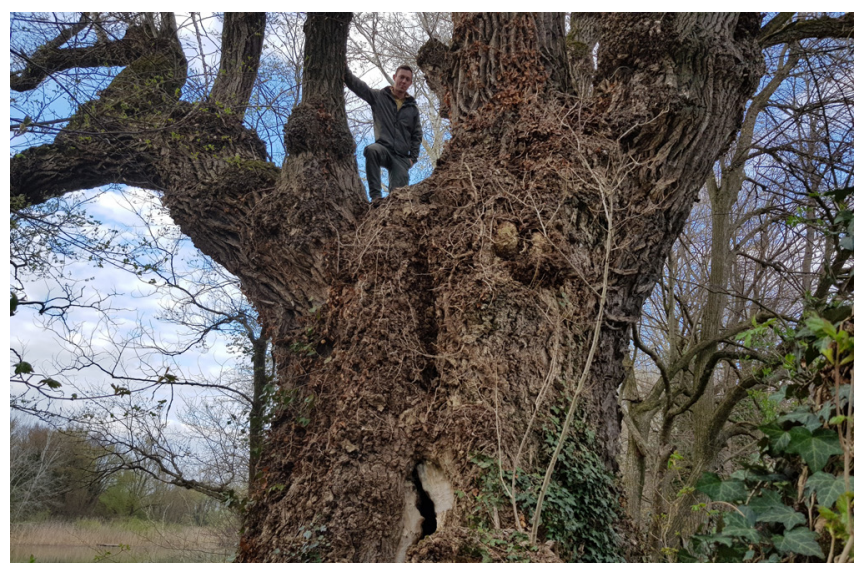

Abb. 3.2.1-3: Alte Schwarzpappel (Populus nigra) an der Mur entlang der ungarisch-

kroatischen Grenze.

\section{Verzicht auf forstliche Nutzung}

Ein gängiger Ansatz, um der Natur die Möglichkeit zu geben, sich ungestört und natürlich zu entwickeln, ist die Definition von No-Management-Areas und die Entwicklung eines Naturschutz-Managementplans. Insbesondere Galeriewälder sind ein Indiz für natürliche Flusssysteme und stellen prioritäre natürliche Lebensräume dar. Zur natürlichen Entwicklung gehört auch ihre mögliche Zerstörung durch Mäandrierung. Da Auwälder unter Druck stehen und die natürliche Entwicklung möglicherweise nicht zu den von den Naturschutzmanagern angestrebten Waldzuständen führt, können bestimmte Managementmaßnahmen wie die Bekämpfung nichtheimischer Arten (Kapitel "Management von nichtheimischen Pflanzen") erforderlich sein, um autochthone Waldgesellschaften zu erhalten (Abb. 3.2.1-4).

\section{Erhöhung der Umtriebszeit}

Die Umtriebszeit umfasst die Phase von der Bestandesbegründung bis zur Ernte. Bei ungleichaltrigen Wäldern bezieht sie sich auf ein defi- 


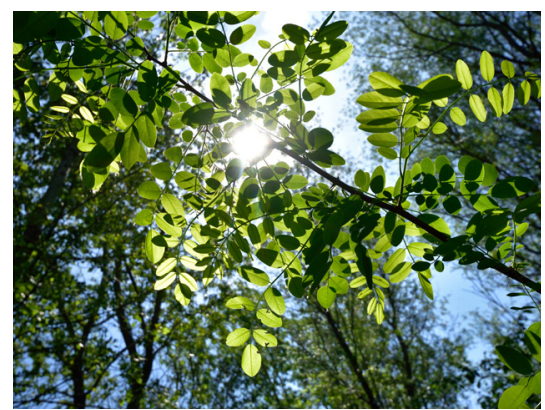

Abb. 3.2.1-4: Invasive nichtheimische Arten wie die Robinie (Robinia pseudoacacia) dringen in die Waldökosysteme ein. niertes Alter des einzelnen Baumes zum Zeitpunkt der Entnahme aus dem Bestand. Eine Erhöhung der Umtriebszeit geht mit einem höheren Reifegrad einher, aber auch mit einem höheren Risiko von Schädlings- und Krankheitsbefall, sowie Mortalität. Daher bietet ein höheres Bestandsalter Lebensräume für Arten, die auf reife Wälder angewiesen sind, und ermöglicht die Bereitstellung von Totholz in großem Umfang.

Vermeidung von Waldfragmentierung und Erhaltung der Landschaftsheterogenität

Auf der Landschaftsebene bezieht sich die strukturelle Vielfalt von Wäldern und Waldrändern auf unterschiedliche Baumartenzusammensetzungen, Altersklassen und Entwicklungsstadien. Dies umfasst auch Lücken mit geringer Waldbedeckung oder unterschiedlichen Bewirtschaftungsintensitäten und Bewirtschaftungssystemen. Waldverlust, Kahlschlag und extensiver Forststraßenbau führen möglicherweise zu einer Fragmentierung der Wälder. Die Reduzierung der Anzahl und Nutzung vorhandener Barrieren innerhalb natürlicher oder naturnaher Wälder stellt den natürlichen Flusslauf wieder her und trägt zu einem natürlicheren Wald bei. Dies kann dadurch geschehen, dass bestehende künstliche Strukturen aus den Flussläufen entfernt. Auf diese Weise werden ausreichend große Gebiete geschaffen, in denen die Entwicklung stabiler Populationen von gefährdeten Tier und Pflanzenarten möglich ist, die sich innerhalb der Areale auch mit anderen Populationen verbinden können.

\section{Durchführung eines aktiven Monitorings}

Aktives Monitoring in Wäldern bezieht sich auf die kontinuierliche Beobachtung verschiedener Arten und Prozesse. Es ist die Grundlage, um Veränderungen im Laufe der Zeit zu erkennen. In der Folge kann das Management entsprechend diesen Veränderungen angepasst werden. Das Monitoring dient außerdem dazu, den Erfolg von Transformations- und Anpassungsmaßnahmen zu bewerten.

Auch im Hinblick auf den Naturschutz ist eine kontinuierliche Überwachung und Kontrolle von Schutzgebieten notwendig, um sicherzustellen, dass die bestehenden Gesetze und Verordnungen eingehalten werden. In diesem Zusammenhang könnte ein staatliches Netz von Rangern eingerichtet werden, die die Einhaltung der bestehenden Vorschriften und Kontrollmaßnahmen überwachen. Dies würde auch das Bewusstsein der Menschen für die bestehenden Vorschriften schärfen. Darüber hinaus werden durch ein Monitoring auch diejenigen Maßnahmen identifiziert, die nicht oder nur unzureichend funktionieren oder angepasst werden müssen.

Implementierung von forstwirtschaftlichen

Zertifizierungssystemen

Die Produktion von Holz und anderen Naturgütern mit Zertifizierung kann zu Vermarktungsvorteilen führen. Das Bewusstsein bei Forstunternehmen für den Nutzen von Kennzeichnungen und Zertifizierun- 
gen als Mindeststandard für eine nachhaltige Holzproduktion wächst. Neben der Biodiversität kann die Waldbewirtschaftung auf diese Weise auch das soziale und wirtschaftliche Wohlergehen der beschäftigten Waldarbeiter und der lokalen Bevölkerung langfristig erhalten bzw. verbessern und wirtschaftliche Vorteile erzielen. Die Unterstützung für den Zertifizierungsprozess muss je nach Möglichkeiten und Hindernissen in den verschiedenen Ländern eingerichtet werden. Beispiele für gute Praktiken sind die Übernahme der Kosten für die erste Zertifizierungsrunde durch ein lokales oder grenzüberschreitendes Projekt, die Unterstützung von Know-how durch verschiedenen Zertifikatsinhabern an diejenigen, die ein solches anstreben, oder die gemeinsame Förderung derjenigen Forstbetriebe, die an gemeinsam festgelegten Standards arbeiten. Die weitere Umsetzung muss von den Waldbewirtschaftern vorangetrieben werden.

Förderung und Umsetzung der Zusammenarbeit zwischen den Sektoren (integrative Planung) auf regionaler und grenzüberschreitender Ebene

Eine Zusammenarbeit von Akteuren und Behörden verschiedener Sektoren auf nationaler und grenzüberschreitender Ebene und unter Berücksichtigung unterschiedlicher Interessen hilft, das Verständnis für Bedürfnisse, gegenseitigen Respekt, Vertrauen und Effizienz zu erhöhen. Eine solche Zusammenarbeit sollte sowohl den Forstsektor und den Naturschutz als auch die Anwohner, die Landwirtschaft und die Wasserwirtschaft umfassen. Sie hat das Potenzial, das Wissen, das Verständnis und das Vertrauen zwischen den Sektoren zu erhöhen und kann neue Synergien schaffen, die dem Erhalt der biologischen Vielfalt dienen.

Das Label des UNESCO-Biosphärenreservats selbst ist für die Vermarktung aller im TBR MDD produzierten Waren geeignet. Für eine weitere Zertifizierung sollte in einem gemeinsamen Verhandlungsprozess mit wichtigen Akteuren der Forstwirtschaft und des Naturschutzes aus dem gesamten TBR MDD die Eignung bestehender forstwirtschaftlicher Zertifizierungssysteme oder -standards (z. B. PEFC, FSC, ProSilva) für die Anwendung in den Übergangs- und Pufferzonen des Biosphärenreservats geprüft werden. Damit könnte die Bewirtschaftung innerhalb der Zonen grenzüberschreitend harmonisiert werden. 


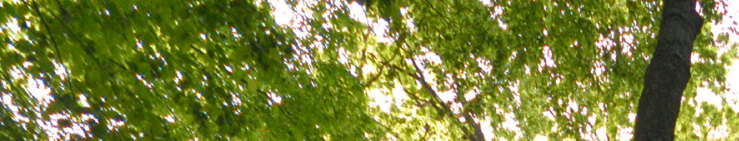

\section{8.}

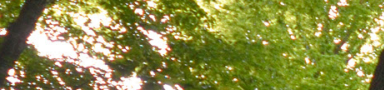

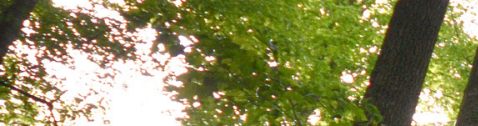

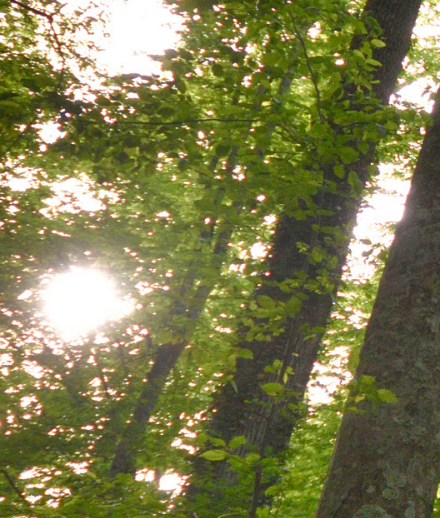

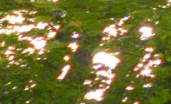

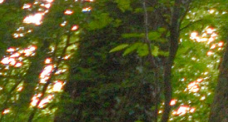

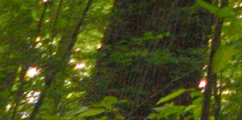

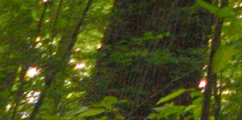

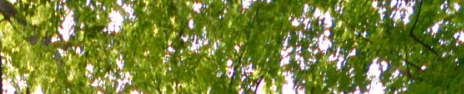

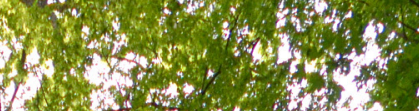

1.7.

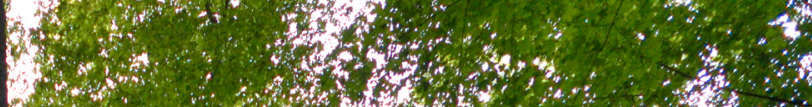

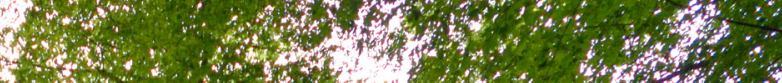

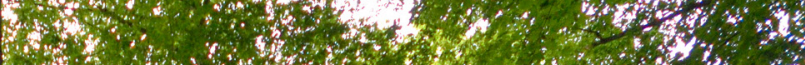

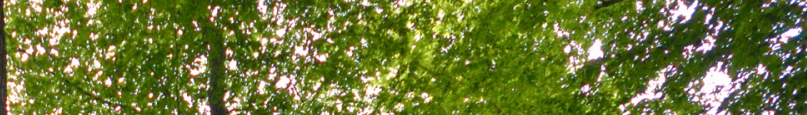

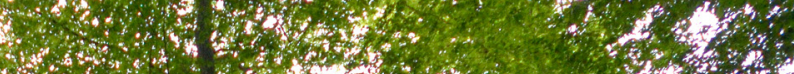
W6.

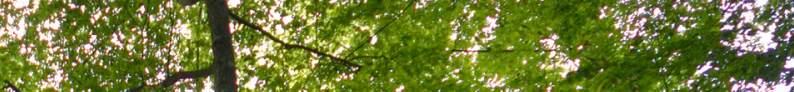
P.

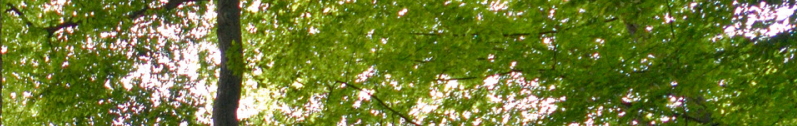

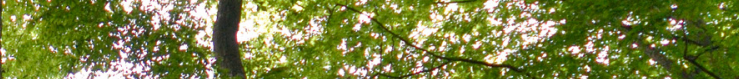

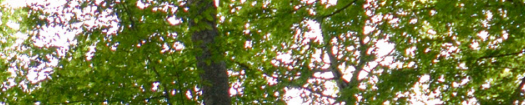

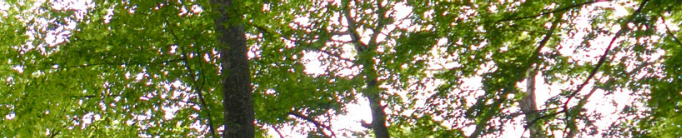
$+2003$ (5) $(1,5)$

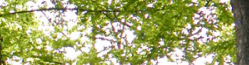
1.6.

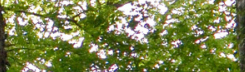

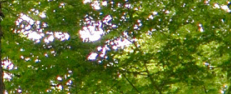

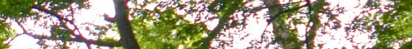

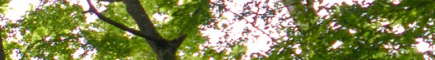

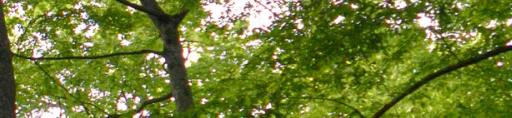
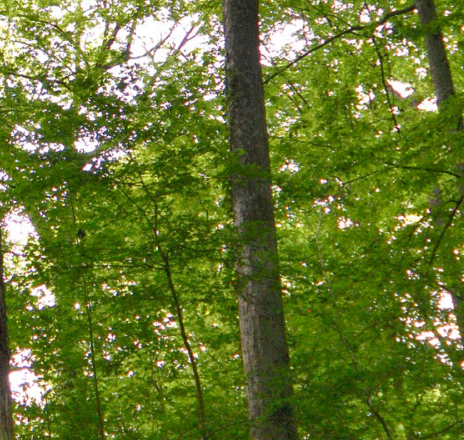

42,10

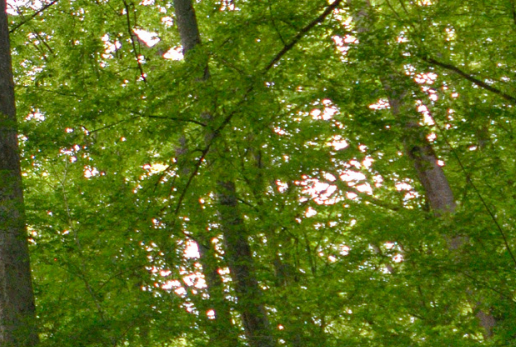

f is at: to

2 


\subsubsection{Potentiale in der Laubwertholzproduktion}

\section{Markus Sallmannshofer, Werner Ruhm, Hannes Schönauer}

Die Harte Au wird nur unregelmäßig bei Spitzenhochwässern und für kurze Dauer überflutet. Sie zeichnet sie daher durch Böden mit höherem Reifegrad und Humusgehalt als die der weichen Au aus. Auf frischen Varianten findet sich ein besonders günstiger Nährstoffhaushalt, eine gute Wasserversorgung und Bodendurchlüftung, so dass vor allem Edellaubbaumarten hier die höchsten Wuchsleistungen erreichen. Schädigungen aufgrund länger andauernder Überschwemmungen sind durch die Flussverbauungen oft kaum mehr zu erwarten. Die besonderen Eigenschaften dieser Standorte prädestinieren sie daher für den Anbau von Edellaubholz. Edellaubhölzer entfalten ihre Leistung und Qualität nur auf gut nährstoff- und wasserversorgten, tiefgründigen Standorten; lediglich bei Eiche ist auch auf trockeneren, nährstoffärmeren Standorten die Produktion von Qualitätsholz möglich.

Laubholzsubmissionen belegen die über Jahrzehnte kontinuierliche Nachfrage nach qualitativ hochwertig produziertem Holz. Ein zielgerichteter Waldbau mit entsprechender Bestandesbegründung und konsequenter Pflege erhöht die Ausbeute hochqualitätiver Stämme (Abb. 3.2.2-1). Wesentliche Weichen für die künftige Wertleistung stellt zudem die genetische Veranlagung (Herkunft). Traditionell werden Laubholzbestände stammzahlreich begründet und besonders lange, astfreie Schäfte angestrebt.

Bisher findet die Wuchsdynamik einzelner Bäume in Bezug auf die gewünschten Eigenschaften des produzierten Holzes in der Regel zu wenig Berücksichtigung. Bei der modernen Laubwertholzproduktion steht im Gegensatz zur Massenware aufgrund der nötigen waldbaulichen Investitionen der Einzelbaum im Vordergrund. Da meist nur eine sehr begrenzte Anzahl der vorhandenen Bäume überhaupt das Potential zur Wertholzproduktion hat, sind nur bei diesen aufwendige Pflegeeingriffe sinnvoll. Die Wertleistung von Laubholzbeständen wird durch die Durchmesser- und Qualitätsentwicklung der Wertträger bestimmt. Durch die richtige Wahl von Standort, Genetik und Erziehung können diese beiden Parameter gesteuert werden. Der Sammelbegriff "Qualität" beim Laubholz umfasst allgemein einen starken astfreien Mantel bei möglichst kleinem inneren astigen Kern, Vollholzigkeit, Geradschaftigkeit und Spannungsarmut bei ausreichender Dimension. Dieses Ideal dürfte auch künftig unverändert bleiben, da es Ausbeute und Wirtschaftlichkeit nachgelagerter Produktionsschritte maßgeblich bestimmt.

\section{Schlüsselparameter Astfreie Schaftlänge}

Bei den meisten Laubholzarten handelt es sich um so genannte Totastverlierer. Bei diesen Baumarten kann die gewünschte astfreie Schaftlänge durch natürliche Astreinigung im Dichtstand erreicht werden.

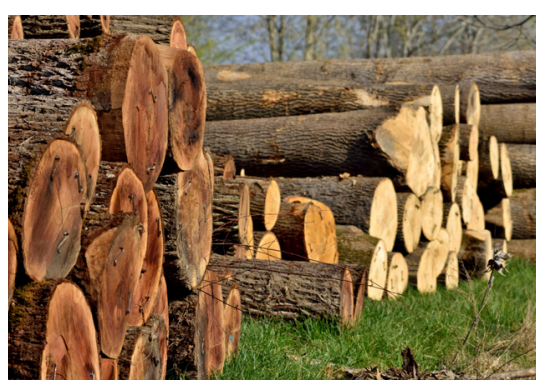

Abb. 3.2.2-1: Hochwertige Stämme in gewünschter Dimension, Qualität und Quantität erfordern eine waldbauliche Planung für die gesamte Umtriebszeit 


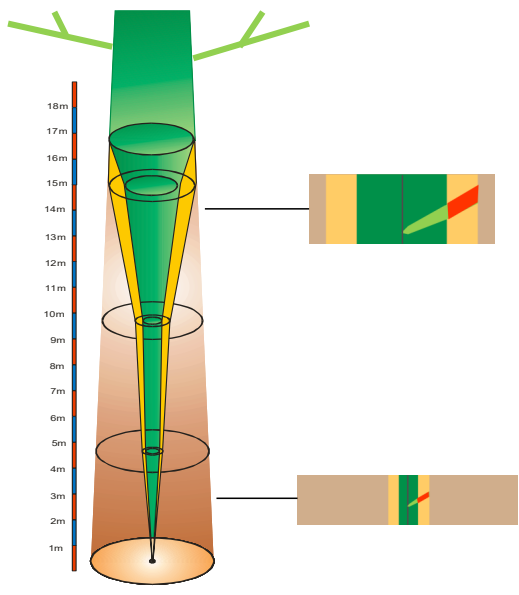

Abb. 3.2.2-2: Schematische Darstellung des inneren astigen Kerns (grün) der der Form einer Karotte ähnelt. Er nimmt mit der Höhe in der Dimension zu, was zu weniger und jüngeren astfreien Wertholzschichten führt (braun).
Bei Totasterhaltern (Pappel, Vogelkirsche) oder bei weitständiger Bestandesbegründung ohne Nebenbestand ist eine Astung unerlässlich, um Qualitätseinbußen zu vermeiden.

$\mathrm{Da}$ die Baumhöhe in erster Linie von den standörtlichen Gegebenheiten abhängig ist, kann als Zielvorgabe für die anzustrebende astfreie Schaftlänge ein Relativwert der Gesamthöhe des ausgewachsenen Baumes herangezogen werden. Um ausreichend grüne Krone für ein rasches Wachstum des astfreien Mantels zu erhalten, haben sich ca. 25 - 30\% (40\%) als Zielvorgabe für die grünastfreie Schaftlänge bewährt. Auf sehr guten Bonitäten mit Oberhöhen von ca. $32 \mathrm{~m}$ bedeutet dies $8-10 \mathrm{~m}$.

Ein weiteres wesentliches Argument für ein relativ kurzes grünastfreies Stammstück ist der innere astige Kern. Unter dieser inneren Astigkeit versteht man die Spuren, welche die im Laufe der Astreinigung abgestorbenen Äste im Inneren des Holzkörpers hinterlassen. Da dieser innere Astkern, ähnlich der From einer Karotte (Abb. 3.2.2-2), mit zunehmender Höhe nach oben hin immer mehr Raum einnimmt und dadurch die astfreien Wertholzschichten immer jünger und somit weniger werden, macht ein weiteres Dichthalten des Bestandes und gezieltes Hinaufschieben der Krone wirtschaftlich keinen Sinn. Am Zopfende sollte das astfreie Wertholz mindestens 2/3 des Durchmessers betragen.

\section{Bestandesbegründung}

Wenn man davon ausgeht, dass bei der Laubwertholzproduktion mehr als $80 \%$ der Gesamtwertleistung i.d.R. vom Endbestand realisiert werden, sollten bei der Bestandesbegründung für den Endbestand und die Pflege die bestmögliche Ausgangssituation geschaffen werden. Das Ziel einer möglichst gleichmäßigen Verteilung der Bäume des Endbestandes kann nur erreicht werden, wenn der angestrebte Endverband im Ausgangsverband bereits enthalten ist.

Naturverjüngung, sofern möglich und genetisch sinnvoll, sollte aus Gründen der Kosteneffizienz und Anpassung genutzt werden. Esche, Bergahorn und Schwarznuss fruktifizieren häufig und ausreichend. Stieleiche ist vor allem in der Jugendphase der Konkurrenz der Edellaubbäume unterlegen und bedarf daher einer entsprechenden Mischwuchsregulierung. Wegen der Neigung vieler Auwaldstandorte zu starkem Kraut- und Strauchwuchs erfordert das Arbeiten mit Naturverjüngung viel waldbauliches Feingefühl. Neben flächigen Schirmschlägen hat sich eine femelartige Erweiterung von Verjüngungskernen als sehr erfolgreich erwiesen.

Fehlt geeignete Naturverjüngung, muss auf Pflanzung zurückgegriffen werden. Mit der Wahl des Pflanzverbandes können Kosten und Nutzen optimiert werden. Ein empfehlenswertes Konzept ist die Mulchung und Anpflanzung in Reihen. Um Kosten zu sparen, wird der Reihenabstand an die angestrebte Kronengröße im Endbestand angepasst. 
Große Kronen ermöglichen einen starken Durchmesserzuwachs. Für Edellaubholzbestände ist somit ein Reihenabstand von 10 - $12 \mathrm{~m}$ mit einem Abstand von $1 \mathrm{~m}$ in der Reihe ausreichend. Damit steht in der Reihe eine ausreichende Anzahl Bäume zur Verfügung, um genügend gutgeformte Stämme für den Endbestand zur Auswahl zu haben.

Dieses stammzahlarme und dadurch kostengünstige Begründungsdesign ermöglicht es daher kostenintensive Pflegemaßnahmen (Formschnitte, Astung) in den Folgejahren durchzuführen. Weiters ist auf den meisten für die Edellaubzucht geeigneten Auwaldstandorten mit einer ausreichenden Anzahl an Mischbaumarten über Naturverjüngung (meist Stockausschläge und Wurzelbrut) zu rechnen. Die „erzieherische" Wirkung dieser Baumarten kann grundsätzlich genutzt werden. Pflanzenzahlen und damit die Bestandesbegründungskosten werden merklich verringert. Zwischenartliche Konkurrenz kann positive Effekte der innerartlichen Konkurrenz ersetzen, wobei jedoch ein sorgfältiges Beobachten der Wuchsrelationen unbedingt notwendig ist. Wesentlich bei solchen Konzepten sind die Berücksichtigung der standortsspezifischen Konkurrenzverhältnisse und bei zu starker Bedrängung im Kronenraum zeitgerechte steuernde Eingriffe, um hohe $\mathrm{H} / \mathrm{D}$-Werte zu verhindern.

Wenn sich kein ausreichender Nebenbestand aus Naturverjüngung entwickelt, besteht die Möglichkeit zur Pflanzung von Pappelreihen zwischen den Edellaubreihen als funktionale Zeitmischung (Abb. 3.2.2-3). Die Pappeln üben positiven Einfluss auf die Qualitätsentwicklung der Edellaubhölzer aus und werden im Alter von ca. 10 Jahren als Industrieholz entnommen. Alternativ kann eine untergeordnete Mischung eingebracht werden (Traubenkirsche, Grauerle, Feldahorn), die als Dauermischung im Bestand verbleibt.

\section{Pflege}

Auf den wüchsigen Auwaldvarianten stellt die Kraut- und Strauchschicht eine starke Konkurrenz dar. Das beschriebene ressourcensparende, stammzahlarme und auf den Endbestand optimierte Begründungsdesign ermöglicht es kostenintensive Pflegemaßnahmen sehr zielgerichtet in den Folgejahren durchzuführen. Im Großwaldbetrieb ist die mechanische Begleitwuchsregulierung kostenmäßig vorteilhaft. Die Kultur muss entlang der Reihen für mindestens 3-4 Jahre freigeschnitten werden. Entlang der Reihe bietet sich ein Rotorschneider an, in der Reihe ein Freischneidegerät. Die Entfernung von Schlingpflanzen kann parallel zu einem optionalen Formschnitt an vielversprechenden Bäumen mit der Handschere durchgeführt werden. Durch die Entnahme von Steil- und Starkästen soll die Bildung eines ausreichend langen, geraden Stammabschnittes begünstigt werden.

Bis zum Erreichen der angestrebten astfreien Schaftlänge wird ansonsten kaum in die Jungbestände eingegriffen, um die für die Qualität entscheidenden Differenzierungs- und Astreinigungsprozesse nicht zu

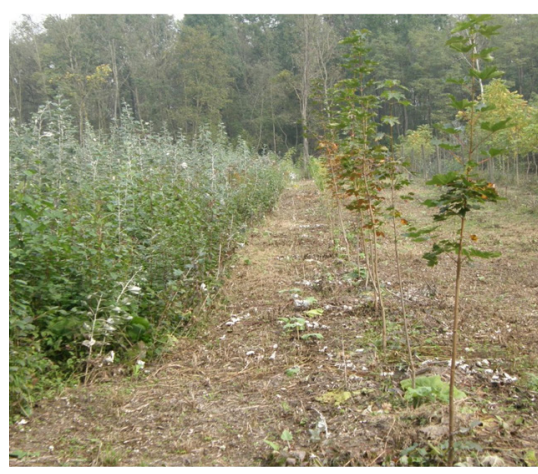

Abb. 3.2.2-3: Ahornreihe mit einem sekundären, dienenden Bestand aus Pappeln im Zwischenraum. Interspezifische Konkurrenz kann positive Effekte der intraspezifischen Konkurrenz ersetzen. Dadurch können Pflanzkosten gespart werden, wobei eine sorgfältige Beobachtung der Wuchsrelationen unerlässlich ist. Die Pappeln haben einen positiven Einfluss auf die qualitative Entwicklung der Laubhölzer und werden bereits im Alter von rund 10 Jahren als Industrieholz geerntet. 


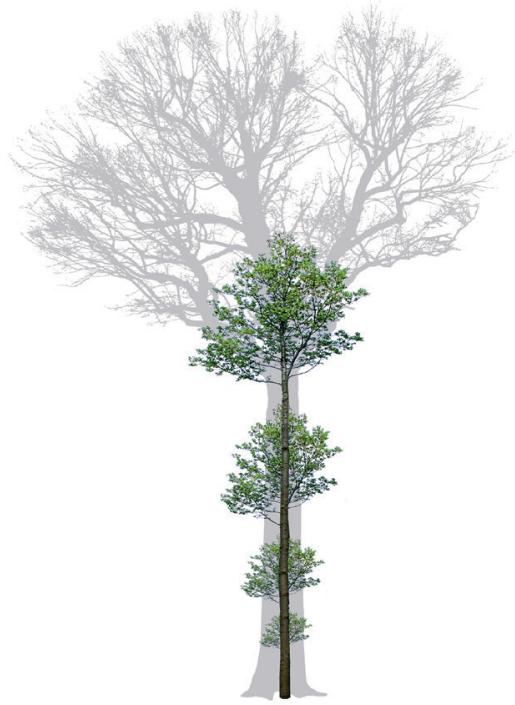

Abb. 3.2.2-4: Für die gewünschte Entwicklung der ausgewählten wirtschaftlich wertvollen Bäume muss der Standraum ab einer gewissen Baumhöhe kontinuierlich erweitert werden, um eine ausreichend grüne Krone für ein schnelles Wachstum des astfreien Mantels zu erhalten und den Kronenansatz in der Höhe zu fixieren. unterbrechen. Eine Mischungsregulation kann jedoch notwendig sein. Durch die Konkurrenz wird das Dickenwachstum gezielt gebremst, die Ausdehnung des astigen Kerns im Inneren des Stammes verringert und das Höhenwachstum stimuliert.

\section{Durchforstung}

Wenn die dem Standortspotential entsprechende grünastfreie Schaftlänge erreicht wird, werden ca. 70-100 Z - Bäume/ha ausgewählt, permanent markiert und konsequent freigestellt. Dieses Kollektiv wird nun bestmöglich durch konsequente Kronenförderung im Dickenwachstum stimuliert. Motor des Dickenwachstums ist eine möglichst breite und lange Krone, denn es besteht ein enger Zusammenhang zwischen der Kronenbreitenentwicklung und dem Dickenwachstum. Unterbleibt die Kronenfreistellung, beginnen die unteren Kronenäste abzusterben und die Kronenbasis wandert weiter nach oben. Der Standraum muss zur gewünschten Entwicklung der Wertträger stetig so erweitert werden, dass sich die Kronenbasis nicht weiter hinauf verschiebt (Abb. 3.2.2-4).

Mehrere selektive Durchforstungseingriffe, die sich die Freistelllung der qualitativ hochwertigsten Bäume zum Ziel haben, führen zum Endbestand. Eine früh beginnende Förderung der Kronenentwicklung steigert das Dickenwachstum, verkürzt bei gegebenem Zieldurchmesser die Umtriebszeit, verringert den Anfall schwacher Sortimente, und mindert das Risiko von altersabhängigen Entwertungen (Fäule, Farbkernbildung). Eingriffe erfolgen nur im Bereich der Z-Bäume. In den Zwischenfeldern wird nur eingegriffen, wenn es für die Stabilität des Bestandes erforderlich ist. Durch Köpfen oder Ringeln kann besonders kontinuierlich freigestellt werden, während die Stammbeschattung bis zu einer gewissen Höhe aufrecht gehalten wird oder mit der Zeit langsam abnimmt.

Der Abstand zwischen den Auslesebäumen richtet sich nach der Kronenschirmfläche, die zur Erreichung einer bestimmten Zielstärke notwendig ist. Um Zielstärken von $50-90 \mathrm{~cm}$ BHD erreichen zu

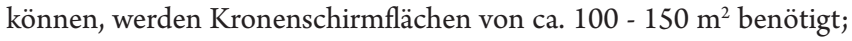
daraus lassen sich flächenbezogene Höchstzahlen ableiten. Bei Bäumen mit großer Kronenexpansionsfähigkeit wie Stieleiche, Esche oder Schwarznuss werden größere mittlere Z-Baumabstände von ca. $12 \mathrm{~m}$ gewählt, womit maximal 70 Z-Bäume/ha Platz finden. Bei Baumarten mit mittlerer Kronenexpansionsfähigkeit wie Vogelkirsche, Elsbeere und die Ahornarten werden bei einem mittleren Z-Baumabstand von ca. $10 \mathrm{~m}$ maximal $100 \mathrm{Z}$-Bäume/ha ausgewählt.

\section{Ausblick und Zusammenfassung}

Diese Methodik optimiert die Wertholzerzeugung dahingehend, dass entsprechend den Wünschen der Abnehmerseite mit starken und vitalen Bäumen gewinnmaximierend produziert wird. Ressourcen werden 
bei der Bestandesbegründung und einzelbaumorientierten Pflege gespart und Erträge durch die erhöhte Qualität gesteigert. In der Literatur wird ein solches Konzept mit Qualifizierung (Phase 1 als Astreinigung bis zur Z-Baumauswahl und Durchforstung) und Dimensionierung (Phase 2) als Zwei-Phasenkonzept zur Laubwertholzproduktion beschrieben. 


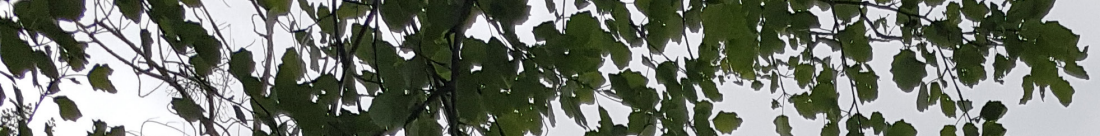

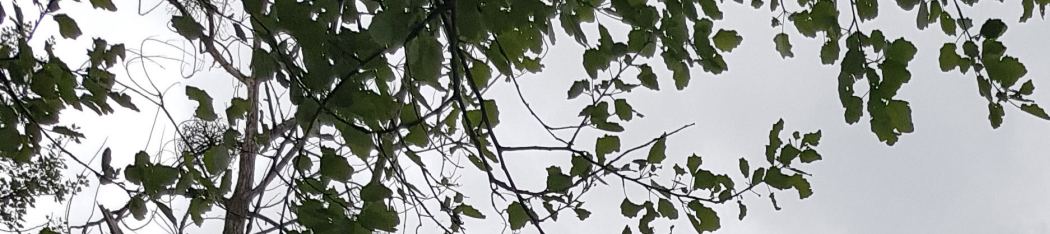

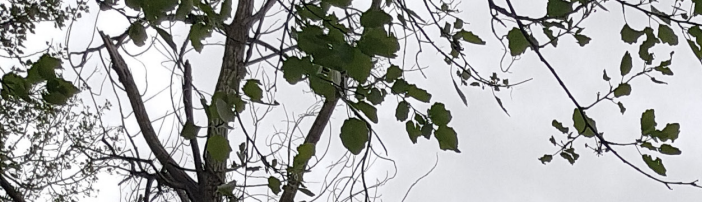
$\frac{1}{2}$

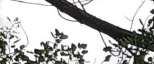

(4)

2.

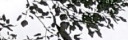
is 35

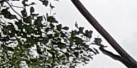

1.6.

4.

,

(4)
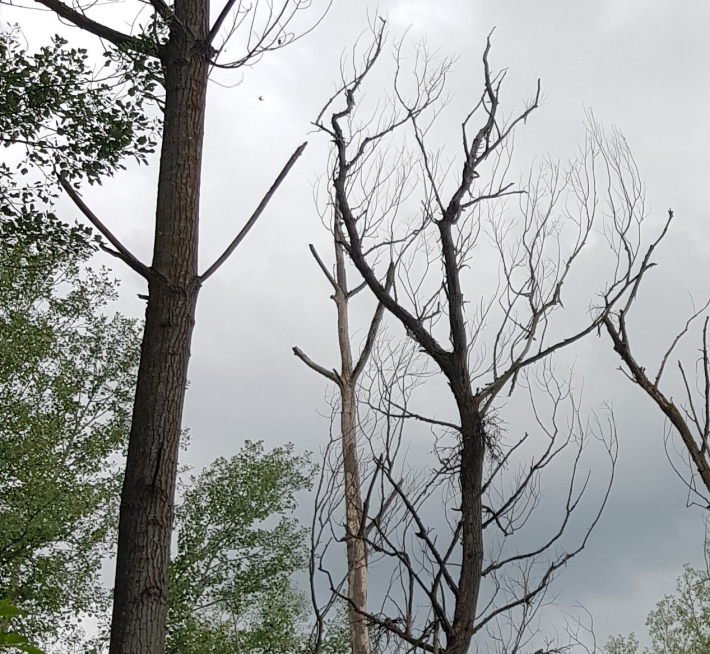

$6 \times$

5

a.

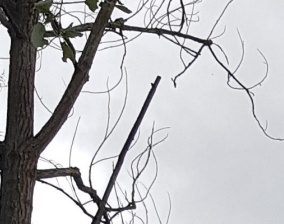

a
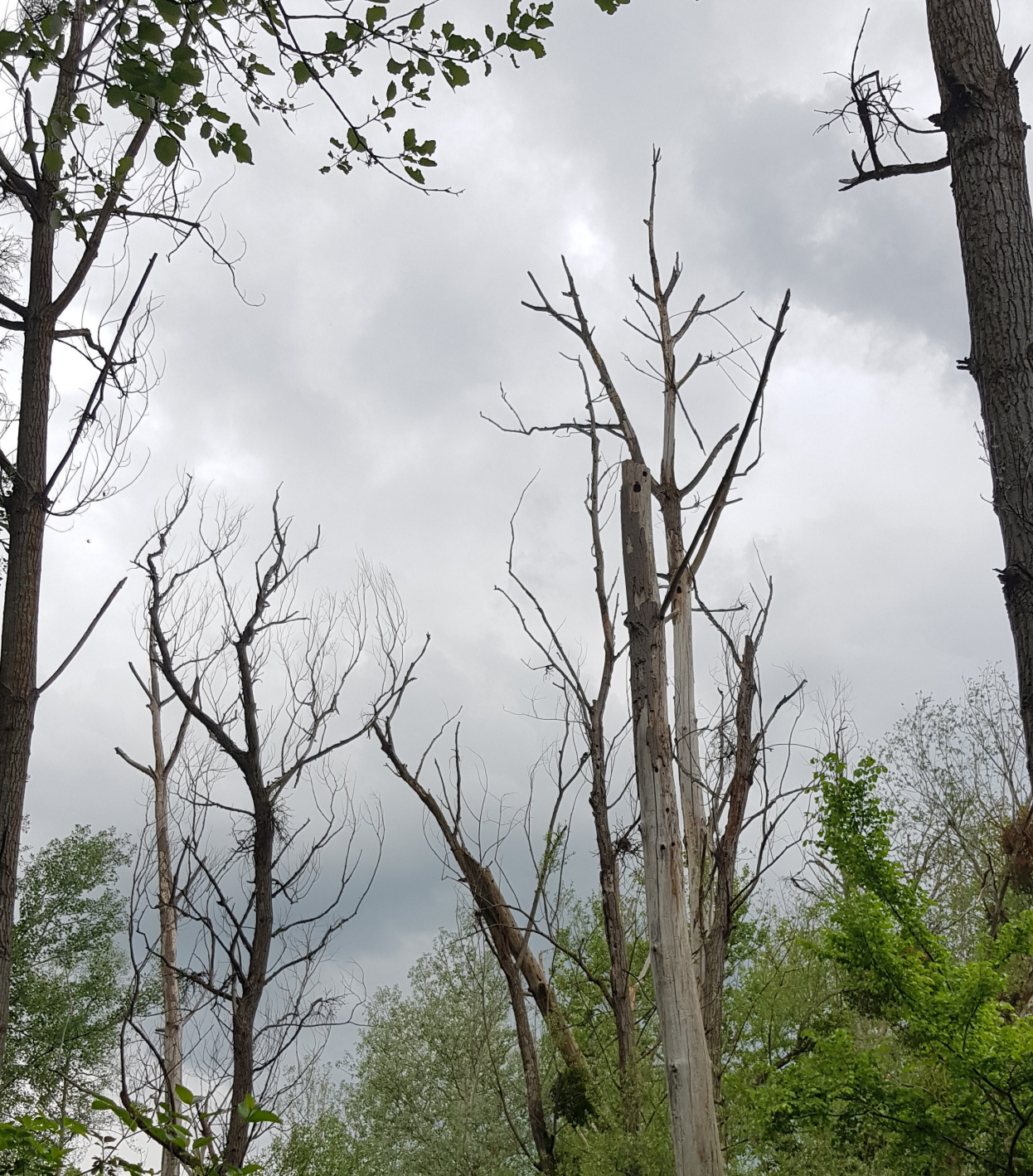

+.,
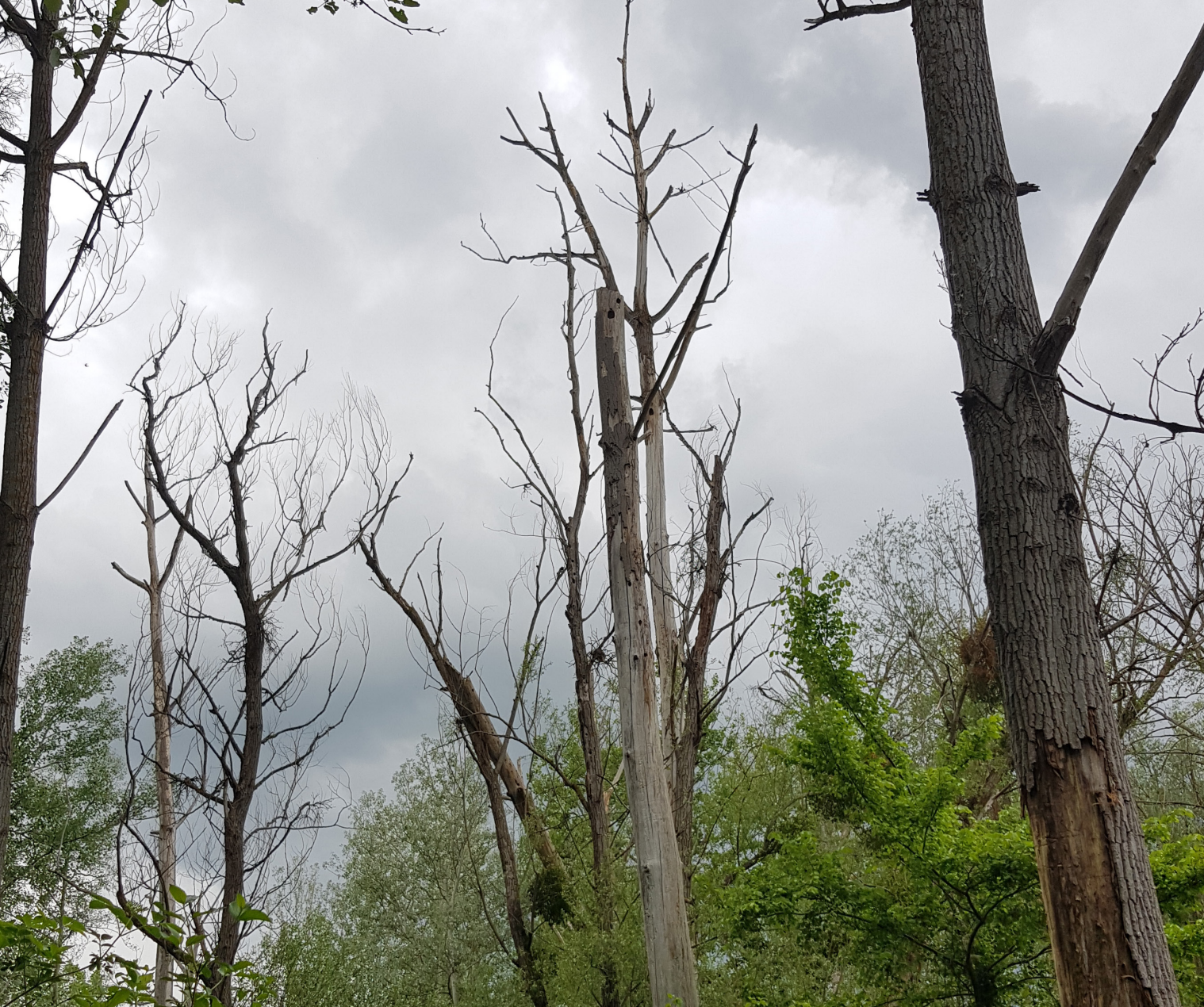

n. FN

4. 5 


\subsubsection{Herausforderungen im Klimawandel}

\section{Katharina Lapin, Maarten de Groot, Debojyoti Chakraborty}

\section{Einleitung}

Der Bewältigung des menschgemachten Klimawandels ist die größte Aufgabe der Menschheit im 21. Jahrhundert. Schutzgebiete leisten weltweit einen wichtigen Beitrag, um den Klimawandel und dessen Folgen abzumildern. Allerdings stellt der grenzüberschreitend und alle Ökosysteme betreffende Klimawandel auch die bisherige Ausweisung von Schutzgebieten und dessen Management vor neue Herausforderungen.

Angesichts der Bedeutung der biologischen Vielfalt, von gefährdeten Lebensräumen und Kulturlandschaften wurden weltweit verschiedenste Typen Schutzgebieten eingerichtet. Im Klimawandel ist die Wirksamkeit dieser Schutzgebiete zu Erreichung der jeweils definierten Schutzziele jedoch in Frage gestellt. Eine Vielzahl an Studien hat bereits gezeigt, dass der Klimawandel zu einem Verlust an wertvollen Lebensräumen und Biodiversität innerhalb der Schutzgebiete führen kann. Auch in Europa wurden die Folgen des Klimawandels für geschützte Lebensräume bereits mehrfach untersucht.

Schutzgebiete speichern etwa $15 \%$ des gebundenen terrestrischen Kohlenstoffs und erbringen Ökosystemleistungen für den Schutz vor Naturgefahren und Katastrophen, liefern Wasser und Nahrung und tragen zur öffentlichen Gesundheit bei. Fast 30 Millionen Hektar europäischer Wälder stehen unter Schutz. Allein zwischen 2005 und 2015 betrug die jährliche Kohlenstoffsenkenleistung der Waldbiomasse 719 Millionen Tonnen Kohlendioxid. Aber der Klimawandel ist auch eine der größten Herausforderungen für Schutzgebiete, insbesondere Waldschutzgebiete. Für die UNESCO Weltnaturerbe Stätten wurden invasive Arten, Klimawandel und Tourismus als die Gefährdungen mit den größten Auswirkungen identifiziert, wobei die Folgen des Klimawandels Klimawandel als die am schnellsten wachsende Bedrohung eingeschätzt wurde.

Auwaldökosysteme gehören zu den am häufigsten geschützten Gebieten in Europa. Sie haben eine besondere Bedeutung als lang- und kurzfristige Kohlenstoffsenke und die Bereitstellung von Ökosystemleistungen, obwohl sie nur $0,5 \%$ bis $1 \%$ der globalen Landfläche bedecken. Daher müssen die Herausforderungen des Klimawandels für Auwaldökosysteme besser verstanden werden, um diese an die zu erwartenden Klimabedingungen anzupassen und die Widerstandsfähigkeit von Auwäldern zu erhöhen.

In diesem Kapitel fassen wir die wichtigsten Herausforderungen des Klimawandels für die Praxis, den Naturschutz und die Waldbewirtschaftung zusammen und geben ihnen einen Ausblick auf Managementstrategien zur Anpassung an den Klimawandel und zur Minderung von dessen Folgen für Auwälder. 


\section{Abiotische Auswirkungen}

Bisherige Beobachtungen zeigen die sehr variablen Reaktionen der Wälder auf den Klimawandel. Zu den abiotischen Herausforderungen gehören Waldbrand- und Sturmschäden, Dürreereignisse sowie ein Rückgang der Niederschläge und Veränderungen in deren jahreszeitlicher Verteilung. Auch die Klimavorhersagen für Europa zeigen ein geografisch sehr unterschiedliches Bild von Veränderungen, einschließlich der Zunahme von hohen Temperaturextremen, Dürreereignissen und Starkniederschlagsereignissen. Extreme Witterungsbedingungen werden zu einem Rückgang der Produktivität und Vitalität der Wälder führen. In Südeuropa wird die Zunahme von Waldbränden vorhergesagt, während in Mitteleuropa eher die Schäden durch Stürme zunehmen werden.

\section{Biotische Auswirkungen}

Die biotischen Auswirkungen sind stark mit den abiotischen Effekten verbunden, denn Temperatur- und Niederschlagsveränderungen beeinflussen auch die Vermehrung, das Wachstum und Überleben von Schädlingen und Konkurrenten und stellen somit biotische Bedrohungen der aktuellen Waldökosysteme dar. Insgesamt werden Waldschäden in Europa am häufigsten durch biotische Einflüsse verursacht. $\mathrm{Zu}$ den biotischen Auswirkungen gehören die kürzlich beobachteten Veränderungen der Wachstumsraten, der Phänologie (z. B. Blattaustrieb), der Baumartenzusammensetzung, die Verschiebung der Artverbreitung und die Zunahme von Schädlingen und Krankheiten. Die Verbreitung vieler Schädlingen und Krankheiten in Wäldern wird sich höchstwahrscheinlich von Südwesten nach Nordosten verschieben , was zu einer Erhöhung der Schäden in Waldökosystemen führen wird. Darüber hinaus wirkt sich der Anstieg der Wintertemperaturen auf die Überlebensmöglichkeiten einiger Schädlingsarten und die Zeitspanne aus, in der die Schädlinge die Bäume befallen können. Infolgedessen kann das Ausmaß der biotischen Bedrohungen zu einer Veränderung der wichtigsten Vegetationstypen Europas führen.

\section{Adaptive Waldbewirtschaftung}

Die Herausforderungen des Klimawandels erfordern sowohl kurzfristige als auch langfristige Managementmaßnahmen. Hier führen wir einige Beispiele für Anpassungsmaßnahmenan, die darauf abzielen, die Stressresistenz, Widerstandsfähigkeit und die dynamischen Reaktion en der Wälder Erhaltung der zu fördern, um die Ökosystemleistungen zu fördern.

- Integrative Raumplanung

Die Resilienz von Schutzgebieten kann durch die Integration von Anpassungsmaßnahmen in die Raumplanung unterstützt werden. Eine Landnutzungsplanung auf Landschaftsebene kann dazu beitragen sektorübergreifende Beschränkungen zu überwinden. 
- Frühwarnsysteme

Die Einrichtung eines Frühwarnsystems für biotische und abiotische Bedrohungen des Klimawandels - eingebettet in einen internationalen transdisziplinären Rahmen - ist entscheidend für den Erfolg des Monitoringsprogramms.

- Waldbauliche Anpassungsmaßnahmen

Waldbauliche Maßnahmen im Rahmen eines adaptiven Managementes zielen darauf $a b$, potentiell gefährdete Wälder in ein resilientes Waldökosystem umzuwandeln unter Berücksichtigung der lokalen Standortbedingungen, Bedürfnisse, Risiken, Bewirtschaftungsziele und Machbarkeit. Kürzere Umtriebszeiten vermindern z. B. das Risiko von Windwurf. Längere Umtriebszeiten hingegen können die Naturverjüngung von Schattbaumarten durch schattige Bedingungen fördern. Ein weiterer Ansatz ist die bewusste Nutzung natürlicher Sukzessionsprozesse und der Migration von Arten. Eine Erhöhung der Baumartenvielfalt wird dazu beitragen die Wälder widerstandsfähiger gegenüber Schädlings- und Krankheitsausbrüchen als Folge des Klimawandels zu machen.

\section{- Auswahl von Baumarten und Samenherkünften}

Die Reaktion von Waldbeständen auf den Klimawandel hängt stark von der jeweiligen Baumart, von der betreffenden Samenherkunft und deren Regenerationspotenzial ab. Die Verwendung von gut an die veränderten Klimabedingungen angepassten heimischen Baumarten und Samenherkünften ist eine weithin akzeptierte Anpassungsmaßnahme. Auch bisher nichtheimische Baumarten sind eine Anpassungsoption, vor ihrer Einführung muss aber eine Risikobewertung durchgeführt werden. Nichtheimische Baumarten, die bereits als invasiv gelten, können nicht zur Anpflanzung empfohlen werden (Kapitel "Management von nichtheimischen Pflanzen”).

- Wiederherstellung von Ökosystemen

Auwaldökosysteme sind durch den Menschen stark verändert worden. Die Begradigung der Flussläufe führte zu Veränderungen des Grundwasserspiegels und der Überschwemmungsdynamiken sowie zu einer Verringerung des Lebensraumverbundes von aquatischen und terrestrischen Ökosystemen. Flussrenaturierungen tragen maßgeblich zur ökologischen Anpassung an den Klimawandel bei (Kapitel "Entscheidung für Natur- oder Kunstverjüngung?”).

\section{Ausblick und Zusammenfassung}

$\mathrm{Zu}$ den größten Herausforderungen des Klimawandels im Hinblick auf Waldökosysteme gehören die Zunahme von Temperaturextremen, Dürre- und Starkniederschlagsereignissen sowie die Ausbreitung von Schädlingen und Krankheiten. In Auwaldökosystemen können eine integrative Raumplanung, Flussrenaturierungen und forstwirtschaftliche Maßnahmen dazu beitragen, die Stressresistenz, Widerstandsfähigkeit und dynamische Reaktion der Wälder zu fördern, um deren Ökosystemleistungen zu erhalten. 



\subsubsection{Wildeinfluss und Wildtiermanagement}

\section{Markus Sallmannshofer, Silvio Schüler (Gyula Kovacs, Silvija Krajter} Ostoić)

\section{Hintergrund der Wildbewirtschaftung}

Autochthone Wildarten sind ein wichtiger Bestandteil heimischer Wälder. Fragmentierte Lebensräume, disjunkte Migrationswege und Störungen durch Verkehr und andere menschliche Aktivitäten zwingen viele Wildarten, sich in ruhige, gut geschützte Bereiche zurückzuziehen. Infolgedessen sind diese Arten heute stärker an Waldökosysteme gebunden, als es von Natur aus der Fall wäre. Auwälder sind hochproduktive Lebensräume und reich an Pflanzenvielfalt, daher sind sie für viele Schalenwildarten wie Rehwild, Rotwild und Schwarzwild besonders attraktiv (Abb. 3.2.4-1, Abb. 3.2.4-2). Die Attraktivität des Waldlebensraumes für Wild wird durch das breite Angebot an Nahrungsquellen und nahrungsunabhängigen Kriterien wie Deckungsstrukturen, dem Waldklima und der geringen Störungshäufigkeit beeinflusst. Zusätzlich zu heimischen Wildarten wurden Dam- und Sikawild sowie Muffelwild in einigen Regionen zu Jagdzwecken eingeführt, da die Jagd auf eine Vielzahl von Wildarten historisch eine gängige Vergnügung adeliger Grundbesitzer war und die Freizeitjagd in den letzten Jahrzehnten als zunehmend wichtige Einkommensquelle für Forstbetriebe angesehen wurde.

Die biotische Tragfähigkeit von Wäldern für Wildtierpopulationen beschreibt, wie groß der Wildbestand ohne natürliche und künstliche Regulierung werden könnte. Sie wird durch die Lebensraumqualität bestimmt. Die ökonomische Tragfähigkeit beschreibt dagegen eine Populationsgröße, die die waldbaulichen Ziele nicht beeinträchtigt. Liegt diese unter der biotischen, treten Wildschäden an Waldverjüngung und Baumbestand auf und damit können wichtige Ökosystemfunktionen beeinträchtigt werden. $\mathrm{Zu}$ den negativen Folgen gehören Probleme bei der Waldverjüngung durch selektiven Verbiss, Stamminfektionen durch Pilze mit daraus resultierender Holzentwertung, Verluste des jährlichen Zuwachses und ein Rückgang der Waldstabilität und Biodiversität (Abb. 3.2.4-3). Daher ist eine ständige Abwägung zwischen dem wirtschaftlichen Nutzen der Jagdeinnahmen und den waldbaulichen Verlusten notwendig. Bei Gesamtkostenberechnungen übersteigen die durch Wildschäden im Wald verursachten Einnahmeverluste oft die Einnahmen aus der Verpachtung von Flächen für die Jagd.

\section{Wildschäden und ihre Bewertung}

Auch wenn der Einfluss des Wildes nicht nur negativ, sondern auch positiv sein kann, ist die Einstufung als Schaden immer subjektiver Natur. Wildschäden können durch den Vergleich des Soll- und Ist-Zustandes im Wald erfasst werden. Der Soll-Zustand ergibt sich aus mehreren

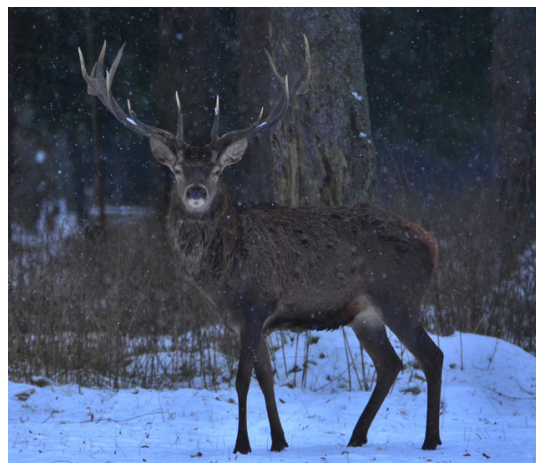

Abbildung 3.2.4-1: Rotwild

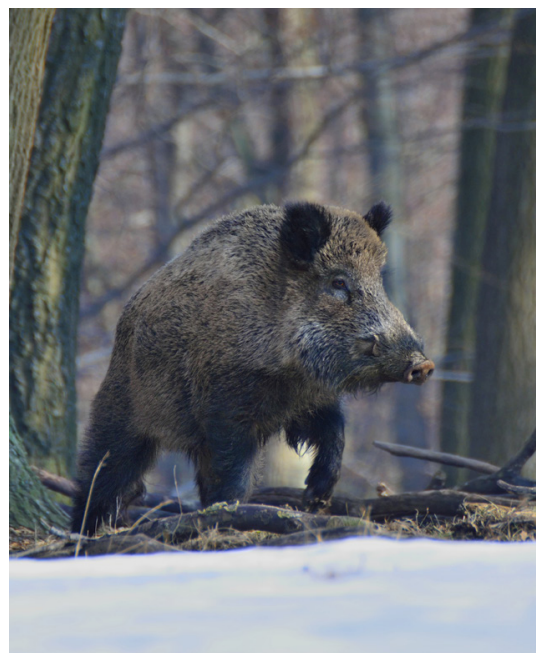

Abbildung 3.2.4-2: Schwarzwild 
Kriterien, wie z. B. dem Bedarf an Waldverjüngung, dem angestrebten Baumartenanteil innerhalb einer bestimmten Verjüngungsschicht und der zu erwartenden Zeit bis zur Etablierung der Naturverjüngung. Der gegenwärtige Waldzustand kann durch eine permanente oder temporäre Stichprobe mittels geeigneter Kennzahlen effektiv beurteilt werden. Solche Kennzahlen sind u. a. die Anzahl der Jungbäume pro Hektar, die Anzahl und der Grad der Schäden sowie der Anteil der Baumarten und der Mischungsart in verschiedenen Waldschichten, Alters- oder Höhenklassen. Neben der Naturverjüngung müssen auch ältere Altersklassen bewertet werden, z. B. in Bezug auf Schälung. Die verschiedenen Kriterien müssen auf den Waldtyp, das Bewirtschaftungsregime, die vorhandenen Wildarten, die angestrebten Waldfunktionen und die erwarteten Ökosystemleistungen bezogen werden.

Wildeinfluss ist jedoch nicht der einzige Grund für Verjüngungsprobleme. Andere Faktoren, die berücksichtigt werden müssen, sind Viehbeweidung, Lichtmangel durch dichte Überschirmung, eine dämmende krautige Vegetation, das Fehlen von Samenbäumen, fehlende Fruktifikation und ein potenzieller Mangel an Pflege (Kapitel "Entscheidung für Natur- oder Kunstverjüngung?”). Ein Standardverfahren zur Beurteilung des Einflusses von Wild auf die Waldverjüngung ist die Einrichtung kleiner eingezäunter Kontrollflächen zur Überwachung und zum Vergleich der auftretenden Naturverjüngung mit und ohne Schutz. Solche Flächen können klein sein (z. B. 3x3 m), sollten aber im gesamten jeweiligen Waldgebiet mehrfach wiederholt werden. Mit zunehmender Diskrepanz zwischen biotischer und ökonomischer Tragfähigkeit steigt der Wilddruck auf Waldpflanzen und Verjüngung und die Notwendigkeit, zusätzliche Wildschutz- und Managementmaßnahmen anzuwenden.

\section{Wildökologische Raumplanung zur Vermeidung von Wildschä- den}

Wildökologische Raumplanung mit dem Ziel des Schutzes von Wildlebensräumen und der Vermeidung von Wildschäden im Wald wird als geeignetes Instrument zur Integration von Wildtieren in das Landmanagement vorgeschlagen. Seine Umsetzung in großem Maßstab erfordert die Einbeziehung aller Beteiligten aus Forstwirtschaft, Jagd, Landwirtschaft, Tourismus und anderen Landnutzungen. Wildökologische Raumplanung sollte auf eine bessere räumliche Verteilung der Wildbestände abzielen, um Schäden zu vermeiden. Mögliche Maßnahmen können die Ausweisung von (saisonalen) Wildzonen, die Wiedervernetzung von Biotopen sowie die Koordination und Modifikation von Jagdaktivitäten sein. Durch die Verringerung der relativen Lebensraumqualität (Attraktivität für Wild im Vergleich zur Umgebung) in gefährdeten Gebieten kann die räumliche Verteilung des Wildes gesteuert werden. 


\section{Professionelle Wildregulierung und jagdliche Maßnahmen}

Um die Attraktivität des Lebensraumes zu verringern, sollten die Störungen innerhalb eines Schwerpunktgebietes erhöht werden, z. B. durch die Konzentration von jagdlichen Maßnahmen. Dies erfordert eine klare Abgrenzung des Gebietes (empfohlen bis zu 100 ha) und eine konsequente Durchsetzung der Maßnahmen. Gleichzeitig müssen Störungen außerhalb des Schwerpunktgebietes gesenkt werden. Eine Bejagung in zeitlichen Intervallen, z. B. eine auf wenige intensive Wochen reduzierte Jagdzeit, kann die Störung senken, während der Aufwand zur Reduzierung der Population abnimmt (da das Wild weniger scheu ist). Zusätzlich kann das Wild in andere Gebiete mit geringer Gefährdung gelenkt werden, indem die Biotopqualität durch Wiesen, spezielle Äsungsflächen oder extensive Fütterung erhöht wird. Fütterung reduziert die Wintermortalität und erhöht die Reproduktionsrate. Sie erfordert eine großräumige Koordination und professionelle Futtervorlage (Qualität, Menge und zeitlich an die Zielart angepasste Fütterungsintervalle). Die Regulierung des Wildes muss einer quantitativen und qualitativen Regulierungsplanung folgen, die auch das Verständnis für das Geschlechterverhältnis des Wildes beinhaltet. Zum Beispiel hat die Regulation der weiblichen Stücke den stärksten Einfluss auf das Populationswachstum. Die Planung muss auch die nicht zählbaren Teile der Population berücksichtigen und kontrollieren (bis $\mathrm{zu}$ 50\% des Rotwildbestandes werden bei der Beobachtung häufig übersehen). Die Abgrenzung von Jagdrevieren muss auf ihre Wirksamkeit überprüft werden. Ständig wechselnde Jagdgewohnheiten (zeitlich und räumlich) verhindern eine Anpassung des Wildes. Geeignete jagdliche Einrichtungen und Infrastruktur sind notwendig. Professionelles Jagdpersonal mit hohem Problembewusstsein kann notwendig sein, nicht kooperative Jagdpächter müssen gekündigt werden. Flexible Pachtverträge mit jährlichen Kündigungsmöglichkeiten und auch der Verkauf von Einzelabschüssen sollten nach Möglichkeit und regionaler Sinnhaftigkeit in Erwägung gezogen werden.

\section{Forstwirtschaftliche Maßnahmen}

Die Anfälligkeit von Waldbeständen gegenüber Wildschäden wird durch die Forstwirtschaft beeinflusst: Das waldbauliche Bewirtschaftungssystem, die Verjüngungsart und Verjüngungszeit sowie Bestandesstruktur, -mischung und Durchforstung sind Einflussgrößen. Förster haben die Aufgabe, den waldbaulichen Erfolg objektiv zu kontrollieren, Sträucher und Baumarten ohne waldbauliches Interesse zu erhalten (Verteilung des Fraßdrucks), technische Schutzmaßnahmen für ökonomisch interessante Baumarten zu veranlassen, mit Jägern zu kooperieren und die Wildregulierung durch das Anlegen von Schussschneisen zu unterstützen. 


\section{Landwirtschaftliche Maßnahmen}

Strukturelemente in der waldnahen Landschaft sind wichtig, damit das Wild den Wald verlassen kann und sich trotzdem geschützt fühlt, insbesondere im Winter. Wiesen können nach Möglichkeit zur Beäsung im Winter stehen gelassen werden, um den Fraßdruck auf die Wälder zu reduzieren.

\section{Technische Schutzvarianten}

Gezwungen durch hohe Wildbestände ist es im grenzüberschreitenden Biosphärenreservat Mur-Drau-Donau gängige Praxis, Natur- und Kunstverjüngungsflächen mit technischen Mitteln zu schützen, da der Wilddruck bisher zu hoch ist, um die Verjüngung sicherzustellen (Abb. 3.2.4-3). Die Wahl des Schutzes hängt von der Wildart und dem zu schützenden Gut ab. Die gängigsten Schutzmaßnahmen sind in der folgenden Tabelle zusammengefasst:

\begin{tabular}{|c|c|c|c|c|}
\hline \multicolumn{5}{|c|}{ Flächenschutz } \\
\hline $\begin{array}{l}\text { Baustahlgitter mit Holz- } \\
\text { pfählen }\end{array}$ & Schutz & Schutz & Äußerst robust & Hohe Installationskosten \\
\hline $\begin{array}{l}\text { Drahtgeflecht mit Holz- } \\
\text { pfählen }\end{array}$ & Schutz & $\begin{array}{c}\text { Nur bei Bodenveran- } \\
\text { kerung }\end{array}$ & Robust & Hohe Installationskosten \\
\hline $\begin{array}{l}\text { Kunststoffnetz mit } \\
\text { Holzpfählen }\end{array}$ & Kein Schutz & Kein Schutz & $\begin{array}{l}\text { Ausreichend gegen } \\
\text { Rehwild } \\
\text { Günstig und einfach zu } \\
\text { installieren }\end{array}$ & Geringe Beständigkeit \\
\hline \multicolumn{5}{|c|}{ Einzelbaumschutz } \\
\hline Drahtgeflecht & Sicher gegen Schälung & anderer Zweck & $\begin{array}{c}\text { Öffnet von allein mit } \\
\text { Durchmesserwachstum }\end{array}$ & $\begin{array}{l}\text { Pflanzen von ausreichen- } \\
\text { der Höhe erforderlich }\end{array}$ \\
\hline
\end{tabular}

In Ungarn, Kroatien und Serbien ist das Rotwild die dominante Wildart, die Schäden in Aufforstungen verursacht. Daher muss die Höhe der Zäune mindestens $230-250 \mathrm{~cm}$ betragen. Auch Rehe können über niedrigere Zäune springen. Wenn nur Eicheln vor Wildschweinen geschützt werden müssen, sind Zäune mit einer Höhe von 120-130 cm ausreichend. (Siehe auch Kapitel "Pappelwirtschaft und Diversität - kein zwangsläufiger Wiederspruch") 


\section{Besuchermanagement}

Lebensräume und Ruhezonen für das Wild in sensiblen Gebieten können durch die Aufklärung von Interessensgruppen, die Einschränkung von Wegen, Leinenpflicht für Hunde und die Vermeidung von Sackgassen geschaffen werden. Besucher müssen zeitlich und räumlich in wenig störungssensiblen Gebieten konzentriert werden.

\section{Naturschutz}

Bewirtschaftungsfreie Gebiete, wie z. B. Kernzonen von Nationalparks, sind für Wild sehr attraktiv. Im Verhältnis zu den umliegenden Lebensräumen sind solche Gebiete oft ruhig und werden als sicher empfunden. Das Wild konzentriert sich in solchen Gebieten in Dichten, die das natürliche Maß übersteigen. Die Folge ist ein hoher Fraßdruck auf die vorhandenen Pflanzen. Abhängig von den Managementzielen kann eine Wildregulierung auch in solchen Gebieten mit hohem Naturschutzwert erforderlich sein, um die Koexistenz mit einer vielfältigen Waldflora und eine natürliche Waldentwicklung zu ermöglichen. Eine

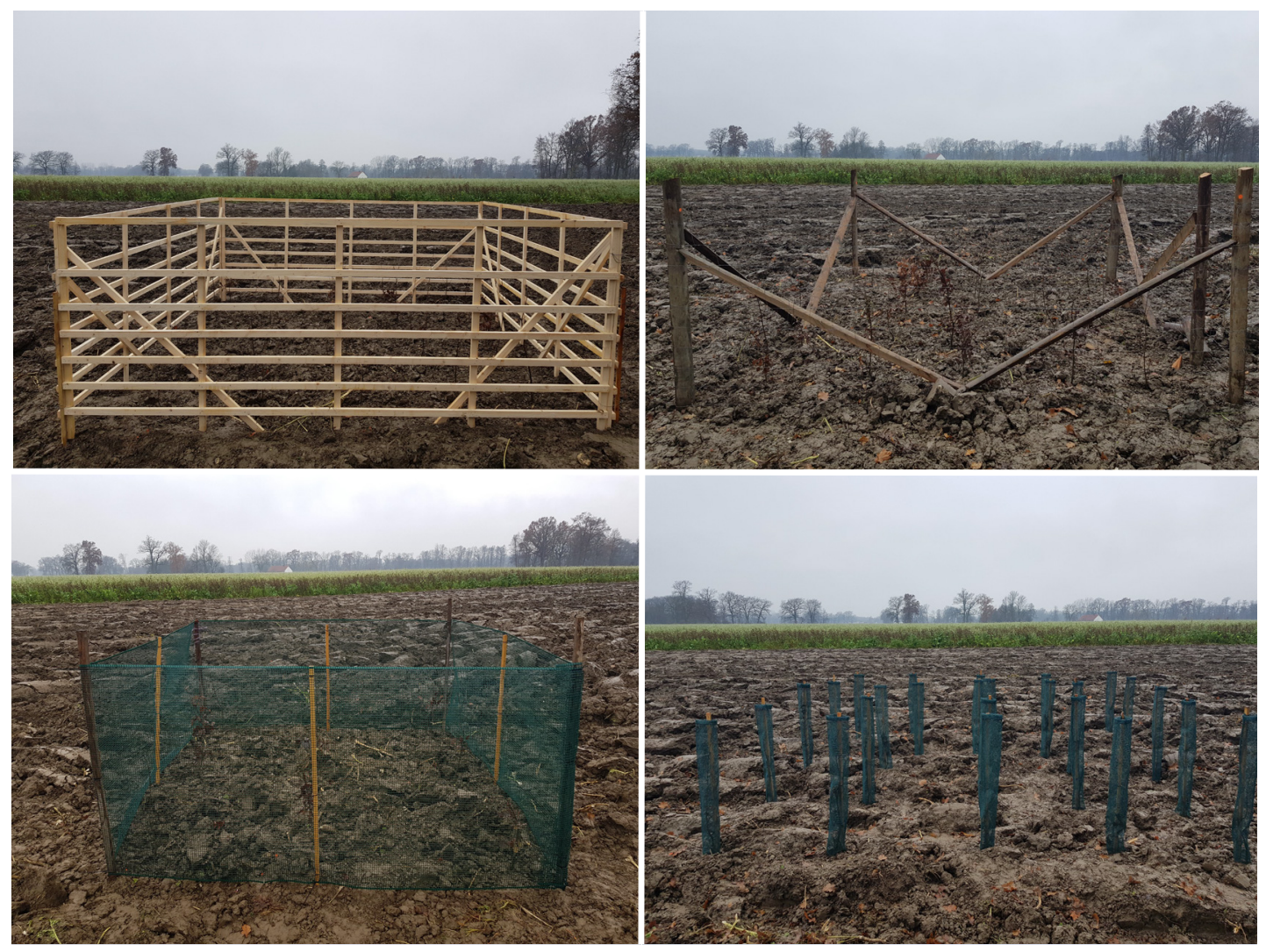

Abbildung 3.2.4-3: Technische Schutzvarianten unterschiedlicher Stärke und Kosten 
Wildregulierung ist insbesondere dann erforderlich, wenn bestimmte Waldtypen oder Pflanzengesellschaften die prioritären Schutzgüter darstellen. Im Gegensatz dazu kann der Einfluss des Wildes als Teil des natürlichen Systems betrachtet werden (hier ist die Intensität maßgeblich), das letztendlich die natürliche Vegetation und die zukünftige Waldzusammensetzung verändern kann, wenn großräumige natürliche Prozesse selbst geschützt werden sollen.

\section{Ausblick und Zusammenfassung}

Das Ziel eines angemessenen Wildtiermanagements ist es, die Koexistenz vielfältiger Baum- und Pflanzengemeinschaften mit Wildbeständen zu ermöglichen, ein nachhaltiges Einkommen sowohl aus forstwirtschaftlichen als auch aus jagdlichen Aktivitäten zu generieren, ländliche Traditionen zu bewahren und hohe ethische und moralische Standards zu erfüllen, wenn eine Regulierung notwendig ist. Wild ist ein wesentlicher Bestandteil unserer Wälder und verursacht nicht von Natur aus Schäden an Wäldern. Die Einstufung von Schäden ist stark subjektiv und ergibt sich aus dem Konflikt mit anderen menschlichen Zielen. In der Forstwirtschaft ist in den letzten Jahrzehnten ein kostenintensiver technischer Schutz der Verjüngung notwendig geworden. Eine Abwägung zwischen Erträgen aus der Bejagung und Verlusten bzw. Schutzkosten in der Forstwirtschaft und im Biodiversitätsmanagement sind erforderlich, um langfristige Ziele des Naturschutzes und der Waldbewirtschaftung zu erreichen. Eine wildökologische Raumplanung auf der räumlichen Ebene der Wildlebensräume unter Einbeziehung aller Beteiligten soll ein intelligentes und ausgewogenes Landmanagement unterstützen und Konflikte vermeiden.

\section{Danksagung}

Dank und Anerkennung gelten Herrn Prof. Dr. Reimoser, dessen Vorlesungen an der Universität für Bodenkultur Wien Grundlagen für dieses Kapitel vermittelten. 


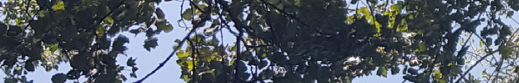

(2)

$20,1,2,4$

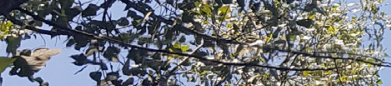

30.7)

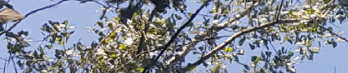

2 5

$x^{2}$ H.

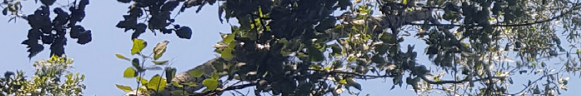

ent.1.5.

x.

tres

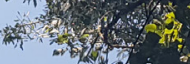

7

into

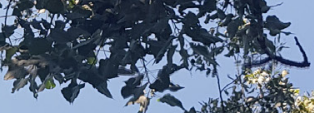

(3)

, the

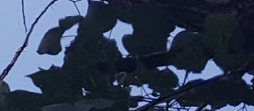

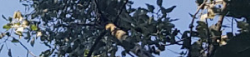

(3)

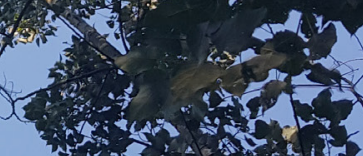

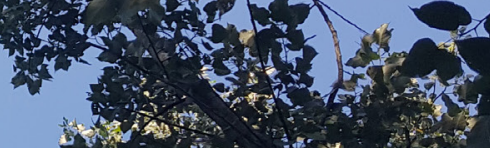

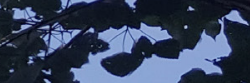

(x)

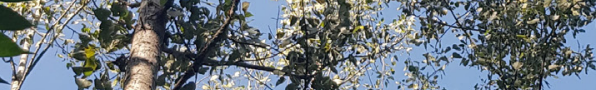
$x^{2}-a^{2}$

$10 \times 2 x^{2}$

8 .

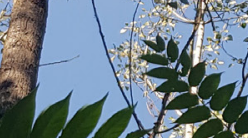

3.

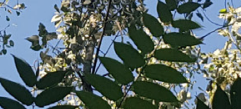

7.

-142

7

(x) 12

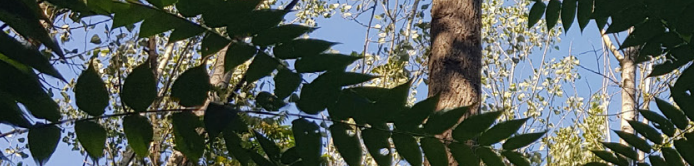

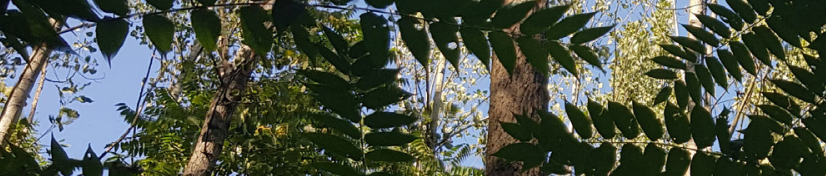
4

to

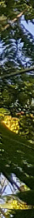

intom

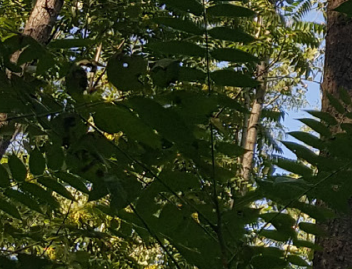

(4)

(4) 3 ,

$+x$

sol?

1.

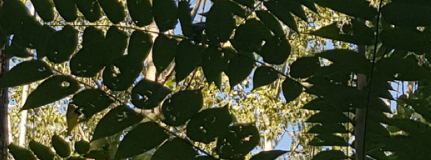

il.

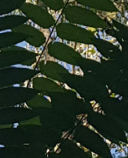

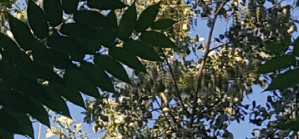

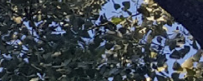

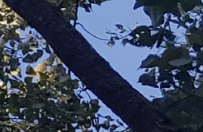

W.

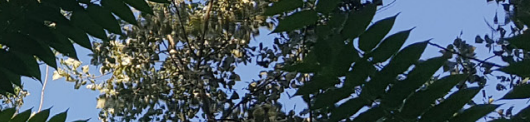

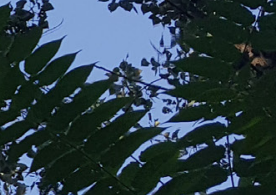
140 . 140 ,

3.

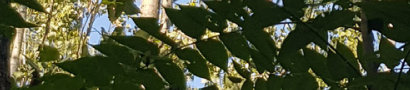

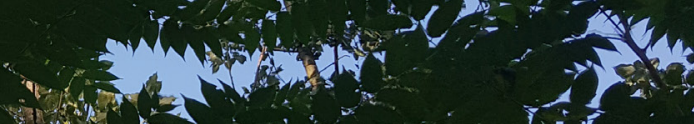

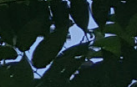

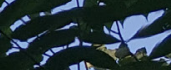

(4)

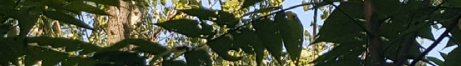

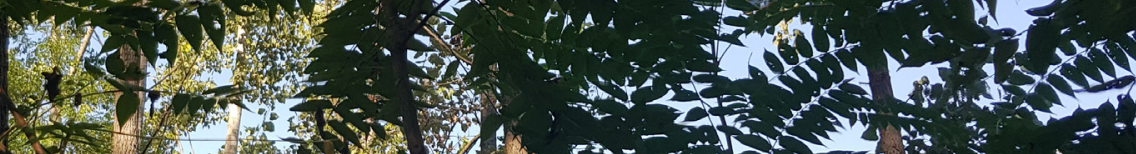

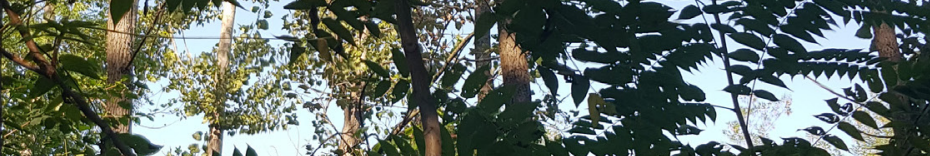

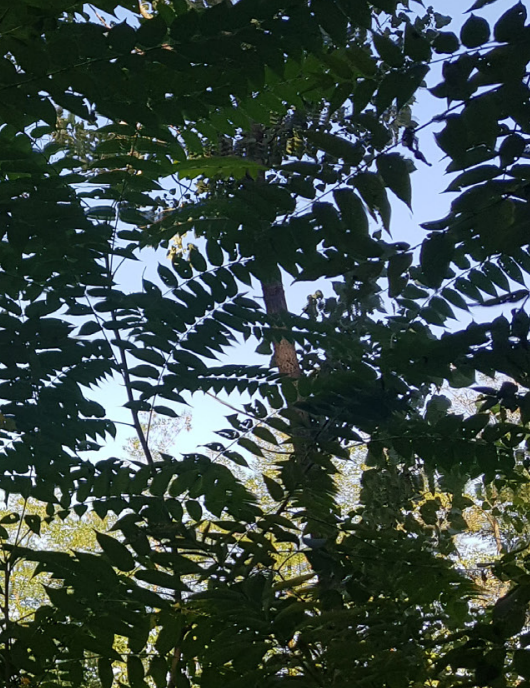




\subsubsection{Management von nichtheimischen Pflanzen}

Katharina Lapin, Aleksander Marinšek, Maarten de Groot, László Demeter, László Nagy, Marjana Westergren

\section{Einleitung}

Gebietsfremde oder nichtheimische Pflanzenarten sind Arten, die außerhalb ihres natürlichen Verbreitungsgebietes eingeführt wurden. Wenn eine nichtheimische Pflanzenart problematisch wird, bezeichnet man sie als invasive nichtheimische Pflanzenart. Sobald sich eine invasive nichtheimische Pflanze in einem neuen Gebiet etabliert hat, kann sie negative ökologische, sozioökonomische und gesundheitliche Auswirkungen haben. Heute sind invasive nichtheimische Pflanzen eine der größten Bedrohungen für die globale und lokale Artenvielfalt, und ihre Ausbreitung ist kaum zu stoppen. Die nährstoffreichen und häufig gestörten Auwälder gehören zu denjenigen Waldtypen, die am anfälligsten für die Invasion nichtheimischer Pflanzen sind. In Auwäldern erleichtert das hohe Nährstoffangebot und die die häufigen von der Natur und vom Menschen ausgelösten Störungen Invasionen. Zusätzlich wirken Flüsse als sehr effektive Ausbreitungskorridore für invasive nichtheimische Pflanzen. Daher ist das Management von invasiven nichtheimischen Pflanzen in Auwäldern sehr wichtig, um die Biodiversität und die Ökosystemleistungen dieses gefährdeten Ökosystems zu erhalten und wiederherzustellen.

Dieses Kapitel des Handbuchs für Auwälder zielt darauf ab, die praxisorientierte Informationen über Managementmaßnahmen zu sammeln und zusammenzufassen, die für jede Phase der biologischen Invasion anwendbar sind: vom ersten Auftreten der invasiven Pflanze bis zur erfolgreichen Ausbreitung in dem neuen Gebiet. Obwohl beabsichtigt wurde, Managementmaßnahmen so umfassend wie möglich zusammenzustellen, muss betont werden, dass jede vorgestellte Managementmaßnahme an die lokalen Gegebenheiten des jeweiligen Gebiets angepasst werden muss. Weiters ist zu beachten, dass bestimmte Bekämpfungsmaßnahmen stark von der Phänologie und anderen ökologischen Merkmalen jeder einzelnen nichtheimischen Pflanzenart beeinflusst werden können. Daher empfiehlt es sich, stets die Verbreitungsbiologie der invasiven nichtheimischen Pflanze zu erheben, bevor die Managementmaßnahmen geplant und umgesetzt werden. Außerdem ist es wichtig, bei der Durchführung von chemischen und nicht-chemischen Managementmaßnahmen die lokale Gesetzgebung zu beachten. Der Zweck dieses Kapitels ist es, auf der Basis gesammelter Daten, die Etablierung und Ausbreitung von invasiven nichtheimischen Pflanzen in Auwäldern zu verhindern. Sobald eine Etablierung besagter Pflanzenarten erfolgt ist, stellt das folgende Kapitel potenzielle Präventionsmaßnahmen. 


\section{Wirkungsmechanismen und Folgenabschätzungen}

$\mathrm{Zu}$ den Bedrohungen, die von invasiven nichtheimischen Pflanzen in Waldökosystemen ausgehen, gehören Hybridisierung, Übertragung von Krankheiten und Artenkonkurrenz. Die Konkurrenz um Ressourcen, z. B. dass eine nichtheimische Pflanze mit heimischen Taxa um Ressourcen (Licht, Wasser, Raum) konkurriert, ist der am häufigsten berichtete Wirkungsmechanismus, der zu schädlichen Auswirkungen auf heimische Taxa in Auwäldern führt. Die Konkurrenz um Licht mit den heimischen Arten wurde z. B. für die invasiven Pflanzenarten Solidago gigantea, Impatiens glandulifera und Conyza canadensis in EichenEschen-Au-Mischwäldern entlang großer Flüsse beobachtet.

Ein weiterer Wirkungsmechanismus invasiver nichtheimischer Pflanzen sind chemische Auswirkungen, wie z. B. die Fähigkeit, chemische und biochemische Bodeneigenschaften zu verändern, was wiederum zu Veränderungen des heimischen Artenreichtums über und unter dem Boden führen kann. Die invasive nichtheimische Pflanzenart Impatiens glandulifera zum Beispiel verändert die Pilz- und Bakteriengemeinschaften im Boden. Darüber hinaus können nichtheimischen Arten die chemische Zusammensetzung bzw. Nährstoffverfügbarkeit im Boden verändern. Ein Beispiel dafür ist die Stickstofffixierung der invasiven Baumart Robinia pseudoacacia, die zu hohen Stickstoffwerten in den oberen Bodenhorizonten führt und sich dadurch negativ auf die Verjüngung heimischer Baumarten auswirkt.

Es gibt mehrere Richtlinien und Gesetze zur Regulierung der Ausbreitung von invasiven nichtheimischen Arten, um die negativen Auswirkungen auf Waldökosysteme zu verringern. Da die finanziellen Mittel für das Management invasiver nichtheimischer Pflanzenarten in der Regel begrenzt sind, wird empfohlen, die vorhandenen und potenziell vorkommenden nichtheimischen Arten nach dem Ausmaß ihrer jeweiligen Umweltauswirkungen zu priorisieren. Die internationale Methodik des EICAT-Protokolls (Environmental Impact Classification of Alien Taxa) kann effektiv angewandt werden, um die Auswirkungen aller nichtheimischen Arten innerhalb einer ganzen taxonomischen Klasse auf der Grundlage einer systematischen Überprüfung der Literatur zu kategorisieren und zu quantifizieren (Abb. 3.2.5-1).

Eine EICAT-Bewertung invasiver nichtheimischer Arten (Insekten, Pilze und Pflanzen) im grenzüberschreitenden Biosphärenreservat Mur-Drau-Donau ergab, dass die nichtheimischen Pflanzen Amorpha fruticosa, Heracleum persicum, Humulus japonicus, Impatiens glandulifera, Reynoutria japonica und Reynoutria sachalinensis zu den nichtheimischen Arten mit den schwerwiegendsten potenziellen Umweltauswirkungen in Auwäldern gehören.

\section{Vorbeugungsmaßnahmen}

Eine große Anzahl menschlicher Aktivitäten unterstützt die Einfüh-

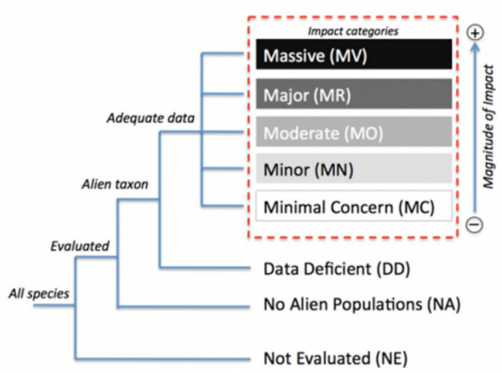

Abb. 3.2.5-1: Die im Bewertungsprozess dargestellten EICAT-Kategorien klassifizieren nichtheimische Arten in eine von fünf Kategorien, je nach dem Ausmaß der schädlichen Auswirkungen auf die Umwelt. 
rung und Ausbreitung invasiver nichtheimischer Pflanzen in Auwäldern. Präventionsmaßnahmen, die darauf abzielen, die menschlichen Aktivitäten sowie die Ausbreitungswege invasiver nichtheimischer Pflanzen zu identifizieren und zu übernehmen, gehören zu den effektivsten und kosteneffizientesten Managementmaßnahmen. In Auwäldern begünstigen beispielsweise Kahlschläge oder starke Bestandeseingriffe die Lichtverhältnisse und die Ressourcenverfügbarkeit für nichtheimische Pflanzenarten. Letztere sind in der Regel Lichtpflanzen (Heliophyten), die durch den Aufbau einer eigenen Struktur und eines eigenen Stoffwechsels an einen Lebensraum mit intensiver Sonneneinstrahlung angepasst sind. Darüber hinaus kann der Bau von Forststraßen und Wanderwegen die Ausbreitung von Samen und Individuen nichtheimischer Pflanzen durch die Bewegung von kontaminiertem Boden und Baumaterial fördern. Daher sollte das Risiko durch Forststraßen als Invasionspfade nicht unterschätzt werden. Futter, das bei der Winterfütterung von Großwild verwendet wird, kann ebenfalls eine Ausbreitungsquelle sein.

Zusätzlich ist es wichtig, die nichtheimischen Pflanzenarten zu identifizieren, um invasive Arten in einem frühen Stadium der Ausbreitung in einem Auwald zu erkennen. Zielgruppenspezifisches Infomaterial kann dazu beitragen, das Wissen über die Risiken invasiver nichtheimischer Pflanzenarten zu erhöhen. Citizen-Science-Programme, wie die DanubeForestHealth Tools, bieten ebenfalls eine große Auswahl an technischen Möglichkeiten mit der Öffentlichkeit zusammenzuarbeiten, um invasive nichtheimische Pflanzen zu identifizieren.

$\mathrm{Zu}$ den Präventionsmaßnahmen gehören auch rechtlich verbindliche und nicht verbindliche Maßnahmen, welche die Ansiedlung invasiver nichtheimischer Arten in einem Gebiet verhindern. Die Verordnung der Europäischen Union (Nr. 1143/2014) über die Prävention und das Management der Einbringung und Ausbreitung invasiver nichtheimischer Arten, die am 1. Januar 2015 in Kraft getreten ist, schränkt beispielsweise das absichtliche oder fahrlässige Einbringen, Vermehren, Züchten, Transportieren, Kaufen, Verkaufen, Verwenden, Tauschen, Halten und Freisetzen invasiver nichtheimischer Arten, die für die EU von Belang sind, in der EU ein. Die aktuelle Liste der invasiven nichtheimischen Arten, die von Belang sind, enthält 36 Pflanzenarten, von denen viele in Ufergebieten vorkommen, wie der Götterbaum (Ailanthus altissima), der Japanische Hopfen (Humulus scandens) oder das Drüsige Springkraut (Impatiens glandulifera).

\section{Risikobewertung}

Manchmal werden nichtheimische Pflanzen, wie z. B. Bäume oder Kräuter, in Wiesensaatgutmischungen, absichtlich in der Forstwirtschaft oder bei der Wiederherstellung von Ökosystemen eingesetzt. In diesen Fällen der absichtlichen Verwendung von nichtheimischen Arten wird die Durchführung einer standortspezifischen Risikobewertung empfohlen. Die Mindeststandards für eine Risikobewertung um- 
fassen folgende Punkte: (1) Grundlegende Artenbeschreibung; (2) Wahrscheinlichkeit der Einbürgerung oder Invasion; (3) Verbreitung, Ausbreitung und Auswirkungen; (4) Bewertung der Einführungswege; (5) Bewertung der Auswirkungen auf die biologische Vielfalt und Ökosysteme; (6) Bewertung der Auswirkungen auf Ökosystemleistungen; (7) Bewertung der sozioökonomischen Auswirkungen; (8) Berücksichtigung des Artenstatus (bedroht oder geschützt) oder des bedrohten Lebensraums; (9) Bewertung zukünftiger Auswirkungen des Klimawandels; (10) Vervollständigung auch bei fehlenden Informationen möglich; (11) Dokumentation der Informationsquellen; (12) Zusammenfassung in konsistenter und interpretierbarer Form; (13) unter Einbezug von Unsicherheiten; (14) unter Einbezug einer Qualitätssicherung. Es wird jedoch empfohlen, sich an einen nationalen Spezialisten zu wenden, der detailliertere Informationen zur Risikobewertung in einem Gebiet und für nichtheimische Arten geben kann.

\section{Monitoring}

Die frühzeitige Erkennung und schnelle Ausrottung in einem frühen Stadium der Invasion ist eine kosteneffektive Maßnahme, um die Ausbreitung invasiver nichtheimischer Pflanzen zu verhindern. In der Regel erfolgt ein Monitoring nach der erfolgreichen Erkennung einer invasiven nichtheimischen Pflanzenpopulation. In den letzten Jahrzehnten wurden viele verschiedene Überwachungssysteme auf lokaler, regionaler und nationaler Ebene eingeführt. Das Grundprinzip eines Monitorings von invasiven nichtheimischen Pflanzen ist die wiederholte Beobachtung von systematisch angelegten Parzellen in einem Gebiet, welches über mehrere Jahre hinweg betroffen ist. Das Monitoring erfordert geschultes Personal und Bestimmungshilfen für die Identifizierung. Auch wurden weitere technische Hilfsmittel entwickelt, um den Überwachungsprozess zu vereinfachen und zu verbessern: Umwelt-DNA (eDNA) zum Beispiel kann für die Überwachung von genetischem Material verwendet werden, das direkt aus Wasseroder Bodenproben gewonnen wird.

\section{Mechanische Bekämpfung}

$\mathrm{Zu}$ den mechanischen Bekämpfungsmaßnahmen gehören das Ausreißen von Hand, Schneiden, Mulchen, Ringeln etc., einschließlich der Verwendung verschiedener Werkzeuge wie Rasenmäher oder Trimmer, um ganze invasive nichtheimische Pflanzen oder Pflanzenteile zu entwurzeln, zu schneiden, zu vergraben, zu ersticken oder zu verbrennen.

Der Erfolg manueller mechanischer Bekämpfungsmethoden, wie z. B. das Ausreißen von Hand, hängt von der Morphologie der Pflanzenart und von den Fähigkeiten und Techniken des geschulten Personals ab. Bei den meisten Pflanzenarten ist es wichtig, das Wurzelsystem sowie die darüber liegenden Pflanzenteile vollständig oder wiederholt zu ent- 


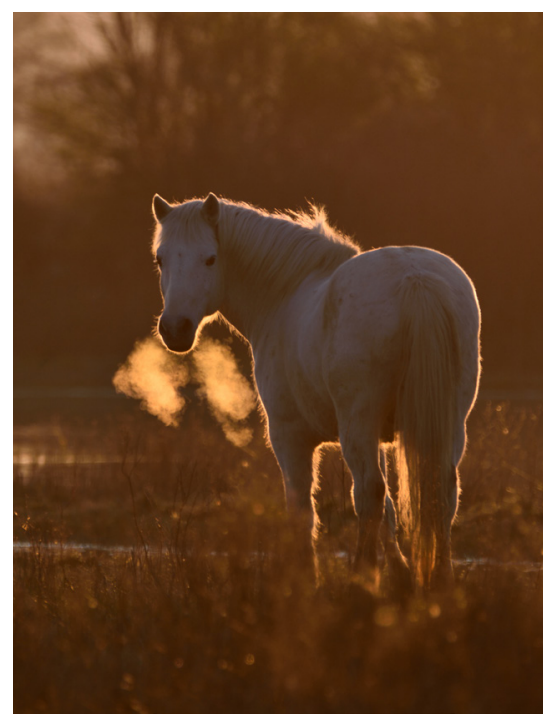

Abb. 3.2.5-3: Beweidung durch Pferde im Naturschutzgebiet Isola Della Cona in Friaul-JulischVenetien, Nordostitalien. fernen, wenn die Art zur vegetativen Vermehrung fähig ist. Manchmal dauert es mehrere Jahre, bis die Pflanze erfolgreich entfernt oder verkümmert ist (z. B. Solidago gigantea/canadensis, Fallopia japonica, F. $x$ bohemica, Acer negundo, Ailanthus altissima, Amorpha fruticosa etc.). In diesem Fall sind Ausdauer und Konsequenz gefragt. Besonderes Augenmerk ist auch auf die Behandlung von Pflanzenresten zu legen. Diese müssen auf Plastikfolien gesammelt und in Plastiksäcken transportiert werden, damit sich Samen, Früchte und andere Pflanzenteile (Möglichkeit der vegetativen Vermehrung!) nicht in anderen Gebieten weiterverbreiten. Pflanzenreste müssen getrocknet, verbrannt oder an den zuständigen Abfall-Stellen entsorgt werden.

Das Zurückschneiden und Beweiden ist eine effektive Lösung für krautige und holzige invasive nichtheimische Arten. Es wird empfohlen, Schnitt- und Beweidungsmaßnahmen vor der Blütezeit und Samenproduktion durchzuführen. Insbesondere die Beweidung ist weniger arbeitsintensiv und hat Berichten zufolge positive Nebeneffekte für die Landschaftsökologie. So kann z. B. die Beweidung mit Rindern, Pferden, Hausschweinen und Schafen unter Berücksichtigung der lokalen Gesetzgebung effektiv eingesetzt werden, um die Ausbreitung nichtheimischer invasiver Straucharten in Auenwäldern zu verhindern (Abb. 3.2.5-2, 3.2.5-3). Sind diese invasiven Straucharten erst einmal etabliert (2-5 Jahre nach der Keimung), erfordert die Reduktion ihres Vorkommens eine geduldige und dauerhafte Beweidung in Auwäldern (z. B. in Pappelplantagen).
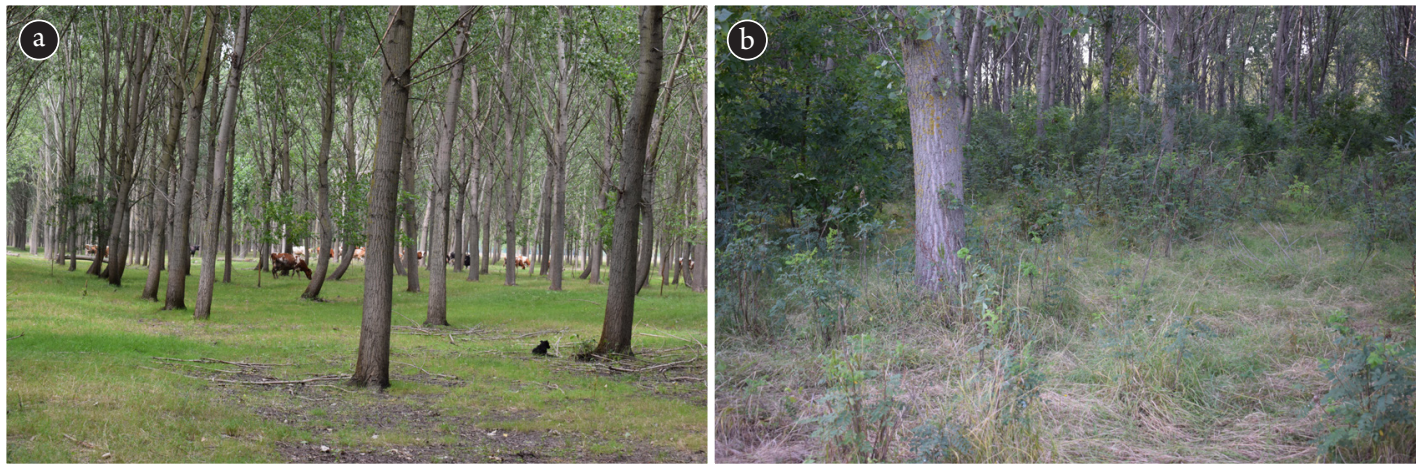

Abb. 3.2.5-2: (Links) Regelmäßige Beweidung verhindert die Etablierung und Ausbreitung von invasiven Straucharten in Pappelplantagen entlang des Timiș-Flusses in Serbien. (Rechts) Dichte Strauchschicht aus Amorpha fructicosa und Fraxinus pennsylvanica in einer nicht beweideten Pappelplantage. 
Mulchen ist eine relativ zerstörungsfreie mechanische Bekämpfungsmethode, die das Licht für die Keimung ausschließt und die Photosynthese hemmt, indem der Keimling mit Stroh, Rinde, Schnittgut, Plastikabdeckungen oder Papier abgedeckt wird. Diese Maßnahme wird in der landwirtschaftlichen Praxis häufig zur Bekämpfung einjährigen Unkräutern eingesetzt. Auch wurde es erfolgreich zur Bekämpfung von Impatiens glandulifera angewandt.

Je nach Gebiet empfiehlt es sich, ein Augenmerk auf Einschränkungen und Fortpflanzungsbiologie der Art zu legen. Im Allgemeinen erfordert der Einsatz mechanischer Bekämpfungsmaßnahmen eine durchdachte Strategie, die Überwachung, Eindämmung, Behandlung und Folgemaßnahmen zur Bewertung des Erfolgs umfasst. In vielen Fällen sind mechanische Bekämpfungsmaßnahmen nur in den Anfangsstadien der Invasion durchführbar. Häufig ist das Ziel der mechanischen Bekämpfung nur mit hohem Aufwand und hohen Kosten zu erreichen. Daher werden sie meist nur in kleinen definierten Gebieten angestrebt. Andererseits sind mechanische Bekämpfungsmaßnahmen, wenn sie richtig angewendet werden, weniger schädlich für die Umwelt und das heimische Ökosystem als chemische Maßnahmen. Dies macht mechanische Bekämpfungsmaßnahmen sehr nützlich für Schutzgebiete, in denen die chemische oder biologische Bekämpfung keine Option oder gesetzlich verboten ist. In Auwäldern wurden mechanische Bekämpfungsmaßnahmen erfolgreich eingesetzt, um kleine Bestände des Drüsigen Springkrauts (Impatiens glandulifera), des Götterbaums (Ailanthus altissima), der Bärenkräuter (Heracleum sp.) oder der Gewöhnlichen Seidenpflanze (Asclepias syriaca) auszurotten.

\section{Chemische Bekämpfung}

Chemische Bekämpfungsmaßnahmen beziehen sich auf das selektive und lokalisierte Sprühen oder gezielte Auftragen von Pflanzenschutzmitteln (PSM). Die Anwendung von Herbiziden, insbesondere die Anwendung von Glyphosat, sind kosteneffiziente chemische Bekämpfungsmaßnahmen, die dazu beitragen, die Störung der Bodenoberfläche und die anschließende Keimung von invasiven nichtheimischen Pflanzen zu vermeiden, aber es wirkt sich negativ auf andere Arten und die Umwelt aus. Die Standorte müssen in den folgenden Jahren überwacht werden, um den Erfolg und die negativen Nebenwirkungen der Behandlung zu bewerten. Gelegentlich muss die Behandlung in den Folgejahren wiederholt werden. Besonders in Auwald-Ökosystemen ist der Einsatz von chemischen Bekämpfungsmaßnahmen nicht zu empfehlen. Darüber hinaus stehen dem Einsatz von Herbiziden in Waldökosystemen oft rechtliche Beschränkungen entgegen.

\section{Biologische Bekämpfung}

Biologische Bekämpfungsmaßnahmen beziehen sich auf die Einführung von lebenden Organismen (biologischen Antagonisten), um die 
Konkurrenzfähigkeit einer invasiven nichtheimischen Pflanzenart zu senken. Diese Maßnahmen können negative Langzeiteffekte haben und erfordern vor der Umsetzung die Konsultation eines lokalen Experten. Nationale und lokale Gesetze müssen beachtet werden, und vor der Freisetzung muss eine angemessene Risikobewertung durchgeführt werden. In der Praxis umfasst die Anwendung von biologischen Bekämpfungsmaßnahmen eine breite Palette von Organismen:

Kaninchenbeweidung wurde z. B. zur Kontrolle der gewöhnlich Seidenpflanze (Asclepias syriaca) im Kiskunság-Nationalpark, Ungarn, eingesetzt. In experimentellen Studien wurden spezifische Rostpilze (Puccinia komarovii var. glanduliferae) zur Bekämpfung von Impatiens glandulifera eingesetzt (Abb. 3.2.5-4) Darüber hinaus gelten Pilze der Gattung Verticillium spp., wie beispielsweise Verticillium nonalfalfae, derzeit als das effektivste biologische Mittel gegen Ailanthus altissima.

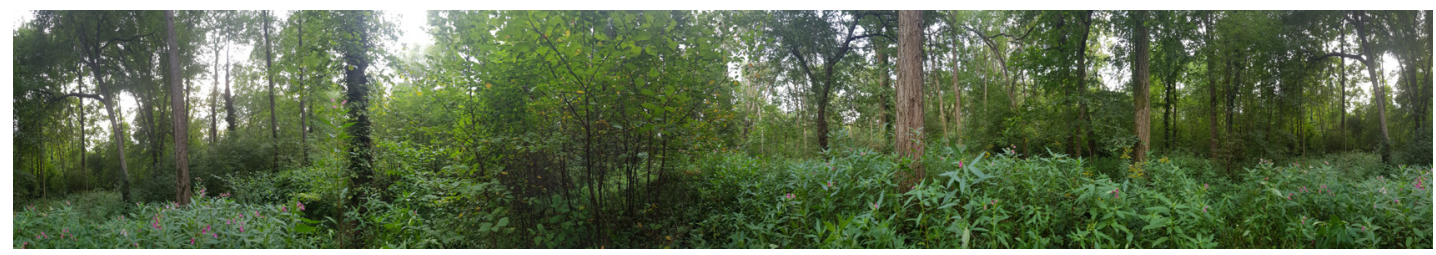

Abb. 3.2.5-4: Invasion durch das Drüsige Springkraut (Impatiens glandulifera) und Reynoutria (Fallopia sachalinensis).

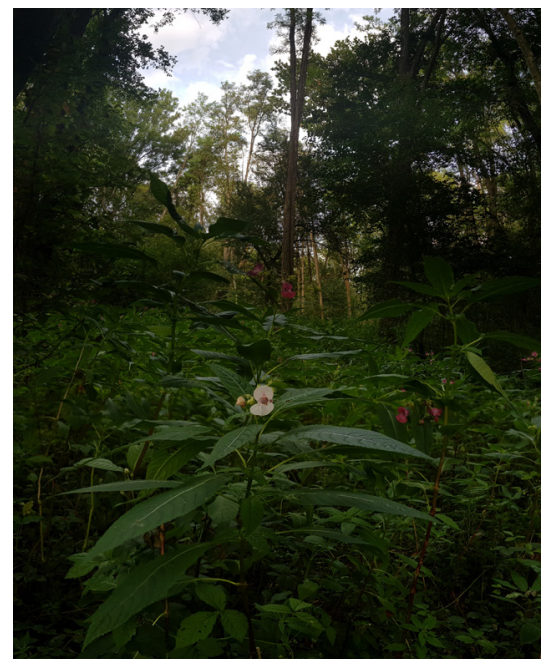

Abb. 3.2.5-5: Das Drüsige Springkraut (Impatiens glandulifera) ist in Asien heimisch.

\section{Anpassung waldbaulicher Maßnahmen}

Die Empfehlungen zur Anpassung waldbaulicher Maßnahmen umfassen präventive Maßnahmen, wie die Empfehlung heimische Baumarten zu pflanzen. Darüber hinaus werden eine kontinuierliche Überschirmung und längere Umtriebszeiten empfohlen, um schattigere Bedingungen zu fördern. Auch die Bodenvorbereitung nach Kahlschlägen sollte vermieden werden, insbesondere wenn das Gebiet regelmäßig überflutet wird, da die Samen invasiver nichtheimischer Arten durch das Wasser leicht in den vorbereiteten Boden transportiert werden können, wo sie ausreichend Licht für Keimung und Wachstum finden. Das zu schwache Durchforsten von Waldflächen sollte vermieden werden, um das Risiko von Störungen zu verringern, die als Einschleppungswege für nichtheimische Pflanzenarten in den Wald dienen können. Waldränder sollten erhalten werden, da ein dichtes, mehrschichtiges Kronendach das Eindringen von invasiven Arten aus der Umgebung verhindern oder reduzieren kann. Das regelmäßige Mähen der Ränder entlang von Waldwegen ist ein effektives Management zur Entschärfung des Verbreitungsrisikos von nichtheimischen Pflanzenarten. Schließlich sollten alternative Bewirtschaftungsmethoden zum einfachen Kahlschlag bevorzugt werden, wie z. B. Einzelstammweise oder kleinflächige Nutzungen, die in der Dauerwaldbewirtschaftung eingesetzt werden. 


\section{Wiederherstellung gestörter Ökosysteme}

Die langfristige Widerstandsfähigkeit von Auwäldern kann durch die Durchführung geeigneter Maßnahmen verbessert werden, um die Wiederherstellung eines Ökosystems zu unterstützen, das durch invasive nichtheimische Pflanzen oder andere invasive Organismen (z. B. Insekten oder Pilze) degradiert, beschädigt oder zerstört wurde. Die Kosten für jegliche Bekämpfungsmaßnahmen können hoch sein und in keinem Verhältnis zum Nutzen stehen. In einigen Fällen können jedoch traditionelle Landnutzungen wie die Waldbeweidung ein kosteneffizientes Instrument zur Wiederherstellung sein.

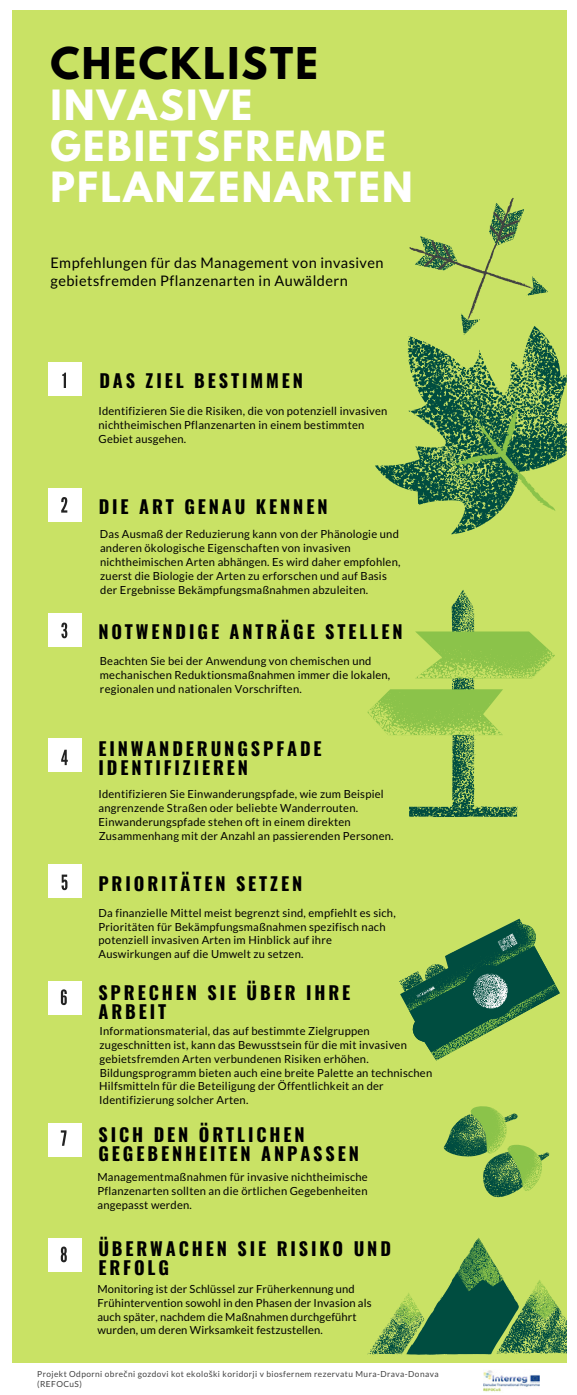

Abb. 3.2.5-7: Checkliste invasiver nichtheimischer Pflanzenarten.

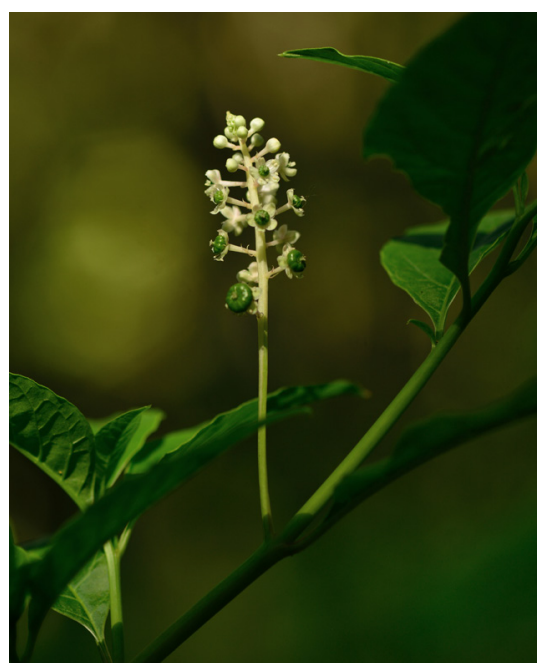

Abb. 3.2.5-6: Die Amerikanische Kermesbeere (Phytolacca americana) ist in Nordamerika heimisch und breitet sich in Europa aus. 


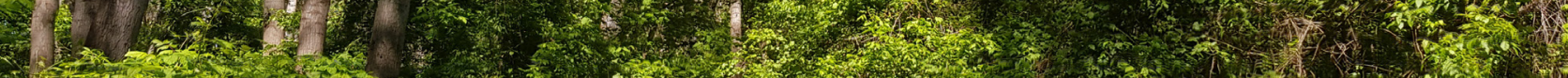

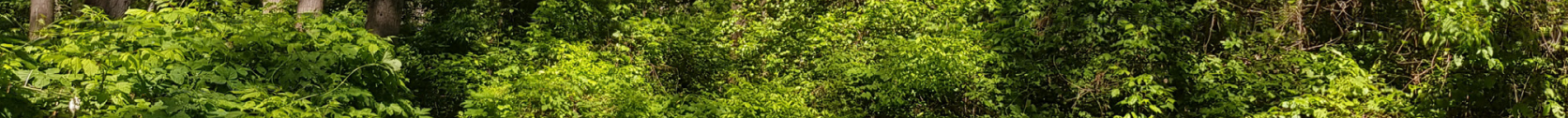

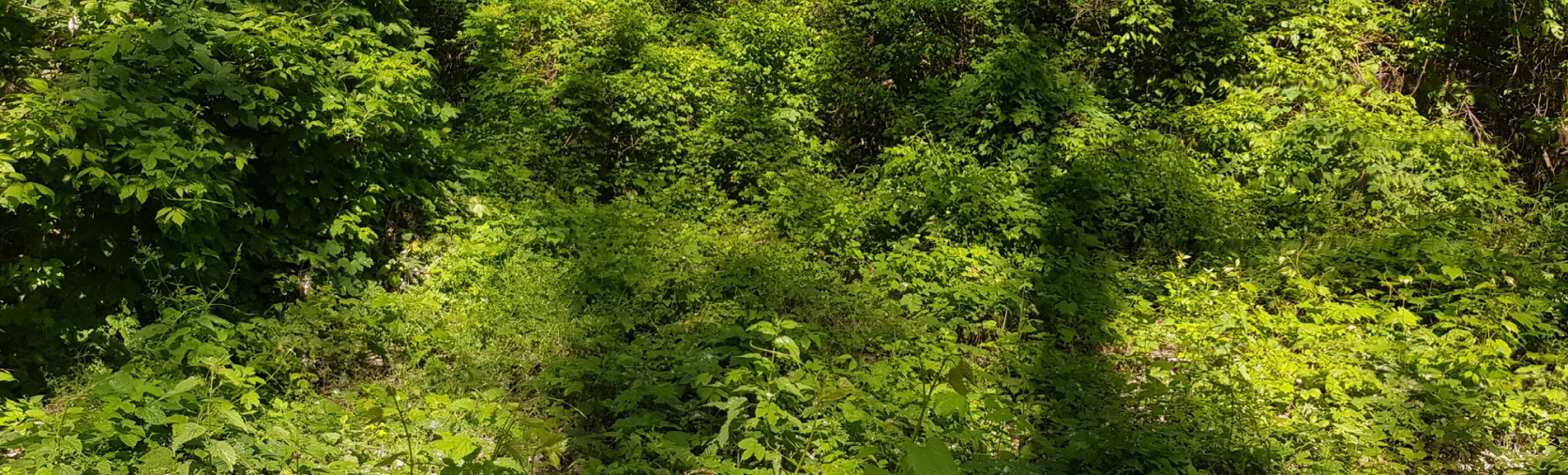




\subsubsection{Pappelwirtschaft und Diversität - kein zwangsläufiger Wiederspruch}

Markus Sallmannshofer, Werner Ruhm

\section{Hintergrund}

Auwälder sind durch die hochproduktiven Böden und kleinstandörtlich wechselnden Bedingungen besonders artenreich und gelten als Biodiversitätshotspots. Viele spezialisierte Pflanzen- und Tierarten sind auf diese Habitate angewiesen. Die ursprünglichen Charakterbaumarten der Weichholzaue, wie verschiedene Weiden, Schwarz- und Silberpappel, sind an die hohe Dynamik der Geländemorphologie, bedingt durch die erodierenden und ablagernde Kräfte von Flüssen, besonders angepasst. Als lichtbedürftige Rohbodenkeimer sind diese Baumarten aber auch auf vegetationsfreie Böden, Sand- und Kiesbänke angewiesen und können Überflutungen besser als andere Baumarten trotzen. Durch die Flussregulierungen unterbleibt diese Dynamik und es können sich die typischen Baumarten nur mehr sehr selten oder auf sekundären Standorten generativ verjüngen. Die abnehmende Überflutungsfrequenz entlang vieler regulierter Flüsse fördert zudem Konkurrenzvegetation, lässt die Waldgesellschaft in der Reifephase voranschreiten und wirkt sich negativ auf die Etablierung von Verjüngung aus.

\section{Pappelzucht}

In der zweiten Hälfte des 19. Jahrhunderts begannen die Züchtung und der Handel von Pappelsorten mit besonderen Eigenschaften wie beispielsweise Krankheitsresistenz. Mit Beginn des 20. Jahrhunderts setzte die Hybridpappelzüchtung ein: besonders schnellwüchsige Kreuzungen zwischen verschiedenen Pappelarten wurden in der Forstwirtschaft populär, der Holzmangel im Zuge des zweiten Weltkriegs führte zur Einführung eigener Pappelforschungsinstitute in vielen Ländern.

Aktuelle Kulturpappelsorten sind raschwüchsig und auf Wuchsform sowie Krankheitsresistenz ausgewählt. Dadurch sinkt die Umtriebszeit bei gesteigerter Qualität. Auf Pappel-Zwangsstandorten leistet keine Baumart vergleichbare Erträge wie entsprechende Pappelsorten - weshalb viele Forstbetriebe auf den Anbau angewiesen sind. Weichholzauwälder und der Übergangsbereich in die Hartholzaue stellen heute vorwiegend die Anbauflächen für Kulturpappeln dar. Der Schwerpunkt liegt in der feuchten Weißpappelau und der frischen Pappelau. Auf optimalen Standorten sind mit den aktuellen, leistungsfähigen Klonen Umtriebszeiten von unter 30 Jahren möglich.

\section{Pappelwirtschaft und Naturschutz}

Der Naturschutz wünscht eine Abkehr von Kulturpappel-Reinbestän- 


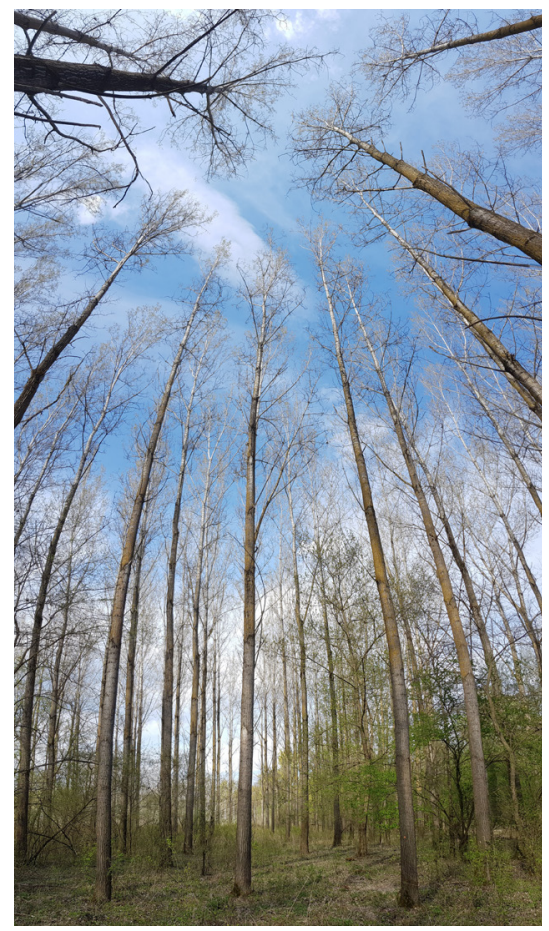

Abb. 3.2.6-1: Pappelreinbestände mit Hybridpappelklonen gehören zu den produktivsten Managementsystemen im Auwald hinsichtlich der Holzproduktion. den (Abb. 3.2.6-1). Sofern kein Interessensausgleich über Förderungen geschaffen wird, erlaubt die wirtschaftliche Situation Forstbetrieben jedoch meist nicht, auf die hochproduktiven Pappelsorten zu verzichten. Die Bewirtschaftungskosten steigen und die Erträge aus Holzverkäufen gehen im langfristigen Mittel kontinuierlich zurück. Im Folgenden wird unter Berücksichtigung der Biologie der Pappel ein Ansatz beschrieben, der ressourceneffizient die biologische Diversität auf Pappelflächen steigert und Astungskosten senken kann.

\section{Begründung von Pappelbeständen}

Pappeln sind sehr lichtbedürftig und Totasterhalter. In der Bewirtschaftung sind daher Weitverbände zweckmäßig. Eine Teilflächenkultur mit einem Reihenabstand von 8 Metern ermöglicht das natürliche Aufkommen eines Nebenbestandes. Als Mischbaumarten im Nebenbestand etablieren sich je nach Standort häufig Weißpappeln, Weiden, Erlen und Traubenkirschen, häufig aus Stock- oder Wurzelausschlägen. Wenn dienende Mischbaumarten von Natur aus nicht aufkommen, kann die Diversität durch eine extensive Pflanzung zwischen den Pappelreihen erhöht werden (Abb. 3.2.6-2).

Für die Begründung müssen die Streifen für die Pappelreihen je nach Standort gemulcht werden. Die Pflanzung kann sowohl mit dem Setzpflug als auch über eine Lochgrabung erfolgen. Als Pflanzmaterial werden hauptsächlich 2-jährige, bewurzelte Großpflanzen (ca. 2,5m und höher) verwendet. Die entstehenden Pflanzreihen wirken auf Waldbesucher oft irritierend, ermöglichen allerdings einen rationellen Arbeitsablauf sowohl bei der Pflanzung als auch bei den notwendigen Pflegeeinsätzen.

Kulturpappelsorten werden als Klone vertrieben. Eine räumliche und auch zeitliche Mischung mehrerer Sorten erhöht die genetische Diversität und sorgt für eine Risikostreuung. Eine baumindividuelle Dokumentation solcher Klonmischungen (z. B. reihenweise) auf der Fläche ist damit Grundvoraussetzung, um den späteren Erfolg der Sorten vergleichen zu können.

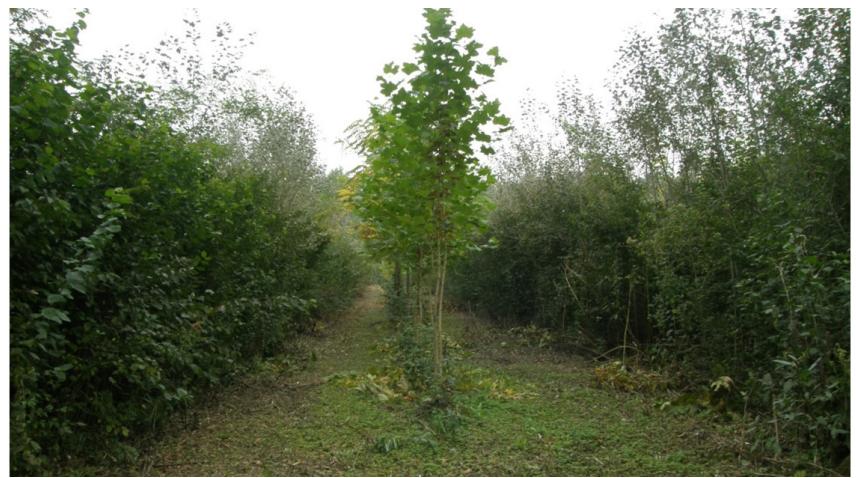

Abb. 3.2.6-2: Ahornbäume zwischen den Pappelreihen. 


\section{Kulturschutz}

Kommt nur Rehwild vor, so reicht ein Anstrich als Fegeschutz. Gegen Rotwild müssen die Pflanzen einzelbaumweise oder flächig mittels Zaun geschützt werden. In Serbien hat sich eine Methode etabliert, in der mit Hasendrahtgeflecht die Pappeln beim Pflanzvorgang eingeschlagen werden. Die Verschließung mit einer leichten Drahtschlaufe verhindert, dass der Baum vom Zaun im Zuge des Dickenwachstums eingeschnürt wird, da sich die Drahtschlafe öffnet (Abb. 3.2.6-3). Probleme treten auf, wenn Rotwild den über den Zaun reichenden Trieb beäst und dabei die Pflanze abbricht (Abb. 3.2.6-4).

\section{Kulturpflege}

Überflutungen unmittelbar nach der Pflanzung heben die noch nicht angewurzelten Pflanzen regelmäßig aus der Erde und erfordern eine Nachbesserung. Die ersten 1-2 Jahre nach der Pflanzung empfiehlt es sich, entlang der Pappelreihen mit einem Rotorschneider freizuschneiden. Bei Bedarf muss die Entfernung von Schlingpflanzen mit der Handschere eingeplant werden, denn das Niederziehen durch wilden Hopfen und Waldrebe stellt in den ersten zwei Jahren eine Gefährdung dar. In Abhängigkeit vom Produktionsziel und Wuchsform können zudem Formschnitte notwendig sein.

\section{Astung}

Zur Produktion von wertvollem Pappelholz wird in meist drei Etappen mit einer Stangensäge bis auf 6 Meter Höhe aufgeastet. Ist ein Nebenbestand vorhanden kann dieser entscheidend zur Dämpfung des Dickenwachstums der Äste beitragen und es können einzelne Etappen der Aufastung eingespart werden.

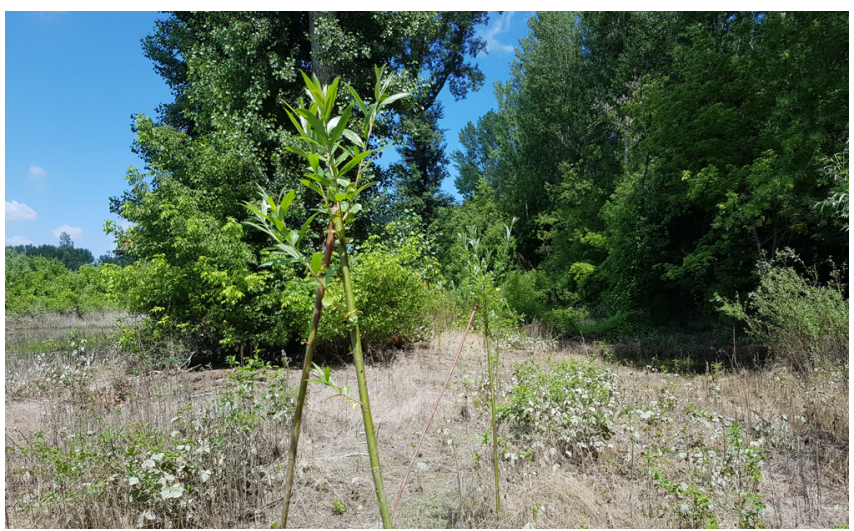

Abb. 3.2.6-4: Wenn Rotwild die jungen Pappeln zum Äsen abknickt, bricht der ganze Trieb (auch oberhalb des Zauns).

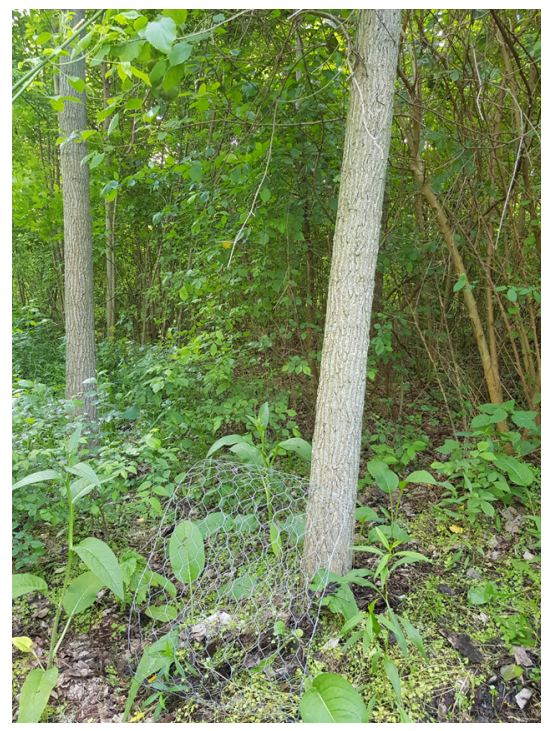

Abb. 3.2.6-3: Um zu verhindern, dass der Baum beim Dickenwachstum durch den Zaun eingeengt wird, ist der Verschluss nur eine leichte Drahtschlaufe, die sich mit zunehmender Dicke öffnet. 


\section{Durchforstung}

Bei der Durchforstung wird im Alter von 7 bis 10 Jahren schematisch auf den Endbestand reduziert (bei einem Pflanzenabstand von $4 \mathrm{Me}$ tern in der Reihe wird z. B. jede zweite Pappel entnommen). Durch die Entnahme werden nicht nur die Pappel-Z-Bäume begünstigt sondern auch der Nebenbestand wird gefördert.

\section{Ausblick}

Durch die Bestandesbegründung mit Kulturpappel im Weitverband kann das Wachstum und die Einzelbaumstabilität erhöht werden, während der Zwischenraum das Aufkommen eines Nebenbestandes ermöglicht. Sowohl Pflanzkosten als auch Astungseingriffe können eingespart werden. Dadurch können sowohl ökonomische als auch ökologische Ziele im Forstbetrieb erreicht werden, ohne von der Pappelproduktion grundsätzlich abzuweichen.

\section{Danksagung}

Dank und Anerkennung gilt Herrn Dr. Tiefenbacher (Forstverwaltung Grafenegg/Austria), aus dessen Betrieb zahlreiche Ideen und Bildaufnahmen stammen. 


\subsubsection{Integration von Totholz in die reguläre Waldbewirtschaftung}

Janine Oettel

\section{Einleitung}

Die Förderung, Erhaltung und Bewirtschaftung von Totholz ist eine Schlüsselkomponente zur Verbesserung des ökologischen Zustands von Wäldern. Totholzeigenschaften wurden als Indikatoren für die Natürlichkeit des Waldes, die Bereitstellung von Ökosystemleistungen und den Zustand der biologischen Vielfalt des Waldes ausgewählt. Internationale Initiativen wie das Übereinkommen über die biologische Vielfalt (CBD), Forest Europe (ehemals Ministerkonferenz zum Schutz der Wälder in Europa) und das Projekt "Biodiversity Baseline" der Europäischen Umweltagentur beinhalten Totholz ebenfalls als Schlüsselindikator für eine nachhaltige Waldbewirtschaftung. In der Folge haben Zertifizierungssysteme, wie FSC und PEFC, Totholz in ihre Standards aufgenommen mit dem Ziel, die Biodiversität in Wäldern zu schützen und den ökologischen Wert von Wäldern zu erhalten.

Totholz trägt erheblich zu den Ökosystemfunktionen und -flüssen in Wäldern bei, indem es das Mikroklima verändert, beispielsweise durch die Erhöhung der Bodenfeuchtigkeit, oder die Verbesserung der Nährstoffverfügbarkeit. Darüber hinaus erleichtert Totholz die natürliche Baumverjüngung, insbesondere in Wäldern in kühlen Klimazonen wie den gemäßigten Bergwäldern. Darüber hinaus sind 25\% der waldbewohnenden Arten auf Totholz angewiesen. So liefert Totholz wichtige Ressourcen für xylobionte (totholzabhängige) Arten wie holzzersetzende Pilze, Arthropoden, Moose, Flechten, Vögel und Fledermäuse.

Die hohe Bedeutung von Totholz für den Artenschutz ist für Käferarten gut dokumentiert. Laut der Europäischen Roten Liste der totholzbewohnenden Käferarten gelten 18\% der 688 untersuchten Arten als bedroht und weitere $13 \%$ als nahezu bedroht in Europa. Sie sind auf Totholz und alte Bäume angewiesen, da sie sich in morschem Holz und Baumhöhlen entwickeln. Es ist daher dringend notwendig, Landschaften und Wälder mit einer breiten Altersstruktur, Baumartenvielfalt und einer ausreichenden Anzahl von Habitatbäumen, sowie einer ausreichenden Menge an Totholz in verschiedenen Zersetzungsstadien zu schaffen.

Während in natürlichen Wäldern Totholzvolumen und -vielfalt (z. B. Zersetzungsgrade, Durchmesser) beeindruckend hoch sind, ist es in bewirtschafteten Wäldern stark reduziert. Dementsprechend sind in Europa viele Arten, die auf Totholz angewiesen sind - insbesondere Arten, die auf bestimmte Eigenschaften von Totholz oder große Mengen an Totholz angewiesen sind - in bewirtschafteten Wäldern stark zurückgegangen und oft auf isolierte Populationen in nicht bewirtschafteten Waldresten reduziert. Es ist bekannt, dass Totholzvolumen und -vielfalt von verschiedenen Faktoren abhängen (z. B. Bestandsalter, natürliche Baumsterblichkeit, Baumartenzusammensetzung) und 
stark von der waldbaulichen Bewirtschaftung abhängig sind. Müller und Bütler (2010) schlagen für das Totholzvolumen Schwellenwerte von $20-50 \mathrm{~m}^{3}$ pro ha vor, die als Mindestanforderung für europäische Wälder angesehen werden können. Die tatsächlichen Durchschnittswerte liegen jedoch in Nordeuropa mit $8 \mathrm{~m}^{3}$ pro ha deutlich darunter, während sie auch in Mittel- und Westeuropa mit $20 \mathrm{~m}^{3}$ pro ha an der Untergrenze liegen.

\section{Auwälder}

Auwälder gelten aufgrund ihrer hohen Produktivität und hohen Biodiversität als besondere Lebensräume. Oft führt die hohe Produktivität zu einem hohen Eintrag von Totholz. Verschiedene Publikationen zeigen, dass die Totholzmengen stark variieren können. So liegt das durchschnittliche Volumen in Österreich bei $51 \mathrm{~m}^{3}$ pro ha, in Polen zwischen 22 und $88 \mathrm{~m}^{3}$ pro ha, in Slowenien zwischen $36-165 \mathrm{~m}^{3}$ pro ha und kann sogar bis zu $206 \mathrm{~m}^{3}$ pro ha betragen, wie aus Italien berichtet wird. Je nach Lage und Distanz zum Fluss kann Totholz auch durch Überschwemmungen fortgeschwemmt und an anderen Stellen angeschwemmt werden.

Der Artenreichtum an xylobionten Käferarten wird aus österreichischen Auenwäldern (Nationalpark Donau-Auen) mit etwa 242 Arten dokumentiert. Dieser hohe Wert unterstreicht deutlich die Bedeutung der Auwälder für die Biodiversität. Verschiedene Studien stimmen darin überein, dass der xylobionte Artenreichtum stark von Totholzvolumen und -durchmesser beeinflusst wird. Im Einzelnen identifizierten Della Rocca et al. (2014) Schwellenwerte von $22 \mathrm{~cm}$ Brusthöhendurchmesser (BHD) und $32 \mathrm{~m}^{3}$ pro ha Totholzvolumen, unterhalb derer der xylobionte Artenreichtum signifikant abnimmt. Zusätzlich

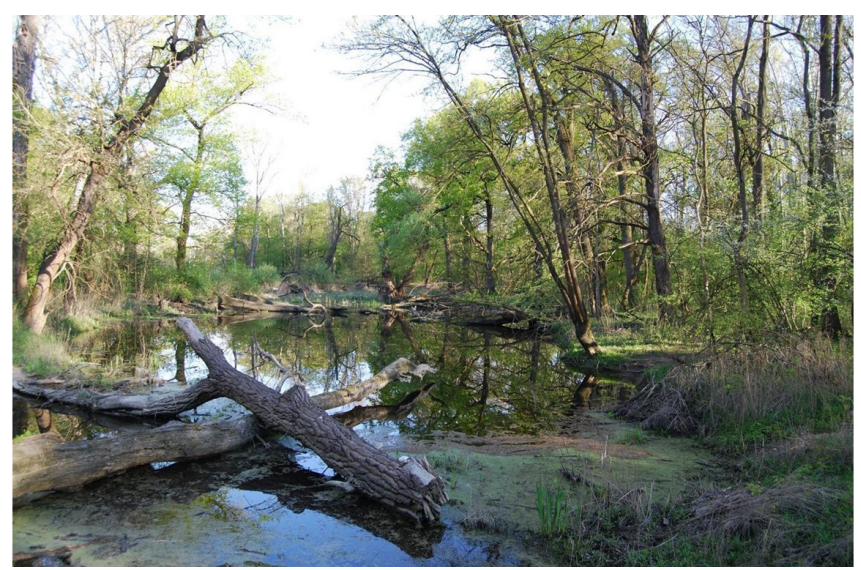

Abb. 3.2.7-1: Totholzmengen von durchschnittlich 30-50 m3ha- 1 in einem Auwald in Österreich. Der Ausschluss von Waldflächen oder einzelner Habitat- bzw. Altbäume aus der Bewirtschaftung sind Optionen, um die Verfügbarkeit von Totholz und damit die Biodiversität im Wald zu fördern. 
beeinflusst die Verfügbarkeit von Totholz in fortgeschrittenen Zersetzungsstadien den Artenreichtum positiv, während Totholz mit geringem Durchmesser sowie eine hohe Bestandesgrundfläche negativ mit dem Artenreichtum korrelieren.

\section{Managementoptionen zur Erhöhung des Totholzanteils}

Die Waldstruktur und das Totholz beeinflussen den Artenreichtum maßgeblich. Die aktive Förderung von Totholz und dessen Integration in die Waldbewirtschaftung sind daher von hoher Bedeutung und werden bereits in den letzten Jahrzehnten in verschiedenen Bewirtschaftungskonzepten umgesetzt. Diese Konzepte erkennen den Wert von Alt- und Totholz an und beinhalten dessen Förderung durch verschiedene Maßnahmen, wie beispielsweise (1) die Einrichtung von Waldreservaten oder (2) das Belassen von Altholzinseln. Zusätzlich können durch (3) das Belassen von Habitatbäumen und (4) die Förderung von stehendem und liegendem Totholz die Restpopulationen xylobionter Arten durch Habitatvernetzung erhalten und ihre Ausbreitung ermöglicht werden.

Empfehlungen zur Erhöhung des Totholzanteils in Auwäldern sind (a) das Belassen von Holzernte-Material vor Ort, (b) das Erhalten von Stümpfen mit einer Höhe von 0,5-1 m und (c) das Ringeln von Einzelbäumen an bevorzugt sonnenexponierten Standorten, um künstlich den Totholzanteil zu erhöhen. Außerdem kann (5) die Verlängerung der Umtriebszeit zu einer kontinuierlichen Versorgung mit Totholz und zu einer Verfügbarkeit von Totholz in späteren Zersetzungsstadien beitragen. Die verschiedenen Managementkonzepte unterscheiden sich jedoch in den Definitionen und Zielwerten für einzelne Maßnahmen. So variiert z. B. die Anzahl der Habitatbäume pro ha von 5 bis

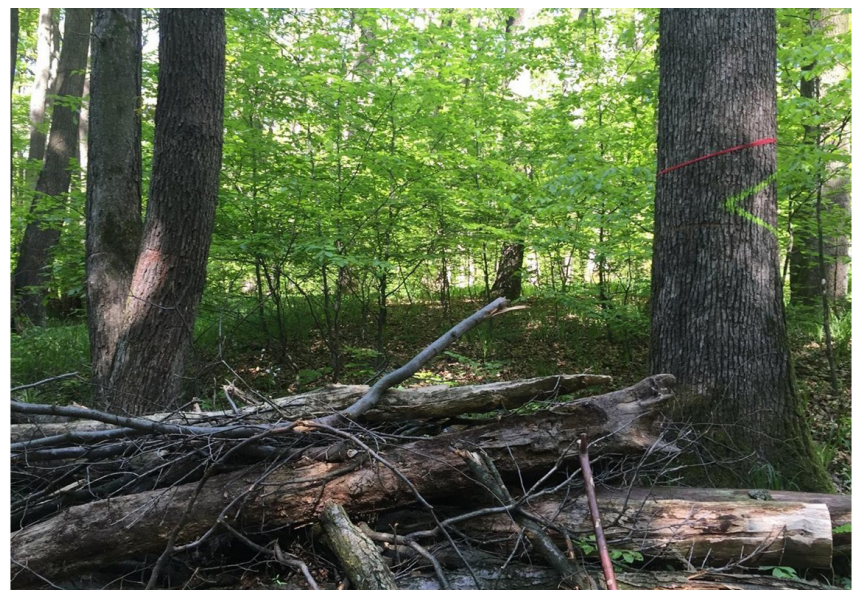

Abb. 3.2.7-2: Anhäufung von Totholz nach Holzerntearbeiten. Durch das Belassen von Ästen, Stammteilen und Stümpfen von geringem wirtschaftlichem Wert während der Holzernte wird die Förderung von Totholz im Rahmen der regulären Bewirtschaftung möglich. 
10, oder die angestrebten Totholzmengen variieren von 20 bis $40 \mathrm{~m}^{3}$ pro ha.

Stehende tote Bäume können im Wald allerdings eine Gefahr für die Verkehrssicherheit und den Arbeitsschutz darstellen. Entlang und im Umfeld von öffentlichen Straßen, Bahnlinien, Forststraßen und anderen Infrastruktureinrichtungen, sowie im Bereich von Gebäuden hat der Schutz von Leben und Gesundheit und damit die Verkehrssicherheit Vorrang. Es ist notwendig, das Risiko von stehenden, toten Bäumen regelmäßig zu beurteilen und diese gegebenenfalls zu fällen. Die Maßnahmen zur Gewährleistung der Arbeits- und Verkehrssicherheit beinhalten das Schneiden von Stümpfen in einem angemessenen Rahmen und soweit dies zur Vermeidung von Gefahren erforderlich ist. Durch das Belassen von ganzen Gruppen an Habitat- oder Altbäumen wird das Risiko auf einer kleineren Anzahl an Flächen konzentriert und damit reduziert.

\section{Zusammenfassung}

Mögliche Maßnahmen zur Integration von Totholz in die reguläre Waldbewirtschaftung sind neben der flächigen Unterschutzstellung, der Ausschluss einzelner ökologisch wertvoller Bäume aus der Bewirtschaftung und die Förderung von stehendem und liegendem Totholz. Dies kann bei der Holzernte durch das Belassen von Ästen, Stämmen und Stümpfen mit geringem wirtschaftlichem Wert realisiert werden. Aspekte des Waldschutzes und der Sicherheit müssen in jedem Fall berücksichtigt werden. Notwendige Maßnahmen sollten auf ein Minimum beschränkt werden, bei gleichzeitiger Gewährleistung der Sicherheit und Reduzierung der Risiken. Totholzvolumina von mindestens $30 \mathrm{~m}^{3}$ pro ha und Totholz mit einem Mindestdurchmesser von $20 \mathrm{~cm}$ haben nachweislich einen positiven Effekt auf totholzbewohnende Arten. Ein gezieltes Totholzmanagement lässt sich so im Rahmen der regulären Waldbewirtschaftung umsetzen. 


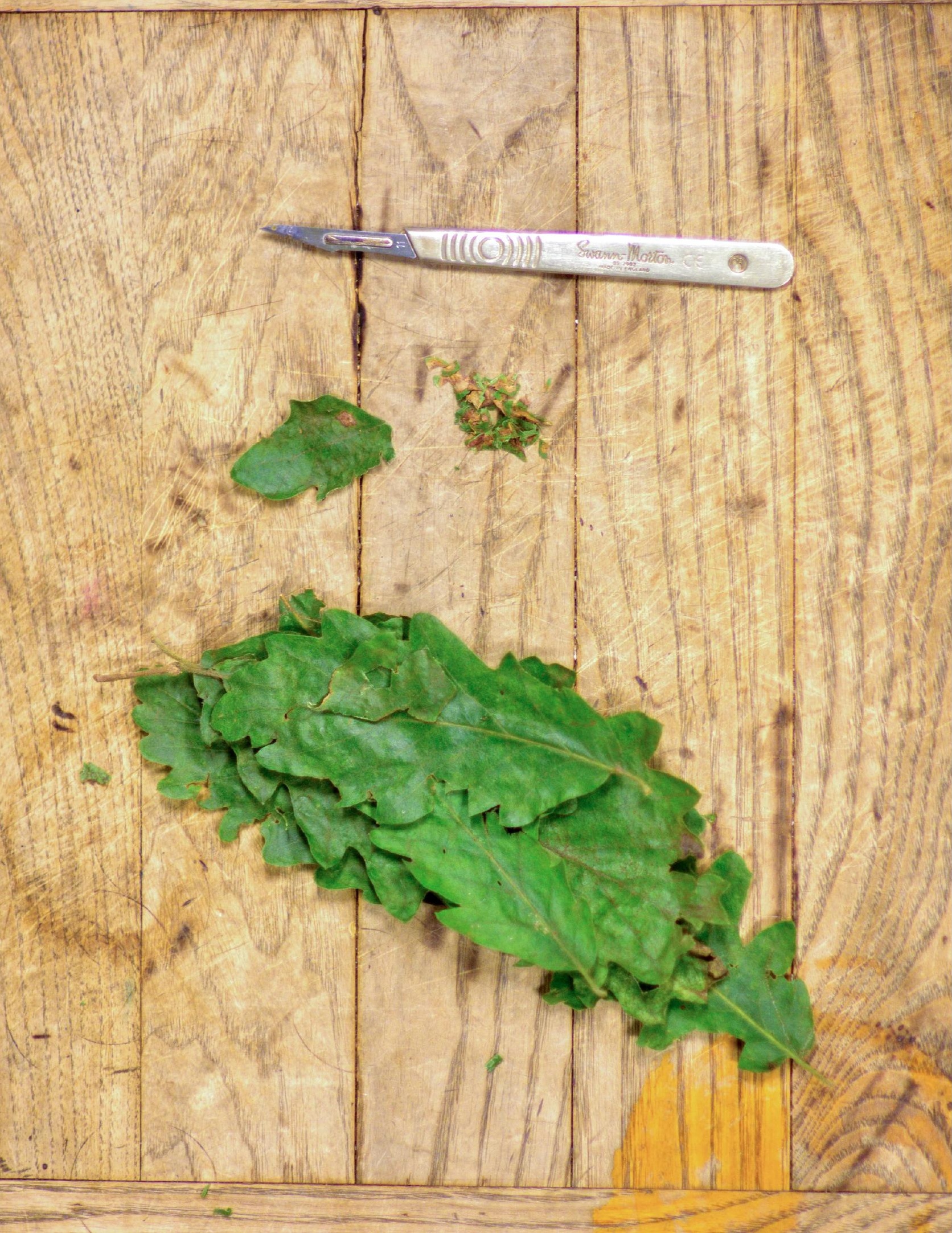




\subsection{Gesundheit der Wälder}

\subsubsection{Forstschädlinge und Krankheiten in einer sich verändernden Welt: Die Bedeutung der Früherkennung}

Maarten de Groot, Thomas Cech, Gernot Hoch, Nikica Ogris, Gyuri Csoka

\section{Massenauftreten tierischer Schädlinge und epidemische Baum- krankheiten, ein aktuelles Problem für flußbegleitende Wälder}

Die Fluss begleitenden Wälder Mitteleuropas stehen durch den weltweiten Handel und den Klimawandel unter starkem Stress. Der globale Handel ermöglicht gebietsfremden Arten die Einwanderung aus ihren natürlichen Herkunftsgebieten in europäische Wälder. Obwohl die meisten dieser Arten harmlos sind, besitzen manche das Potential invasiv zu werden und damit die Biodiversität zu beinträchtigen sowie die Wirtschaft und die Gesundheit des Menschen zu schädigen. Andererseits war das vergangene Jahrzehnt als Folge des fortschreitenden Klimawandels durch einen globalen Temperaturanstieg sowie eine $\mathrm{Zu}-$ nahme der Häufigkeit extremer Witterungsereignisse gekennzeichnet. Diese beiden Faktoren schwächen die Waldbäume und begünstigen bestimmte (heimische) Schädlinge und Baumkrankheiten, was Epidemien zur Folge haben kann. Diese Arten werden daher auch als eruptive Schädlinge und Krankheitserreger bezeichnet.

Fluss begleitenden Wälder (Auen) sind besonders empfindlich, da sie mehrheitlich in Tieflagen mit oft hohen Temperaturen vorkommen und infolge von Überflutungsereignissen starkem Stress ausgesetzt sind. Sie stehen darüberhinaus auch unter hohem Druck seitens des Menschen, sei es durch Umbau der Wälder in Monokulturen oder auch durch eine Überbeanspruchung durch die Erholung suchende Bevölkerung. Fast sämtliche Baumarten in den zentraleuropäischen Flussauen sind derzeit von verschiedenen Schädlingen und Krankheiten bedroht, was bereits merkbare Folgen zeitigt. So geht beispielsweise der Anteil der beiden Eschenarten Fraxinus excelsior und F. angustifolia seit etwa einem Jahrzehnt als Folge des invasiven Eschen-Triebsterbens (Hymenoscyphus fraxineus, Kapitel "Eschen-Triebsterben - eine schwerwiegende Bedrohung der Biodiversität in Auwäldern") zurück. Eichen leiden unter einem Komplex von Schädigungsfaktoren, die zu Eichensterben führen (Kapitel „Eichensterben - Beispiel für ein Krankheitsphänomen durch verschiedene interagierende kausale Faktoren") sowie Massenaufteten des Schwammspinners (Lymantria dispar) oder Goldafter (Euproctis chrysorrhoea). Mehrere Erlenarten werden von Phytophthora alni, Armillaria spp und Neonectria sp. befallen, die in manchen Gebieten extremes Zurücksterben auslösen. Die bisherigen Beispiele umfassen nur bereits vorhandene Arten von Schädlingen und Krankheitserregern, bei anderen Arten ist die Invasion in naher Zukunft zu erwarten. Der Asiatische Eschenprachtkäfer (Agrilus planipennis) breitet sich von Russland und der Ukraine aus langsam nach Westen aus. Seine Ankunft in Zentraleuropa ist in wenigen Dekaden 
zu erwarten. Die Art führt zum Absterben von Eschen. Der Asiatische Laubholzbockkäfer (Anoplophora glabripennis) und Zitrusbockkäfer (Anoplophora chinensis) haben die Flussauen noch nicht erreicht, doch sind massive Folgen für diese Ökosysteme zu erwarten, wenn sie eingeschleppt werden, da sie mehrere Laubhölzer bedrohen. Um derartigen Waldschutz-Problemen wirkungsvoll zu begegnen, sollten Maßnahmen geplant und vorbereitet werden.

\section{Wie können epidemisch auftretende Schädlinge und Krankheiten entschärft werden?}

Frühwarnsysteme und sofortige Reaktion sind die entscheidensten Grundvoraussetzungen für ein effektives Management forstlicher Schädlinge und Krankheiten. Im Falle eruptiver heimischer Arten heisst das, dass der Praktiker bereits vor dem Entstehen eines Krankheitsherdes Maßnahmen setzen kann, wohingegen bei potentiellen invasiven nichtheimischen Arten dies so früh wie möglich nach deren Ankunft mit dem Ziel einer Ausrottung erfolgen soll. Die Identifikation des Schadfaktors im Stadium einer noch begrenzten Verbreitung hat hier Schlüsselfunktion. Das gegenständliche Kapitel soll den Praktiker in seinen Bemühungen, Schädlinge und Krankheiten aufzuspüren, unterstützen, indem sowohl Methoden erklärt sowie Schädlinge und Krankheiten charakterisiert werden.

\section{Methoden zur Erkennung tierischer Schädlinge}

Das Hauptaugenmerk liegt hier auf drei Vorgangsweisen: visuelle Erfassung von Symptomen, Insektenfallen und andere Detektionsmethoden.

Der erste Schritt zur Erkennung potentieller Ausbrüche von Schädlingen und invasiver gebietsfremder Insektenarten ist das (zeitaufwändige!) aufmerksame Beobachten der Vorgänge im Wald mit dem Wissen, wonach gesucht werden muss. Dabei kommt der Ansprache von Symptomen und Anzeichen von Schädlingen höchste Bedeutung zu. Oft ist der Schädling selber nicht das Erste, was ins Auge fällt, wohingegen Symptome oft schon aus der Distanz auffallen. Das augenfälligste Merkmal kann das Absterben des Baumes oder von Teilen der Krone bzw. die Vergilbung der Blätter oder die völlige Entlaubung sein. Symptome dieser Art sollten genauer überprüft werden.

Insekten können vier verschiedenen Schädigungsgruppen zugeteilt werden: rinden- und holzbohrende Arten, laubfressende Arten, baumsaftsaugende Arten und gallenbildende Arten (Abb.3.3.1-1). Rindenund Holzbewohner sind oft Käfer oder Schmetterlinge, bei denen die Larven im Holz oder unter der Borke fressen. Eine besonders bedeutende Gruppe sind die Borkenkäfer (Coleoptera: Curculionidae: Scolytinae), die sehr typische und oft artspezifische Fraßsysteme anlegen. Prachtkäfer (Coleoptera: Buprestidae) legen zickzackartig gewundene Gänge unter der Borke mit einem typisch ovalen oder D-förmigen 

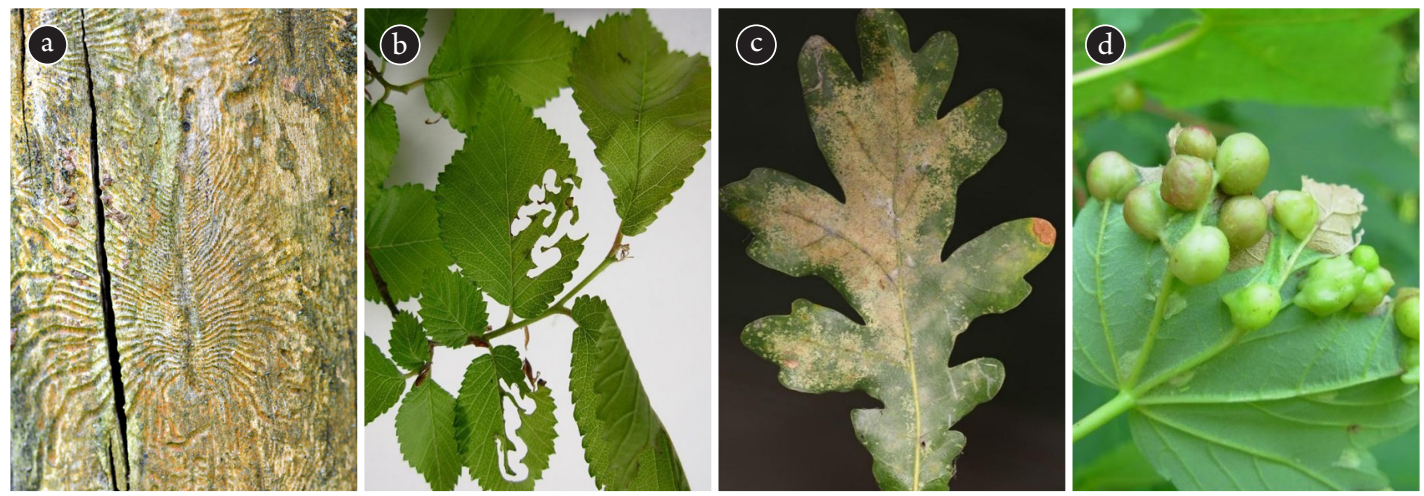

Abb. 3.3.1-1: Verschiedene Typen von Schäden, verursacht von Insekten: a) Brutbild des Großen Ulmensplintkäfers (Scolytus scolytus), b) Blattfraß durch die Japanische Ulmenblattwespe (Aproceros leucopoda), c) Saugschäden durch die Amerikanische Eichennetzwanze (Corythucha arcuata) und d) Gallen der Ahorngallwespe (Pediaspis aceris). (Photos: G. Csoka, G. Hoch)

Schlupfloch an. Bei Bockkäfern (Coleoptera: Cerambycidae) sind die Gangsysteme eher unregelmäßig geformt und die Schlupflöcher sind eher oval bis rund. Blattfressende Insekten können Bäume zur Gänze entlauben. Die meisten sind Schmetterlinge (Lepidoptera) im Larvenstadium, Larven von Blattwespen (Hymenoptera: Symphyta) oder Käfer (Coleoptera). Die Arten sind oft wirtsspezifisch und auf bestimmte Fressmuster spezialisiert - manche Arten fressen nur im Inneren von Blättern oder Nadeln (Minierer). Allerdings reicht das Fraßbild allein oft nicht zur Bestimmung der Insektenart aus. Deshalb ist es notwendig, das Insekt nachzuweisen. Blattfressende Insekten werden am besten an Bäumen untersucht, bei denen nur Teile der Krone betroffen sind: hier ist mit aktiven Insekten zu rechnen und hier sollte gesammelt werden. Manchmal können andere Indikatoren für Insektenfraß (Eigelege, Raupennester etc.) bei der Identifikation hilfreich sein. Baumsaftsaugende Insekten entfalten ihre Aktivität auf Blättern, Trieben, Zweigen und sogar am Stamm und finden sich häufig in der Familie der Wanzen (Hemiptera). Die Schäden sind durch Verfärbung der Blätter oder Nadeln auffällig. Dies kann die ganze Krone erfassen und vorzeitige Blattverluste können eine Folge sein (Abb. 3.3.1-2). Die vierte Gruppe, gallenbildende Arthropoden, befällt ausgewachsene Bäume und Jungbäume. Milben (Acari), Gallmücken (Diptera: Cecidomyiidae), Läuse (Homoptera: Adelgidae) und Gallwespen (Hymenoptera: Cynipidae) können am Baum die Bildung auffälliger und oft auch artspezifischer Gallenformen auslösen. Die Arten legen Eier in verschiedene Organe des Baumes und ihre Larven induzieren die Gallenbildung, die durch die Pflanzengewebe erfolgt. Die Schäden sind zwar gewöhnlich nicht bedrohlich, doch kann Massenbefall die Photosynthesebilanz des Baumes beeinträchtigen. Auch können Interaktionen mit Pathogenen auftreten, für die Gallen Eintrittspforten darstellen. Gallen finden sich auf Blättern, Zweigen/ Ästen und Samen. Weitere Informationen zu forstschädlichen Insekten sind in unseren Literaturemfehlungen und vielen Internetseiten 
(www.invasive.org, http://www.skodcoviadrevin.sk/, www.evportal.hu, www.zdravgozd.si) zu finden. In vielen Fällen verursacht der Fraß durch Larven typische Schadbilder (z. B. bei blattfressenden Schmetterlingsraupen, Larven von im Holz bohrenden Insekten unter der Borke). Im Allgemeinen sind adulte Insekten (Imagines) nicht leicht zu finden, weshalb andere Methoden zur Anwendung kommen. Eine davon ist die Aufstellung von Fallen oder Ködern. Eine Reihe von Fallentypen ist nicht für den Fang bestimmter Arten oder von Gruppen von Arten spezifiziert. Ein Beispiel dafür sind solche, die am Waldrand exponiert werden und in denen alles gefangen wird, was gerade vorbeifliegt. Daraus ergibt sich das Problem, dass sehr viele verschiedene Arten gefangen werden. Für nachtaktive Mottenarten sind Lichtfallen praktikabel, die mit aufladbaren Akkus versorgt werden. Andere Arten werden durch bestimmte Farben angelockt (Läuse, aber auch Käfer wie Prachtkäfer).

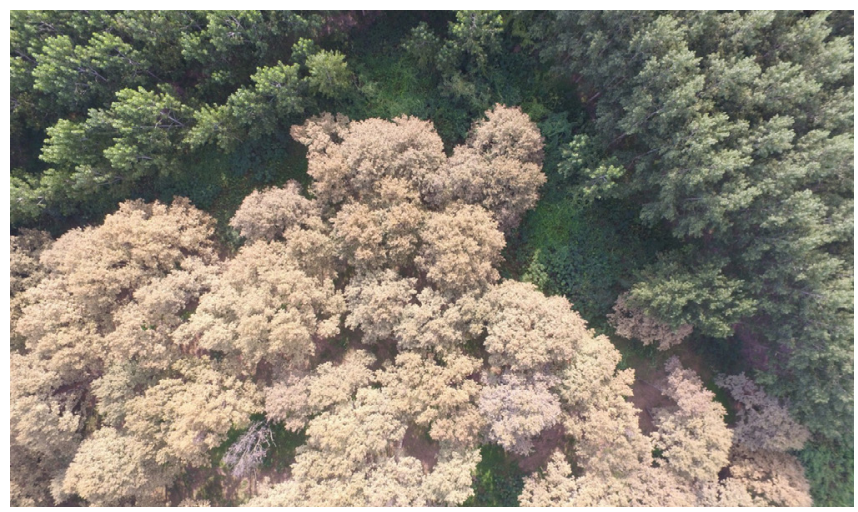

Abb. 3.3.1-2: Ein von der Eichennetzwanze (Corythucha arcuata) befallener Eichenbestand in Serbien umgeben von Pappeln und Weidenbeständen.

Der Asiatische Eschenprachtkäfer beispielsweise wird mit grünen und violetten Fallen angelockt. Gefärbte Fallen sind oft Klebfallen, an denen die Insekten haften bleiben. Zusätzlich werden Insekten oft mittels spezifischer Duftstoffe (zum Beispiel vom Baum emittierte flüchtige Substanzen) oder mittels Pheromonen angelockt. Erstere locken meist mehrere Insektenarten an, für die die betreffende Baumart als Fraßoder Brutbaum interessant ist. Demgegenüber werden Pheromone vom Insekt produziert und ihre Wirkung ist meist artspezifisch. Leider sind noch nicht alle Pheromone analysiert und eine synthetische Herstellung fehlt noch für viele Insektenarten. Vielversprechend sind Fallen, die mit Mischungen verschiedener Lockstoffe bestückt sind. Mit diesen könnten Artengruppen gefangen werden, die sonst schwer nachzuweisen sind.

Als weitere Methode ist die Detektion von Schadinsekten mittels Spürhunden besonders vielversprechend. Spürhunde haben sich zum Aufspüren von Arten wie dem Asiatischen Laubholzbockkäfer, dem Zitrusbockkäfer und dem Eschenprachtkäfer an Importstellen (Häfen, 
Zollstationen etc.) aber auch in Befallsgebieten als sehr geeignet erwiesen. Spürhunde sind auch zur Detektion von eruptiven Arten wie dem Buchdrucker (Ips typographus) geeignet. Allerdings müssen die Hunde vor dem Einsatz trainiert werden, um die jeweilige Art richtig aufzuspüren.

Vor kurzem rückte die Fernerkundung in den Mittelpunkt der Methoden zur Erfassung von Gradationen in Wäldern. Diese Methoden können wichtige Informationen zur Ausdehnung von Schadensherden geben. Allerdings ist es in den meisten Fällen nicht möglich, damit die ursächlichen Arten zu identifizieren. Bilder von Flügen mit Drohnen über schwer zugänglichem Gelände können zur Früherkennung von Kronenschäden beitragen.

\section{Methoden zur Erkennung von Krankheiten}

Krankheiten von Bäumen und Sträuchern werden größtenteils von Pilzen oder pilzartigen Organismen, seltener von Bakterien, Viren und virusartigen Organismen verursacht. Die meisten Arten besitzen nur mikroskopische Strukturen, was eine richtige Bestimmung im Feld schwierig macht.

Die Zuordnung von Symptomen zu Organismen pilzlicher/bakterieller oder viraler Natur im Feld beruht auf der Kenntnis spezifischer Symptome und/oder dem Nachweis und der Identifikation reproduktiver Strukturen des Pathogens. In der Literatur zur Diagnostik werden die Symptome gewöhnlich zu Gruppen zusammengefasst, je nachdem welche Pflanzenorgane betroffen sind: Blätter/Nadeln, Triebe/Zweige/Äste, Stamm, Wurzeln und Blüten/Früchte.

Ähnlich wie bei den tierischen Schädlingen sind die Krankheitserreger in ihrer Aktivität oft auf ein oder einige Typen von Pflanzenorganen beschränkt: Krankheiten (meist pilzlicher Natur), die Blätter oder Nadeln erfassen, sind gewöhnlich eher spezifisch das heißt, sie treten oft nur auf diesen Organen auf.

Weiters sind sie meistens wirtsspezifisch auf Gattungsebene, und die Morphologie und die Größe der Symptome (Flecken) sind oft recht charakteristisch: wir finden hier sogar Beispiele, wo der ursächliche Organismus makroskopisch im Feld identifiziert werden kann (Beispiel: Teerfleckenkrankheit des Ahorns, Rhytisma acerinum).

Allerdings gibt es auch Pathogene, die verschiedene Pflanzenorgane befallen können (Beispiel: Hymenoscyphus fraxineus, Ursache des Eschen-Triebsterbens, kann Blattflecken, verfärbte Blattspindeln, Trieb-, Zweig-, Ast- und Stammnekrosen sowie Wurzelhals-Nekrosen, Nekrosen an Grobwurzeln und schließlich auch eine Holzverfärbung verursachen).

In Rinden-Nekrosen pilzlichen Ursprungs entwickeln sich oft reproduktive Organe des Pilzes, die auf der Rindenoberfläche meistens als erscheinen. Zwar deutet deren Auftreten stark auf den pilzlichen Ursprung der Läsion hin, doch erfordert die Identifikation mikro- 
skopische Analysen durch ein Diagnoselabor. In Nekrosen, die von Hymenoscyphus fraxineus verursacht werden, gehören die sichtbaren Pilzfruchtkörper immer zu sekundären Rindenpilzen, die vom Hymenoscyphus-Zurücksterben profitieren.

Eine Gruppe von Pilzarten, die leichter zu erkennen sind, produziert größere und meist Konsolen-förmige Fruchtkörper. Diese gehören zu den „Höheren“ Pilzen oder Basidiomyzeten und sind gewöhnlich Fäule verursachende Holzbewohner, die allerdings fast immer über Wunden in das Holz eindringen (Wundfäule-Erreger). Einige Arten können von Fachleuten im Feld anhand der Morphologie und der Größe ihrer Fruchtkörper bestimmt werden.

Zweifellos die schwierigste Gruppe sowohl, was die Erkennung wie auch (vor allem!) die Identifikation betrifft, umfassen die im Wurzelsystem der Gehölze aktiven Krankheitserreger. Der Praktiker ist auf das Vorhandensein bestimmter Symptome in der Krone oder am Stamm, die auf Wurzelkrankheiten schließen lassen, angewiesen: typischerweise ist das eine gleichmäßig die gesamte Krone erfassende Degeneration. Das Laub ist spärlich, die Blätter sind deutlich kleiner als gewöhnlich, der Zuwachs geht überall in der Krone zurück, oft zeigt sich eine überreiche Samenbildung (Notfruktifikation). Am Stamm reagieren die Bäume auf Stress oder Krankheitserreger im Wurzelraum oft mit Saftfluss. Eine Kombination der beschriebenen Krankheitssymptome in der Krone mit Saftaustritt am Stamm wird meist als Symptomkomplex von Krankheitserregern aus der pilzartigen Gattung Phytophthora angesehen, doch können auch einige andere Pathogene oder sogar abiotischer Stress alleine gleiche Symptome auslösen.

Um Krankheiten von Gehölzen im Feld zu erkennen, sollten, basierend auf einem detaillierten Wissen zu Pathogen-typischen charakteristischen Merkmalen, sämtliche vorhandenen Symptome inkl. Stadien von Symptomen sorgfältig und umfassend schriftlich und mit Fotos dokumentiert werden. Die Proben für eine Diagnose durch ein Labor müssen für manche Krankheitserreger spezifische Voraussetzungen erfüllen, sie sollten aber generell reichlich und vor allem signifikant für die beobachteten Symptome sein, sowie verschiedene Abbaustadien der betroffenen Pflanzenteile repräsentieren (Proben, die nur aus bereits abgestorbenen Pflanzengeweben bestehen, führen den Diagnostiker kaum zum ursächlichen Schadorganismus, sondern zu einer Garnitur von sekundären Besiedlern).

Proben von Blättern sollten vor dem Versenden an das Labor gepresst und getrocknet werden. Alle Proben sollten in eher trockenem $\mathrm{Zu}$ standsein (niemals luftdicht in Kunststoffsäcken verpacken!), jegliche Zersetzungsprozesse unter feuchten Bedingungen (Verschimmeln!) sollten strikt vermieden werden.

Die Diagnose von Phytophthora folgt gewöhnlich zwei verschiedenen Techniken. Wenn Läsionen am Stamm (Saftaustritt!) vorhanden sind, kann der Erreger direkt aus symptomatischen Rindengeweben auf speziellen Nährböden isoliert werden. Die genaue Vorgangssweise ist in 


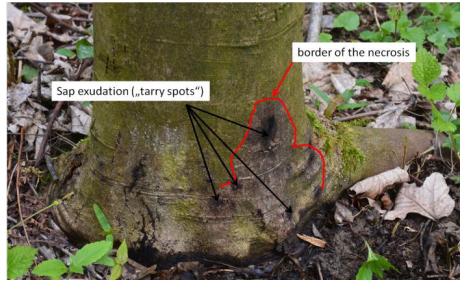

\section{Sample active necroses}

Sample only from active (fresh) necroses. These are light brown to reddish, not quite dry, not blackish, and not decomposed. They have a fruity odour and do not stink (bacteria or yeasts).

Take a sample from the stem necroses. Remove the outer bark tissue in the transition zone between dead and living inner bark tissue (=edge of the lesion) with a sharp knife or a chisel. Clean the knife or chisel immediately afterwards with $70 \%$ ethanol. Using a knife, cut out approx. $10 \times 5 \mathrm{~cm}, 2-5 \mathrm{~mm}$ thick shields from the inner bark tissue; the samples must contain the border between dead and living tissue!

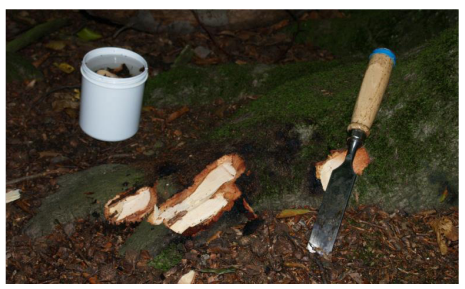

\section{Store the samples}

The samples must be placed immediately in a watertight jar containing tap water. After 10 minutes, make the first water change (replace brown water with fresh tap water). Repeat this procedure every 2 hours until the water is no longer discoloured, two to three times depending on the tree species.

Abb. 3.3.1-3: Phytophthora - Entnahme von Proben aus symptomatischen Stamm-Geweben.

Abb. 3.3.1-3 erläutert. Wenn Rinden-Läsionen fehlen, die Kronensymptome hingegen auf Wurzeln-zerstörende Phytophthora-Arten schlieBen lassen, sollten aus dem Bereich der Rhizosphaere Bodenproben genommen werden: dazu sollte die organische Bodenauflage rund um die Stammbasis an vier Stellen (den Himmelsrichtungen folgend) bis $\mathrm{zu}$ einer Tiefe von etwa $10 \mathrm{~cm}$ entfernt werden. Aus dem darunter befindlichen Boden sollten Feinwurzeln de Baumes enthaltende Proben genommen werden (pro Loch etwa eine Schaufel voll). Die vier Einzelproben können zu einer Probe vermengt werden und davon dann etwa $1 \mathrm{~kg}$ entnommen werden. Diese Probe kann bis zur Analyse im Labor einige Monate trocken aufbewahrt werden.

Darüberhinaus können Pilze mittels Sporenfallen erfasst werden. Dies ist die schnellste Methode zum Sammeln sowohl abgestorbener wie auch für die Kultur geeigneter luftbürtiger Pilzsporen. Die Methode ist zur Identifikation sowie zur Quantifizierung von Pilzsporen, zur Klassifikation auf Gattungsebene, oder in der Luft vorhandener morphologisch ähnlicher Gruppen, unabhängig von der Lebensfähigkeit „geeignet“ Im Handel werden einige verschiedene Modelle wie bei- 
spielsweise die Burkard oder die Lanzoni-Falle angeboten. AndersonSammler sind gewöhnlich für das Sammeln von Pilzsporen für die Kultur der Pilze ausgerüstet; diese haben mehrere Öffnungen, durch die die Sporen direkt auf ein oder mehrere Petrischalen mit Pilznährböden gelangen. Sporenfallen und Sporensammler für die Kultur von Pilzen geben unterschiedliche Bilder der Sporensituation in der Luft wieder: Sporenfallen erfassen sowohl abgestorbene wie auch keimfähige Sporen, während die Sporensammler für die Kultur nur die keimfähigen Sporen detektieren. Dabei sind auch das Nährmedium sowie die Temperatur bei der Inkubation zu berücksichtigen.

Einige pathogene Pilze sind Insekten-bürtig, d.h. die Insekten fungieren als Vektoren. Die Insekten tragen oft Sporen der Pilze in speziellen Strukturen am Körper („Mycangien“) und lösen die Infektion aus, wenn sie Brutgänge anlegen. Beispiele dafür sind die TausendCanker-Krankheit, verursacht durch den Pilz Geosmithia morbida, mit dem Walnuss-Zweigkäfer Pityophthorus juglandis als Vektor, die Holländische Ulmenwelke, verursacht durch die beiden Pilzarten Ophiostoma ulmi und O. novo-ulmi, mit Ulmensplintkäfern (Scolytus sp.) als Überträger, sowie die Kiefernwelke, verursacht durch den Fadenwurm Bursaphelenchus xylophilus, der von Bockkäfern aus der Gattung Monochamus übertragen wird. Für die Früherkennung von Krankheiten, die von Insekten auf Waldbäume übertragen werden, verwenden wir Fallen, die mit spezifischen Lockstoffen (Pheromonen), wie oben beschrieben, ausgerüstet sind.

\section{Management-Empfehlungen zur Erkennung invasiver nicht hei-} mischer Arten sowie eruptiver forstlicher Schadfaktoren

- $\quad$ Ein Monitoring-System sollte mit einem geeigneten Design (Anzahl und Position der Fallen) basierend auf dem Risiko durch die Schadfaktoren etabliert werden

- Für die einzelnen Arten sollten die richtigen Methoden zur Anwendung kommen. Vor dem Beginn sollte man wissen, wonach man suchen will.

- Der Survey zur Erfassung potentieller invasiver nicht heimischer Arten oder eruptiver Schadfaktoren sollte früh genug, vor dem Schadensauftreten beginnen

- Bewusstseinsfördernde Kampagnen; die Öffentlichkeit sollte in die Erfassung von Ausbreitungsherden von Schädlingen oder Auftreten invasiver Arten eingebunden werden

- Experten sollten zu Rate gezogen werden, in vielen Fällen profitieren beide Seiten von einer derartigen Kooperation

- Feedback zu den angewendeten Methoden

- Unterstützung bei der Feldarbeit

- Regelmäßige Teilnahme an Trainingskursen, da häufig neue 
Schädlinge und Krankheiten auftauchen

- Nutzung des vorhandenen Informationssystems DanubeForestHealth (www.danubeforesthealth.eu) zur Identifikation der Schadfaktoren und Bericht über Schädlinge und Krankheiten

\section{Ausblick und Zusammenfassung}

Schädlinge und Krankheiten können schwere Folgen für flussbegleitende Wälder haben. Um diese zu verringern sollte ein System zur Früherkennung etabliert werden. Im Projekt REFOCuS wurde ein Informationssystem (DanubeForestHealth) erarbeitet. Im gegenständlichen Kapitel werden die Symptome und Erkennungsmerkmale von Schädlingen und Krankheiten von Gehölzen erläutert. Zum Erkennen von Insekten sind die besten Methoden die Überprüfung von Bäumen auf Symptome, die Verwendung von Fallen aber auch die Fernerkundung. Auch für Krankheiten ist die Analyse von Symptomen im Feld sehr wichtig, aber für die Identifikation vieler Arten ist ein Labor notwendig. Weitere Methoden sind Sporenfallen und das Sammeln von Krankheitsvektoren wie Insekten. Auf der Basis der beschriebenen Detektionsmethoden werden Empfehlungen für das Management gegeben.

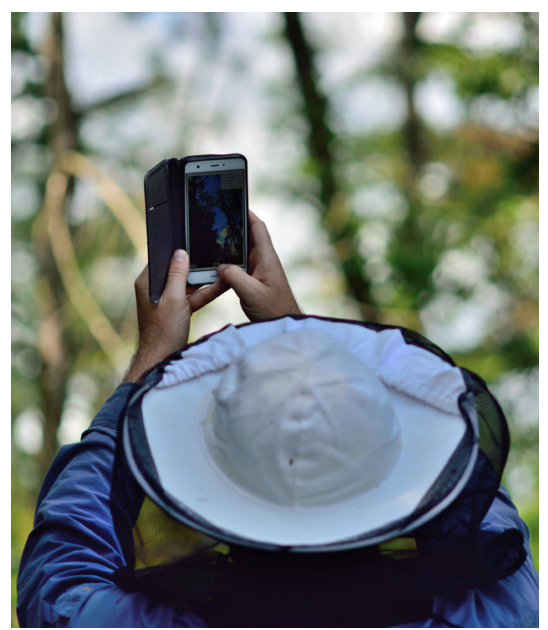

Abb. 3.3.1-4: Anwendung der Smartphone App Danubeforesthealth bei einer Feldbeobachtung. 


\subsubsection{Krankheiten der Pappel und Pappelhybriden unter besonderer Berücksichtigung von Management- Empfehlungen}

Milica Zlatković, Predrag Pap, Imola Tenorio-Baigorria, András Koltay, Nikica Ogris, Thomas Cech

\section{Krankheiten der Blätter}

\section{Blattrost}

Blattrost, verursacht durch Melampsora spp. ist die häufigste Krankheit der Pappeln, besonders in Plantagen und Forstgärten. Bei der Produktion der Pappeln stellt der Blattrost eines der Schlüsselprobleme dar. Das typische Krankheitssymptom ist ein feines, gelb-oranges „Pulver“ aus Sporen, das die Unterseite der Blätter bedeckt (Abb. 3.3.2-1, 3.3.22). Die Infektion erfolgt im Frühjahr, aber typische Symptome sind im Sommer am auffälligsten, wenn die Krankheit zu vorzeitigem Blattfall führt.

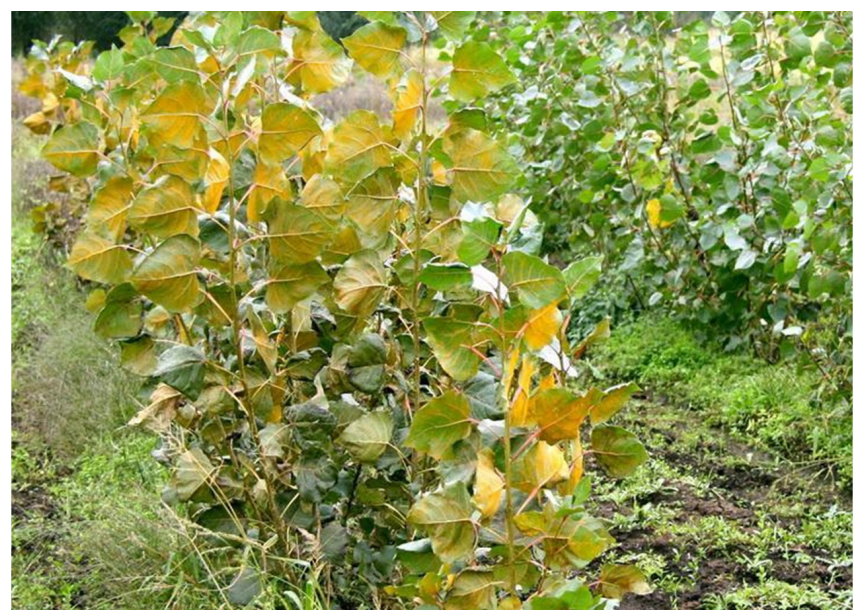

Abb. 3.3.2-1: Blattrost auf Blättern von Populus $\times$ canadensis.

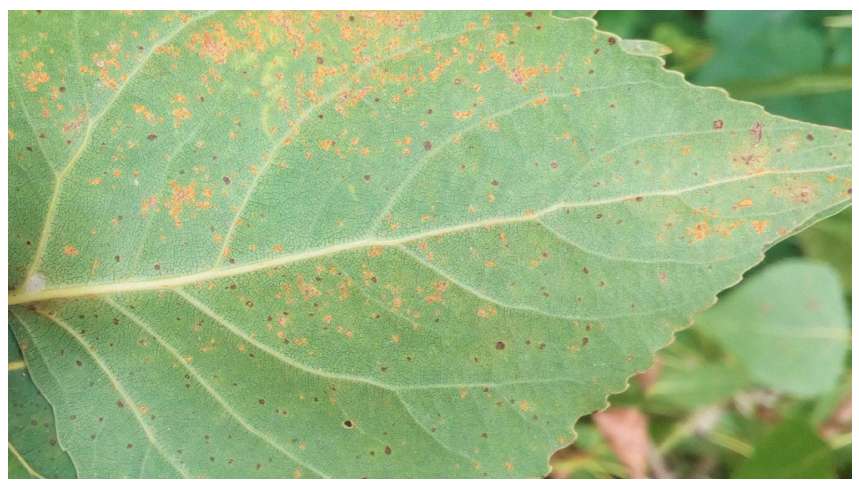

Abb. 3.3.2-2: Blattrost und Marssonina-Krankheit auf der Unterseite eines Blattes von Populus $\times$ canadensis. 


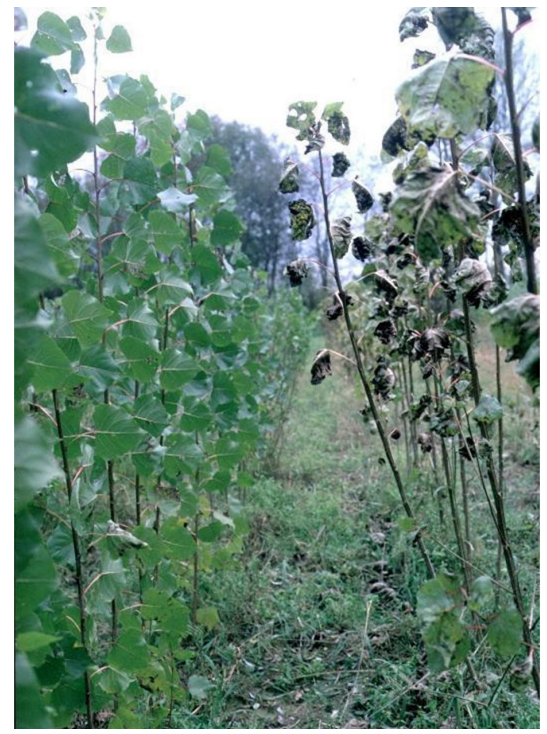

Abb. 3.3.2-3: Marssonina-Blattflecken verursacht durch Drepanopeziza brunnea: rechts stark infizierte Blätter eines empfindlichen Populus $\times$ canadensis-Klons ("I-214"); links resistenter Klon.

\section{Marssonina-Blattflecken}

Blattflecken, verursacht durch Drepanopeziza brunnea (Ellis \& Everh.) Rossman \& W.C. Allen treten vor allem in Pappel-Plantagen und Forstgärten auf. Typische Krankheitssymptome sind bräunliche Flecken auf den Blättern (Abb. 3.3.2-2, 3.3.2-3). Im fortgeschrittenen Stadium des Krankheitsverlaufes verfärben sich die Blätter zuerst gelb, dann bronzebraun und können auch vorzeitig abfallen. Populus $\times$ canadensis Klone sind besonders krankheitsempfindlich (Abb. 3.3.2-2, 3.3.2-3).

\section{1c. Ökologie und ökonomische Bedeutung von Blattkrankheiten}

Pilzarten, die Blattkrankheiten verursachen, sind gewöhnlich „primäre Parasiten “ und können daher gesunde Pflanzenteile befallen. Wenn sie nicht zeitgerecht bekämpft werden, können Blattkrankheiten insbesondere in intensiv bewirtschafteten Pappel-Plantagen das Wachstum der Pflanzen und damit die Holzproduktion beeinträchtigen. Schwere Infektionen können das Wachstumspotential durch eine Verringerung der Photosynthese-aktiven Blattfläche herabsetzen. Nach dem vorzeitigen Blattfall während der Vegetationszeit vorhandene Blattnarben stellen eine perfekte Eintrittspforte für sekundäre Pathogene dar. Wiederholte Infektionen und vorzeitiger Blattfall hoch empfindlicher Klone schwächen die Pflanzen und prädisponieren sie für andere biotische und abiotische Stressfaktoren wie Krankheiten am Stamm (z. B. Dothichiza populea), Insekten, Hitze- und Trockenstress. Diese anderen „Stressfaktoren“ führen oft zum Absterben der Bäume. Produktionsflächen in Forstgärten sind besonders empfindlich, da sie gewöhnlich dicht bepflanzt werden und die relative Luftfeuchtigkeit hoch ist: beides begünstigt die Krankheit. Blattkrankheiten repräsentieren einen der häufigsten „Feinde“ der Pappelkultur und sollten daher weder vom Pappelzüchter während der Selektion der Klone noch vom Pappelproduzenten während der Anlage und der Pflege von Pappel-Plantagen ignoriert werden.

\section{Empfehlungen zum Krankheitsmanagement}

- Die effektivste Methode Blattkrankheiten zu vermeiden ist die Auswahl resistenter oder zumindest toleranter Pappelklone.

- $\quad$ Rostpilze sind durch eine komplexe Ökologie gekennzeichnet und benötigen oft zwei verschiedene Wirtspflanzenarten um ihren Lebenszyklus zu durchlaufen. Die zweite Wirtsart (Sekundärwirt) ist für die jeweilige Rostpilzart spezifisch. Pappelproduzenten müssen über eine ausreichende Kenntnis der Sekundärwirte verfügen, um die Anlage von Pappel-Plantagen im Nahbereich dieser Wirtspflanzen zu vermeiden oder dieselben im Umfeld der Plantagen auszurotten.

- Sollten die oben angeführten Empfehlungen nicht durchführbar sein, können speziell in Forstgärten vorbeugend Fungizide (z. B. auf Kupfer- oder Carbamid-Basis) angewendet werden, doch müssen diese vor Infektionsbeginn eingesetzt werden.

- Pathogene an Blättern können auf abgefallenen Blättern in der 
Laubstreu überdauern und ihren Lebenszyklus vollenden. Deshalb ist das Entfernen des Fallaubes oder zumindest das Bedecken des Laubes mit Erde vor Beginn der nächsten Vegtationsperiode essentiell zur Bekämpfung der Krankheiten.

- Blattkrankheiten können auch durch Einhaltung eines geeigneten Pflanzenabstandes vermieden werden, wobei hier auch das Kurzhalten der Begleitvegetation notwendig ist, um die Luftfeuchtigkeit möglichst niedrig zu halten.

- $\quad$ Ein sorgfältiges Monitoring der Blattkrankheiten sollte Teil eines integrierten Managements von Pathogenen in Pappelplantagen sein. Es besteht nicht nur die Gefahr, dass neue aggressive Stämme bzw. Arten von Pathogenen importiert werden, sondern es können sich auch die bestehenden Populationen der Krankheitserreger ändern und langfristig die Wirtsresistenz überwinden.

- Blattkrankheiten kommen auch in natürlichen Pappelwäldern vor, wo die hohe Luftfeuchtigkeit die Krankheitsentwicklung begünstigt. Da die Krankheiten eher zwischen genetisch gleichen Wirtspflanzen übertragen werden, ist die Erhaltung einer genetischen Vielfalt das effektivste Mittel, diese Krankheiten in natürlichen Auwäldern zu vermeiden.

\section{Krankheiten an Ästen und Stämmen}

Pilze

\section{Dothichiza-Krankheit}

Die Dothichiza-Krankheit, verursacht durch Chondroplea populea (Sacc. \& Briard) Kleb. (syn. Dothichiza populea Sacc. \& Briard. ist eine der häufigsten und weit verbreitesten Krankheiten von Pappeln in Intensivkulturen. Diese Krankheit war die Ursache für das Scheitern der großflächigen Produktion bestimmter Pappelklone und -sorten trotz deren hohen Wuchsleistungen und anderen Qualitätsmerkmalen. Die Infektion erfolgt meist im Spätherbst oder Winter, wenn sich der Wirtsbaum in Winteruhe befindet, doch sind auch im Frühjahr Infektionen möglich. Ein besonderes Merkmal dieses Pathogens ist die lange Inkubationszeit von bis zu einem Jahr, bis die ersten Symptome erscheinen. Am anfälligsten sind gestresste Pappeln in Forstgärten oder jungen Plantagen, vor allem, wenn die Pflanzen auf zu sandhältigen Böden wachsen und an periodischem Wassermangel leiden.

Erste Symptome sind schwarze nekrotische Läsionen auf der Rinde (Abb. 3.3.2-4). Schreitet die Krankheit fort, so sinkt die Oberfläche der Läsion ein, am Rand bildet sich im Lauf der Zeit Wundkallus als „Versuch“ des Wirts das Wachstum der Läsion „abzustoppen“ und die Läsion entwickelt sich zum Canker. Darüberhinaus entwickeln sich in der Läsion schwarze Pilzfruchtkörper (Abb. 3.3.2-4), die in Reihen oder konzentrischen Kreisen um die ursprüngliche Infektionsstelle angeordnet sind.

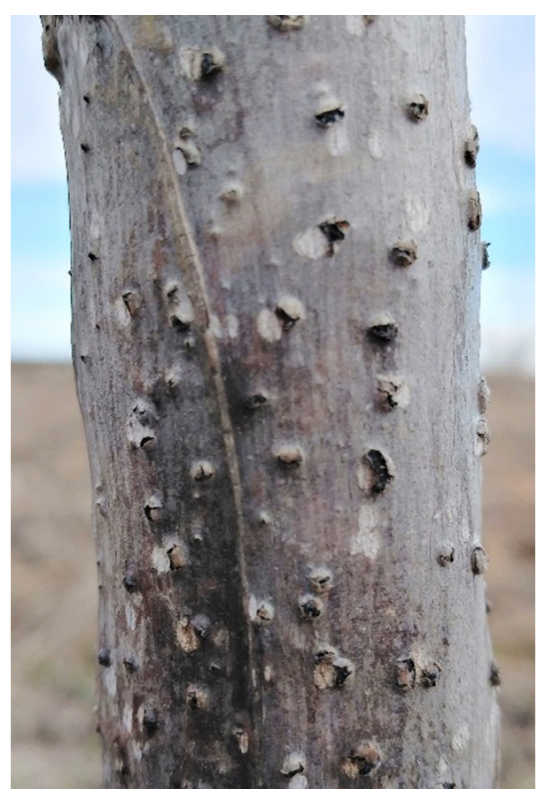

Abb. 3.3.2-4. Dothichiza-Läsion mit Fruchtkörpern (Pyknidien) in der Rinde eines jungen Populus $\times$ canadensis Baumes. 
Chondroplea populea infiziert über Wunden und natürliche Eintrittspforten, weshalb die Läsionen im Zentrum oft eine Blattnarbe oder Rindenverletzungen erkennen lassen. In schweren Fällen kann der Canker den Ast oder Stamm abschnüren. Pflanzen, die eine Infektion überleben, sind gewöhnlich anfällig für Windbruch oder sie weisen eine Wertminderung des Holzes auf.

Cytospora Canker

Cytospora-Läsionen, verursacht durch Cytospora spp. sind eine häufige Krankheitserscheinung in natürlichen Wäldern, Plantagen und Baumschulen. Diese Krankheitserreger rufen ähnlich wie C. populea eingesunkene Läsionen hervor. Allerdings sind die Fruchtkörper von Cytospora deutlich kleiner als bei Chondroplea. Sie erscheinen unregelmäßig verteilt und entlassen Sporen in orangen, gelblich-weissen oder rötlichen Massen, die zu einer Verfärbung der Rinde führen (Abb. 3.3.2-5, 3.3.2-6). Cytospora-Arten infizieren meist durch verschiedene abiotische oder biotische Stressfaktoren geschwächte Pflanzen. Sie finden sich an Bäumen aller Altersstufen, besonders auf Individuen, die schon deutliches Zurücksterben (meist infolge Befalls durch die Dothichiza-Krankheit) zeigen. Pappelstecklinge, die nicht angewurzelt sind, werden oft kurz nach der Pflanzung von Cytospora-Arten befallen (Abb.3.3.2-6).

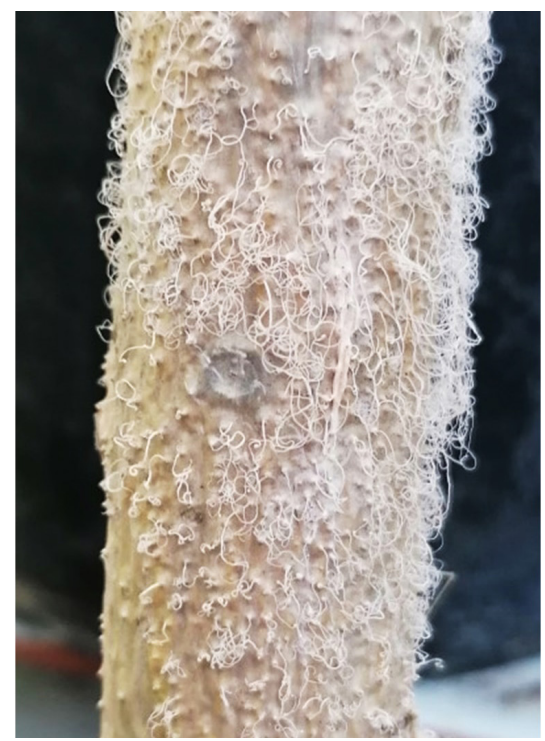

Abb. 3.3.2-6: Weißliche Sporenmassen von Cytospora sp. aus Fruchtkörpern (Pyknidien) an der Oberfläche von abgestorbenen Rindenteilen eines Populus $\times$ canadensis Wurzelstecklings.

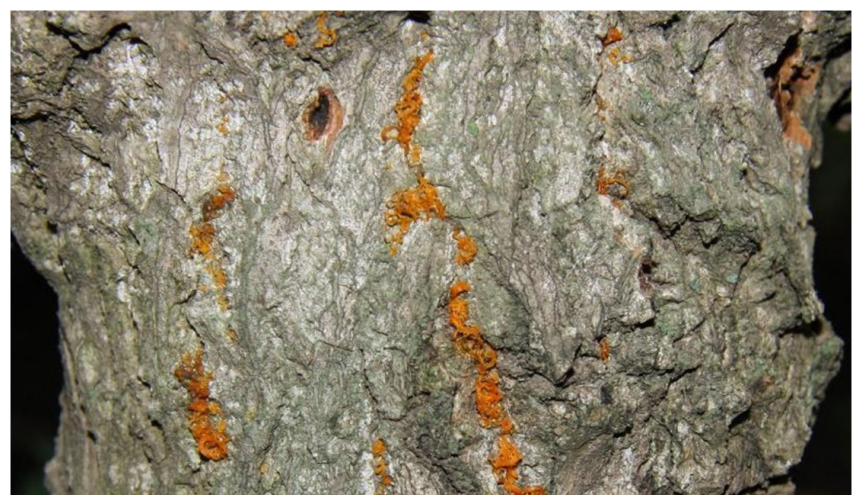

Abb. 3.3.2-5: Orange gefärbte Sporentropfen von Cytospora sp. treten aus Fruchtkörpern (Pyknidien) an der Oberfläche von abgestorbenen Rindenteilen einer Populus $\times$ canadensis auf.

\section{Bakterielle Krankheiten}

Lonsdalea-Canker

Läsionen (Canker), verursacht durch das Bakterium Lonsdalea populi stellen eine extrem gefährliche Krankheit von Populus $\times$ canadensis in Europa dar. Das Bakterium infiziert Pappeln in Baumschulen und jungen Pflanzungen. Typische Krankheitssymptome erscheinen im Sommer und im Herbst bei warmer und feuchter Witterung: Ast- und Stamm-Läsionen mit Rissen in der Rinde sowie reichlich klebrige und oft schaumige Exudate mit fauligem Geruch, die aus den Rissen aus- 
treten (Abb. 3.3.2-7 a, b). Bei Luftkontakt dunkeln die Exudate nach und verursachen eine Verfärbung der Rinde (Abb. 3.3.2-7 b). Darüberhinaus locken die Exudate verschiedene Insekten (auch Marienkäfer und Stinkwanzen) an, von denen man annimmt, dass sie als Vektoren der Krankheit fungieren. Manchmal fällt die infizierte Rinde von der mittlerweile eingesunkenen Läsion ab und faules Holz mit Gärgeruch und einer cremefarbenen Masse weißer Exudate tritt darunter in Erscheinung (Abb.3.3.2-7 c). Im fortgeschrittenen Stadium der Infektion können die Läsionen das Zurücksterben der Krone verursachen und die erkrankten Bäume sterben innerhalb weniger Wochen ab. Die Läsionen können mehrere Meter Länge erreichen und am Stamm an verschiedenen Abschnitten erscheinen. In seltenen Fällen reagiert der Baum mit massiver Kallusbildung rund um die Läsionen und diese können verheilen.

Allerdings ist das Holz für die Verwertung als Schnittholz oder für die Furniererzeugung wertlos. Bei Herbst- oder Winterstürmen kommt es meist zu Stammbrüchen (Abb. 3.3.2-7 d).
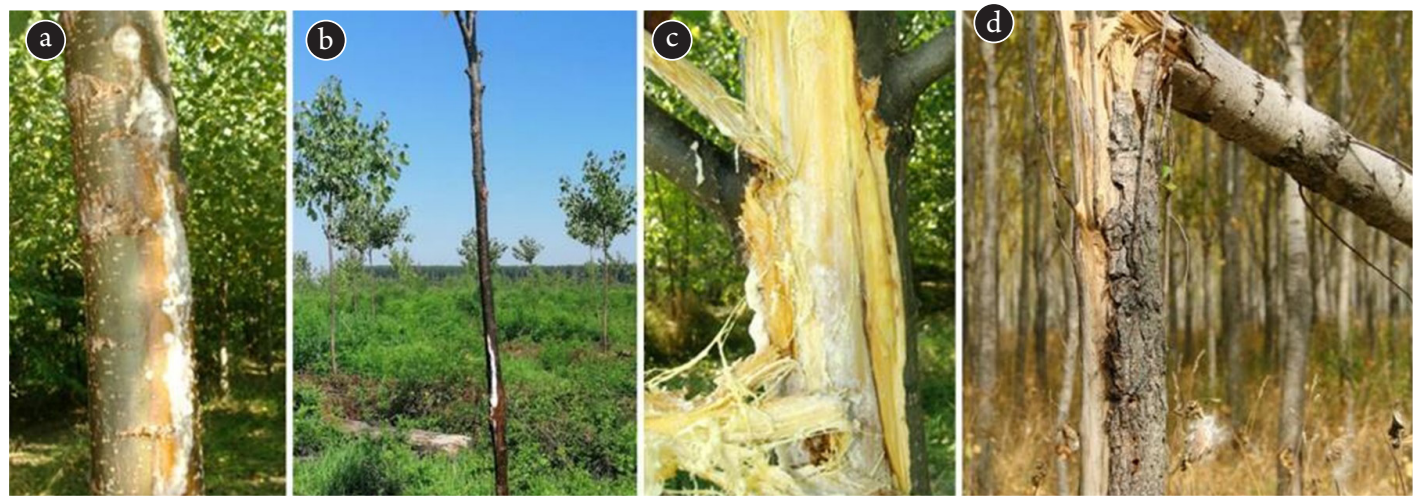

Abb. 3.3.2-7: Symptome der Bakterienkrankheit von Populus $\times$ canadensis, verursacht von Lonsdalea populi in Serbien und Ungarn. a. Weißer, schaumiger Baumsaft tritt aus Rindenrissen aus. b. Canker mit Exudaten und Rindenverfärbung. Dieser Baum war von Sciapteron tabaniformis vorgeschädigt. c. Die Rinde löst sich ab und gibt weiße, cremeartige Exudate und faules Holz mit Gärungsgeruch frei. d. Die Bildung der Exudate kommt im Herbst zum Stillstand, doch der Baum bricht durch Wind ab.

\section{Ökologie und wirtschaftliche Folgen von Ast- und}

\section{Stammkrankheiten}

Krankheiten des Stammes haben strukturelle Änderungen im Holz und daher signifikante Qualitätsverluste zur Folge. Pilze, die Äste und Stämme infizieren, sind üblicherweise "Wundparasiten" und "fakultative Parasiten” und dringen über Wunden oder natürliche Eintrittsstellen in den Baum ein bzw. infizieren ihn, wenn er unter Stress steht. Derartige Krankheitserreger können selbst von kleinen beabsichtigten oder nicht beabsichtigten Verletzungen, wie sie als Folge verschiedenster Praktiken bei der Baumpflege oder durch mangelhaftes Management zu erwarten sind, ausgelöst werden. Auch ein vorzeitiger Blattfall durch Blattkrankheiten, Schäden durch Insekten und extreme Klimaereignis- 
se (z. B. anhaltende Staunässe infolge exzessiver Niederschläge, aber auch Wassermangel nach Trockenzeiten sowie "Hitzewellen") und/ oder für die Pappelkultur ungeeignete Böden können Ast- und Stammkrankheiten auslösen. Das Zusammenwirken sowie die Sukzession von Krankheiten sind sowohl in natürlichen Pappelwäldern wie auch in intensiv bewirtschafteten Pappel-Plantagen häufig.

\section{Empfehlungen zum Krankheitsmanagement}

- Die Auswahl resistenter oder mindestens toleranter Klone wird gegenwärtig als bestes Mittel zur Kontrolle von Krankheiten durch Chondroplea und Lonsdalea angesehen.

- $\quad$ Ein erfolgreicher Managment-Ansatz um Ast- und Stammkrankheiten der Pappeln in den Griff zu bekommen, besteht auch darin, den alllgemeinen Gesundheitszustand und die Wüchsigkeit der Bäume durch verschiedene Kulturpraktiken zu fördern. Dazu gehören Düngemaßnahmen, Bewässerungsmaßnahmen (zur Vermeidung von Trockenstress speziell im Sommer) und die strikte Vermeidung jeglicher mechanischer Verletzungen.

- $\quad$ Äste mit Cankern bzw. nekrotischen Läsionen sollten entfernt werden, um ein Eindringen des Krankheitserregers in den Stamm zu verhindern. Derartige sanitäre Maßnahmen sollten unterhalb der Läsion im lebenden Teil erfolgen und Schnittwunden sollten mit Wundwachs versiegelt oder mit Fungiziden (Präparate auf Kupferbasis haben beispielsweise auch Schutzwirkungen gegen bakterielle Erreger) behandelt werden. Die Maßnahmen sollten während der Vegetationsruhe abgeschlossen werden und die Werkzeuge nach der Verwendung bei erkrankten Bäumen desinfiziert werden.

- Die Pflanzen sollten gegen schädliche Insekten sorgfältig geschützt werden, da diese die Pflanzen schwächen, Krankheiten verbreiten sowie Verletzungen verursachen, die Pathogenen als Eintrittspforten dienen können.

- $\quad$ Es ist ebenfalls notwendig, dass Pappelproduzenten Maßnahmen setzen, die Infektionen durch Blattkrankheiten zu reduzieren. Dazu gehören Unkrautbekämpfung und die Einhaltung eines optimalen Pflanzenabstandes.

- $\quad \mathrm{Zu}$ den guten Kulturpraktiken gehört auch die Pflanzung gegen Blattkrankheiten resistenter oder toleranter sowie optimal für das Umfeld geeigneter Klone.

- Baumschulen und Pflanzungen sollten nur an Standorten mit für die Pappelkultur geeigneten Böden etabliert werden, um eine Schwächung der Pflanzen zu verhindern.

- Stecklinge sollten nur von kräftigen und gesunden Pflanzen genommen werden. Der Zeitpunkt der Pflanzung sollte zur Reduktion von Stress in Perioden mit ausreichender Wasserversorgung und bei optimalen Temperaturen gewählt werden. 
- Pathogene, die Ast- und Stammkrankheiten verusachen, können auf Holz- und Rindenabfällen am Boden überleben, weshalb es besonders wichtig ist, dieses Material sorgfältig zu entfernen.

- Stark infizierte Baumindividuen (Stamm-Läsionen und/oder Bakterienfluss) sollten gefällt werden, bevor ökonomische Schäden eintreten und so schnell wie möglich vom Standort entfernt werden, um die Krankheitsausbreitung zu verringern.

- Das Verbringen von Bodenmaterial von Flächen mit Auftreten der Lonsdalea-Krankheit ist zu vermeiden. Dazu gehört auch Erdmaterial an Pflanzen und Werkzeugen.

Auswahl und Zucht krankheitsresistenter Sorten wird als die beste Lösung zur Kontrolle von Ast- und Zweigkrankheiten in natürlichen Pappelwäldern angesehen.

\section{Krankheiten des Wurzelsystems}

Bei Pappeln werden Krankheiten der Wurzeln meistens von Pilzen und pilzartigen Organismen verursacht. Armillaria spp., Phytophthora spp., Pythium spp. und Phytopythium spp. sind mit dem Zurücksterben und Wurzelfäule von Populus spp. in natürlichen Wäldern, Pflanzungen und Baumschulen assoziiert. Natürliche Pappelwälder treten in den alluvialen Tieflagen entlang der großen Flüsse auf, wo wasserreiche Böden und saisonale Überschwemmungen günstige Bedingungen für die Ausbreitung, Infektion und das Überdauern von pilzartigen Organismen wie Phytophthora spp. schaffen. Spezifische Management-Empfehlungen finden Sie im Kapitel "Maßnahmen gegen die Ausbreitung von Phytophthora in Fluss begleitenden Wäldern”.

\section{Schlussfolgerungen}

Intensivkulturen von Pappeln sind gegenüber Attacken von Krankheitserregern besonders empfindlich, da bevorzugt hoch produktive ("superior") Klone mit geringer genetischer Bandbreite großflächig angepflanzt werden. Deshalb sind Programme zur Verbesserung der Pappelkultur, die kontinuierlich auf die Auswahl neuer resistenter oder zumindest krankheitstoleranter, an lokale Klimabedingungen angepasste Klone mit einem optimalen Wachstumspotential ausgerichtet sind, eine weitverbreitete Management-Strategie. Darüberhinaus sollten umweltfreundliche biologische Bekämpfungsstrategien, wo immer diese möglich erscheinen, sowie Kulturpraktiken, die Angriffe von Pathogenen minimieren, zur Anwendung kommen. 


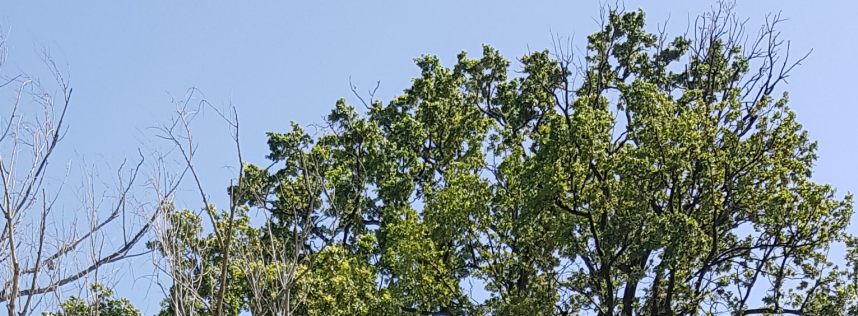
s.mes (2)

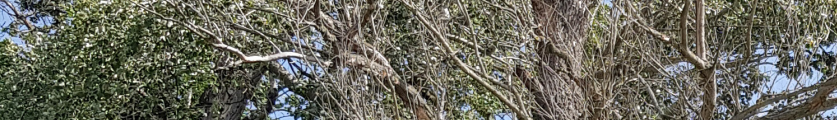

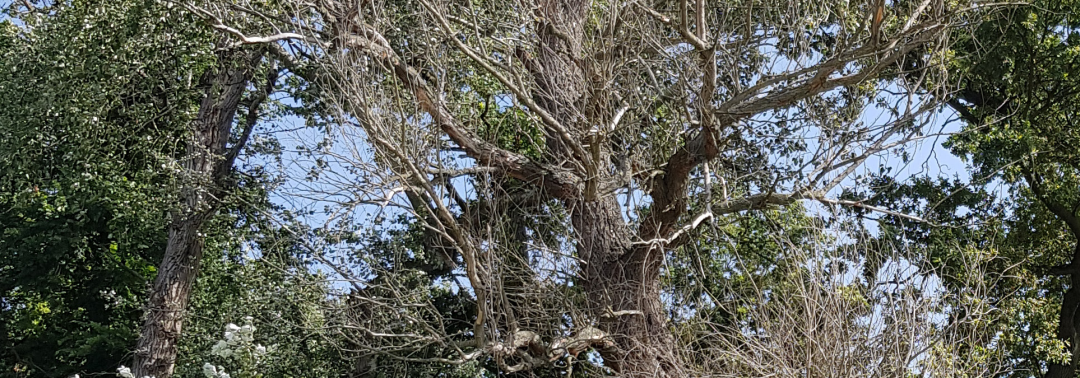

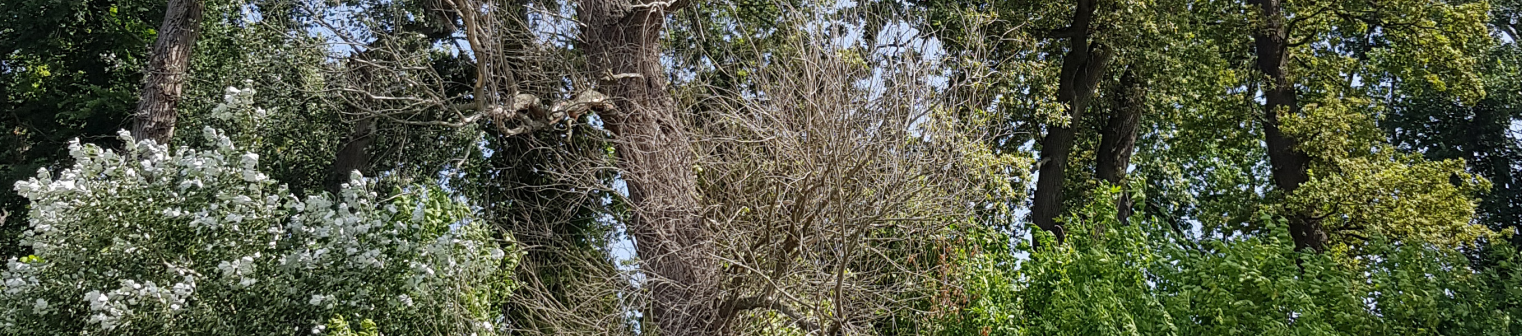
$\ln ^{2}$

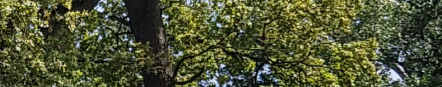

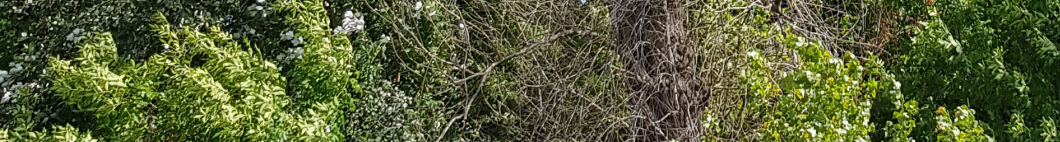

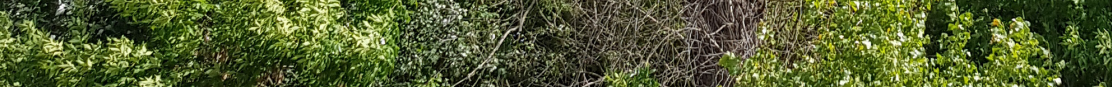

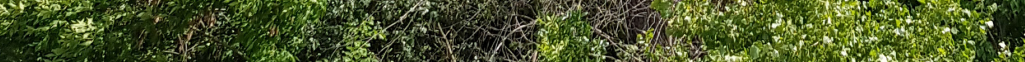

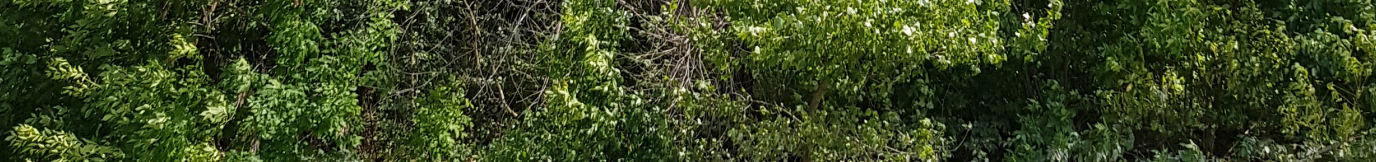
30.7 . 1.7.

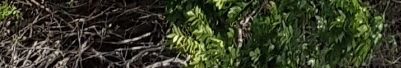




\subsubsection{Eichensterben - Beispiel für ein Krankheitsphänomen durch verschiedene interagierende kausale Faktoren}

Thomas L. Cech

\section{Einleitung}

Eichensterben ist ein Komplex von Krankheitssymptomen von Eichen (Quercus spp.), der in Europa und Nordamerika seit mehr als 100 Jahren bekannt ist. Das Syndrom umfasst Kronenverlichtung, das Zurücksterben von Ästen und schließlich das Absterben der Bäume infolge der Interaktion abiotischer und biotischer Faktoren (Abb. 3.3.3-1). Das bisher letzte überregionale Auftreten in Europa erfolgte von den späten 1970iger Jahren bis zum Beginn der 1990iger Jahre. Zu dieser Zeit war eine Hypothese, dass es ausschließlich von bestimmten Welkepilzen (Ophiostoma sp.) verursacht wird, was allerdings nicht bestätigt werden konnte. Die Entdeckung zahlreicher, mit dem Eichensterben assoziierter Schadfaktoren löste eine vielseitige Forschungstätigkeit aus, an der Wissenschaftlerinnen und Wissenschaftler aus einem breiten Spektrum von Fachdisziplinen beteiligt waren. Wenn auch die Bedeutung der einzelnen kausalen Faktoren und die Art und Weise ihres Zusammenwirkens nicht immer identifiziert werden konnten, wurde das Eichensterben doch im Allgemeinen als eine Kombination einer Anzahl von Kronen und Stamm schädigenden Insekten, Wurzelpathogenen (z. B. Phytophthora, Gymnopilus fusipes, Armillaria spp.), Spätfrostereignissen, Wassermangel infolge extremer Trockenperioden und menschlichen Eingriffen in den Wasserhaushalt verstanden. In zahlreichen europäischen Ländern führte die exzessive Nutzung von Grundwasserreserven durch die Landwirtschaft sowie Trockenlegungen von Feuchtstandorten und Fließgewässern und die „Bereinigung“ der Landschaft von kleinflächigen Waldbeständen (siehe Kapitel „Relevanz und Gefährung der Auwälder") zu Veränderungen des Bodenwasserhaushaltes. Ende der 1990iger Jahre nahmen die Schäden durch das Eichensterbens ab und es kam in vielen Eichenbeständen zur Erholung.

Vor einigen Jahren wurde ein schneller fortschreitendes Absterbensphänomen in Vereinigten Königreich als Akutes Eichensterben (AOD) beschrieben. Dieses ist durch Saftfluss am Stamm von Eichen (Abb. 3.3.3-2) und einen damit verbundenen Befall durch bestimmte Bakteriearten (Brenneria spp. und andere) sowie rindenbrütende Prachtkäfer (Agrilus spp.) charakterisiert.

\section{Erkennung und Nachweis}

Da die Symptome des Eichensterbens infolge unterschiedlicher und auch zeitlichen Änderungen unterliegender Faktoren deutlich variieren können, ist das Erkennen der beteiligten Faktoren eine erste Voraussetzung zur Abgrenzung des Absterbensphänomens von monokausalen Schädigungsursachen (wie z. B. Kronenverlichtungen als Folge

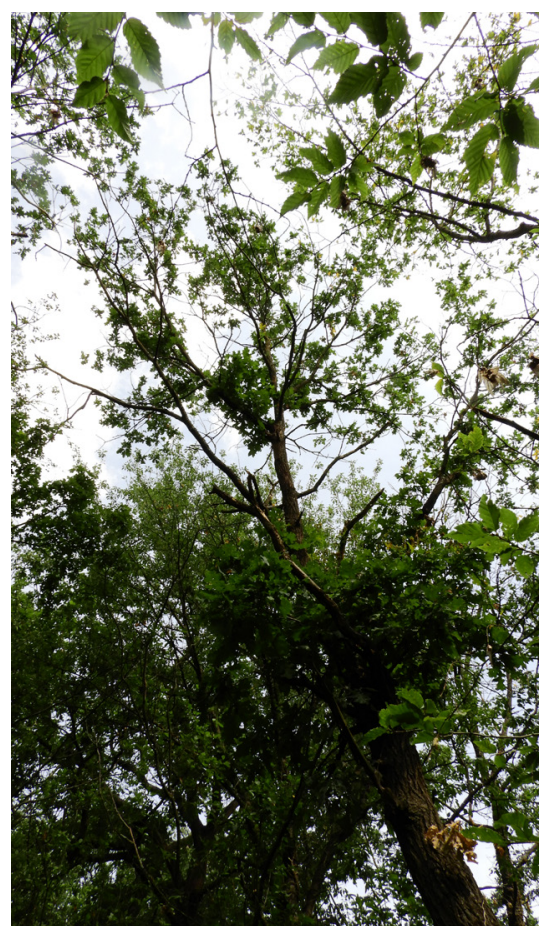

Abb. 3.3.3-1: Das Syndrom des Eichensterbens umfasst Kronenverlichtung und Zurücksterben von Ästen.

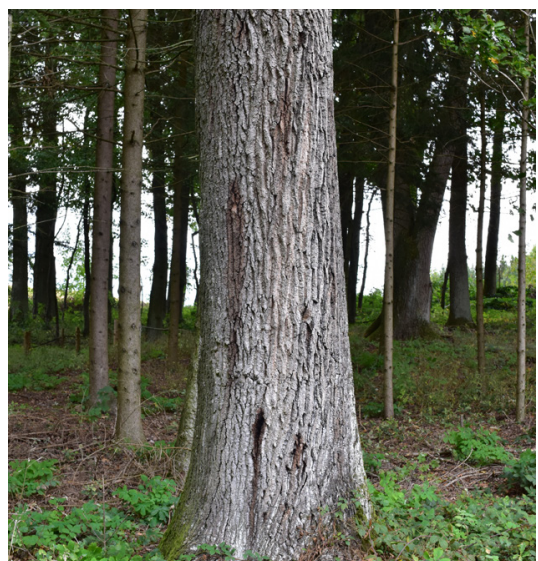

Abb. 3.3.3-2: Am Stamm „blutende“ Eichen. 
von laubfressenden Insekten). Gewöhnlich erfassen die Symptome die gesamte Krone: der Blattbesatz ist spärlich, die Blätter erreichen nicht die normale Größe und sie sind manchmal gelblich statt dunkelgrün. Oft geht das Längenwachstum der Triebe zurück (gestauchter Wuchs), typisch sind dichte Blattbüschel an den Zweigen. Diese Symptome werden meist von einem fortschreitenden Zurücksterben von Zweigen bzw. einzelnen Ästen begleitet oder abgelöst. Nach einigen Jahren zeigen die Bäume eine stark geschädigte Krone mit zahlreichen abgestorbenen Ästen. Die Bäume reagieren gewöhnlich mit der Bildung von Wasserreisern am Stamm. Allerdings können diese auch eine Reaktion des Baumes auf eine plötzliche Exposition gegenüber starker Besonnung nach Durchforstungsmaßnahmnen sein. Gelegentlich sterben die Bäume, doch wurden auch Erholungserscheinungen beobachtet. Kronensymptome (Blattgröße, Blattzahl, Farbe des Laubes) sowie der Verlichtungsgrad sollten erfasst und dokumentiert werden. Die Krone sollte sorgfältig auf laubschädigende (fressende- oder saugende) Insekten, Eichenmehltau und andere Blattkrankheiten untersucht werden. Dafür sind hochwertige Ferngläser erforderlich. Zusätzlich sollten Blätter, die vom Boden aus erreichbar sind, auf Vorhandensein von Insekten, Flecken oder Belägen von Pilzmyzelien überprüft und für Diagnosen im Labor gesammelt werden. Abgestorbene Äste sollten auf das Vorhandensein von mechanischen Schäden überprüft werden. Größere Wunden (durch Sturm, Blitzschlag, Schnittmaßnahmen oder Verbiss- bzw. Schälschäden) an der Basis eines abgestorbenen Astes oder unterhalb davon am Stamm sind keine Symptome des Eichensterbens, wenn solche Verletzungen offensichtlich das Absterben des Astes verursacht haben. Im Gegensatz dazu können Risse abiotischen Stress (am häufigsten durch Frost oder Trockenheit) anzeigen: in späteren Stadien können Risse mechanischen Schäden ähneln, weshalb verschiedene Entwicklungsstadien unterucht werden sollten. Bei der Untersuchung des Stammes sollte sorgfältig nach Rindenläsionen (Canker) und derem Ursprung gesucht werden. Canker können von verschiedenen Pilzarten verursascht werden (z. B. Biscogniauxia mediterranea, Fusicoccum quercus, Stereum rugosum, Pezicula cinnamomea). Weiters sind Stellen mit teerartigem Saftaustritt ein deutliches Indiz für Schädigungen lebender Rindengewebe. Diese sind meistens Wurzelhals-Läsionen oder isolierte Läsionen am Stamm durch den pilzähnlichen Organismus Phytophthora. Bei Eichen ist es am ehesten $P$. cinnamomi und nur selten andere Arten wie etwa $P$. ramorum, die in Nordamerika für das plötzliche Eichensterben (Sudden Oak Death, SOD) verantwortliche Art. Sind großflächige Nekrosen am Stamm vorhanden, die sich vom Wurzelhals ausgehend nach oben ausbreiten, jedoch keinerlei Spuren von minierenden Insekten, sollten Rindenproben zum Nachweis von Phytophthora genommen werden.

Teerartige Flecken, die mit relativ kleinen $(5-10 \mathrm{~cm})$ Rindenläsionen verbunden sind, die sich nicht zungenförmig vom Wurzelhals aus ausdehnen, hingegen Spuren von Fraßgängen von Prachtkäfern oder deren Larven (Zweipunktiger Eichenprachtkäfer, Agrilus biguttatus) 
erkennen lassen, deuten auf das vergleichsweise neue Phänomen des Aktuen Eichensterbens (Acute Oak Decline, AOD) hin. In solchen Fällen sollte das frische Exudat mit Hilfe von Wattestäbchen aufgesammelt werden und diese dann in Röhrchen an ein Diagnoselabor zur Bestimmung der Bakterienart gesendet werden. Treten Symptome in der gesamten Krone auf (dünne Krone, kleine Blätter), die Wurzelschäden anzeigen, jedoch keine Läsionen am Stamm, sollten Bodenproben genommen werden, um Phytophthora aus der Feinwurzelregion des Baumes zu ködern: mehrere Phytophthora-Arten können Feinwurzeln von Eichen infizieren und eine progressive Abnahme der Vitalität der Bäume verursachen.

Besonders zwei parasitische Pilzarten profitieren von Trockenstress in Eichenbeständen. Hallimasch-Arten (Armillaria spp.), die viele verschiedene Gehölzarten angreifen können, sind am Vorhandensein wurzelähnlicher Myzelstränge (Rhizomorphen), weißlicher Myzellappen unter der Rinde sowie charakteristischer Fruchtkörper (Herbst) leicht zu erkennen. Schäden durch Hallimasch-Befall nehmen üblicherweise nach Trockenstress oder anderen, sogar biotischen Stresseinwirkungen (z. B. Hymenoscyphus-Eschentriebsterben) zu. Im typischen Fall zerstört der Pilz relativ schnell das gesamte Wurzelsystem. Der Spindelige Rübling (Gymnopus fusipes) greift Grobwurzeln an. Er bildet spindelförmige Fruchtkörper ab Mitte des Sommers und verursacht eine charakteristische orange Verfärbung des Holzkörpers infizierter Wurzeln. Dieser Krankheitserreger hat in den vergangenen Jahren als Folge aussergewöhnlich trockener und heißer Sommerwitterung zunehmend an Bedeutung gewonnen. Anders als beim Hallimasch kann die Zerstörung des Wurzelsystems durch den Spindeligen Rübling allerdings viele Jahre dauern.

Nach Erfassung und Dokumentation der am Baum bzw. am Standort vorhandenen Schädlinge und Krankheiten sollten Klimadaten der vergangenen 10 bis 20 Jahre von der nächstgelegenen Wetterstation erhoben und auf extreme Situationen wie Trockenheit, Hitze- oder Frostperioden überprüft werden.

\section{Managementstrategien}

Wenn das Auftreten einer komplexen Schädigung an einem Eichenstandort evident ist, sollten die geplanten Strategien auf den als wesentlich und entscheidend erachteten Schadensfaktoren aufbauen. Basierend auf der Annahme, dass jedes Eichensterbensphänomen grundsätzlich als Stressfolge zu verstehen ist, sollte jede Maßnahme, die zur Stärkung der Eichen beitragen kann, in Erwägung gezogen werden. Selbstverständlich sollten jedwede Maßnahmen, die Trockenlegungen oder Grundwasserabsenkungen zur Folge haben, strikt vermieden werden.

Standorte mit zunehmendem Einfluss durch Witterungsextreme erfordern Baumindividuen, die imstande sind, diesen Extremsituationen 
$\mathrm{zu}$ widerstehen. Dies kann durch waldbauliche Maßnahmen wie etwa eine zeitgerechte Durchforstung, den Umbau von Reinbeständen zu Mischbeständen, aber auch durch Schutzmaßnahmen gegen Wildschäden und Schäden durch Weidevieh sowie eine Minimierung von Schäden durch Verletzungen erzielt werden. In Mischbeständen ist die Anzahl jeder Baumart viel geringer als in Reinbeständen und die meist baumartenspezifischen Schädlinge und Pathogene sind beim Aufbau von bedrohlichen Populationen weniger effektiv. Eichenbestände sollten mit passendem, an lokale Gegebenheiten adaptiertem Saatgut regeneriert werden, wobei auch die fortschreitende Klimänderung berücksichtigt werden sollte. Nicht angepasste Eichen können durch gefährliche Krankheitserreger existentiell bedroht sein; das zeigt sich gegenwärtig in Österreich und der Tschechischen Republik beim Absterben von Roteichen (Quercus rubra), an dem der Spindelige Rübling entscheidend beteiligt ist: Roteichen sind besonders anfällig für Gymnopus fusipes-Wurzelfäule, wenn die Baumart in basischen Böden wächst und unter Trockenstress zu leiden hat (Abb.3.3.3-3).

\section{Ausblick und Zusammenfassung}

Eichensterben ist ein komplexes Gefüge von Störungen, die durch die Interaktion abiotischer und biotischer Stressfaktoren verursacht werden. Zur Erkennung und Interpretation des Krankheitskomplexes sind sowohl eine sorgfältige Erfassung aller beteiligten Faktoren wie eine Analyse der Klimasituation des betroffenen Bestandes erforderlich. Abgesehen von spezifischen Maßnahmen gegen einzelne Schädlinge und Krankheitserreger kann das Eichensterben nur mittels waldbaulicher und waldhygienischer Maßnahmen, die auf eine Stärkung der Widerstandfähigkeit der Bäume ausgerichtet sind, begrenzt oder abgeschwächt werden. Auf Landschaftebene sollte der natürliche Wasserhaushalt der flussbegleitenden Bestände wiederhergestellt und dann erhalten werden.

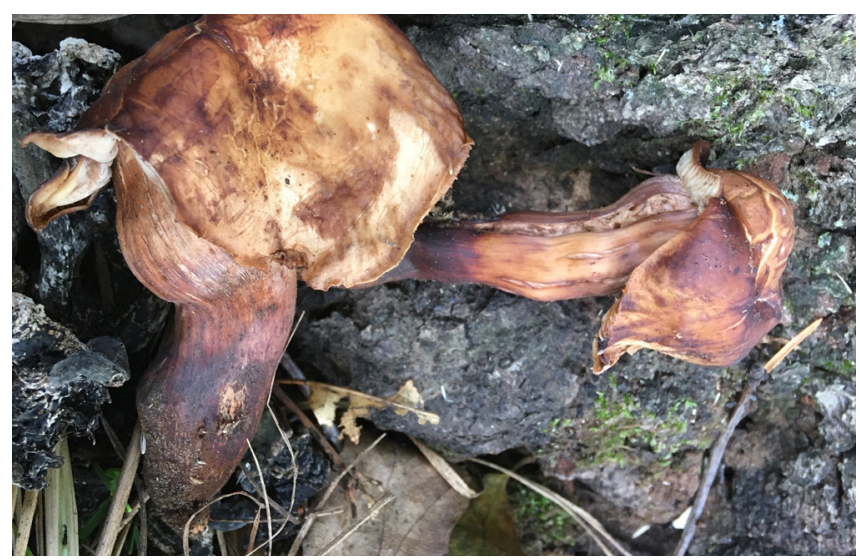

Abb. 3.3.3-3: Gymnopus fusipes - Wurzelfäule bei Quercus rubra. 


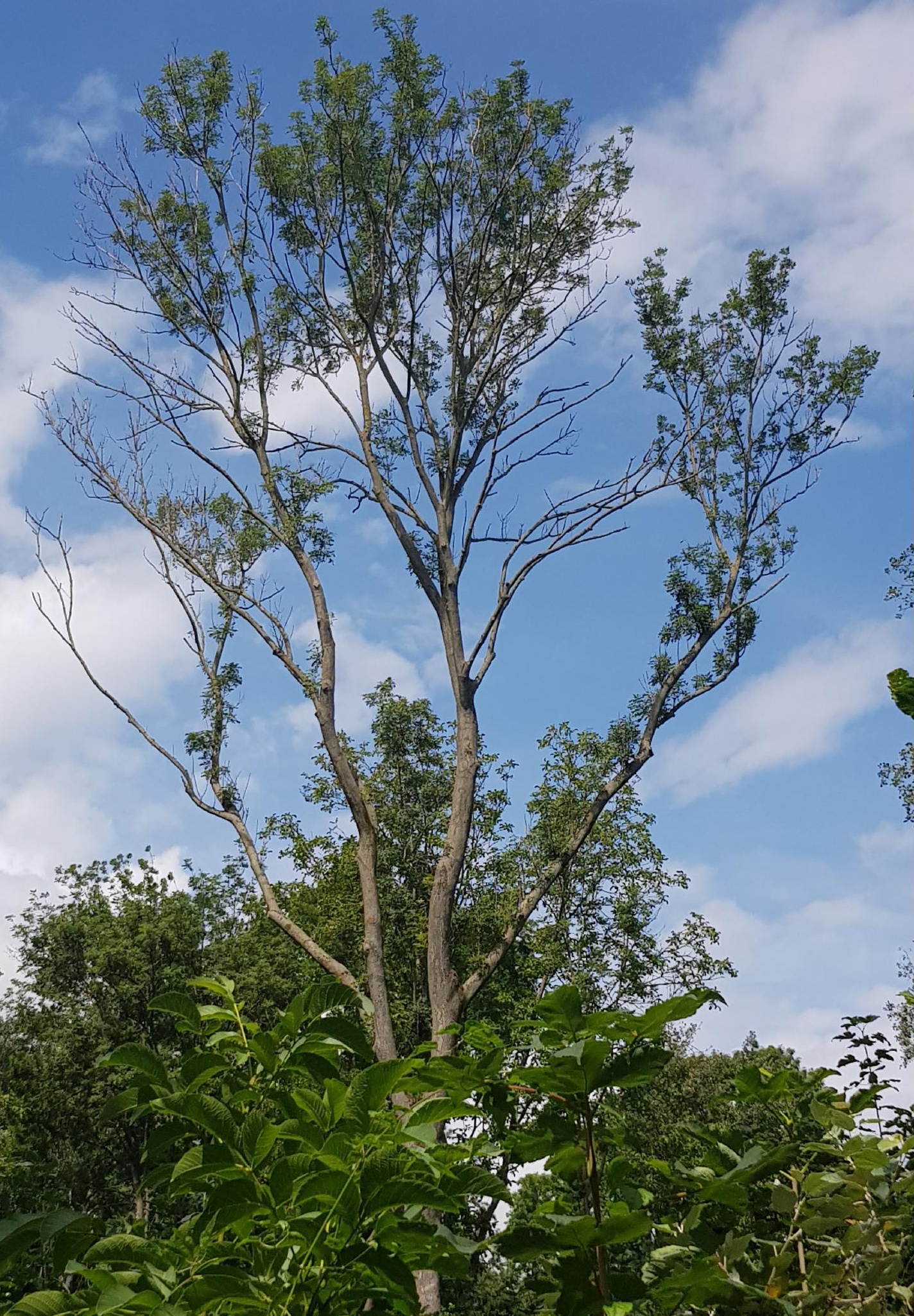




\subsubsection{Eschen-Triebsterben - eine schwerwiegende Bedrohung der Biodiversität in Auwäldern}

Thomas L. Cech, Katharina Schwanda

\section{Einleitung}

Das Eschen-Triebsterben ist eine schwerwiegende Krankheit mehrerer Eschenarten (Fraxinus spp., Abb. 3.3.4-1). Ursache ist der Pilz Hymenoscyphus fraxineus. Das Pathogen erfasste Eschen in Europa erstmals in den frühen 1990iger Jahren. Es breitete sich von den Baltischen Staaten und Polen aus; in der ersten Dekade der 2000er Jahre erreichte die Krankheit Mitteleuropa, zeigte epidemischen Charakter und repräsentiert jetzt eines der bedrohlichsten Waldschutz-Probleme Europas. Die Krankheit erfasst alle Altersklassen von Eschen. Die Schäden sind bei jungen Bäumen schwerwiegender als bei älteren, wo die Krankheit gewöhnlich chronisch verläuft. Allerdings fallen selbst alte Bäume der Krankheit zum Opfer, bedingt durch wiederholte Infektionen und sekundäre Krankheitserreger. Die Pilzart ist an der in Europa am weitesten verbreiteten Eschenart, der Europäischen Esche ( $F$. excelsior) sowie an der Schmalblättrigen Esche (F. angustifolia) hoch pathogen. In Ostasien, der Herkunftsregion der Pilzart, verursacht die Art nur geringe Schäden an den dort heimischen Eschenarten. Der Modus der Einwanderung nach Europa ist noch nicht vollständig geklärt. Am wahrscheinlichsten sind der Handel sowie die Verbringung von Pflanzen und Pflanzenmaterial für die Einschleppung des Krankheitserregers in Europa verantwortlich. Eschen haben eine enorme ökonomische wie auch ökologische Bedeutung. Das Holz hat für die Erzeugung von Möbeln, Funieren, Bodenbelägen, Verbundholz, Werkzeug-Griffen und Sportgeräten einen hohen Wert. Während Trockenperioden können die Blätter Futter für Vieh in ländlichen Gebieten lie-

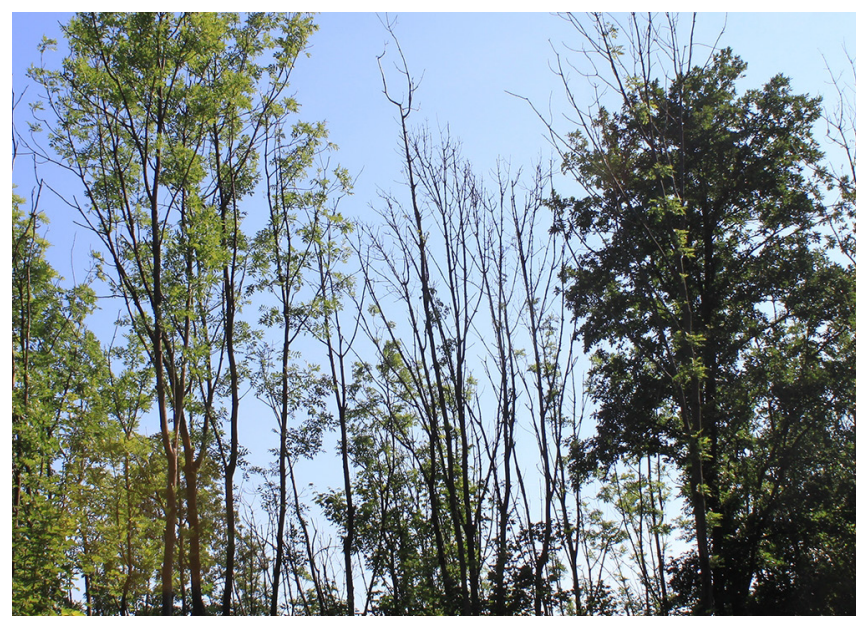

Abb. 3.3.4-1: Eschen-Triebsterben ist eine schwerwiegende Krankheit mehrerer Eschenarten, verursacht durch die Pilzart Hymenoscyphus fraxineus. 
fern. Weiters enthält die Rinde Substanzen mit medizinisch relevantem Potential (z. B. Eigenschaften gegen Malaria). Der ökologische Wert ist enorm: Eschen sind Habitate für eine große Zahl von Insekten, Pilzen, Flechten und Moosen, wovon einige wovon einige nur an der Esche vorkommen.

Aus diesem Grund ist zu erwarten, dass das Eschen-Triebsterben eine massive Bedrohung der Biodiversität speziell in Fluss begleitenden Wäldern, die bereits durch den Verlust von Ulmen, Erlen und Eichen als Folge der Holländischen Ulmenwelke, der Phytophthora-Krankheit der Erle (Phytophthora alni) und anderer Phytophthora-Arten verarmt sind, darstellt. Der Verlust eines hohen Anteils an Eschen wird vermutlich eine Kaskade von ökologischen Auswirkungen auf die Ökosystemleistungen sowie die Biodiversität auslösen. Darüber hinaus würde der exzessive Verlust der Eschen speziell in Fluss begleitenden Wäldern Lücken schaffen, die von invasiven Arten krautiger Pflanzen aber auch Baumarten wie Acer negundo, Ailanthus altissima, oder Juglans nigra aufgefüllt werden können.

\section{Infektion und Krankheitsentwicklung}

Hymenoscyphus fraxineus infiziert primär grüne Blätter von Eschen mit luftbürtigen Sporen, die in kleinen Fruchtkörpern auf Blattresten in der Laubstreu gebildet werden (Abb. 3.3.4-2). Erste Symptome sind unspezifische braune Flecken auf den Blattfiedern. Nach der Infektion wächst das Pilzmyzel in die Blattspindel, danach über den Blattstiel in Triebe und schließlich in verholzte Teile der Esche. Im Holz verursacht die Infektion eine grauliche bis bräunliche Verfärbung. In der Folge kommt es an den Trieben zur Entwicklung ausgedehnter Rindenläsionen und durch Abschnürung zum Zurücksterben. Die infizierten Blätter fallen im Herbst ab und schwarze Flächen (Stromata) erscheinen vorwiegend auf den Blattspindeln und Blattstielen aber auch auf Adern der Blattfiedern. Im folgenden Frühling und Sommer wachsen aus dem Stroma kleine weiße, etwa 2-7 mm große Fruchtkörper. Aus diesen werden Sporen, abhängig von lokalen Klimabedingungen, hauptsächlich vom späten Juni bis September entlassen, und der Krankheitszyklus des Eschen-Triebsterbens beginnt von Neuem.

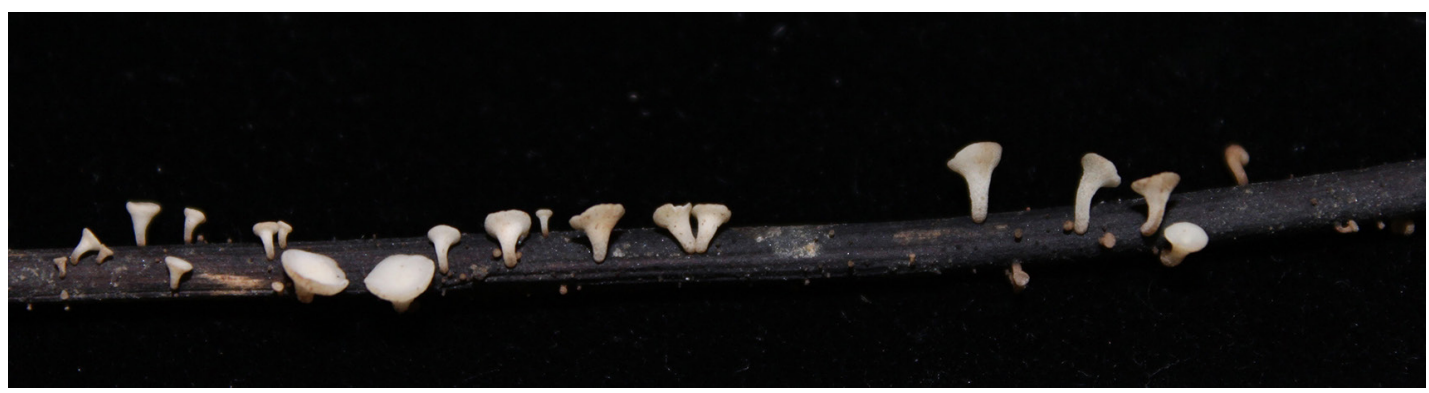

Abb. 3.3.4-2: Fruchtkörper von Hymenoscyphus fraxineus auf Blattresten in der Laubstreu. 
Die Bildung von Fruchtkörpern und Sporen erfordert Feuchtigkeit. Auf feuchten Böden erscheinen die weißen Scheibchen in kurzer Zeit und produzieren infektiöse Sporen; wenn die Fruchtkörper austrocknen schrumpfen sie ein. Aus diesem Grund erreicht die Sporenproduktion ihr Maximum an Standorten mit kontinuierlich hoher Luftfeuchtigkeit über dem Erdboden. Das schwarze Pilzstroma ist außerordentlich fruchtbar: eine einzelne Blattspindel kann während der gesamten Vegetationsperiode Fruchtkörper entwickeln und das selbst über mehrere Jahre hinweg.

Bedingt durch die mit einigen Monaten sehr lange Dauer der Sporenproduktion können nur ausgedehnte Trockenperioden eine signifikante Reduktion der Inokulum-Produktion bewirken. Darüber hinaus können die Sporen von $H$. fraxineus den Baum auch an der Stammbasis und am Wurzelhals über Korkzellen infizieren und dort Rindenläsionen sowie Holzverfärbung verursachen. Dies erleichtert den Befall durch Folgepilze (meistens Armillaria spp.) die das Absterben der Wirtsbäume beschleunigen.

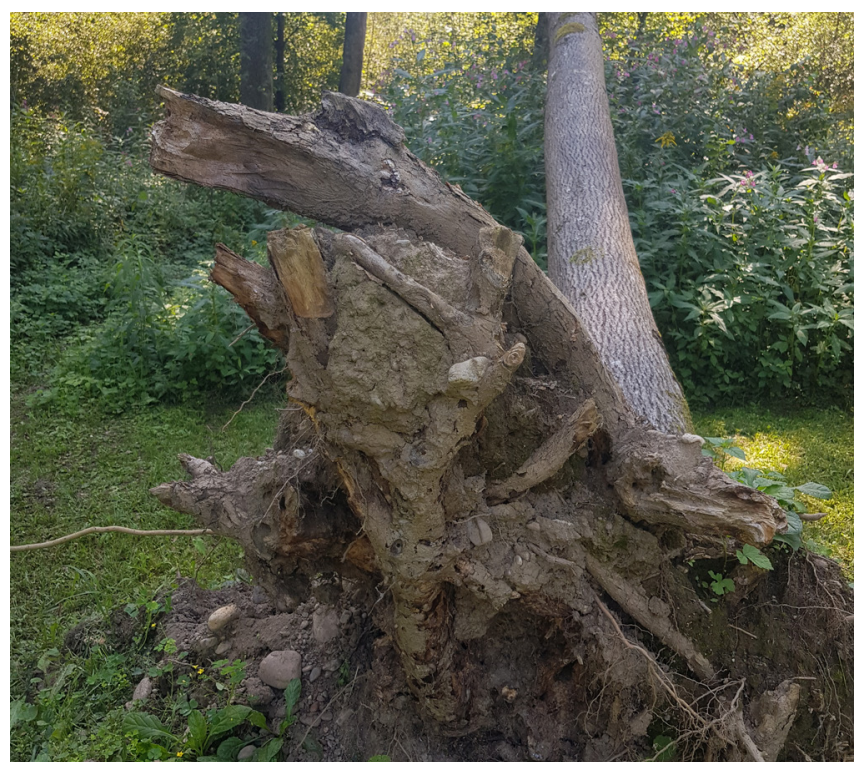

Abb. 3.3.4-3: Der Befall von Eschen durch sekundäre Besiedler, vorwiegend Armillaria spp., beschleunigt den Krankheitsverlauf und das Absterben der Wirtsbäume. Als Folge der Ausbreitung von Fäule im Wurzelraum und am Stamm wurden in mehreren Ländern zunehmend Stammbrüche und Windwürfe beobachtet.

Als Folge der Infektion durch Wurzelfäuleerreger wurden in mehreren Ländern zunehmend Stammbrüche sowie Windwürfe beobachtet (Abb. 3.3.4-3). Dadurch wird die Baumstablität stark reduziert und die Fällung zahlloser Bäume entlang von Straßen und Wanderwegen als Sicherheitsmaßnahme notwendig. 


\section{Managementstrategien}

Flussbegleitende Wälder bieten dem Krankheitserreger günstige Voraussetzungen für die Ausbreitung. Daher verursacht das Eschen-Triebsterben gerade in diesen Wäldern die größten Verluste an Eschen. Im Nahbereich großer Wasserflächen ist die Luftfeuchtigkeit hoch, was zusätzlich durch einen dichten Unterwuchs, der die Durchlüftung behindert, noch verstärkt wird. Andererseits kann ein strukturierter und dichter Unterwuchs die ausgeschleuderten Sporen daran hindern, die Blätter in der Krone zu erreichen. Auch Überschwemmungen können einen begrenzenden Effekt auf das Infektionspotentiasl haben; Schlammablagerungen können die Blattspindeln der Eschen bedecken und den Sporenausstoß verhindern. Dieses Phänomen wurde auf österreichischen Monitoringflächen entlang von Flüssen beobachtet. Allerdings ist zu erwarten, dass in den im Allgemeinen an Eschen reichen Auwäldern derartige Effekte von Überschwemmungen angesichts der hohen Dichte infizierter Bäume, die große Mengen Inokulum produzieren, aufgehoben werden.

Gegenwärtig gibt es zwei verschiedene Ansätze zur Bekämpfung des Eschen-Triebsterbens:

- Förderung der genetisch vererbten Resistenz oder Toleranz einer geringen Zahl von Eschen gegen $H$. fraxineus.

- Waldhygienische und waldbauliche Strategien.

\section{Förderung natürlicher Resistenz}

Das Eschen-Triebsterben ist ein nahezu ubiquitäres Phänomen in den Waldbeständen Mitteleuropas; Bestände mit einem hohen Anteil betroffener Bäume sind nicht selten, speziell in Fluss begleitenden Wäldern mit einem hohen Anteil an Reinbeständen. Allerdings fallen selbst in stark durchseuchten Beständen Baumindividuen auf, die keine oder nur schwache Symptome zeigen. Das wurde als vererbte Resistenz oder Toleranz bestätigt und in einigen Ländern untersucht. Züchtungsprogramme zur Produktion von Pflanzgut, das geeignet ist, dem EschenTriebsterben zu widerstehen, sind in Entwicklung. Zusätzlich zu dieser Option könnte auch die Förderung von Individuen mit vermutlicher Resistenz in Eschenbeständen zu einem Anstieg der Resistenz in den Eschen-Populationen führen. Das erfordert die selektive Erhaltung von Individuen, die keine oder nur geringe Symptome aufweisen sowie Maßnahmen zur Unterstützung der Regeneration dieser Bäume. In diesem Sinn werden das Einzäunen von Flächen um symptomlose Eschen zur Abwehr von Wildschäden sowie das Freihalten der Flächen von konkurrierenden Baumarten in Waldbeständen, die vom EschenTriebsterben betroffen sind, empfohlen. 
Hygienische und waldbauliche Strategien zur Begrenzung der Folgen des Eschen-Triebsterbens in Fluss begleitenden Wäldern

Die Krankheitsintensität in Eschenbeständen steht mit der Bestandesdichte und dem Alter des Bestandes in Beziehung, d.h. die Häufigkeit neuer Infektionen ist in dichteren und jüngeren Beständen höher. Umgekehrt wird eine höhere Beimischung anderer Baumarten die Wahrscheinlichkeit neuer Infektionen reduzieren. Daher sollte der Prozess der natürlichen Selektion prinzipiell gesichert werden und die Entwicklung von Mischbeständen mit niedrigem bis moderatem Eschenanteil sollte mit Hilfe geeigneter anderer Baumarten unterstützt werden. Weiters bieten offene Bestände schlechtere Infektionsbedingungen, da sie trockener und gewöhnlich wärmer als geschlossene und weniger durchlüftete Bestände sind. Allerdings sollten unter Berücksichtigung der Verbreitung der Sporen durch Wind, hygienische Maßnahmen, die auf eine Reduktion des Infektionspotentiales des EschenTriebsterbens am Standort ausgerichtet sind, Teil eines regionalen Konzeptes sein, da die Sporen von Nachbarbeständen aus, in denen keine Maßnahmen erfolgen, bis zu mehreren 100 Metern weit heran geweht werden können. Einige Studien erbrachten den Nachweis des Einflusses der Baumartenzusammensetzung auf die Krankheitsintensität. Das könnte durch eine erhöhte Dekompostierung der infizierten Blattspindeln in bestimmten Typen von Laubstreu erklärt werden. Beispielsweise beschleunigte Laubstreu von Linden (Tilia spp.) den biologischen Abbau infektiöser Eschen-Blattstiele signifikant. Einer Studie in der Tschechischen Republik von 2013 zufolge war die Intensität des Eschen-Triebsterbens mit dem Anteil an den Eschen beigemischten Nadelhölzern (hauptsächlich Abies und Pinus) negativ korreliert.

\section{Strategien in Bezug auf sekundäre Schädlinge und Pathogene}

Während des vergangenen Jahrzehntes wurden sekundäre Pathogene als Besiedler von Eschen, die von $H$. fraxineus infiziert waren, immer häufiger. Dies betrifft in erster Linie Wurzelfäule-Erreger wie z. B. Hallimasch (Armillaria spp.). Hallimasch-Arten werden durch verschiedene Stress-Typen, denen die Wirtsbäume ausgesetzt sind, am häufigsten aber durch Trockenstress begünstigt. Eschen, die viele Jahre lang vom Triebsterben betroffen sind und speziell solche, die bereits basale Stamm-Läsionen aufweisen, sind dadurch geschwächt und werden zunehmend vom Hallimasch und anderen Stamm- bzw. Wurzelkrankheiten erfasst. Dieses Phänomen wurde während der vergangenen Jahre in einigen Ländern nahezu ubiquitär; Eschen-Ökosysteme in Fluss begleitenden Wälder waren die ersten, die diese fatalen Prozesse zeigten (z. B. entlang der Donau in Österreich). Wo Eschenwälder multiple Ökosystemleistungen erbringen, ist die Sicherheit bei der Arbeit sowie bei der Erholung im Wald insbesondere entlang von Forststraßen und Wanderwegen von großer Bedeutung. Um diesen Risiken effizienter entgegen zu treten, werden Diagnosemethoden zur Beurteilung der Baumstabilität erarbeitet. 


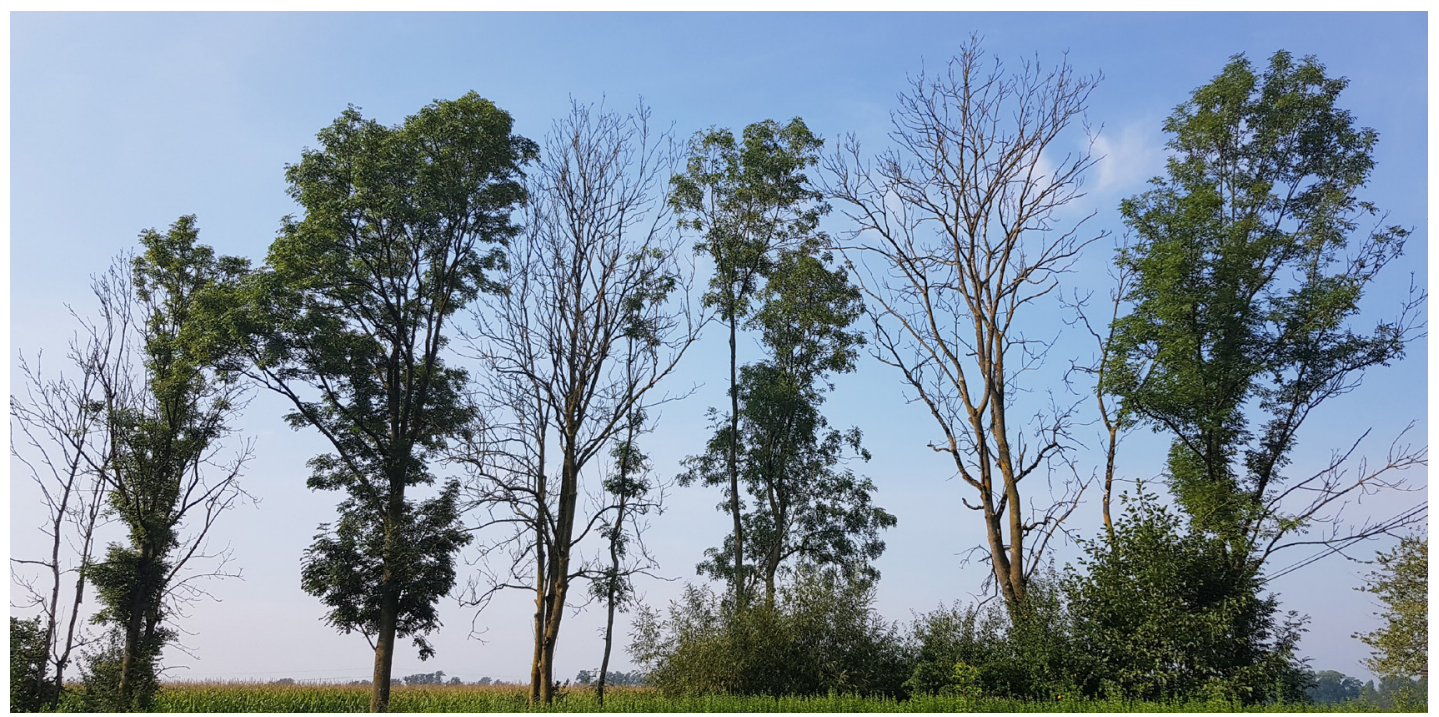

Abb. 3.3.4-4: Verschiedene Stadien des Eschen-Triebsterbens in einer Gruppe von Eschen in der Steiermark.

Unter den Insekten ist der Eschenbastkäfer (Hylesinus fraxini) der wahrscheinlichste Nutznießer, doch hat sich diese Art bisher nicht $\mathrm{zu}$ einem bedeutenderen sekundären Faktor entwickelt, dem auch Eschen ohne Triebsterben zum Opfer fallen. Generell ist die Erfassung von Symptomen am Baum ein wichtiges Instrument zur Entscheidung über mögliche Maßnahmen.

\section{Ausblick und Zusammenfassung}

Der Ersatz von stark vom Triebsterben betroffenen Eschen durch verschiedene andere Laubgehölze wie etwa Prunus avium, Quercus spp. oder Juglans regia und die Erhaltung eines insgesamt niedrigen Anteils von Eschen ist als die beste Chance, das Risiko von Totalverlusten der Esche in Fluss begleitenden Wäldern zu vermindern, anzusehen. $\mathrm{Zu}$ sätzlich ist die Förderung der natürlichen Resistenz durch Auswahl und Schutz krankheitsfreier Baumindividuen eine Option zur natürlichen Anpassung an den neuen Selektionsfaktor. Programme zur Züchtung und Vermehrung resistenter Bäume können ebenfalls angepasstes Pflanzenmaterial für die kommenden Jahre bereitstellen. In Wäldern, die der Habitat-Konservierung dienen, sollte die natürliche Sukzession ermöglicht werden. Da Hymenoscyphus fraxineus durch Wind verbreitet wird, sollte jede waldbauliche oder waldhygienische Maßnahme zur Verringerung des Infektionspotentiales in infizierten Eschenbeständen nur im Rahmen eines regionalen Konzeptes erfolgen. 


\subsection{5 "Esche in Not”: Das österreichische Züchtungs- und Erhaltungsprogramm für Fraxinus excelsior}

Gregor M. Unger, Heino Konrad, Katharina Schwanda, Thomas L. Cech, Gernot Hoch, Andreas Fera, Thomas Kirisits, und Thomas Geburek

Das Bundesforschungszentrum für Wald (BFW) startete 2015 gemeinsam mit der Universität für Bodenkultur Wien (BOKU) das Projekt „Bedrohtes Erbgut Esche“ („Esche in Not“, http://www.esche-in-not.at/). Dieses Vorhaben verfolgte die Ziele, vermutlich resistente Eschen in vom Eschentriebsterben schwer geschädigten Waldbeständen in ganz Österreich zu lokalisieren, ihre Krankheitsresistenz anhand angezogener Nachkommen unter hohem natürlichen Infektionsdruck (hohe Sporenbelastung) durch den Eschentriebsterben-Erreger (Hymenoscyphus fraxineus) im Rahmen einer Nachkommenschaftsprüfung im BFW-Versuchsgarten Tulln (NÖ) zu erheben und herausragend resistente Genotypen für die Züchtung auszuwählen. Sowohl die europaweit wichtige Gemeine Esche (Fraxinus excelsior) als auch die im Nordosten Österreichs (hauptsächlich in Auwäldern entlang des Flusses March) vorkommende Schmalblättrige Esche (F. angustifolia), sind für die durch den invasiven nichtheimischen Ascomyceten $H$. fraxineus verursachte Krankheit des Eschentriebsterbens hochanfällig (siehe Kapitel „Eschen-Triebsterben - eine schwerwiegende Bedrohung der Biodiversität in Auwäldern“).

Seit 2005 hat sich der Erreger über ganz Österreich verbreitet und führte aufgrund einer massiven Schädigung von befallenen Bäumen bis hin zu deren Absterben, zu einer erheblichen Veränderung in der Baumartenzusammensetzung und Ökologie von Auwäldern. Aufgrund des flächigen Ausfalls über alle Altersklassen hinweg ist die nachhaltige Waldbewirtschaftung mit dem Edellaubholz Esche weitgehend zum Erliegen gekommen. Geschädigte Altbäume werden zunehmend gefällt und natürliche Verjüngung kommt kaum auf. Allerdings sind in stark betroffenen Beständen immer wieder einzelne gering geschädigte Bäume zu beobachten, die höchstwahrscheinlich eine hohe genetisch bedingte, vererbbare Resistenz bzw. Toleranz gegenüber dem Erreger des Eschentriebsterbens aufweisen.

Hinweise auf Unterschiede in der Krankheitsresistenz von F. excelsior gegenüber $H$. fraxineus in Österreich stammen hauptsächlich von Erhebungen in drei Eschen-Samenplantagen, die von 1993 bis 2000 angelegt wurden und jeweils aus 50 bis 70 gepfropften Klonen ausgewählter Plusbäume mit forstlich erwünschten Eigenschaften bestehen. Die in diesen Samenplantagen von der BOKU von 2009 bis 2011 durchgeführten Schadansprachen dokumentierten eine große Variation in der Schädigung von Eschen-Klonen, welche von fast keinem $(<5 \%)$ bis zu massivem Triebsterben reichte. Obwohl die Triebsterbensintensität in späteren Jahren gestiegen ist und sich der Gesundheitszustand vieler Klone erheblich verschlechtert hat, waren im Jahr 2018 einige Genotypen noch immer in einem geringen Ausmaß von der Krankheit 
betroffen. Diese Beobachtungen und zahlreiche andere europäische Untersuchungen haben gezeigt, dass die Krankheitsresistenz zu einem großen Teil genetisch bedingt ist und eine hohe Erblichkeit besitzt; das heißt diese Eigenschaft wird effektiv von Elternbäumen an ihre Nachkommen vererbt. Resistenzzüchtung wurde daher als eine vielversprechende Strategie erachtet, um die Esche als eine der wichtigsten Laubbaumarten für die Forstwirtschaft und den Naturschutz in Österreich $\mathrm{zu}$ erhalten.

Die erste Projektphase von „Esche in Not“ (2015-2019) zeigte, dass der Ansatz von $e x$-situ-Erhaltungsmaßnahmen und Resistenzzüchtung vielversprechend ist, um die Baumart Esche zu erhalten. Es wurden strenge Kriterien für die Auswahl von Waldbeständen und Einzelbäumen definiert: nur Bestände mit hohem Schädigungsgrad (was auf einen hohen lokalen Infektionsdruck durch $H$. fraxineus hinweist) wurden herangezogen und die für eine Beerntung ausgewählten Eschen sollten keine Wurzelhalsnekrosen und nur vernachlässigbare Kronenschäden aufweisen. Ferner war der Durchmesser in Brusthöhe (BHD) auf 20-25 cm (maximal $30 \mathrm{~cm}$ ) begrenzt und nur Bäume mit Früchten (weibliche und zwittrige Exemplare) wurden ausgewählt. Basierend auf diesen Kriterien wurden in den Jahren 2015 und 2017 insgesamt 716 scheinbar resistente Einzelbäume in ganz Österreich für die Samenernte ausgewählt. Nach der Anzucht der Einzelbaumabsaaten konnten von 2017 bis 2020 vier Nachkommenschaftsprüfungen mit insgesamt 35.718 Sämlingen im BFW-Versuchsgarten in Tulln (Resistenztests R1 bis R4; Abb. 3.3.5-1) angelegt und natürlichen Infektionen durch $H$. fraxineus ausgesetzt werden. Sämlinge von stark geschädigten Mut-

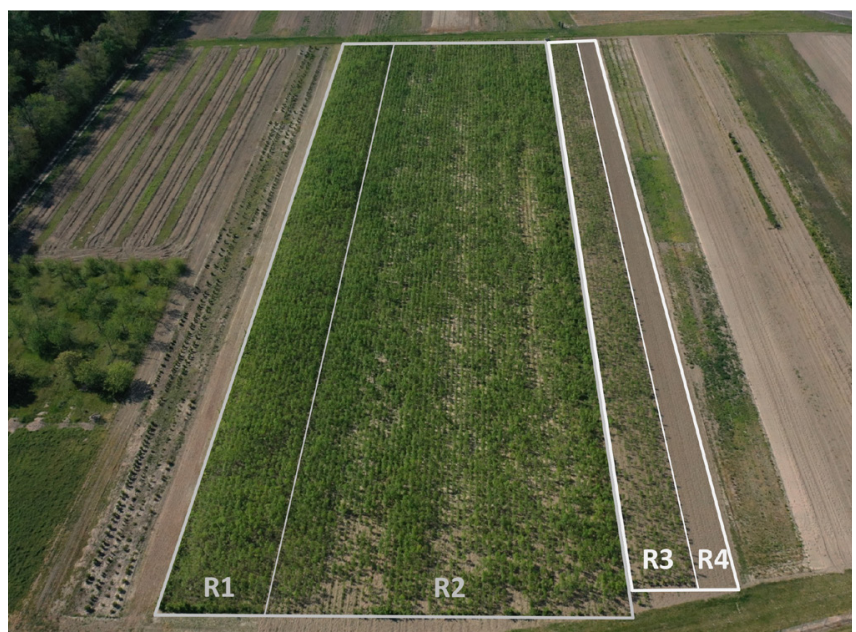

Abb. 3.3.5-1: Drohnenaufnahme der im Rahmen von "Esche in Not" angelegten Testflächen zur Nachkommenschaftsprüfung im BFW Versuchsgarten in Tulln (NÖ). Aufgrund von zwei Ernte-Jahren (2015 und 2017) sowie des Überliegen von Eschen-Saatgut wurden vier separate, aber aneinander angrenzende Resistenztests R1 bis R4, angelegt (Aufnahme vom 08.05.2020). 
terbäumen wurden als negative Kontrollen in den Feldversuch integriert.

Um auf das Resistenzniveau der Sämlinge in den Versuchen schließen zu können, wurde jedes Prüfglied hinsichtlich der Triebsterbensintensität (Hauptstamm, Seitenzweige, Wurzelhals) jährlich im Sommer unter Verwendung eines mehrstufigen Bonitur-Schemas ( $1=0 \%$ Schädigung; 6 = 100\% Schädigung, Pflanze abgestorben; Abb. 3.3.5-2) angesprochen. Der Anteil gesunder Sämlinge im Versuch R1 (Anlage 2017) ist von 2018 bis 2020 erheblich gesunken (Abb. 3.3.5-2). Bei der ersten Bewertung im Jahr 2018 wiesen 82,4\% (4.970 von 6.030) der Sämlinge überhaupt keine Schädigung durch das Eschentriebsterben auf. Dieser Anteil ging 2019 auf 57,6\% und 2020 auf 24,0\% zurück. Einige Halbgeschwisterfamilien waren insgesamt nur in geringem Ausmaß von der Krankheit betroffen. Ebenso unterscheidet sich die Triebsterbensintensität der Nachkommen stark in Abhängigkeit von ihren Mutterbäumen, was mit der Auffassung übereinstimmt, dass F. excelsior eine genetisch determinierte, vererbbare Resistenz gegenüber H. fraxineus besitzt. Die Versuchsfläche R2 (Anlage 2018, Ansprachen in den Jahren 2019 und 2020) zeigte einen ähnlichen Trend der Krankheitsentwicklung wie Fläche R1. Testfläche R3 (Anlage 2019) wurde bisher nur einmal (2020) evaluiert, und Fläche R4 (Anlage 2020) wird zum ersten Mal im Jahr 2021 hinsichtlich Triebsterbensintensität angesprochen werden.

Die hohe Intensität des Eschentriebsterbens auf der Versuchsfläche R1 deutet auf einen hohen Infektionsdruck durch $H$. fraxineus im BFWVersuchsgarten hin. Dadurch ist sichergestellt, dass nur Genotypen mit überdurchschnittlicher Krankheitsresistenz für die weitere Resistenzzüchtung ausgewählt werden. Während die Krankheitsintensität

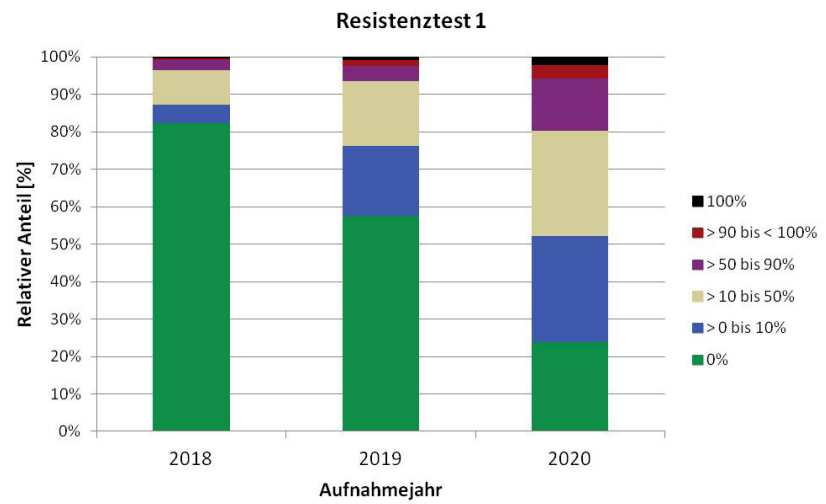

Abb. 3.3.5-2: Entwicklung der Triebsterbensintensität im Resistenztest 1 (R1) von 2018 bis 2020. Gestapelte Balken zeigen die relative Verteilung der Eschenpflanzen auf die sechs Schadklassen (R1 wurde 2017 mit 6.330 einjährigen Sämlingen von 426 Mutterbäumen angelegt). 


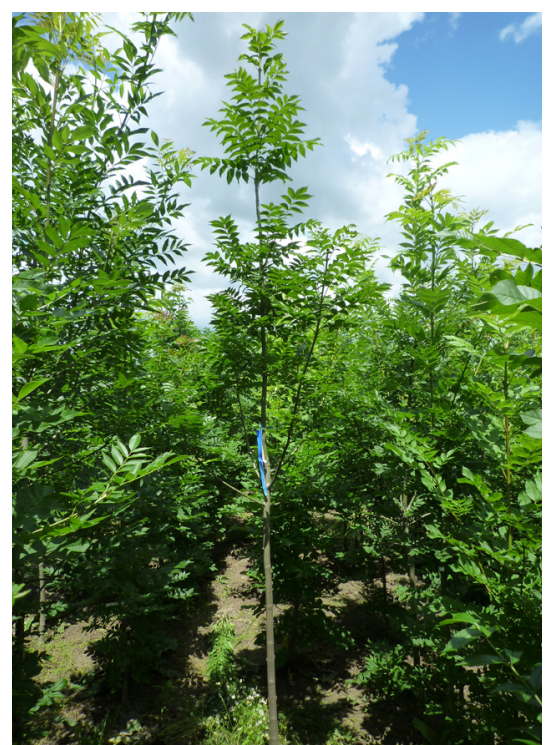

Abb. 3.3.5-3: Dreijähriger Elite-Baum von Fraxinus excelsior im Resistenztest R2 von „Esche in Not", der zur vegetativen Vermehrung und weiteren Resistenzzüchtung ausgewählt wurde. Der Baum stammt von einer insgesamt gering geschädigten Einzelbaumabsaat und war bis 2020 (nach zwei Erhebungen) überhaupt noch nicht durch das Eschentriebsterben geschädigt (Aufnahme vom 24.06.2020). im Laufe der Zeit wahrscheinlich weiter zunehmen wird (vermutlich aber langsamer), ist zu erwarten, dass ein beträchtlicher Teil der bisher gesunden und nur geringfügig geschädigten Eschen weiterhin überdurchschnittlich abschneiden wird.

Die Projektphase II (2019-2024) konzentriert sich auf die Charakterisierung und Auswahl überlegener Genotypen in den vier Nachkommenschaftsprüfungen. Gesunde Individuen werden unter den Nachkommen mit insgesamt geringer Triebsterbensintensität ausgewählt (Abb. 3.3.5-3) und zusätzlich mithilfe von molekularen Resistenzmarkern auf ihre geringe Anfälligkeit gegenüber dem Eschentriebsterben überprüft. Genotypen, die aufgrund dieser Eigenschaften ausgewählt wurden, werden schließlich durch künstliche Inokulation mit $H$. fraxineus und Armillaria spp. (Hallimasch-Arten), die sekundäre, aber wichtige Krankheitserreger an durch das Triebsterben geschädigten Eschen sind, abschließend noch einmal getestet. Parallel dazu werden gärtnerische Techniken zur Optimierung der Vermehrung der Esche über Grünstecklinge und durch Pfropfung getestet. Am Ende der Phase II ist die Anlage von Feldversuchen unter Verwendung einer endgültigen Auswahl an Nachkommen (wenn möglich durch Stecklinge vermehrt) sowie die Einrichtung einer oder mehrerer Samenplantagen geplant. Die Einrichtung neuer Eschen-Samenplantagen mit einer großen Anzahl an lokal angepassten und resistenten Klonen sollte dazu beitragen, das Hauptproblem für die Entwicklung eines hohen Resistenzniveaus in natürlichen Populationen - das verstreute Vorkommen der wenigen hochresistenten Bäume und die dadurch erschwerte Paarung zwischen diesen, wodurch die Resistenzeigenschaften nicht an die Verjüngung weitergegeben werden - zu überwinden.

Neben der Erhaltungsinitiative für die Gemeine Esche wurde 2018 das Projekt „QEsche“ zur Resistenzzüchtung bei Fraxinus angustifolia mit einem ähnlichen Ansatz gestartet. Im natürlichen Verbreitungsgebiet von F. angustifolia in Österreich sind alte Bäume bisher nur gering geschädigt, aber das Eschentriebsterben wirkt sich stark negativ auf die natürliche und künstliche Verjüngung dieser Baumart aus. Daher wurden die Auswahlkriterien für resistente Bäume dahingehend geändert, dass insbesondere junge Bäume mit einem BHD von weniger als $20 \mathrm{~cm}$ berücksichtigt wurden. Das übergeordnete Ziel des Projekts „QEsche“ ist die Einrichtung von Feldversuchen mit vegetativ vermehrten Eliteklonen und Sämlingen von mutmaßlich resistenten samentragenden Bäumen. Diese Versuchsflächen werden die Grundlage für die weitere ex-situ-Erhaltung und Resistenzzüchtung auch bei dieser Art bilden.

Ex-situ-Erhaltungsmaßnahmen, wie die hier beschriebenen, sollten durch in-situ-Erhaltung von potenziell krankheitsresistenten Individuen der beiden Eschen-Arten ergänzt werden. In den letzten Jahren und insbesondere seit 2016 wurden in großem Ausmaß Einzelbäume und ganze Bestände der Esche gefällt. In vielen Fällen werden diese Eingriffe undifferenziert durchgeführt, was bedeutet, dass Bäume unabhängig von ihrem Gesundheitszustand geschlägert werden. Um jedoch die 
Anpassung der Eschen-Populationen an den neuartigen Selektionsfaktor $H$. fraxineus zu unterstützen, empfehlen wir dringend, außergewöhnlich krankheitstolerante Eschen, insbesondere in stark befallenen Beständen, zu erhalten und zu fördern und ihre natürliche Verjüngung zu ermöglichen. Das Schicksal der Gemeinen und Schmalblättrigen Esche hängt nicht nur von den Initiativen zur Resistenzzüchtung ab, sondern liegt auch in den Händen von Waldbesitzern, Förstern und anderen Praktikern, die sich an der Erhaltung dieser ökologisch und wirtschaftlich wertvollen Baumarten beteiligen und auch bereit sind, widerstandsfähigeres Vermehrungsgut von Fraxinus spp. zu verwenden.

\section{Danksagung}

"Esche in Not" (DaFNEplus Nr. 101113 und 101476) wird durch das Ministerium für Landwirtschaft, Regionen und Tourismus (BMLRT), die Landwirtschaftskammer Österreich, die Landesforstdirektionen aller Bundesländer, den Forst- und Landwirtschaftsbetrieb der Stadt Wien (MA 49), den Österreichischen Forstverein und die Naturschutzabteilungen der Bundesländer Salzburg und Oberösterreich finanziell unterstützt. "QEsche” (2018-2022) wird von der Österreichischen Bundesregierung, den Bundesländern und der Europäischen Union (Europäischer Landwirtschaftsfonds für die Entwicklung des ländlichen Raums) finanziell unterstützt. Wir danken allen Mitarbeitern des BFW-Versuchsgarten Tulln (NÖ) sowie vielen KollegInnen des BFW für ihre umfassende technische Unterstützung. 


\subsubsection{Maßnahmen gegen die Ausbreitung von Phytophthora in Fluss begleitenden Wäldern}

Thomas L. Cech

\section{Einführung}

Die Gattung Phytophthora (Chromista, Peronosporaceae) umfasst Erreger von Pflanzenkrankheiten, die weltweit an krautigen wie verholzten Pflanzen Schäden verursachen. Als mehrheitlich Wurzeln bewohnende Arten werden sie hauptsächlich mit Pflanzgut, durch frei fließendes Wasser, manchmal auch durch andere menschliche Aktivitäten (z. B. Tourismus, Forstwirtschaft) und seltener durch Wind und Regentropfen verbreitet. Viele Arten haben sich in tropischen Wäldern entwickelt, wo sie sich an ein weites Wirtspflanzenspektrum adaptierten. Arten wie die weit verbreitete P. cinnamomi können einige tausend Pflanzenarten infizieren. Oft „entdecken“ Phytophthora-Arten neue Wirtspflanzen, die speziell anfällig sind und gewöhnlich schwer geschädigt werden, da eine Co-Evolution zwischen ihnen und den Krankheitserregern nicht stattfand. Ein zweiter Faktor, der die Gefahr, die von diesen Pathogenen ausgeht, verstärkt, ist die häufige Hybridisierung, die mit Änderungen der Pathogenität einhergeht. In diesem Zusammenhang ist das Risiko in Baumschulen besonders hoch, da hier eine Vielfalt von Pflanzenarten mit großen Individuenzahlen in enger Nachbarschaft wächst.

Phytophthora Arten benötigen Wasser zur Entwicklung und zur Verbreitung der am meisten infektiösen Einheiten, der Zoosporen. Letztere werden in Regentropfen, im Bodenwasser und besonders im Wasser von Teichen, Seen und Flüssen freigesetzt. Die Folgen für natürliche Ökosysteme sind bei einiger Arten enorm (beispielsweise von P. cinnamomi auf Wälder in Australien, $P$. ramorum auf Nordamerikanische Redwood-Wälder, und P. austrocedrae auf südamerikanische Chilezedern-Wälder) und effektive Gegenmaßnahmen sind vergleichsweise dürftig. Die meisten Aktivitäten gegen diese Desaster zielen auf die Prevention von Infektionen ab, es wurden nur wenige kurative Bekämpfungsstrategien entwickelt.

Das Risiko durch Wurzeln und Wurzelhals infizierende PhytophthoraArten ist für Fluss begleitende Wälder aufgrund der häufigen Überschwemmungen, die für dieses Ökosystem charakteristisch sind, besonders hoch. Überschwemmungen ermöglichen unvermeidlich die Verseuchung von Wäldern entlang der Flüsse, da Flusswasser immer Keime verschiedener Phytophthora-Arten enthält. In Europa ist die Phytophthora-Krankheit der Erlen (Alnus sp.), verursacht von der Hybridart P. x alni und anderen P. Arten (Abb. 3.3.6-1, 3.3.6-2) das eindrucksvollste Beispiel. Ab den 1990iger Jahren wurden Millionen gepflanzter Erlen von Wurzelhals- und Stammbasis-Läsionen als Folge infizierter Wurzelsysteme erfasst. Die in den Rindenläsionen gebildeten Zoosporen wurden während natürlicher Überschwemmungsereignisse im Flusswasser freigesetzt und infizierten flussabwärts wachsen-

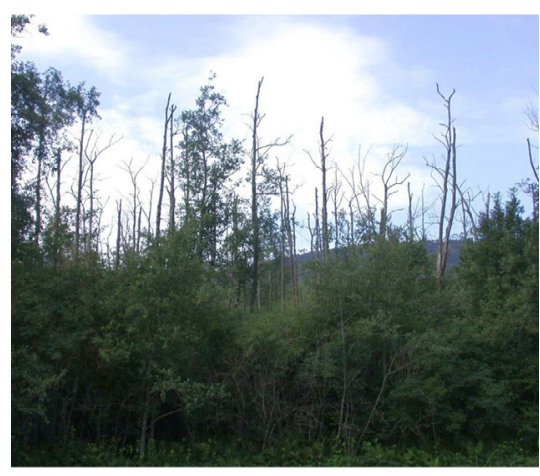

Abb. 3.3.6-1: Seit den 199iger Jahren erschienen an Millionen gepflanzter Erlen Phytophthora-Wurzelhalsund Stamm-Läsionen als Folge von Infektionen des Wurzelsystems mit der Folge des Erlensterbens. 


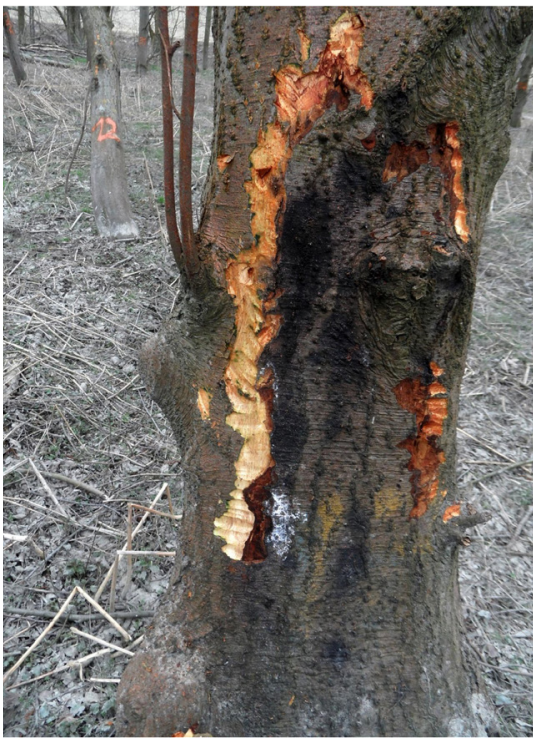

Abb. 3.3.6-2: Stammläsionen durch Phytophthora Infektionen. de gesunde Erlen an der Stammbasis; die Infektionen wurden schnell stammumfassend und führten zum Absterben der Bäume.

\section{Präventive versus kurative Strategien}

Die schwerwiegensten Folgen von Phytophthora zeitigen Wurzel- und Wurzelhals-Infektionen: diese sind gewöhnlich letal für die Bäume. Allerdings sind einige kurative Methoden möglich. Unter den am meisten effektiven Maßnahmen zur Überlebenssicherung der betroffenen Bäume ist die Behandlung der Stammrinde mit bestimmten Phosphit-Präparaten. Diese stimulieren Abwehrmechanismen der Bäume (Bildung von Wundkallus) sowie das Wachstum von Feinwurzeln. Diese Behandlungstechnik kommt gewöhnlich bei Einzelbäumen im urbanen Bereich zur Anwendung, im Wald ist sie hingegen kaum machbar. Aus diesem Grund sind präventive Maßnahmen, die auf die Minimierung der Ausbreitung von Phytophthora in flussbegleitenden Wäldern ausgerichtet sind, die erste Wahl.

\section{Adaptierung von Forstgärten zur Phytophthora-freien Pflanzen- produktion}

Die Produktion von Phytophthora-freien Pflanzen stellt die Forstgärten und Baumschulen vor einige Herausforderungen. Die Vermeidung der Einschleppung der Keime in Pflanzgut muss mit regulärem Monitoring sowie Überwachungssystemen der Pflanzenschutzdienste verknüpft sein. Unter den entscheidenden Voraussetzungen sind das Unterbinden des Austausches von Pflanzgut mit anderen Baumschulen und das Vermeiden der Infektion der jungen Pflanzen, die vorwiegend die Folge der Beregnung mit kontaminiertem Flusswasser ist, die wichtigsten.

Forstgärten und Baumschulen müssen garantieren, dass

- Keine Einschleppung von Phytophthora-Keimen in die Produktionsflächen über Pflanzgut aus anderen Baumschulen erfolgt

- Keine Einschleppung von Phytophthora-Keimen in die Produktionsflächen durch Beregnungssysteme erfolgt

- Keine Einschleppung von Phytophthora-Keimen in die Produktionsflächen im Zuge von Überschwemmungen durch Gewässer im Nahbereich erfolgt

- Keine Einschleppung von Phytophthora-Keimen in die Produktionsflächen durch kontaminiertes Erdmaterial, Werkzeuge, Kleidung, Schuhwerk oder Fahrzeuge erfolgt

\section{Saatgut}

Obwohl vergleichsweise wenige Phytophthora - Arten mit Saatgut verschleppt werden, sollten die folgenden Sicherheitsmaßnahmen eingehalten werden:

- Vermeidung der Saatgutgewinnung von als infiziert bekannten 
oder wahrscheinlich infizierten Pflanzen oder Flächen

- Vermeidung der Saatgutgewinnung durch Aufsammeln der Samen vom Boden oder (wenn möglich) aus einer Höhe bis zu $0.5 \mathrm{~m}$ über dem Boden (Spritzwasser)

- Oberflächensterilisation vor der Lagerung und vor der Aussaat

- Entfernen symptomatischer Samen (besonders bei großen Samen) vor der Aussaat

- $\quad$ Saatgut-Behandlung zur Bekämpfung von Krankheitserregern (z. B. Hitzebehandlung, Chemische Bekämpfung)

In Risikofällen ist vor der Aussaat (abhängig von der Pflanzenart), eine Analyse durch ein Diagnoselabor essentiell.

\section{Pflanzenproduktion}

Containerware ist im Zusammenhang mit einer Phytophthora-freien Pflanzenproduktion zu bevorzugen, da das Substrat vorher sterilisiert und danach von jeglicher Kontamination sauber gehalten werden kann. Das Risiko ist bei wurzelnackten Pflanzen, die auf Produktionsflächen im Freien herangezogen werden, höher, da hier eine Reihe von unvorhersehbaren Wegen der Kontamination gegeben ist. Für Container-Pflanzgut sind folgende Maßnahmen entscheidend:

- Sterilisation des Substrates durch Hitzebehandlung (mindestens 2 Stunden bei $60^{\circ} \mathrm{C}$ ) vor der Aussaat oder der Pflanzung von Stecklingen. Die Überprüfung der Effektivität erfordert Checks durch ein Diagnoselabor.

- Aufstellung der Pflanzen auf den Produktionsflächen entweder am Boden ohne mögliche Einflüsse durch den gewachsenen Boden bzw. freies Wasser, oder, vorzugsweise, in mindestens $1 \mathrm{~m}$ Höhe über dem Boden. Jeglicher Kontakt des Laubes mit dem gewachsenen Boden sowie mit Sprühwasser ist zu vermeiden.

- Pflanzensets dürfen niemals mit anderen Pflanzen, die in nicht sterilisiertem Substrat wachsen, vermischt werden. Während der Dauer der Pflanzenproduktion muss jeglicher Kontakt mit frei fließendem Wasser ausgeschlossen werden.

- Beregnungstechniken, durch die das Laub $>24$ Stunden benässt wird, sind zu vermeiden. Sprinkler dürfen nur in der Früh zum Einsatz kommen, um eine rasche Austrocknung zu gewährleisten.

Die Beregnung sollte vorzugsweise durch Brunnen-, Grund- oder Leitungswasser erfolgen, da diese Wasserquellen gewöhnlich frei von Phytophthora-Keimen sind. Für Forstgärten und Baumschulen, die auf Wasser von Teichen oder Flüssen angewiesen sind, ist eine Behandlung des Wassers obligat: Beregnungswasser kann zur Entfernung von Krankheitserregern gefiltert werden. Diese Praxis ist jedoch eher für größere Forstgärten oder Baumschulen geeignet, da die Systeme kostspielig sind (auch in der Erhaltung) und viel Platz erfordern. Darüber hinaus bieten die Systeme nicht die Garantie, dass das Wasser vollstän- 
dig von Phytophthora-Keimen frei ist. Beregnungswasser kann auch chemisch dekontaminiert werden. Handelsübliche Chlorprodukte sind geeignet, Keime abzutöten, allerdings müssen bei großflächiger Anwendung gesetzliche Einschränkungen in Betracht gezogen werden.

Zur Absicherung der Effektivität sollten durch ein Diagnoselabor stichprobenartige Überprüfungen des Substrates auf Phytophthora durchgeführt werden. Zusätzlich sind Analysen sowohl des Substrates und der Pflanzen unmittelbar vor der Auslieferung der Pflanzen an Kunden oder andere Baumschulen unumgänglich. Das Beregnungswasser muss durch ein Diagnoselabor periodisch auf Kontamination mit Phytophthora analysiert werden.

Weitere vorbeugende Strategien gegen die Invasion von Phytophthora in flussbegleitende Wälder

Die Verbreitung von Phytophthora durch Überschwemmungen kann nur unterbunden werden, indem der Eintrag der Keime in die Gewässer verhindert wird, und dieses erfordert die Ausweitung der angeführten Maßnahmen auf die Zierpflanzenproduktion. Weiters muss auch die Waldbewirtschaftung bestimmte Hygienemaßnahmen umsetzen: Harvester beispielsweise können die Keime mit kontaminierten Ketten verbreiten und bei der Konstruktion von Forststraßen wird oft waldfremdes Material als Straßenbelag verwendet. Alles in allem ist ein gesteigertes Bewusstsein der Bevölkerung zu den Risiken durch infiziertes Pflanzgut notwendig, um die oben angeführten kostspieligen Maßnahmen zu untermauern.

\section{Ausblick und Zusammenfassung}

Eine Verringerung des Risikos von Phytophthora Infektionen in flussbegleitenden Wäldern kann nur mit präventiven Maßnahmen mit einer nachhaltigen Balance zwischen Pathogen und Bäumen erzielt werden. Außerdem ist eine integrierte und umfassende Herangehensweise notwendig, bei der die Pflanzenproduktion und der Pflanzenhandel, aber auch die Waldbewirtschaftung und das Landschaftsmanagement im urbanen Raum einbezogen werden müssen. Zudem ist eine Bewußtseinssteigerung der Öffentlichkeit gegenüber den Risiken derartiger Pathogene erforderlich. Anpassungen der Pflanzenschutz-Gesetze sowie intensivierte Informationskampagnien für ein weites Spektrum von Personen, die mit Gehölzen zu tun haben sowie für die Öffentlichkeit sind hier notwendig. 


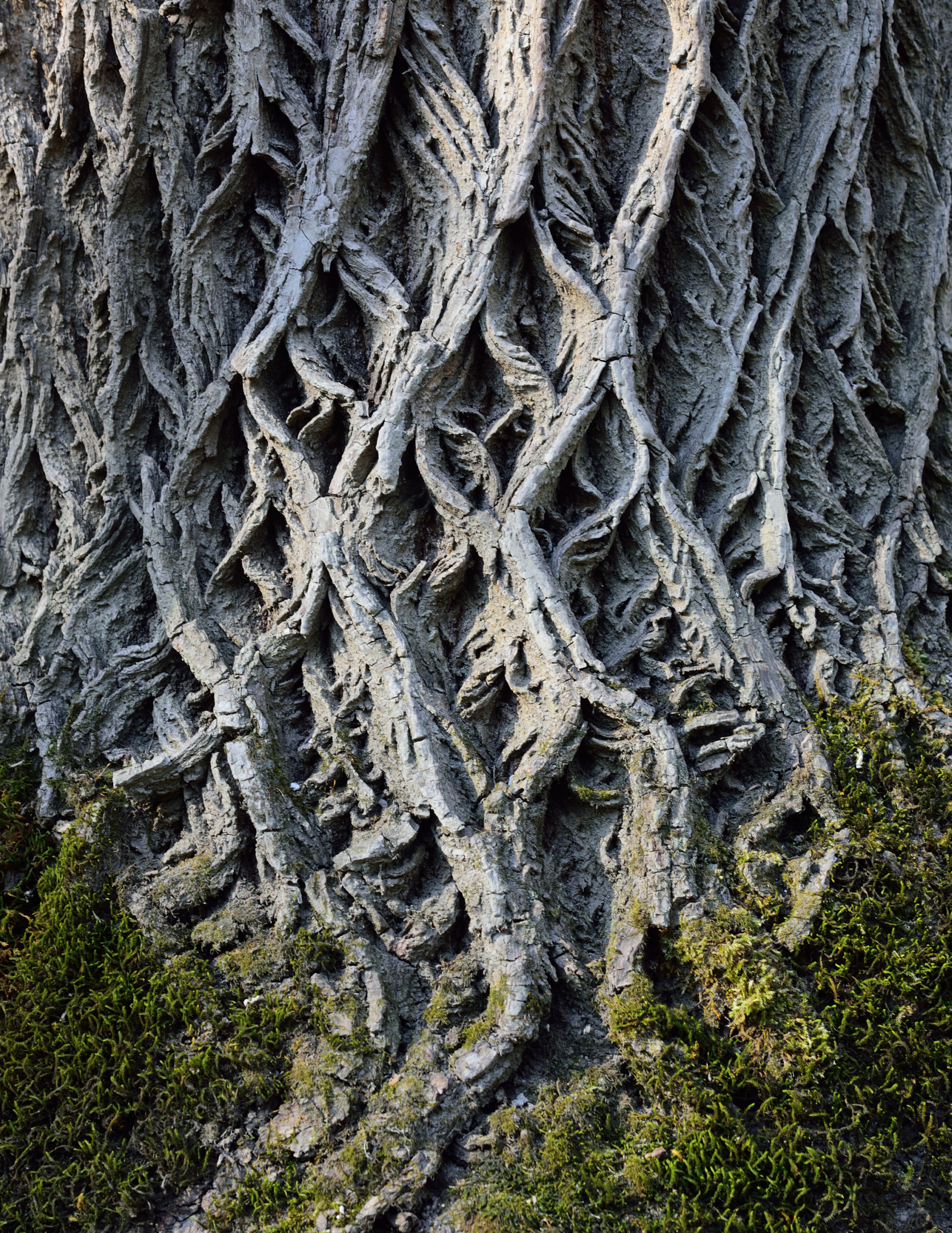




\section{Anhang}

\subsection{Baumartenvorkommen und Samentransfer}

\subsubsection{Baumartenverbreitungsmodelle im Klimawandel}
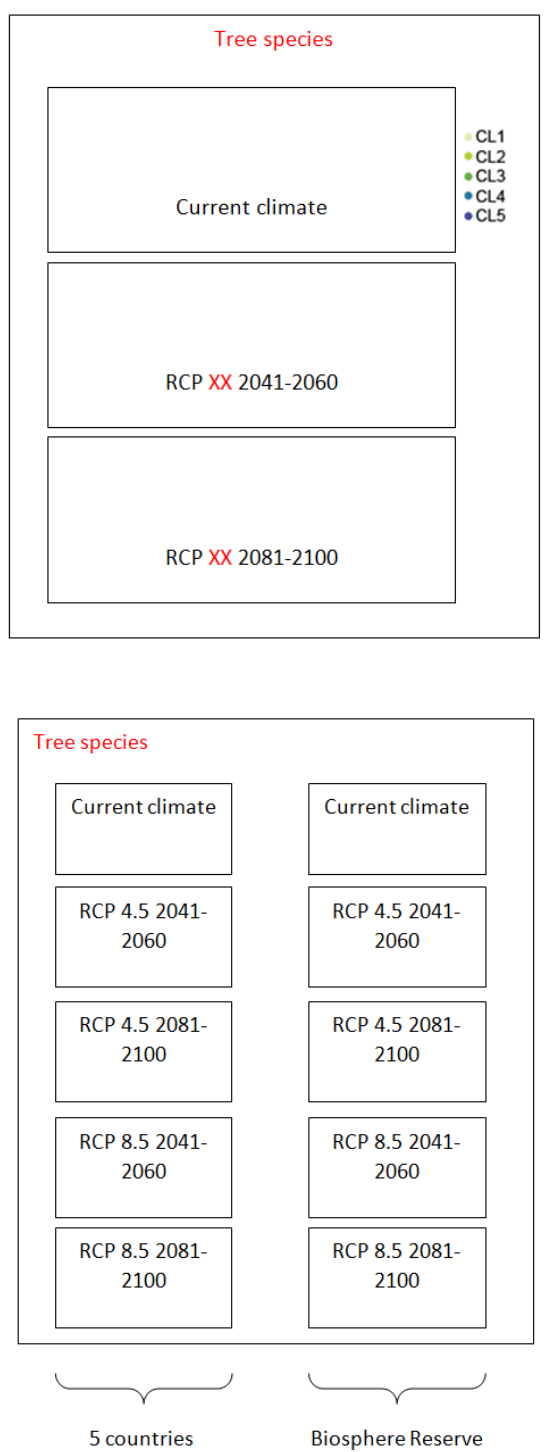

Für acht wichtige heimische Baumarten und zwei nichtheimische Baumarten wurden im Projekt REFOCuS Baumartenverbreitungsmodelle entwickelt, die die Eignung dieser Baumarten für die Länder Slowenien, Österreich, Ungarn, Serbien und Kroatien sowie spezifisch für die Region des TBR MDD beschreiben. Diese Modelle wurden für das gegenwärtige Klima und zwei möglich Klimaszenarien der Zukunft (RCP 4.5, RCP 8.5) angewendet und daraus Karten erstellt. Das Szenario RCP 8.5 beschreibt die Klimaentwicklung bei weiter steigenden Treibhausgasemissionen, die für weite Teile Europas einen Temperaturanstieg zwischen 3 und $5{ }^{\circ} \mathrm{C}$ gegenüber der Periode 1971-2000 bedeuten würde. Das Szenario RCP 4.5 beschreibt einen moderateren Anstieg der Treibhausgasemissionen, der für Europa einen Temperaturanstieg zwischen 1 und $3{ }^{\circ} \mathrm{C}$ zur Folge haben würde.

Eine Auswahl von 10 Karten je Baumart (kombiniert auf einer Seite) zeigt die potentiellen Veränderung der Baumarteneignung im Laufe des 21. Jahrhundert für die beiden Klimawandelszenarios RCP 4.5 und RCP 8.5. Die linke Seite des Kartenblatts zeigt die fünf Projektländer, die rechte Seite zeigt die detailiertere Entwicklung im Biospärenreservat Mur-Drau-Donau. Alle Karten zeigen die Vorkommenswahrscheinlichkeit der Arten, die auf Basis zahlreicher und für die jeweiligen Baumarten relevanten Klimavariablen beruht. Rote und weiße Flächen zeigen eine niedrige „Vorkommenswahrscheinlichkeit“ an und grün ein hohe.

\subsubsection{Samentransferzonen}

Zusätzlich zu den Karten der potentiellen Baumartenverbreitung im Klimawandel wurden im Projekt REFOCuS Samentransferzonen für die Auswahl des am besten geeigneten forstlichen Vermehrungsgutes entwickelt. Diese Karten richten sich ausschließlich nach den Baumartenvorkommen und den klimatischen Bedingungen, aber nicht nach Ländergrenzen und den bisherigen nationalen Herkunftsgebieten. Ebenso wie die Karten der Baumartenverbreitung sind die Samentransferzonen für die beiden o. g. Klimawandelszenarien verfügbar, wobei jedes Szenario auf einem eigenen Kartenblatt abgebildet ist. Jedes Kartenblatt zeigt die Samentransferzonen bei derzeitigen Klima und dem erwarteten Klima zur Mitte (2041-2060) und zum Ende (2081-2100) des Jahrhundert. Dabei ist zu beachten, dass die Farben zu allen drei Zeitpunkten eine ähnliches Klima charakterisieren: die drei Karten zeigen also die Verschiebung des Klimas im Laufe des Jahrhunderts. 
Alle farbigen Regionen weisen für die jeweilige Baumart zumindest eine Vorkommenswahrscheinlichkeit von 0,5 an (Ausnahme Ulmus laevis: diese hat aufgrund der hohen ökologischen Bedeutung nur eine Vorkommenswahrscheinlichkeit von 0,2). Weiß dargestellte Flächen zeigen Regionen an, in denen die Vorkommenswahrscheinlichkeit unter den o. g. Schwellenwerten liegt und damit vorraussichtlich nicht vorkommt bzw. vorkommen kann. Jede Farbe kennzeichnet eine Region mit sehr ähnlichen Klimabedingungen, für welche eine lokale Anpassung der Baumpopulationen erwartet werden kann. Diese Klimagruppen bzw. Cluster - Samentransferzonen wurden mit Cluster CL1, CL2, CL3, etc. bezeichnet. Dementsprechend, sind Regionen z. B. mit CL1 klimatisch ähnlicher zueinander als zu Regionen mit anderen Clustern.

\section{Download Links zu den hoch aufgelösten Karten}

\section{Baumart 1: Alnus glutinosa}

\section{https://danubeforesthealth.eu/dat/Output3.3/Alnus glutinosa/}

\section{Baumart 2: Fraxinus angustifolia}

\section{https://danubeforesthealth.eu/dat/Output3.3/Fraxinus angustifolia/}

Baumart 3: Fraxinus excelsior

https://danubeforesthealth.eu/dat/Output3.3/Fraxinus_excelsior/

Baumart 4: Populus nigra

https://danubeforesthealth.eu/dat/Output3.3/Populus_nigra/

Baumart 5: Quercus robur

https://danubeforesthealth.eu/dat/Output3.3/Quercus_robur/

\section{Baumart 6: Ulmus leavis}

https://danubeforesthealth.eu/dat/Output3.3/Ulmus laevis/

Anmerkung: Die Karten der Samentransferzonen sind auf diejeinigen Regionen beschränkt, in denen die jeweilige Baumart zumindest eine Vorkommenswahrscheinlichkeit von 0,5 aufweist. Weiß dargestellte Flächen zeigen Regionen an, in denen die Vorkommenswahrscheinlichkeit unter diesem Schwellenwert liegt. Aufgrund der hohen naturschutzfachlichen Bedeutung wurde dieser Schwellenwert für Ulmus laevis auf eine Vorkommenswahrscheinlichkeit von 0,2 reduziert.

\section{Baumart 7: Ulmus minor}

https://danubeforesthealth.eu/dat/Output3.3/Ulmus_minor/

Zusätzliche Baumart 1: Salix alba

https://danubeforesthealth.eu/dat/Output3.3/Additional species/Salix_alba_occurrence.pdf

Zusätzliche Baumart 2: Juglans nigra

https://danubeforesthealth.eu/dat/Output3.3/Additional species/Juglans_nigra_occurrence.pdf

Zusätzliche Baumart 3: Robinia pseudoacacia

https://danubeforesthealth.eu/dat/Output3.3/Additional_species/Robinia_pseudoacacia occurence.pdf 


\subsection{Baumarten-Portraits}

Viktoria Valenta

\subsubsection{Autochthone Baumarten}

\section{Alnus glutinosa - gemeine Erle}
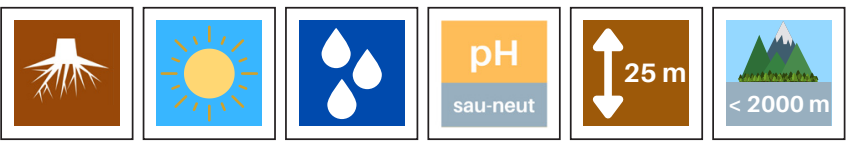

Die Gemeine oder Schwarzerle (Alnus glutinosa (L.) Gaertn.) ist ein mittelgroßer, aber schnellwüchsiger Laubbaum, der eine Höhe von 10-25 m (max. 40 m) erreicht und bis zu 120 Jahre alt wird. Die Krone ist kegelförmig und der Stamm gerade mit glatter brauner Borke, die mit dem Alter dunkler und rauer wird. Das Holz wird meist in der Möbelindustrie verwendet, ist nicht für den Außenbereich, aber für den Unterwasserbau geeignet.

\section{Verbreitung, Lebensraum \& Ökologie}

Alnus glutinosa ist in ganz Europa zu finden, von Nordafrika bis auf ca. $65^{\circ}$ Nord und von Irland bis Russland, wo Trockenheit der begrenzende Faktor ist. Sie wächst auf einer Vielzahl von Bodentypen: während sie trockene oder arme Böden (Kiese und Sande) toleriert, wächst sie besser in feuchten, nassen Bedingungen und kann Überschwemmungen besser überstehen als andere Arten (Überschwemmungstoleranz "sehr hoch"). Alnus glutinosa kann einen Jahresniederschlag von 400 - $2.000 \mathrm{~mm}$ tolerieren. Die Schwarzerle ist in der Lage, gestörte Bereiche schnell zu besiedeln, da sie eine symbiotische Beziehung mit dem Bakterium Frankia alni eingeht, das ihr die Stickstofffixierung ermöglicht. Als Teil gemischter Auengemeinschaften ist diese Eigenschaft auch für andere Arten (Betula spp., Fraxinus spp., Quercus spp, Salix spp.) von Vorteil, die dazu neigen, Alnus glutinosa zu verdrängen, sobald sich das Kronendach schließt und nicht mehr genügend Licht für diese Pionierart durchlässt.

Die Baumart ist im gesamten Gebiet des Biosphärenreservats Mur-Drau-Donau von Österreich bis Serbien zu finden.

\section{Forstwirtschaft \& Klimawandel}

Die Schwarzerle gilt als wichtige Baumart, sowohl wegen ihrer vielfältigen Holzverwendung, vor allem bei der Möbelherstellung und im Innenausbau, als auch wegen ihrer Eignung für die Stabilisierung von Flussufern. Da sie relativ viel Stickstoff in ihren Blättern speichert, verbessert ihre Streuschicht im Herbst die Bodenfruchtbarkeit. Darüber hinaus bietet sie den ganzen Winter über wertvolle Nahrung für Wildtiere. Allerdings ist die Aufforstung mit Erlen derzeit problematisch, da sie stark durch eine Krankheit bedroht ist, die durch den Pilz Phytophthora alni verursacht wird, der sich in Europa ausbreitet.

Der Klimawandel kann sich auf verschiedene Weise auf die europäischen Schwarzerlen auswirken: Sie könnte ihr natürliches Verbreitungsgebiet weiter nach Norden ausdehnen, wo sie durch die Länge und Intensität der Fröste begrenzt ist. Abnehmende Niederschlagsmengen hingegen werden sich negativ auf ihre Verbreitung und Überlebensrate auswirken.

\section{Beschreibung}

Blätter: verkehrt eiförmig, doppelt gezähnt, gezackte Spitze (zur Unterscheidung von A. incana), dunkelgrün; Bodenverbesserung

Blüten: einhäusig, junge Knospen sind sehr klebrig "glutinosa”; weiblich: rote, männlich: gelbe Kätzchen, entwickeln sich im Herbst des Vorjahres, und erscheinen früh im Frühjahr; windbestäubt

Früchte/Samen: eiförmig; unreif graugrün, später dunkelbraun, holzig; korkige Schwimmkammern; Verbreitung über Wind oder Wasser; geringe Keimfähigkeit

Rinde: glatt, anfangs grün-grau; später eckige Längsrisse 
Fraxinus angustifolia - Schmalblättrige Esche
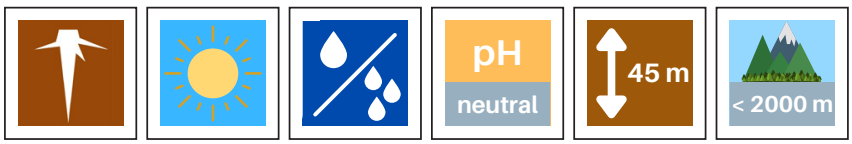

Die Schmalblättrige Esche (Fraxinus angustifolia Vahl) ist ein relativ schnell wachsender Laubbaum, der zwischen $40 \mathrm{~m}$ und $45 \mathrm{~m}$ hoch wird. Die Krone ist kuppelförmig und das Holz ist, ähnlich wie das der Gemeinen Esche (F. excelsior), besonders fest und biegsam, gleichzeitig aber wenig dauerhaft. Das Holz ist vielseitig einsetzbar und eignet sich als Massivholz oder Furnier besonders für den Möbelbau und die Innenausstattung.

\section{Verbreitung, Lebensraum \& Ökologie}

Die Schmalblättrige Esche kommt in ganz Mittelsüdeuropa, Nordwestafrika und im Nahen Osten vor. Sie überschneidet sich teilweise mit der Verbreitung der Gemeinen Esche (F. excelsior), mit der sie hybridisieren kann. Die Schmalblättrige Esche wächst in Auenwäldern mit feuchten, durchlüfteten Böden. Ihre Überschwemmungstoleranz ist "hoch". Auf trockeneren Standorten ist sie auch in höheren Lagen zu finden. Frost schränkt die Verbreitung in höheren Lagen ein. Als lichtbedürftige Art ist sie Teil von Laubmischwäldern zusammen mit z. B. Pappeln (Populus spp.), Weiden (Salix spp.) oder Ahorn (Acer spp.).

Die Baumart ist in allen Ländern von Serbien bis Österreich zu finden, wo sie ihre nördliche Grenze hat. Sie überschneidet sich vor allem in den zentralen Teilen des Biosphärenreservats Mur-Drau-Donau mit Fraxinus excelsior, verdrängt diese aber in Richtung Südosten.

\section{Forstwirtschaft \& Klimawandel}

Bestände werden meist über künstliche Begründung (Forstpflanzen) angelegt, da das Arbeiten mit Naturverjüngung von $F$. angustifolia aufgrund ihrer Empfindlichkeit gegenüber konkurrenzierender Begleitflora sehr schwierig ist. Sie benötigt ein mildes Klima und Niederschläge zwischen 400 und $800 \mathrm{~mm}$. Frost ist wahrscheinlich ein wichtiger Faktor, der die Verbreitung der Art einschränkt. Daher könnte sie ihr Verbreitungsgebiet vergrößern, wenn das europäische Klima wärmer wird.

\section{Beschreibung}

Blätter: zusammengesetzt, ungerade gefiedert, 3-8 cm lang, glänzend grün, unbehaart

Blüten: einhäusig; Blütenstand: einfache, unverzweigte Traube (zusammengesetzte Rispe bei F. excelsior), 1030 Blüten; windbestäubt; blühen im zeitigen Frühjahr; braune Endknospen

Früchte/Samen: Flügelnussfrucht, 3-4 cm; Reifung Ende Sommer

Rinde: grau, glatt, wird rissig 
Fraxinus excelsior - Europäische Esche
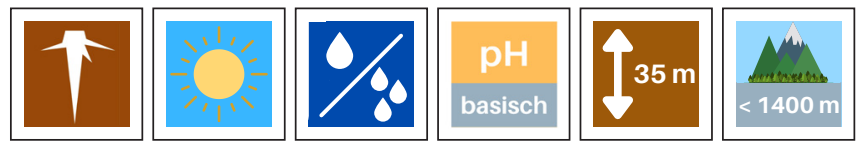

Die Gemeine Esche (Fraxinus excelsior L.) ist eine relativ schnellwüchsige Laubbaumart. Sie wird bis zu 300 Jahre alt und wächst 20-35 m (max. 45 m) hoch. Der Stamm ist lang und gerade mit einer offenen und gewölbten Krone. Die Rinde ist hellgrau und glatt, entwickelt aber mit dem Alter Risse. Das Holz ist hell, stark und zäh, aber ziemlich biegsam. Es wird aufgrund seiner strukturellen Eigenschaften für Werkzeuge und Sportgeräte, Fußböden und Musikinstrumente verwendet.

\section{Verbreitung, Lebensraum \& Ökologie}

Die Gemeine Esche kommt in ganz Europa vor, von der Atlantikküste bis in die nördlichen Teile des Nahen Ostens - weiter als die beiden anderen europäischen Eschenarten, die Schmalblättrige Esche (F. angustifolia) und die MannaEsche (F. ornus). Die Gemeine Esche ist eine bestandsbildende Art der harten Au, wächst aber auch in Gebirgsregionen in feuchten Bachtälern. Sie wächst am besten auf tiefgründigen, nährstoffreichen, ausreichend durchlüfteten Böden mit hohem Schluff- oder Tonanteil, aber auch auf eher trockenen, kalkhaltigen Böden. Hier hat sie ihren zweiten Verbreitungsschwerpunkt, oft auch als Kalkesche beschrieben. Sie verträgt saisonale Staunässe, aber keine längeren Überschwemmungen - ihre Überschwemmungstoleranz liegt zwischen 60 und 102 Tagen. Diese Esche ist in ihren jungen Stadien aufgrund ihrer Schattentoleranz dominant, wird aber nach den ersten Jahren stark lichtbedürftig.

Die Baumart ist im gesamten Gebiet des Biosphärenreservats Mur-Drau-Donau zu finden, wird aber in Ungarn und Kroatien in Richtung Serbien zunehmend durch Fraxinus angustifolia ersetzt.

\section{Forstwirtschaft \& Klimawandel}

Die Gemeine Esche verjüngt sich leicht und reichhaltig. Die jährliche Samenproduktion setzt im Alter von etwa 20 bis 30 Jahren ein, wobei alle 2-5 Jahre eine reichlichere Produktion stattfindet. Die indirekte Bedeutung für die Forstwirtschaft beruht auf ihrem dichten Wurzelsystem, das rutschgefährdete Hänge sowie Bach- und Flussufer stabilisiert.

Diese Esche würde im Allgemeinen gut mit der globalen Erwärmung zurechtkommen, wenn sie nicht von einem Pilz (Hymenoscyphus fraxineus, auch bekannt als Chalara fraxinea) bedroht wäre, der die Ursache des Eschentriebsterbens ist. Dieser breitet sich seit Anfang der 1990er Jahre in Europa aus und verursacht in nahezu allen Ländern ein massives Absterben. Diese Krankheit erhöht auch die Anfälligkeit für andere Schädlinge und Krankheiten, wie den Eschenprachtkäfer (Agrilus planipennis) - ein invasiver Käfer aus Ostasien mit holzbohrenden Larven, der in den frühen 2000er Jahren erstmals in Europa gefunden wurde.

\section{Beschreibung}

Blätter: zusammengesetzt, mit 9-13 Fiederblättchen, ungerade gefiedert, gezähnt; Blätter entfalten sich relativ spät im Frühjahr und werden noch grün abgeworfen; Bodenverbesserung

Blüten: komplexe Sexualität, einhäusig, zweihäusig; Blütenstände zusammengesetzte Rispe (einfache, unverzweigte Traube bei F. angustifolia); windbestäubt; in Trauben von 100-400; schwarze Endknospen; dunkelrote Blüten

Früchte/Samen: ovale Flügelnussfrüchte, 2-5 cm lang, in Trauben; Samen ruhen 2 Jahre lang

Rinde: grau, glatt, später rissig 
Populus alba - Weißpappel

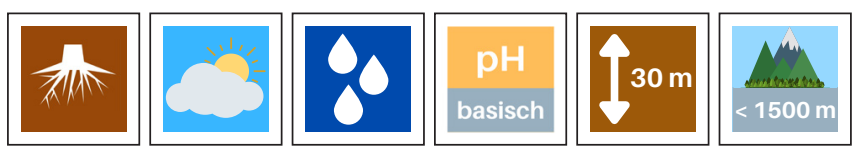

Die Weißpappel (Populus alba L.) ist ein großer Baum, der bis zu 400 Jahre alt und etwa $30 \mathrm{~m}$ hoch werden kann. Der Stamm ist unregelmäßig mit einer abgerundeten Krone. Das Holz hat keine große wirtschaftliche Bedeutung, wird aber im Energiesektor und in Vermehrungs- und Zuchtprogrammen verwendet.

\section{Verbreitung, Lebensraum \& Ökologie}

Die Weißpappel ist in Mittel- und Südeuropa in Au- und Küstenwäldern zu finden. Wie andere Pappeln bevorzugt sie feuchte, lockere, kiesig-lehmige, nährstoffreiche Böden. Sie toleriert bis zu einem gewissen Grad lang anhaltende Überschwemmungen und einen geringen Salzgehalt des Bodens. Sie ist eine schnellwüchsige, lichtbedürftige Art, die in früh- bis mittel-seralen Beständen häufig vorkommt. Die Weißpappel hybridisiert mit anderen Pappelarten, wie der Zitterpappel (P. tremula) und bildet Mischbestände mit Eschen (Salix spp.), Ulmen (Ulmus spp.), Eichen (Quercus spp.) und anderen.

Die Baumart kommt im gesamten Gebiet des Biosphärenreservats Mur-Drau-Donau von Österreich bis Serbien vor. Sie überschneidet sich mit dem Verbreitungsgebiet anderer Pappelarten, darunter P. nigra.

\section{Forstwirtschaft \& Klimawandel}

Da die Weißpappel als sehr verjüngungsfreudig (Stockausschläge, Wurzelbrut und bei entsprechender Keimbettbeschaffenheit auch generativ) sowie als hitze- und frosttolerant gilt, wird sie im Zusammenhang mit der globalen Erwärmung an Bedeutung gewinnen. Aufgrund ihres ausgedehnten, anpassungsfähigen Wurzelsystems kann sie Dünen stabilisieren und wird daher in Pionierwäldern in Küstennähe geschätzt. Entlang von Flussufern und Straßenrändern dient sie als Windschutz und Erosionsschutz.

Beschreibung

Blätter: wechselständig, variabel, 3-5 Lappen, grob gezähnt, 6-12 cm; oberseits glänzend dunkelgrün, unterseits weiß mit dichter Behaarung

Blüten: diözisch; Blüte vor dem Blattaustrieb

Früchte/Samen: männliche Kätzchen grau mit roten Staubgefäßen; weibliche Kätzchen grau-grün, flauschige Samen im Frühsommer

Rinde: cremeweiß mit schwarzen rautenförmigen Flecken (junge Bäume); schwarz und rissig (Basis der älteren Bäume) 


\section{Populus nigra - Schwarzpappel}
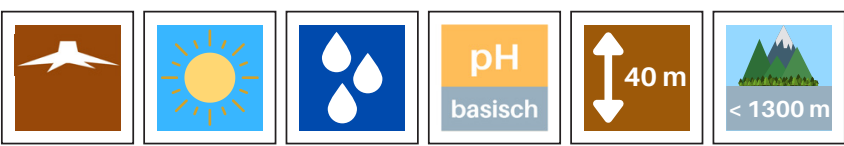

Die Schwarzpappel (Populus nigra L.) ist ein schnellwüchsiger Laubbaum, der Wuchshöhen von bis zu $40 \mathrm{~m}$ und ein Alter von bis zu 400 Jahren (meist 100) erreicht. Er entwickelt starke Äste und eine breite, tief angesetzte Krone. Das Holz wird für Möbel, aber auch in der Papierherstellung und im Bioenergiesektor verwendet.

\section{Verbreitung, Lebensraum \& Ökologie}

Populus nigra ist in ganz Europa - vom Mittelmeerraum bis zu den Britischen Inseln - in Nordafrika und bis nach Zentralasien zu finden. Sie ist eine wichtige Art der Auwälder, wo ihre Fortpflanzung eng mit den jährlichen Hochwasserzyklen verbunden ist. Die Verbreitung der Samen erfolgt über Wind und Wasser, die Keimung ist abhängig von den Boden-Wasser-Verhältnissen. Auch die Wurzelentwicklung ist von der Bodenfeuchtigkeit nach Hochwasserereignissen abhängig. Optimal sind feuchte, tiefgründige und nährstoffreiche Waldböden. Kalkhaltige Standorte werden bevorzugt, staunasse und saure Standorte werden gemieden. Hohe Wasserstände und hohe Temperaturen werden toleriert, Dürreperioden sind jedoch problematisch. Als Pionierart ist sie lichtbedürftig und kann gestörte Standorte besiedeln, vor allem durch vegetative Verjüngung. Sie kann leicht mit anderen Pappeln hybridisieren und kommt in Mischwäldern zusammen mit anderen Salicaceae wie Weißpappel (P.alba) und Weiden (Salix spp.), aber auch mit Erlen (Alnus spp.), Ulmen (Ulmus spp.) und Ahornen (Acer spp.) vor.

Die Baumart ist im gesamten Gebiet des Biosphärenreservats Mur-Drau-Donau von Österreich bis Serbien zu finden.

\section{Forstwirtschaft \& Klimawandel}

Obwohl Schwarzpappeln ökologisch bedeutsam sind und sich problemlos über Stecklinge vermehren lassen, gehören sie zu den am stärksten bedrohten Baumarten in Europa. Da sie leicht hybridisieren, sind sie in verschiedenen Zuchtprogrammen wichtig, z. B. zur Gewinnung von Populus x euramericana (P. deltoides $x$ P. nigra) und anderen Hybriden. Diese Hybriden werden weit verbreitet angepflanzt. Der Transfer von Genen aus Hybridklonen in den Genpool von Populus nigra wird als Bedrohung der genetischen Vielfalt dieser Art angesehen. Allerdings sind solche Hybriden auch besser an verschiedene klimatische Bedingungen und Waldschädlinge angepasst. Pappeln erbringen wichtige Ökosystemleistungen, wie z. B. den Schutz von Wassereinzugsgebieten, die Stabilisierung des Bodens und den Erosionsschutz. Außerdem emittieren sie flüchtige organische Verbindungen wie Isopren, die einen Einfluss auf den Klimawandel haben könnten.

\section{Beschreibung}

Blätter: variabel, länger als breit, dreieckig, kahl, gezähnter Rand, hellere Oberseite

Blüten: zweihäusig (entweder männlich oder weiblich); männlich: rote, hängende Kätzchen; weiblich: gelbliche Kätzchen; Blüten erscheinen vor den Blättern; windbestäubt

Früchte/Samen: Kapseln, dick, spitz, grünlich-braun, gestielt; Samen sind behaart

Rinde: gräulich, später dunkler, tief rissig 


\section{Prunus avium - Vogelkirsche}
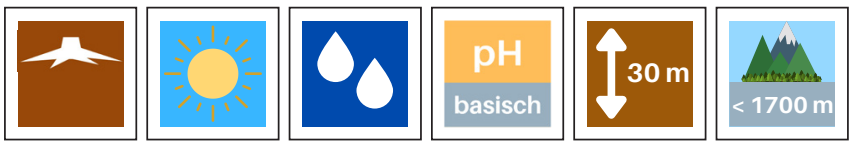

Prunus avium (L.), die Vogel- oder Wildkirsche, ist ein mittelgroßer, schnellwüchsiger Baum, der etwa 15-30 m hoch und meist 70-100 Jahre alt wird. Er entwickelt einen meist geraden Stamm mit dünner, grauer Rinde. Die Vogelkirsche ist einer der wichtigsten Laubbäume der Familie der Rosaceae in Europa. Das Holz ist feinfaserig und dicht mit deutlich gefärbtem Kernholz, das für den Möbelbau, dekorative Tischlerarbeiten und Musikinstrumente verwendet wird.

\section{Verbreitung, Lebensraum \& Ökologie}

Die Vogelkirsche hat in den gemäßigten Waldregionen Europas ein sehr großes natürliches Verbreitungsgebiet: Von den Britischen Inseln und Skandinavien im Norden bis nach Südspanien, dem Maghreb und dem Kaukasus im Süden findet man sie in planaren bis submontanen Gebieten. Ihre natürlichen Bestände sind jedoch meist zerstreut, angepflanzte und eingebürgerte Formen sind allerdings recht weit verbreitet zu finden. Sie wächst an den Ufern von Bächen und an Waldrändern. Die Vogelkirsche hat mittlere bis hohe Nährstoffansprüche und kommt mit verschiedenen Bodentypen zurecht, bevorzugt aber frische, kalkhaltige Böden mit guter Wasserversorgung an sonnigen Standorten. Sie verträgt keine Staunässe und ist empfindlich gegenüber Trockenheit. Sie kann als Pionierart angesehen werden, die Blößen durch Samen oder Ableger besiedeln kann. In der Jugend wächst sie schnell bis zu einem Alter von etwa 40 Jahren, was ihr einen Wettbewerbsvorteil in der frühen Sukzession verschafft, aber in späteren Stadien wird sie oft von anderen Laubhölzern verdrängt. Als Mitglied von Mischwäldern ist sie zusammen mit Buchen (Fagus spp.), Eichen (Quercus spp.), Hainbuchen (Carpinus betulus), Ahornen (Acer spp.) und Ulmen (Ulmus spp.) zu finden.

Prunus avium ist von Österreich bis Serbien zu finden. Sie kommt im Gebiet des Biosphärenreservats Mur-Drau-Donau vor, ist aber in Nordserbien und Ostungarn nicht anzutreffen.

\section{Forstwirtschaft \& Klimawandel}

Prunus avium ist die Wildform der domestizierten Süßkirsche, deren Früchte (zusammen mit der Sauerkirsche P. cerasus) wirtschaftlich sehr wichtige Esskirschen sind. Sie wird oft zum Vogelschutz und zur Erhaltung der Artenvielfalt gepflanzt. Die Vogelkirsche wird neben anderen Edellaubbaumarten zur Aufforstung von landwirtschaftlichen Flächen genutzt. Aufgrund ihres Wurzelsystems eignet sie sich für den Bodenerosionsschutz und die Hangstabilisierung. In Bezug auf den Klimawandel gilt sie als Gewinnerin, sofern die Trockenheit nicht über längere Zeiträume anhält, da der Niederschlag in den südlichen Teilen ihres Verbreitungsgebietes bereits ein limitierender Faktor ist. Im Norden wird sie jedoch durch kältere Bedingungen begrenzt, was sich mit einer Klimaerwärmung ändern wird. Dies könnte ihre Anfälligkeit für bestimmte Schädlinge und Krankheiten (z. B. Schwammspinner Lymatria dispar, Cherry Leaf Roll Virus CLRV) stark erhöhen, wenn die Bedingungen ungünstiger werden.

\section{Beschreibung}

Blätter: länglich verkehrt eiförmig, lang zugespitzt, grob gezähnt; Stängel mit roten Nektardrüsen; im Herbst gelb bis rot; bodenverbessernd

Blüten: einhäusig, zwittrig; Büschel von 2-5 weißen Blüten; insektenbestäubt

Früchte/Samen: rot-violette Steinfrüchte, lang gestielt, 1-2 cm im Durchmesser, glänzend; bittersüß, essbar; spätes Frühjahr bis Sommer; vogelverbreitet

Rinde: glatt, glänzend graubraun, große horizontale Lentizellen; horizontal schälend 


\section{Quercus robur - Stieleiche}
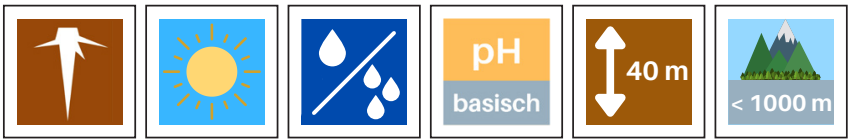

Quercus robur L. (Stieleiche) ist ein großer Laubbaum, der bis über $40 \mathrm{~m}$ hoch und über 1000 Jahre alt wird. Stieleichen variieren in der Form, mit einer unregelmäßigen Krone, die viel Sonnenlicht durchlässt. Der Stamm kann bei Solitärbäumen reich verzweigt sein, mit grauer bis brauner Rinde, die zerklüftet ist und tiefe Längsrisse aufweist. Das sehr harte, schwere und vielseitige Holz wird in der Möbel- und Bauindustrie und wegen seiner Beständigkeit gegen Flüssigkeiten als Fässer und im Schiffsbau verwendet.

Verbreitung, Lebensraum \& Ökologie

Wie Quercus petraea (Traubeneiche) ist Quercus robur in ganz Europa zu finden - von Südnorwegen im Norden bis zum Mittelmeerraum im Süden, wo sie mit anderen Eichen (Q. frainetto und Q. pubescens) hybridisiert. Sie ist eine wichtige Art des Aumischwaldes und kommt auf frischen bis feuchten, lehm- und tonreichen, schweren Böden in warmen Lagen vor. Sie toleriert Böden mit schlechter Nährstoffversorgung. Regelmäßige Überschwemmungen stellen kein Problem dar und aufgrund ihrer tiefen Pfahlwurzeln kann sie auch mäßige Trockenheit verkraften. Die Stieleiche ist eine lichtbedürftige Art, die ihre Blätter relativ spät entwickelt und dadurch Sonnenlicht auf den Waldboden durchlässt. Dies vermeidet nicht nur Schäden durch Spätfröste, sondern ermöglicht auch eine vielfältige Verjüngung. Die Stieleiche ist eine Pionierart in Gebieten wie Ebenen und Hügeln, aber eine Spätsukzessionsart in Auen und Tälern. Eichen kommen zusammen mit Hainbuchen (Carpinus betulus) vor und bilden die Carpinion betuli-Allianz, zu der auch Arten wie Eschen (Fraxinus excelsior und F. angustifolia) und Ahorne (Acer campestre, A. platanoides) gehören.

Die Baumart ist im gesamten Gebiet des Biosphärenreservats Mur-Drau-Donau zu finden.

\section{Forstwirtschaft \& Klimawandel}

Eichen brauchen in der Jugend viel Licht und intensive Pflege und gelten daher in der Forstwirtschaft als anspruchsvolle Baumarten. Es ist möglich, bei entsprechender Kronenpflege wertvolles Holz ab einem Alter von 90-120 Jahren zu gewinnen - wirtschaftliche Umtriebszeiten liegen bei etwa 130 Jahren. Eichen lassen sich gut im Stockausschlag vermehren, doch diese Ausschläge stellen keine optimale Voraussetzung für die Wertholzproduktion dar. Wo es möglich ist, sollte der Naturverjüngung der Vorzug gegeben werden. Wo Pflanzungen notwendig sind, ist die Verwendung geeigneter Herkünfte besonders wichtig. Eichen bieten eine wertvolle Nahrungsquelle für verschiedene Tiere, von Säugetieren über Vögel bis hin zu Insekten. Forstschädlinge wie der Eichenmehltau (Erysiphe alphitoides syn. Microspaera alphitoides) und der Eichenprozessionsspinner (Thaumetopoea processionea) können schwere Schäden verursachen und die Produktivität einschränken, indem sie verhindern, dass das Licht die Blätter erreicht bzw. die Bäume entlauben. Eine relativ neue Bedrohung ist das akute Eichensterben, das neben anderen Gründen (Luftverschmutzung, ungeeignete Pflegemaßnahmen) auf den Klimawandel zurückgeführt werden kann.

\section{Beschreibung}

Blätter: einfach, verkehrt-eiförmig-länglich, rund gelappt; $16 \mathrm{~cm}$ lang; kurzer Stiel $(2-7 \mathrm{~mm}$; Unterschied zu Q. petraea); Oberseite stumpf-dunkelgrün, Blattgrund mit Adern

Blüten: einhäusig; windbestäubt; weiblich: klein, rötlich, unauffällig; männlich: gelb-grüne hängende Kätzchen; erscheinen kurz nach den ersten Blättern

Früchte/Samen: Eicheln, in schuppigem Becher, mit langen Stielen (Unterschied zu Q. petraea) und Längsstreifen, große Entwicklungsreserven

Rinde: grau bis braun, im Alter tiefe Längsrisse 


\section{Ulmus laevis - Flatterulme}
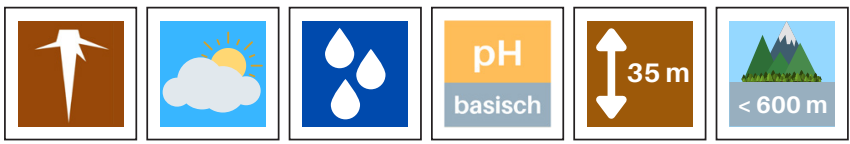

Ulmus laevis Pall., die Flatterulme ist ein mittelgroßer Laubbaum, der bis zu $35 \mathrm{~m}$ hoch und weit über 100 Jahre alt werden kann. Die Krone ist sehr variabel, von kuppelförmig bis kegelförmig. Der Stamm hat eine gefurchte, graubraune Rinde. Das Besondere ist die Ausbildung von Brettwurzeln - Verbindungen zwischen Wurzeln und Stamm - wie sie sonst vor allem bei Regenwaldarten vorkommen. Ulmen haben im Allgemeinen eine gute Holzqualität und sind für die Verwendung unter Wasser geeignet. Aufgrund der lebhaften Maserung gehört das Holz der Flatterulme, ebenso wie das der anderen Ulmenarten zu den dekorativsten Holzarten für den Innenausbau und den Möbelbau.

\section{Verbreitung, Lebensraum \& Ökologie}

Von den drei in Europa heimischen Ulmenarten (U. laevis, U. glabra und U. minor) hat die Flatterulme ein östlicheres Verbreitungsgebiet von Zentralfrankreich bis zum Uralgebirge. Ulmen sind in Überschwemmungsgebieten und in der Nähe von Flüssen und Bächen zu finden. Sie bevorzugen nährstoffreiche und periodisch überschwemmte Böden (ihre Überschwemmungstoleranz liegt bei ca. 119 Tagen/Jahr), können aber auch mäßig trockene Böden vertragen. Die Flatterulme eignet sich als Mischbaumart in Eichenwäldern und kommt zusammen mit Weiden (Salix spp.), Pappeln (Populus spp.), Erlen (Alnus spp.) und Eschen (Fraxinus spp.) vor.

Die Baumart ist im gesamten Gebiet des Biosphärenreservats Mur-Drau-Donau von Serbien bis Österreich zu finden.

Forstwirtschaft \& Klimawandel

Ulmen werden genutzt, um die Bodenerosion entlang von Flussufern abzumildern, besonders U. laevis kommt an gestörten und überfluteten Standorten gut zurecht. Durch die Regulierung von Wassereinzugsgebieten und den Verlust von Lebensraum sind ihre Populationen jedoch klein und fragmentiert geworden. In Zukunft muss ein besonderes Augenmerk auf die genetische Vielfalt der Art gelegt werden, da Ausbrüche des Ulmensterbens (Dutch Elm Disease, DED) in den letzten Jahrhunderten zu Verlusten im Genpool geführt haben, was zusammen mit Landschaftsveränderungen die Bewältigung des Klimawandels erschweren könnte.

\section{Beschreibung}

Blätter: unterschiedlich; wechselständig, dunkelgrün, an der Spitze zugespitzt, gezähnt, auf der Oberseite glatt und flaumig; wirft die Blätter früher ab als U. minor

Blüten: zwittrig, einhäusig; langstielig; erscheinen vor den Blättern; Trauben von 10-30; langstielig (2 cm), ohne Blütenblätter, dunkelrot; windbestäubt

Früchte/Samen: eiförmige Flügelnussfrüchte; einzelne zentrale Nuss, Membran mit haar-fransigem Rand; reift im späten Frühjahr

Rinde: braun-grau, tief gefurcht 


\section{Ulmus minor - Feldulme}
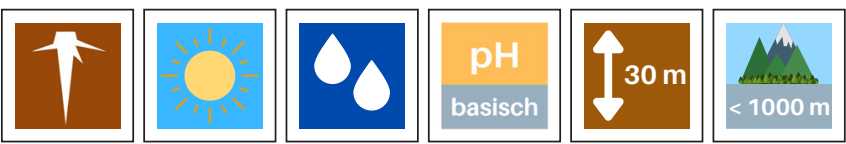

Die Feldulme (Ulmus minor Mill.) ist ein mittelgroßer Laubbaum, der bis zu $30 \mathrm{~m}$ hoch und in Ausnahmefällen bis zu 600 Jahre alt wird. Die Krone ist abgerundet und die Rinde des Stammes ist rau und leicht gefurcht, oft mit Korkstreifen. Die Holzverwendung entspricht weitgehend der der Flatter- und der Bergulme, die alle drei gemeinsam unter dem Begriff Rüster vermarktet werden. Im Vergleich zur Flatterulme ist das Kernholz rötlich-schokoladenbraun und unterscheidet sich vom gelblichweiß bis grau gefärbten Splintholz.

Verbreitung, Lebensraum \& Ökologie

Ulmus minor hat die südlichere Verbreitung der drei europäischen Ulmenarten (U. laevis und U. glabra). Sie ist im Süden bis in den Iran, Israel und Algerien zu finden; die nördlichste Ausdehnung ist jedoch das Baltikum. Dieser Uferbaum wächst entlang von Bächen in Süd- und Mitteleuropa und in bewaldeten Steppen im Norden, da er sowohl mit Staunässe (Überschwemmungstoleranz von bis zu 151 Tagen) als auch mit Trockenstress umgehen kann. Die Feldulme ist eine lichtbedürftige, schnellwüchsige Pionierart, die sich recht schnell vermehren kann. Sie ist Teil von gemischten Auwaldgesellschaften zusammen mit Eschen (Fraxinus spp.), Weiden (Salix spp.) und Eichen (Quercus spp.).

Die Baumart ist im gesamten Gebiet des Biosphärenreservats Mur-Drau-Donau von Serbien bis in die östlichen und nördlichen Regionen Österreichs zu finden.

Forstwirtschaft \& Klimawandel

Ulmen werden verwendet, um die Bodenerosion entlang von Flussufern abzumildern, wobei Ulmus minor Überschwemmungen besser verträgt als andere Arten, wie die Gemeine Esche (Fraxinus excelsior). Besonders die Feldulme wurde auch an Straßenrändern und in städtischen Gebieten verwendet, da sie sich leicht wieder austreiben und durch Ableger vermehren kann. Traditionell wurde sie auch zur Herstellung von Kleinholzprodukten und Tierfutter genutzt, wobei diese Verwendungen heute keine Rolle mehr spielen.

Ausbrüche des Ulmensterbens (Dutch Elm Disease, DED) im letzten Jahrhundert haben die Feldulme und ihren Genpool stark in Mitleidenschaft gezogen, so dass sie als regional am stärksten bedrohte Ulmenart auf der Roten Liste der gefährdeten Arten steht. Die Ursache für das massive Ulmensterben ist eine Infektion mit dem Schlauchpilz Ophiostoma novo-ulmi. Der Pilz wird durch die Ulmensplintkäfer übertragen, wenn diese an Ästen gesunder Ulmen fressen.

Die Feldulme hybridisiert mit der Bergulme (U. glabra) - wodurch Zwischenformen entstehen, die als Ulmus $x$ holandica (Holländische Ulme) bekannt sind - und mit der sibirischen Ulme (U. pumila), die aus Asien eingeführt wurde. Im Allgemeinen ist Ulmus minor eine sehr polymorphe und genetisch komplexe Art, mit mehreren Unterarten und Varietäten, die an unterschiedliche Bedingungen angepasst sind, was in einem sich verändernden Klima ein Vorteil sein kann. Studien in Deutschland haben zum Beispiel gezeigt, dass U. minor zu den am besten angepassten Arten für ein wärmeres und trockeneres Klima gehört.

\section{Beschreibung}

Blätter: asymmetrisch, kahl, glänzend; haben nur eine Spitze (anders als bei der Bergulme); gezähnt, 4-10 cm lang; schwarze Drüsen entlang der Blattadern

Blüten: einhäusig, zwittrig; Büschel von 10-30, geschlossen am Trieb; glockenförmig, purpurrot; erscheinen im Frühjahr vor den Blättern

Früchte/Samen: eiförmige Flügelnussfrüchte, einzelner Nusssamen über der Mitte der Flügelmembran; Reife im späten Frühjahr

Rinde: rau, gefurcht, oft mit Korkstreifen 


\section{Salix spp. - Weiden}
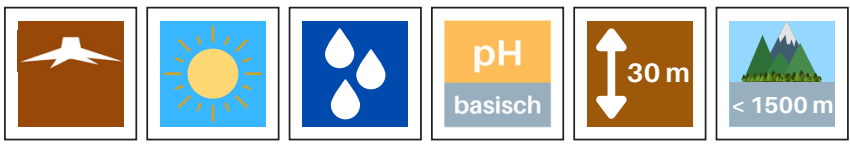

Weiden (Salix spp.) sind schnell wachsende Laubbäume und Sträucher, die als Bäume eine Höhe von bis zu 30 m erreichen, relativ kurzlebig sind und maximal bis zu 100 Jahre alt werden. Es gibt eine hohe Anzahl an Weidenarten in Europa, die eine Vielzahl von wirtschaftlichen Verwendungen haben, darunter Holz für Sportgeräte, Körbe und Zäune, Tannin und Salicin und andere Nichtholzprodukte.

\section{Verbreitung, Lebensraum \& Ökologie}

In Europa sind Weiden vom Mittelmeerraum bis zu den Britischen Inseln und dem Baltikum zu finden. Sie kommen von Spanien bis China vor, hauptsächlich in gemäßigten und borealen Wäldern. Anders als bei anderen Taxa nimmt die Anzahl der Weidenarten vom Süden zum Norden hin zu.

Weiden können recht leicht hybridisieren und wurden in großem Umfang kultiviert, so dass ihr natürliches Verbreitungsgebiet schwer zu bestimmen ist. Die Silberweide (Salix alba L.) ist in Auwäldern weit verbreitet. Wie andere Weidenarten kann sie auf einer Vielzahl von Böden vorkommen, vorausgesetzt, die Wurzeln haben Zugang zu Wasser. Weiden bevorzugen lehmige (S. fragilis) oder schluffige ( $S$. alba), kalkhaltige (S. caprea) oder sandige Böden (S. purpurea). Sie sind im Allgemeinen sehr tolerant gegenüber Überschwemmungen, wobei S. alba besonders gut mit Überschwemmungen zurechtkommt (Überschwemmungstoleranz von bis zu 300 Tagen/Jahr). Andere Arten sind etwas anfälliger für ständige Überschwemmungen, wie z. B. S. caprea, nehmen aber immer noch einen hohen Rang im Vergleich zu anderen Ufergehölzen ein. Salix-Arten sind lichtbedürftig und vertragen Schatten nicht sehr gut. Sie wachsen meist in offenen Bereichen. S. caprea ist jedoch eine der wenigen Weidenarten, die im Unterholz von Wäldern vorkommt. Weiden kommen in Mischwäldern zusammen mit Arten wie Buche (Fagus spp.), Ulme (Ulmus spp.), Eiche (Quercus spp.) und Pappel (Populus spp.) vor.

Weidenarten, darunter Salix alba, S. caprea und S. purpurea, sind im gesamten Gebiet des Biosphärenreservats Mur-Drau-Donau von Österreich bis Serbien zu finden.

\section{Forstwirtschaft \& Klimawandel}

Weiden kreuzen sich leicht untereinander, was zu mehreren Hybriden führt, darunter Salix x rubens (S. alba x S. fragilis), Salix x margaretea (S. purpurea $x$ S. fragilis) und Salix $x$ wimmeriana (S. purpurea $x$ S. caprea). Diese Tatsache könnte bei der Anpassung an den Klimawandel helfen, da die Hybriden genutzt werden können, um stark gestörte Lebensräume zurückzugewinnen, wo andere Arten nicht mehr zurechtkommen. Darüber hinaus können die meisten Weiden durch Stockausschlag vermehrt und geschneitelt werden und sich vegetativ aus Ablegern vermehren. Eine Ausnahme ist die Salweide (S. caprea), die nur gelegentlich durch Stecklinge vegetativ vermehrt werden kann.

In Bezug auf Ökosystemleistungen sind Weiden unter anderem wichtig für den Schutz von Wassereinzugsgebieten, die Bodenstabilisierung und die Erosionsminderung. Sie werden bei der Wiederherstellung von Ökosystemen und der Phytosanierung eingesetzt, aber auch in der landwirtschaftlichen Landschaftsgestaltung als Hecken und Windschutz.

Weiden sind in Europa in einer Vielzahl von klimatischen Bedingungen zu finden. Mit einem sich ändernden Klima ist eine Veränderung der Baumartenzusammensetzung in Europas Wäldern zu erwarten, so dass einige Weidenarten andere in ihrem ursprünglichen Verbreitungsgebiet ersetzen könnten. Weiden können Überschwemmungen tolerieren, aber Arten, die in gezeitenabhängigen Feuchtgebieten wachsen (z. B. S. alba und S. viminalis), werden auch von der Salzintrusion aufgrund des Klimawandels betroffen sein. Es wurde gezeigt, dass ausgewachsene Bäume mit solchen oligohalinen Bedingungen zurechtkommen.

\section{Beschreibung}

Blätter: lang und schmal (lanzettlich), fein gezähnt; oberseits silbergrau, unterseits dicht weiß behaart; wechselständig

Blüten: zweihäusig; männliche Kätzchen gelb, bis $5 \mathrm{~cm}$ lang; weibliche Kätzchen grünlich-gelb, werden flaumig weiß, kürzer; erscheinen im zeitigen Frühjahr vor den Blättern; insektenbestäubt

Früchte/Samen: Kapselfrüchte, graufilzig, eiförmig; ohne Stiel; sehr kleine Samen

Rinde: rötlich bis graubraun, später gelb-grau; Längsrisse 


\subsubsection{Alternative Baumarten und Klone}

\section{Juglans nigra - Schwarznuss}
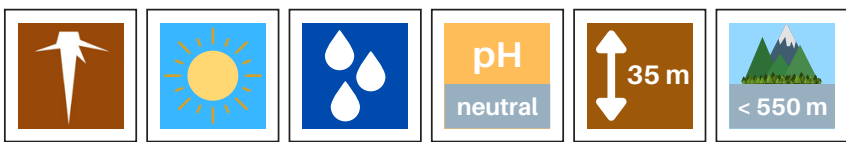

Die Schwarznuss (Juglans nigra L.) ist ein schnellwüchsiger, lichtbedürftiger Laubbaum, der aus Nordamerika eingeführt wurde. Sie wird 25-35 m (max. $40 \mathrm{~m}$ ) hoch und 200-300 Jahre alt. Sie entwickelt lange, bis zu $2 \mathrm{~m}$ dicke Stämme mit einer breiten Krone. Das Holz besitzt eine hohe Festigkeit, ist gerad- und feinfaserig und zäh. Es zählt zu den teuersten Möbelhölzern der Welt, wird aber auch für Fußböden, Furniere, Skulpturen und Musikinstrumente verwendet.

\section{Verbreitung, Lebensraum \& Ökologie}

Das ursprüngliche Verbreitungsgebiet der Schwarznuss ist Nordamerika, einschließlich der östlichen und zentralen Teile der USA und des südlichen Ontarios. Nach Europa wurde sie wahrscheinlich zu Beginn des 17. Jahrhunderts eingeführt. Seitdem wurde sie in etwa 15 europäischen Ländern als Zier- und Waldbaum angepflanzt. Juglans nigra benötigt nährstoffreiche (z. B. Ca, K, Mg), lehmige Böden mit einem pH-Wert von 6-7. Sie verträgt keinen Kalkstein, ist empfindlich gegen Pseudogley und verlangt einen tiefgründigen Boden $(>60 \mathrm{~cm})$ über kalkhaltigem Grundgestein. Ideale Standorte sind an süd- oder südwestlich ausgerichteten Hängen in warmen und geschützten Lagen. Hier kann das weitverzweigte Wurzelsystem mit tiefer Pfahlwurzel sowohl Baum als auch Boden stabilisieren. Die Böden müssen gut durchlässig sein, aber ständig mit Wasser versorgt werden - entweder mit Grundwasser oder mit Regen (Mindestjahresniederschlag variiert von $600 \mathrm{~mm}$ bis $900 \mathrm{~mm}$ ). Ausgewachsene Bäume können Überschwemmungen von bis zu 90 Tagen während der Wachstumsperiode überstehen. Berichte über Trockenheitsresistenz variieren von mäßig resistent bis sehr empfindlich. Sie kann jedoch Sommertrockenheit tolerieren, wenn der Boden ausreichend gesättigt ist. Sämlinge können durch Verbiss von Tieren wie Rehen oder Wühlmäusen beschädigt werden. Allerdings ist die Schwarznuss auf die Samenverbreitung durch Nagetiere und Vögel angewiesen, für welche die Nüsse (wie für den Menschen) sehr nahrhaft sind.

Heimisch in Nordamerika, wurde Juglans nigra in alle Partnerländer eingeführt. In Österreich fanden die ersten Versuchsanbauten in den Donau-Auwäldern gegen Ende des 19. Jahrhunderts statt. In Slowenien und Serbien wurde die Schwarznuss erstmals gegen Ende des 19. Jahrhunderts (1889 bzw. 1890) in die Wälder eingeführt. In Serbien bedeckt sie heute etwa 0,1 \% der nationalen Wälder. In Ungarn wurde Juglans nigra erstmals im 18 . Jahrhundert eingeführt und bedeckt heute ca. 0,4\% der Waldfläche und gilt als eine der wertvollsten exotischen Baumarten. In Kroatien wurden die ersten Kulturen der Schwarznuss um 1890 angelegt.

\section{Forstwirtschaft \& Klimawandel}

Die Schwarznuss wird hauptsächlich für die Produktion von hochwertigem Holz angebaut. Juglans nigra ist sehr lichtbedürftig und verträgt keinen Schatten, besonders als ausgewachsener Baum. Aufgrund dieser geringen Schattentoleranz ist eine natürliche Verjüngung über Samen selten. Die Schwarznuss wird überwiegend mit 1-jährigen Sämlingen kultiviert aber auch die Saat scheint eine erfolgsversprechende Methode zu sein. Junge Sämlinge wachsen schnell mit bis zu $1 \mathrm{~m}$ pro Jahr. Sie beginnen im Alter von etwa 8 bis 10 Jahren zu fruchten, wenn sie 7-8 m hoch sind. Bedeutende Samenerträge sind ab 20-30 Jahren zu erwarten. In Mischbeständen werden sie mit Arten wie Esche (Fraxinus spp.), Ahorn (Acer spp.) oder Eiche (Quercus spp.) kultiviert, wo sie schneller wachsen als die heimischen Arten. Die Schwarznuss ist auch anfällig für Schädlinge und Krankheiten (z. B. Thousand cankers disease, TCD). Da die Schwarznuss mit niedrigen Wintertemperaturen (bis zu $-40^{\circ} \mathrm{C}$ ) zurechtkommt, besteht ein geringes Risiko von Frostschäden. Allerdings sind sie sehr empfindlich gegenüber Spätfrost im Frühjahr, was ihre Verbreitung einschränkt. Da die Schwarznuss wärmeliebend ist und von Haus aus nur auf nährstoffreichen, gut wasserversorgten Standorten wächst, dürfte ihre Bedeutung im Klimawandel noch zunehmen. 


\section{Beschreibung}

Blätter: zusammengesetzt, gleichmäßig gefiedert, zugespitzt, 9-23 Fiederblättchen; wechselständig; gesägter Rand; dunkelgrün, auf der Unterseite behaart

Blüten: einhäusig; männliche Kätzchen hängend, $8-10 \mathrm{~cm}$; weibliche Blüten endständig, Büschel von 2-5, erscheinen vor den männlichen; selbstkompatibel

Früchte/Samen: grünliche Schale, geriffelte Nuss, $8 \mathrm{~cm}$ Durchmesser; reifen im Oktober; Verbreitung durch Vögel und Nagetiere

Rinde: grau-schwarz, tief in dünne Furchen gefurcht 


\section{Populus $x$ euramericana - "Hybridpappel”}
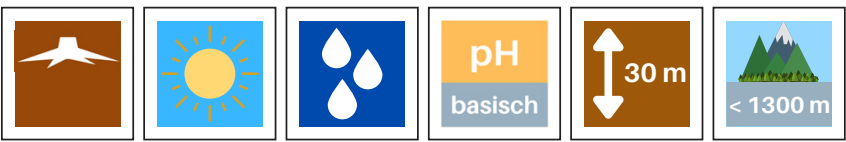

Die Hybridpappel Populus x euramericana erreicht eine Höhe von über $30 \mathrm{~m}$. Sie ist ein schnellwüchsiger Baum mit den Elternarten P. nigra aus Europa und P. deltoides aus Nordamerika. Die vielen Varietäten unterscheiden sich stärker in ihrer Wuchsleistung sowie in ihren ökologischen Ansprüchen als in ihrer Morphologie, was eine taxonomische Bearbeitung sehr erschwert. Die Hybriden bieten Anpassungsfähigkeit an verschiedene Boden- und Klimabedingungen sowie an einige Schädlinge und Krankheiten, was sie für die Forstwirtschaft attraktiv macht.

Verbreitung, Lebensraum \& Ökologie

Kanadische Pappeln aus Nordamerika wurden von der Forstwirtschaft gegen Ende des 19. Jahrhunderts mit verschiedenen europäischen Pappelarten gekreuzt. Populus $x$ euramericana wird kultiviert und kommt in vielen europäischen Ländern wild vor. P. x euramericana benötigt für ein gutes Wachstum gut durchlüftete und wasserversorgte eutrophe Böden - besonders günstig sind sandig-lehmige Bodenarten im $\mathrm{pH}$-Bereich von 6,0 bis 7,5. Pappeln sind schnell wachsende Bäume, die in der Jugend sehr lichtbedürftig sind und daher Pioniere bei der Besiedlung von Freiflächen sind. Vor allem auf Auwaldstandorten, die bei Hochwasser überflutet werden, aber auch auf Ruderalstandorten sind Hybridpappeln zu finden. Im Bereich der Silberweidenaue sind Hybridpappeln wegen zu starker Überflutung nicht dauerhaft überlebensfähig. Sie werden daher am häufigsten auf den reiferen Standorten der Weichen Au am Übergang zur Harten Au gepflanzt. Populus $x$ euramericana ist sehr regenerationsfähig - nach dem Schnitt bildet sie bereits im ersten Jahr meterlange Triebe. Sie vermehrt sich vegetativ durch Wurzelsprossen aus bis zu $35 \mathrm{~m}$ langen Wurzeln.

Populus $x$ euramericana wird im gesamten Biosphärenreservat Mur-Drau-Donau von Österreich bis Serbien in unterschiedlichem Ausmaß angebaut.

\section{Forstwirtschaft \& Klimawandel}

Hybridpappeln werden wegen ihrer sehr geraden Stammausbildung zur Holzproduktion gepflanzt - sie liefern helles, weiches, diffusporiges Holz. Aufgrund ihres schnellen Wachstums sind auf guten Standorten Umtriebszeiten von 25 Jahren möglich - neuerdings werden auch spezielle Klone in extremer Kurzumtriebszeit zur Energiegewinnung angebaut. Der prognostizierte Klimawandel wird die Art-Hybriden begünstigen, da sie auf ansonsten geeigneten Standorten auch Dürreperioden und andere Wetterextreme überstehen können.

In Bezug auf die Forstwirtschaft mit Hybridpappeln steht die Sortenzüchtung im Vordergrund, da Krankheiten ein Problem darstellen: Rostpilzbefall an den Blättern ist die wichtigste Krankheit bei Pappeln. Zwei Pilzarten aus der Gattung Melampsora befallen P. x euramericana (M. allii-populina Kleb. und M. larici-populina Kleb.). Zusätzlich besiedelt der Pilz Dothichiza populea bereits durch Frost geschädigte Äste. Er ist ein typischer Schwächeparasit, der an Standorten mit schwankendem Wasserhaushalt oder Staunässe vermehrt auftritt. Nur durch die ständige Entwicklung neuer Sorten können solche Krankheiten in Schach gehalten werden. Ein weiteres Problem für P. x euramericana ist die weiße Mistel, Viscum album, die nur Hybridpappeln, nicht aber heimische Schwarzpappeln befällt.

\section{Beschreibung}

Blätter: austreibende Blätter rötlich (bei Schwarzpappeln grün) und an den Rändern behaart; oft Drüsen an der Basis des Blattstiels; ausgewachsene Blätter dreieckig mit langen, ausgebreiteten Spitze; 7-10 cm lang und an den Rändern gezähnt bis gekerbt; langer Blattstiel ist seitlich abgeflacht

Blüten: zweihäusig, männliche und weibliche Blütenstände bis zu $9 \mathrm{~cm}$ lange, hängende Kätzchen; Hybridpappeln werden hauptsächlich als männliche Klone vermehrt.

Früchte/Samen: Kapseln, dick, spitz, grünlich-braun, gestielt; Samen sind behaart

Rinde: hellgrau, rissig; horizontale Korkwülste (anders als bei Schwarzpappel) 


\section{Robinie pseudoacacia - Robinie}
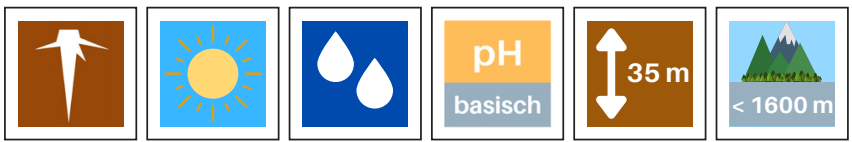

Robinia pseudoacacia L., die Robinie, ist ein schnellwüchsiger, mittelgroßer, sommergrüner Baum, der aus Nordamerika nach Europa eingeführt wurde. Er kann bis zu 35 m hoch werden und wird etwa 60-100 Jahre alt. Die Stammform weist eine hohe Variabilität auf (von stark gekrümmt bis sehr gerade, je nach Sorte). Das Holz ist langlebig und resistent gegen Insektenfraß und Pilzbefall, es ist das resistenteste Holz in Mitteleuropa. Es wird für Fußböden und Möbel, aufgrund der hohen Resistenz aber auch für den Außenbereich (Fassaden, Spielplätze), für den Bootsbau und Eisenbahnschwellen verwendet. Zusätzlich kann es als Brennholz und zur Biomasseproduktion verwendet werden.

Verbreitung, Lebensraum \& Ökologie

Das natürliche Verbreitungsgebiet der Robinie liegt im östlichen Nordamerika, vor allem in den Appalachen bis in Höhenlagen von 1.500 m. Nach Europa wurde sie bereits im 17. Jahrhundert als Zier- und Parkbaum eingeführt und im 18. und 19. Jahrhundert weit verbreitet angepflanzt. Die forstliche Nutzung hat zunächst eine sehr untergeordnete Rolle gespielt. Seitdem hat sie sich auf dem ganzen Kontinent eingebürgert. Heute findet man sie von Portugal bis zum Kaukasus und von Skandinavien bis Süditalien. Robinia pseudoacacia ist eine lichtbedürftige Pionierart, die in einer Vielzahl von Bodenbedingungen von sauer ( $\mathrm{pH} 3$ ) bis alkalisch ( $\mathrm{pH} 8$ ) wächst. Sie toleriert trockene und salzige Standorte, meidet aber nasse (geringe Überschwemmungstoleranz) und verdichtete Standorte. Der bevorzugte mittlere Jahresniederschlagsbereich liegt bei 700-2000 mm. Die Robinie ist sehr frostempfindlich und stellt in geschlossenen, schattigen Beständen eine schwache Konkurrenz dar. In offenen Bereichen, wie Waldrändern oder gestörten Böden, ist sie jedoch sehr konkurrenzstark. Sie ist auf sehr nährstoffarmen Standorten zu finden, da sie eine symbiotische Beziehung mit Rhizobien-Bakterien eingeht, die es ihr ermöglicht, Luftstickstoff zu fixieren und damit die Bodenbedingungen auch für andere Arten zu verändern. Von dieser Fähigkeit profitiert sie, wenn sie jung ist und dadurch sehr schnell wächst. Bereits im Alter von drei Jahren beginnt sie zu blühen und Samen zu produzieren, was sie zu einer wichtigen Nahrungsquelle für Insekten wie Bienen und Schmetterlinge macht.

Die Robinie ist in allen Ländern des Biosphärenreservats Mur-Drau-Donau zu finden, wobei sie in Ungarn die am weitesten verbreitete Baumart ist und etwa $24 \%$ der bewaldeten Fläche einnimmt.

\section{Forstwirtschaft \& Klimawandel}

In einigen Gebieten Europas wurde die Verwendung der Robinie in der Forstwirtschaft stark gefördert, heute wird sie in mehreren europäischen Datenbanken als stark invasive Baumart eingestuft. Aufgrund ihres schnellen Wachstums, ihrer hohen Vermehrungsfähigkeit durch Stockausschlag und Wurzelbrut und ihrer Fähigkeit zur Bodenverbesserung kann sie zur Rekultivierung von Brachfächen wie ehemaligen Bergbaustandorten eingesetzt werden. Allerdings kann diese Bodenanreicherung auch zur Verdrängung seltener heimischer Arten führen, die auf nährstoffarme Standorte angewiesen sind. So hat die Robinie die Fähigkeit, ganze Ökosysteme zu verändern. Managementmaßnahmen zur Entfernung der Robinie sind arbeits- und zeitintensiv sowie teuer und konzentrieren sich auf die Ringelung, da das Umschneiden der Bäume den Wiederaustrieb fördert. Daher sollte ihre Einführung gut überlegt sein und die Risiken und Vorteile vorher abgewogen werden. Wo es als sicher für den Anbau gilt und der waldbauliche Zweck klar definiert ist, kann sie hochwertige Produkte mit Eigenschaften wie hoher Schlagzähigkeit, Zugfestigkeit und Dauerhaftigkeit ohne Imprägnierung liefern. Da Frost ein begrenzender Faktor ist, ist zu erwarten, dass ihre Verbreitung aufgrund des Klimawandels zunehmen wird und sie heimische Arten in ihren Ökosystemen und in der Forstwirtschaft verdrängen könnte.

\section{Beschreibung}

Blätter: zusammengesetzt, gefiedert, 2-12 Paare, 10-30 cm; Blattspreiten länglich, elliptisch bis eiförmig; gegenständig; Dornenpaar am Grund

Blüten: einhäusig, zwittrig; weiß bis cremefarben, innen gelb gefleckt; gruppiert in hängenden Trauben, $10-20 \mathrm{~cm}$ lang

Früchte/Samen: Hülsenfrucht; dunkelbraune Schoten, 5-10 cm; 4-10 Samen; hängend im Winter; Verbreitung über Schwerkraft und Wind; Fruchtbildung 1-2/Jahr

Rinde: graubraun bis dunkelbraun; im Alter längsrissig werdend 


\subsection{Glossar}

\begin{tabular}{|c|c|}
\hline Begriff & Erklärung \\
\hline Adaptation, Anpassung & $\begin{array}{l}\text { Der Begriff Anpassung hat verschiedene Bedeutungen. } \\
\text { Auf biologischer Ebene bezeichnet Anpassung die Leistung eines Individuums oder einer } \\
\text { Gruppe von Individuen (Population) sein Verhalten, Wachstum, physiologische Leistung } \\
\text { (also jegliche Lebensäußerung) auf die jeweiligen, u. U. auch veränderlichen Umweltbedin- } \\
\text { gungen abzustimmen, um sein Überleben und seine Reproduktionsfähigkeit zu verbessern. } \\
\text { Auf Ebene der Gesellschaft bzw. eines Waldbewirtschafters wird unter Anpassung die } \\
\text { Veränderung des Verhaltens oder der Waldbewirtschaftung beschrieben, um besser mit zu- } \\
\text { künftigen Bedingungen umgehen zu können. Für die Waldbewirtschaftung wird vor allem } \\
\text { die Anpassung an den Klimawandel diskutiert. }\end{array}$ \\
\hline Anpassungsfähigkeit & $\begin{array}{l}\text { Siehe Anpassung. Die Anpassungsfähigkeit gibt das Vermögen eines Individuums oder } \\
\text { einer Gruppe von Individuen (Population) an, auf Umweltveränderungen (insb. Klima- } \\
\text { wandel) durch Veränderungen seiner physiologischen, morphologischen oder genetischen } \\
\text { Eigenschaften zu reagieren. }\end{array}$ \\
\hline Autochthon & $\begin{array}{l}\text { Bodenständigkeit. Ein Waldbestand (bzw. eine Baumpopulation) wird als autochthon } \\
\text { (bodenständig) bezeichnet, wenn er nach bestem Wissen, aus natürlicher Verjüngung } \\
\text { hervorgegangen ist und ggf. charakteristische Eigenschaften aufweist, die ihn von anderen } \\
\text { Beständen unterscheiden. }\end{array}$ \\
\hline $\begin{array}{l}\text { Bakterienfluss oder } \\
\text { Exudate }\end{array}$ & $\begin{array}{l}\text { Absonderung einer Flüssigkeit am Stamm: Zeichen einer bakteriellen Infektion die haupt- } \\
\text { sächlich aus Bakterien besteht. }\end{array}$ \\
\hline $\begin{array}{l}\text { Canker oder Baum- } \\
\text { krebs }\end{array}$ & $\begin{array}{l}\text { Wucherung an Rinde, Stamm oder Zweig, die von einer parasitischen Infektion hervor- } \\
\text { gerufen wird und durch die Reaktion des Baumes entsteht, bei der Kalluszellen zum Ab- } \\
\text { schluss der Infektion bzw. Wundheilung gebildet werden. }\end{array}$ \\
\hline Ergänzungspflanzung & $\begin{array}{l}\text { Eine Form der künstichen Verjüngung, bei der eine bestehende Naturverjüngung durch die } \\
\text { Pflanzung zusätzlicher Sämlinge ergänzt wird, um die ökologischen, gesellschaftlichen oder } \\
\text { wirtschaftlichen Leistungen des Waldes zu verbessern. }\end{array}$ \\
\hline $\begin{array}{l}\text { Forstliches Vermeh- } \\
\text { rungsgut }\end{array}$ & $\begin{array}{l}\text { Vermehrungsgut der Baumarten und ihrer künstlichen Hybriden, die für forstliche Zwecke } \\
\text { in den Mitgliedstaaten der Europäischen Union von Bedeutung sind. Vermehrungsgut um- } \\
\text { fasst Saatgut (Zapfen, Fruchtstände, Früchte und Samen), Pflanzenteile (Spross-, Blatt- und } \\
\text { Wurzelstecklinge, Explantate und Embryonen für mikrovegetative Vermehrung, Knospen, } \\
\text { Absenker, Ableger, Wurzeln, Pfropfreiser, Steckhölzer, Setzstangen und andere Pflanzentei- } \\
\text { le) sowie Pflanzgut (aus Saatgut oder Pflanzenteilen angezogene Pflanzen oder aus Natur- } \\
\text { verjüngung geworbene Pflanzen). }\end{array}$ \\
\hline Fruchtkörper & $\begin{array}{l}\text { Fortpflanzungsorgane mehrzelliger Pilze, in denen die Sporen zur Vermehrung ausgebildet } \\
\text { werden. }\end{array}$ \\
\hline $\begin{array}{l}\text { Genetische Ressour- } \\
\text { cen }\end{array}$ & $\begin{array}{l}\text { Genetisches Material von aktuellem oder potentiellem Wert, wobei genetisches Material } \\
\text { jegliches Pflanzenmaterial umfasst, das funktionell Gene an Nachkommen weitergeben } \\
\text { kann. Siehe auch forstliches Vermehrungsgut. }\end{array}$ \\
\hline
\end{tabular}




\begin{tabular}{|c|c|}
\hline Begriff & Erklärung \\
\hline Genetische Vielfalt & $\begin{array}{l}\text { Variation zwischen Individuen, sowie innerhalb und zwischen Populationen einer Art, die } \\
\text { auf den Unterschieden ihrer Gene beruht. }\end{array}$ \\
\hline $\begin{array}{l}\text { Natürliche Selektion } \\
\text { (Auslese) }\end{array}$ & $\begin{array}{l}\text { Eine der grundlegenden Mechanismen der Evolution. Vorraussetzung für natürliche Selek- } \\
\text { tion ist das Vorhandensein von Unterschieden in bestimmten Merkmalen (bei Bäumen z.B. } \\
\text { Wachstum, Zeitpunkt das Austriebs, Resistenz gegenüber Schädlingen, etc.), wobei diese } \\
\text { Unterschiede genetisch bedingt sein müssen, d.h. sie müssen ganz oder teilweise an die } \\
\text { Nachkommen vererbt werden können. Natürliche Selektion entsteht, wenn die jeweilige } \\
\text { Ausprägung der vererbten Merkmale für das betroffene Individuum zu einem besseren } \\
\text { Wachstum und Überleben, einer besseren Ausbreitung und einer verbesserten Produktion } \\
\text { von Nachkommen führt. }\end{array}$ \\
\hline Nekrotische Läsion & $\begin{array}{l}\text { Ein schwarzer, abgestorbener Abschnitte der Rinde, des Stamms oder eines Astes ohne } \\
\text { Kallusbildung. }\end{array}$ \\
\hline Niederwald & $\begin{array}{l}\text { Ein Wald, dessen Bewirtschaftung sich durch das regelmäßige flächige Zurückschneiden } \\
\text { bzw. Fällen von Sträuchern und Bäumen auszeichnet und bei dem sich die gefällten Bäume } \\
\text { überwiegend vegetativ vermehren, d.h. die nächste Generation treibt aus den verbliebenen } \\
\text { Wurzelstöcken aus. Diese traditionelle Art der der Waldbewirtschaftung wurde vor allem } \\
\text { zur Brennholzproduktion eingesetzt. }\end{array}$ \\
\hline Population & $\begin{array}{l}\text { Eine Gruppe von Individuen derselben Art, die gemeimsam in einem bestimmten Gebiet } \\
\text { vorkommt und die sich untereinander fortpflanzen können. }\end{array}$ \\
\hline Rhachis & Blattstiel und Hauptnerv eines Blattes \\
\hline Ringeln, Ringelung & $\begin{array}{l}\text { Stammumfassende Entfernung der Rinde und der darunterliegenden Kambiumschicht, } \\
\text { um den Transport von Phloemsaft (wässrige Lösung in der die Photosyntheseprodukte } \\
\text { gelöst sind und die von der Krone in den Stamm und die Wurzeln transportiert wird) zu } \\
\text { unterbinden. Durch das Ringeln wird der Baum nachhaltig geschädigt und langsam zum } \\
\text { Absterben gebracht. }\end{array}$ \\
\hline Untersaat & $\begin{array}{l}\text { Direktausaat von Baumsamen in Waldbeständen, die verjüngt werden sollen unter vollem } \\
\text { oder aufgelichtetem Schirm - wird auch genutzt, um Naturverjüngung durch zusätzliche } \\
\text { Saat zu ergänzen. }\end{array}$ \\
\hline Wertholzsubmission & $\begin{array}{l}\text { Öffentliche Auktion auf der wertvolle Einzelstämme von Laub- und Nadelholz verkauft } \\
\text { werden. }\end{array}$ \\
\hline
\end{tabular}




\subsection{Referenzen pro Kapitel}

\subsection{Fallstudie: Sicht von Interessensgruppen auf die Bewirtschaftung und den Schutz von Auwäldern im Bio- sphärenreservat Mur-Drau-Donau}

1. Interreg Danube REFOCuS D6.1.1. (2019) Report on the overview of the national legislations of the five countries constituting Biosphere Reserve Mura-Drava-Danube and EU regulations and directives relevant for health, conservation and management of riparian forests.

2. Interreg Danube REFOCuS. WP6 Policy Interface. (2020). Report from the Online stakeholders workshop: How to harmonize forest management planning and nature conservation in riparian forests of Biosphere Reserve Mura-Drava-Danube?

3. Stevanov M, Tarjan Tobolka A, Kljajic L, Kičić M, Krott M (2021) Analysis of conflicting interests on the example of the special nature reserve in Serbia: empirically analytical approach. Šumarski list 145(3-4), 155-167. https://doi.org/10.31298/sl.145.3-4.5

\subsection{Relevanz und Gefährdung der Auwälder}

1. Allard G, Sigaud P (2005). Alien Invasive Species: Impacts on Forests and Forestry - A Review. Forest Resources Development Service Working Paper FBS/8E Forest Resources Division FAO, Rome, Italy Forestry Department. Retrieved March 30, 2020, from http://www.fao.org/3/i6854e/J6854E06.htm

2. Arcanum (2017) Historical Maps of the Habsburg Empire First Military Survey 1763-1787. Österreichischen Staatsarchiv. Retrieved from http://mapire.eu/en/

3. Bastian O, Bernhardt A (1993) Anthropogenic landscape changes in Central Europe and the role of bioindication. Landscape Ecology 8(2) 139-151. https://doi.org/10.1007/BF00141593

4. Bebber DP (2015) Range-Expanding Pests and Pathogens in a Warming World. Annual Review of Phytopathology 53(1) 335-356. https://doi.org/10.1146/annurev-phyto-080614-120207

5. Bonacci O, Oskorš D (2010) The changes in the lower Drava River water level, discharge and suspended sediment regime. Environmental Earth Sciences 59(8) 1661-1670. https://doi.org/10.1007/s12665-009-0148-8

6. Bonacci O, Oskoruš D (2008) The influence of three Croatian hydroelectric power plants operation on the river Drava hydrological and sediment regime. Hydrological Forecasting. Retrieved from http://ksh.fgg.uni-lisi/bled2008/cd_2008/05_Floods, morphological processes, erosion, sediment transport and sedimentation/005_Bonacci.pdf

7. Boyd IL, Freer-Smith PH, Gilligan CA, Godfray HCJ (2013, November 15) The consequence of tree pests and diseases for ecosystem services. Science. American Association for the Advancement of Science. https://doi.org/10.1126/science.1235773

8. Charles H, Dukes JS (2007) Impacts of Invasive Species on Ecosystem Services. Biological Invasions (193) 293-310. https://doi.org/10.1007/978-3-540-36920-2

9. Dukes JS, Pontius J, Orwig D. et al. (2009) Responses of insect pests, pathogens, and invasive plant species to climate change in the forests of northeastern North America: What can we predict? This article is one of a selection of papers from NE Forests 2100: A Synthesis of Climate Change Impacts on Forests of the Northeastern US and Eastern Canada. Canadian Journal of Forest Research 39(2) 231-248. https://doi.org/10.1139/X08-171

10. Dyakov NR (2019) Testing for assembly rules along disturbance gradients in a riparian broadleaved forest. Applied Ecology \& Environmental Research 17(1) 1-13. https://doi.org/10.15666/aeer/1701

11. Dyderski MK, Paź S, Frelich LE, Jagodziński AM (2018) How much does climate change threaten European forest tree species distributions? Global Change Biology 24(3) 1150-1163.https://doi.org/10.1111/gcb.13925

12. EIONET (2020) (No Title). Retrieved January 14, 2021, from https://www.eionet.europa.eu/article17/

13. European Commission. EUR-Lex - 52020DC0380 - EN - EUR-Lex (2020). Brussels. Retrieved from https://eur-lex.europa.eu/legal-content/EN/TXT/?qid=1590574123338\&uri=CELEX:52020DC0380

14. Floods and River Management - The British Geographer. (n.d.). Retrieved April 7, 2020, from http://thebritishgeographer:weebly.com/floods-and-river-management.html

15. Forest Europe (2021) About Forest Europe - Forest Europe. Retrieved January 14, 2021, from https://foresteurope.org/foresteurope/

16. FOREST EUROPE, Liaison Unit Bratislava (2019) Human Health and Sustainable Forest Management. Marušáková L' and Sallmannshofer M (ed.) FOREST EUROPE Study. 
17. Globevnik L, Kaligaric M (2005) Hydrological changes of the Mura River in Slovenia, accompanied with habitat deterioration in riverine space. RMZ - Materials and Geoenvironment 52(1) 45-49.

18. Habersack H (2016) Wasserbau, Schifffahrt und Ökologie an der Donau - Pilotprojekt Bad Deutsch-Altenburg. Osterreichische Wasser- und Abfallwirtschaft 68(5-6) 190-192. https://doi.org/10.1007/s00506-016-0316-5

19. Hansen EM (2008) Alien forest pathogens: Phytophthora species are changing world forests. Boreal Environment Research 13(SUPPL. A) 33-41.

20. Hulme PE (2009) Trade, transport and trouble: managing invasive species pathways in an era of globalization. Journal of Applied Ecology 46(1) 10-18. https://doi.org/10.1111/j.1365-2664.2008.01600.x

21. IPCC (2019) Climate change and land. Intergovernmental Panel on Climate Change Special Report on Climate Change, Desertification, Land Degradation, Sustainable Land Management, Food Security, and Greenhouse gas fluxes in Terrestrial Ecosystems. https://www.ipcc.ch/srcel/

22. Jungwirth M, Muhar S, Schmutz S (2002) Re-establishing and assessing ecological integrity in riverine landscapes. Freshwater Biology 47(4) 867-887. https://doi.org/10.1046/j.1365-2427.2002.00914.X

23. Kautz M, Meddens AJH, Hall RJ, Arneth A (2017) Biotic disturbances in Northern Hemisphere forests - a synthesis of recent data, uncertainties and implications for forest monitoring and modelling. Global Ecology and Biogeography. Blackwell Publishing Ltd. https://doi.org/10.1111/geb.12558

24. Kevey B (2018) Floodplain forests. In Springer Geography (Vol. PartF5, pp. 299-336). https://doi.org/10.1007/978-3-319-92816-6_18

25. Klimo E, Hager H, Matič S, Anič I, Kulhavý J (2008) Floodplain forests of the temperate zone of Europe, Lesnická Práce 623p

26. Kwak TJ, Naiman RJ, Bilby RE (2000) Pacific Coastal River Ecology and ManagementRiver Ecology and Management: Lessons from the Pacific Coastal Ecoregion. Ecology 81(3) 882. https://doi.org/10.2307/177387

27. Leyer I, Mosner E, Lehmann B (2012) Managing floodplain-forest restoration in European river landscapes combining ecological and flood-protection issues. Ecological Applications 22(1) 240-249. https://doi.org/10.1890/11-0021.1

28. Lundström J, Öhman K, Laudon H (2018) Buffer zone alternatives in forest planning using a decision support system. Scandinavian Journal of Forest Research 33(5) 493-501. https://doi.org/10.1080/02827581.2018.1441900

29. Meyerson LA, Mooney HA (2007) Invasive alien species in an era of globalization. Frontiers in Ecology and the Environment 5(4) 199-208. https://doi.org/10.1890/1540-9295(2007)5[199:IASIAE]2.0.CO;2

30. Millennium Ecosystem Assessment (2005) ECOSYSTEMS AND HUMAN WELL-BEING: WETLANDS AND WATER Synthesis. (N. D. C. Max Finlayson, Rebecca D’Cruz, Ed.). World Resources Institute.

31. Monclus R, Dreyer E, Villar M et al. (2006). Impact of drought on productivity and water use efficiency in 29 genotypes of Populus deltoides x Populus nigra. New Phytologist 169(4) 765-777. https://doi.org/10.1111/j.1469-8137.2005.01630.x

32. Mosner E, Liepelt S, Ziegenhagen B, Leyer I (2012) Floodplain willows in fragmented river landscapes: Understanding spatio-temporal genetic patterns as a basis for restoration plantings. Biological Conservation 153 211-218.

https://doi.org/10.1016/i.biocon.2012.05.005

33. Nadal-Sala D, Hartig F, Gracia CA, Sabaté S (2019) Global warming likely to enhance black locust (Robinia pseudoacacia L.) growth in a Mediterranean riparian forest. Forest Ecology and Management 449 117448. https://doi.org/10.1016/j;foreco.2019.117448

34. Nagy RC, Porder S, Neill C, Brando P, Quintino RM, Do Nascimento SA (2015) Structure and composition of altered riparian forests in an agricultural Amazonian landscape. Ecological Applications 25(6) 1725-1738. https://doi.org/10.1890/14-1740.1

35. Netsvetov M, Prokopuk Y, Puchałka R, Koprowski M (2019) River Regulation Causes Rapid Changes in Relationships Between Floodplain Oak Growth and Environmental Variables 10(February) 1-11. https://doi.org/10.3389/fpls.2019.00096

36. Nilsson C, Berggren K (2000) Alterations of Riparian Ecosystems Caused by River Regulation. BioScience 50(9) 783. https://doi.org/10.1641/0006-3568(2000)050[0783:aorecb]2.0.00;2

37. Nilsson C, Berggren K (2000) Effects of dams and regulations on riparian zones. BioScience 50(9) 783. Retrieved from https://academic.oup.com/bioscience/article-abstract/50/9/783/269505

38. Nisbet D, Kreutzweiser D, Sibley P, Scarr T (2015) Ecological risks posed by emerald ash borer to riparian forest habitats: A review and problem formulation with management implications. https://doi.org/10.1016/j.foreco.2015.08.030

39. OJEC. (1992). EUR-Lex - 31992L0043 - EN - EUR-Lex. Retrieved January 14, 2021, from https://eur-lex.europa.eu/legal-content/EN/ TXT/?uri=celex\%3A31992L0043 
40. Onaindia M, Fernández de Manuel B, Madariaga I, Rodríguez-Loinaz G (2013) Co-benefits and trade-offs between biodiversity, carbon storage and water flow regulation. Forest Ecology and Management 289 1-9. https://doi.org/10.1016/i.foreco.2012.10.010

41. Planty-Tabacchi A-M, Tabacchi E, Naiman RJ, Deferrari C, Decamps H (1996) Invasibility of Species-Rich Communities in Riparian Zones. Conservation Biology 10(2) 598-607.https://doi.org/10.1046/j.1523-1739.1996.10020598.x

42. Pureswaran DS, Roques A, Battisti A (2018) Forest Insects and Climate Change. Curr Forestry Rep 4 35-50.

https://doi.org/10.1007/s40725-018-0075-6

43. Ramsfield TD, Bentz BJ, Faccoli M, Jactel H, Brockerhoff EG (2016) Forest health in a changing world: effects of globalization and climate change on forest insect and pathogen impacts. https://doi.org/10.1093/forestry/cpw018

44. Regier N, Streb S, Cocozza C, Schaub M, Cherubini P, Zeeman SC, Frey B (2009) Drought tolerance of two black poplar (Populus nigra L.) clones: Contribution of carbohydrates and oxidative stress defence. Plant, Cell and Environment 32(12) $1724-1736$. https://doi.org/10.1111/j.1365-3040.2009.02030.x

45. Richardson DM, Holmes PM, Esler KJ et al. (2007) Riparian vegetation: degradation, alien plant invasions, and restoration prospects. Diversity and Distributions 13(1) 126-139. https://doi.org/10.1111/j.1366-9516.2006.00314.x

46. Roder G, Sofia G, Wu Z, Tarolli P (2017). Assessment of Social Vulnerability to floods in the floodplain of northern Italy. Weather, Climate, and Society, 9(4), 717-737. https://doi.org/10.1175/WCAS-D-16-0090.1

47. Rosenberg DM, Berkes F, Bodaly RA, Hecky RE, Kelly CA, Rudd JWM (1997) Large-scale impacts of hydroelectric development. Environmental Reviews 5(1) 27-54. https://doi.org/10.1139/er-5-1-27

48. Sanjou M, Okamoto T, Nezu I (2018) Experimental study on fluid energy reduction through a flood protection forest. Journal of Flood Risk Management 11(4) e12339. https://doi.org/10.1111/jfr3.12339

49. Schnitzler A, Hale BW, Alsum E (2005) Biodiversity of floodplain forests in Europe and eastern North America: A comparative study of the Rhine and Mississippi Valleys. Biodiversity and Conservation 14(1) 97-117 https://doi.org/10.1007/s10531-005-4056-2

50. Schnitzler A, Hale BW, Alsum EM (2007) Examining native and exotic species diversity in European riparian forests. Biological Conservation 138(1-2) 146-156. https://doi.org/10.1016/j.biocon.2007.04.010

51. Seidl R, Thom D, Kautz M et al. (2017, June 1). Forest disturbances under climate change. Nature Climate Change. Nature Publishing Group. https://doi.org/10.1038/nclimate3303

52. Sikorska D, Sikorski P, Archiciński P, Chormański J, Hopkins RJ (2019) You Can't See the Woods for the Trees: Invasive Acer negundo L. in Urban Riparian Forests Harms Biodiversity and Limits Recreation Activity. Sustainability 11(20) 5838.

https://doi.org/10.3390/su11205838

53. Smulders MJM, Cottrell J, Lefèvre F et al. (2008) Structure of the genetic diversity in black poplar (Populus nigra L.) populations across European river systems: Consequences for conservation and restoration. Forest Ecology and Management 255 $1388-1399$. https://doi.org/10.1016/j.foreco.2007.10.063

54. Spinoni J, Naumann G, Vogt JV (2017) Pan-European seasonal trends and recent changes of drought frequency and severity. Global and Planetary Change 148 113-130. https://doi.org/10.1016/i.gloplacha.2016.11.013

55. Stagge JH, Kingston DG, Tallaksen LM, Hannah DM (2017) Observed drought indices show increasing divergence across Europe. Scientific Reports 7(1) 1-10. https://doi.org/10.1038/s41598-017-14283-2

56. Sturrock RN, Frankel SJ, Brown AV et al. (2011). Climate change and forest diseases. Plant Pathology. https://doi.org/10.1111/i.1365-3059.2010.02406.x

57. Thompson I, Mackey B, McNulty S, Mosseler A (2009) Forest Resilience, Biodiversity, and Climate Change: a synthesis of the biodiversity/resilience/stability relationship in forest ecosystems. Secretariat of the Convention on Biological Diversity, Montreal. Technical Series no. 43. Secretariat of the Convention on Biological Diversity (Vol. 43)

58. Tiwari T, Lundström J, Kuglerová L, Laudon H, Öhman K, Ågren AM (2016) Cost of riparian buffer zones: A comparison of hydrologically adapted site-specific riparian buffers with traditional fixed widths. Water Resources Research 52(2) 1056-1069 https:// doi.org/10.1002/2015WR018014

59. Tockner K, Stanford JA (2002) Riverine flood plains: Present state and future trends. Environmental Conservation 29(3) 308-330. https://doi.org/10.1017/S037689290200022X

60. UNESCO (n.d.) Convention on Wetlands of International Importance especially as Waterfowl Habitat. 1971. Retrieved January 14, 2021, from http://portal.unesco.org/en/ev.php-URL ID=15398\&URL_DO=DO TOPIC\&URL SECTION=201.html 
61. van Lierop P, Lindquist E, Sathyapala S, Franceschini G (2015) Global forest area disturbance from fire, insect pests, diseases and severe weather events. Forest Ecology and Management 352 78-88. https://doi.org/10.1016/jiforeco.2015.06.010

62. Vilà M, Hulme PE (2017) Non-native Species, Ecosystem Services, and Human Well-Being. In Impact of Biological Invasions on Ecosystem Services (pp. 1-14). Springer International Publishing. https://doi.org/10.1007/978-3-319-45121-3__

63. Von Holle B, Simberloff D (2005) Ecological resistance to biological invasion overwhelmed by propagule pressure. Ecology 86(12) 3212-3218. https://doi.org/10.1890/05-0427

64. Wraber M (1951) Gozdna vegetacijska slika in gozdnogojitveni problemi Prekmurja. Geografski vestnik, 23, 179-230

65. Zedler JB, Kercher S (2004) Causes and consequences of invasive plants in wetlands: Opportunities, opportunists, and outcomes. Critical Reviews in Plant Sciences 23(5) 431-452. https://doi.org/10.1080/07352680490514673

\subsection{Bewirtschaftung von Auwaldökosystemen}

1. Bentrup G (2008) Conservation buffers: design guidelines for buffers, corridors, and greenways. Asheville. Gen. Tech. Rep. SRS109. Asheville, NC: U.S. Department of Agriculture, Forest Service, Southern Research Station. 110 p. https://www.srs.fs.usda.gov/pubs/33522

2. Connell JH (1978) Diversity in tropical rain forests and coral reefs. Science 199(4335) 1302-1310. https://doi.org/10.1126/science.199.4335.1302

3. Dakskobler I, Kutnar L, Šilc U (2013) Poplavni, močvirni in obrežni gozdovi v Sloveniji: gozdovi vrb, jelš, dolgopecljatega bresta, velikega in ozkolistnega jesena, doba in rdečega bora ob rekah in potokih. Silva Slovenica, Gozdarski inštitut Slovenije. http://eprints.gozdis.si/id/eprint/477

4. Environment Canada (2013) How much environment is enough? Third edition. Toronto.

5. Forman RT (1995) Land Mosaics: The Ecology of Landscapes and Regions. Cambridge University Press.

6. Forman RT, Godron M (1989) Landscape ecology. Environmental Conservation 16(1) 619. https://doi.org/10.1017/S0376892900008766

7. Kapos V, Lysenko I (2000) Assessing forest integrity and naturalness in relation to biodiversity. Retrieved January 14, 2021, from https://www.researchgate.net/publication/242321742_Assessing_forest_integrity_and_naturalness_in_relation_to_biodiversity

8. Karr JR, Dudley DR (1981) Ecological perspective on water quality goals. Environmental Management, 5(1) 55-68. https://doi.org/10.1007/BF01866609

9. Kovač M, Ferreira A (ed) (2017) Vzorčni upravljavski načrt za gozdna območja Natura 2000 - primer poplavnih gozdov ob Muri. Ljubljana. Gozdarski inštitut Slovenije.

10. Kovač M, Kutnar L, Hladnik D (2016) Assessing biodiversity and conservation status of the Natura 2000 forest habitat types: Tools for designated forestlands stewardship. Forest Ecology and Management 359 256-267. https://doi.org/10.1016/j.foreco.2015.10.011

11. Kutnar L, Marinšek A (2016) Stanje raziskovanih gozdnih habitatnih tipov ob Muri. In: Ferreira A, Planinšek S (ed), GoForMura: upravljanje gozdnih habitatnih tipov in vrst v izbranih območjih Natura 2000 ob Muri. Silva Slovenica, Gozdarski inštitut Slovenije. https://doi.org/10.20315/sfs.149

12. Maurer BA (1993) Biological diversity, ecological integrity, and neotropical migrants: new perspectives for wildlife management. In: Finch, Deborah M.; Stangel, Peter W. (eds.). Status and management of neotropical migratory birds: September 21-25, 1992, Estes Park, Colorado. Gen. Tech. Rep. RM-229. Fort Collins, Colo.: Rocky Mountain Forest and Range Experiment Station, U.S. Dept. of Agriculture, Forest Service: 24-31 https://www.fs.usda.gov/treesearch/pubs/22884

13. Noss RF (1990) Indicators for Monitoring Biodiversity: A Hierarchical Approach. Conservation Biology. https://doi.org/10.1111/j.1523-1739.1990.tb00309.x

14. Parrish JD, Braun DP, Unnasch RS (2003) Are we conserving what we say we are? Measuring ecological integrity within protected areas. BioScience. American Institute of Biological Sciences. https://doi.org/10.1641/0006-3568 (2003)053[0851:AWCWWS]2.0.CO;2

15. Roberts MR, Gilliam FS (1995) Patterns and mechanisms of plant diversity in forested ecosystems: Implications for forest management. Ecological Applications 5(4) 969-977. https://doi.org/10.2307/2269348

16. Sallmannshofer M, Chakraborty D, Vacik H et al. (2021) Continent-Wide Tree Species Distribution Models May Mislead Regional Management Decisions: A Case Study in the Transboundary Biosphere Reserve Mura-Drava-Danube. Forests 12330. https://doi.org/10.3390/12030330

17. Schlaepfer R (1997) Ecosystem-based management of natural resources: a step towards sustainable development. Retrieved from https://bibliotecadigital.infor.cl/handle/20.500.12220/5660 
18. Yachi S, Loreau M (1999) Biodiversity and ecosystem productivity in a fluctuating environment: The insurance hypothesis. Proceedings of the National Academy of Sciences of the United States of America 96(4) 1463-1468.

https://doi.org/10.1073/pnas.96.4.1463

\subsection{Struktur und Ökologie der Flussauenlandschaft}

1. Bayley PB (1995) Understanding Large River: Floodplain Ecosystems. BioScience 45(3) 153-158. https://doi.org/10.2307/1312554

2. Čater M, Levanič T (2015) Physiological and growth response of Quercus robur in Slovenia. Dendrobiology 74 3-12. https://doi.org/10.12657/denbio.074.001

3. Dakskobler I, Kutnar L, Šilc U (2013) Poplavni, močvirni in obrežni gozdovi v Sloveniji: gozdovi vrb, jelš, dolgopecljatega bresta, velikega in ozkolistnega jesena, doba in rdečega bora ob rekah in potokih. Silva Slovenica, Gozdarski inštitut Slovenije.

http://eprints.gozdis.si/id/eprint/477

4. Forman RT (1995) Land Mosaics: The Ecology of Landscapes and Regions. Cambridge University Press.

5. Hager H, Schume H, Tiefenbacher H, Buchleitner E (2007) Forest Management Systems and Regeneration. In P. Hobza (Ed.), Forest management systems and regeneration of floodplain forest sites: reviewed proceedings from the international conference (pp. 41-60). Brno: Mendel University of Agriculture and Forestry, Czech Forest Society.

6. Langhans SD, Tiegs SD, Gessner MO, Tockner K (2008) Leaf-decomposition heterogeneity across a riverine floodplain mosaic. Aquatic Sciences 70 337-346. https://doi.org/10.1007/s00027-008-8062-9

7. Tumajer J, Treml V (2016) Response of floodplain pedunculate oak (Quercus robur L.) tree-ring width and vessel anatomy to climatic trends and extreme hydroclimatic events. Forest Ecology and Management 379 185-194.

https://doi.org/10.1016/j.foreco.2016.08.013

8. Ward JV, Tockner K, Arscott DB, Claret C (2002) Riverine landscape diversity. Freshwater Biology 47(4) 517-539.

https://doi.org/10.1046/i.1365-2427.2002.00893.x

\subsection{Waldhabitattypen}

1. Dakskobler I, Kutnar L, Šilc U (2013) Poplavni, močvirni in obrežni gozdovi v Sloveniji: gozdovi vrb, jelš, dolgopecljatega bresta, velikega in ozkolistnega jesena, doba in rdečega bora ob rekah in potokih. Silva Slovenica, Gozdarski inštitut Slovenije.

http://eprints.gozdis.si/id/eprint/477

2. Dobrovolný L (2014) Potential of natural regeneration of Quercus robur L. in floodplain forests in the southern part of the Czech Republic. Journal of Forest Science 60(12) 534-539. https://doi.org/10.17221/83/2014-jfs

3. EIONET. (2020). (No Title). Retrieved January 14, 2021, from https://www.eionet.europa.eu/article17/

4. European Commission (2013) Interpretation Manual of European Union Habitats, version EUR 28.DG Environment http://ec.europa.eu/environment/nature/legislation/habitatsdirective/docs/Int_Manual_EU28.pdf

5. Hager H, Schume H, Tiefenbacher H, Buchleitner E (2007) Forest Management Systems and Regeneration. In P. Hobza (Ed.), Forest management systems and regeneration of floodplain forest sites: reviewed proceedings from the international conference (pp. 41-60). Brno: Mendel University of Agriculture and Forestry, Czech Forest Society.

6. Marinšek A, Kutnar L (2017) Occurrence of invasive alien plant species in the floodplain forests along the Mura River in Slovenia. Periodicum Biologorum 119(4) 251-260. https://doi.org/10.18054/pb.v119i4.4933

7. Milanović Đ, Brujić J, Đug S, Muratović E, Lukić Bilela L (2015) Vodič kroz tipove staništa BiH prema Direktivi o staništima EU. Prospect C\&S, Brussels https://www.researchgatenet/publication/290770268_Vodic_kroz_tipove_stanista_BiH_prema_Direktivi_o stanistima_EU

8. Mölder A, Meyer P, Nagel RV (2019) Integrative management to sustain biodiversity and ecological continuity in Central European temperate oak (Quercus robur, Q. petraea) forests: An overview. Forest Ecology and Management 437 $324-339$. https://doi.org/10.1016/jiforeco.2019.01.006

9. Plišo Vusić I, Šapić I, Vukelić J (2019) Prepoznavanje i kartiranje šumskih staništa Natura 2000 u Hrvatskoj (I) - 91E0*, aluvijalne šume s crnom johom Alnus glutinosa i običnim jasenom Fraxinus excelsior (Alno-Padion, Alnion incanae, Salicion albae) Identification and mapping of Natura 2000 fore. Šumarski list 143(5-6) 255-263. https://doi.org/10.31298/sl.143.5-6.7

10. Plišo Vusić I, Šapić I, Vukelić J (2019) Prepoznavanje i kartiranje šumskih staništa Natura 2000 u Hrvatskoj (II) - 91F0, poplavne šume s vrstama Quercus robur, Ulmus laevis, Ulmus minor, Fraxinus angustifolia; 91L0, hrastovo-grabove šume ilirskoga područja. Šumarski list 143(9-10) 461-467. https://doi.org/10.31298/sl.143.9-10.7 
11. Schütz JP, Saniga M, Diaci J, Vrška T (2016) Comparing close-to-nature silviculture with processes in pristine forests: lessons from Central Europe. Annals of Forest Science 73 911-921. https://doi.org/10.1007/s13595-016-0579-9

12. Viher, E (2011) Uspešnost saditve nižinskih dobovih sestojev v Prekmurju / Efficiency of planting lowland forest stands of Pedunculate oak in Prekmurje. Graduation thesis, University in Ljubljana https://repozitorij.uni-lj,si/IzpisGradiva.php?id=16025

13. Ward JV, Tockner K, Arscott DB, Claret C (2002) Riverine landscape diversity. Freshwater Biology 47(4) 517-539. https://doi.org/10.1046/j.1365-2427.2002.00893.X

\subsection{Gängige Waldbewirtschaftungsformen in Auwäldern}

1. Buckley R, Castley J, Pegas F, Mossaz A, Steven R (2012) A population accounting approach to assess tourism contributions to conservation of IUCN-Redlisted mammal species. PLoS ONE, 7(9) e44134. https://doi.org/10.1371/journal.pone.0044134

2. Čater M, Kutnar L, Accetto M (2001) Slovenian lowland and floodplain forests. In Klimo E, Hager H (ed) The Floodplain forests in Europe. European Forestry Institute 233-248.

3. Fujimori T (2001) Silvicultural Strategies for Sustainable Forest Management. In Ecological and Silvicultural Strategies for Sustainable Forest Management. Elsevier Science

4. Johann E (2007) Traditional forest management under the influence of science and industry: The story of the alpine cultural landscapes. Forest Ecology and Management 249(1-2) 54-62. https://doi.org/10.1016/i.forec0.2007.04.049

5. KIB (1929) Privredni planovi za područje šumske uprave Dolnja Lendava za Gospodarstvene jedinice: Kobilje-Bukovnica, Dobrovnik, Crni lug, Redič-Sv. Mikluš, Murska šuma. 1929 - 1938. Direkcija šuma Križevačke imovne občine u Bjelovaru.

6. Machar I (2009) Coppice-with-standards in floodplain forests - a new subject for nature protection. J. For. Sci. 55 306-311. https://doi.org/10.17221/87/2008-jfs

7. Mosandl R, Summa J, Stimm B (2010) Coppice-With-Standards: Management Options for an Ancient Forest System. Forestry Ideas 16(1)

8. Müllerová J, Szabó P, Hédl R (2014) The rise and fall of traditional forest management in southern Moravia: A history of the past 700 years. Forest Ecology and Management 331 104-115. https://doi.org/10.1016/j.foreco.2014.07.032

9. Peterken GF (1996) Natural woodland: ecology and conservation in northern temperate regions. Cambridge University Press, Cambridge

10. Piussi P (2006) Close to nature forestry criteria and coppice management. In Diaci J (ed) Nature-based forestry in central Europe: alternatives to industrial forestry and strict preservation. University of Ljubljana, Ljubljana, pp 27-37

11. Schütz J-Ph (2002) Die Plenterung und ihre unterschiedlichen Formen. Skript zu Vorlesung Waldbau II und Waldbau IV. ETH Zentrum, Zürich

12. Vild O, Roleček J, Hédl R, Kopecký M, Utinek D (2013) Experimental restoration of coppice-with-standards: Response of understorey vegetation from the conservation perspective. Forest Ecology and Management 310 234-241. https://doi.org/10.1016/j.foreco.2013.07.056

\subsubsection{Entscheidung für Natur- oder Kunstverjüngung?}

1. Brundu G, Pauchard A, Pyšek P et al. (2020) Global guidelines for the sustainable use of non-native trees to prevent tree invasions and mitigate their negative impacts. NeoBiota 61 65-116 https://doi.org/10.3897/neobiota.61.58380

2. Medved M, Bajc M, Božič G et al. (2013) Gospodarjenje z gozdom za lastnike gozdov. Ljubljana: Kmečki glas, 2013, 311 pp.

3. REFOCuS output O3.1: http://www.interreg-danube.eu/uploads/media/approved_project_output/0001/38/f96aa53b7b6e761e140aceb8d49a014449ab1076.pdf

\subsubsection{Geeignetes forstliches Vermehrungsgut zur Anpassung der Wälder an den Klimawandel}

1. Aitken SN, Bemmels JB (2016) Time to get moving: Assisted gene flow of forest trees. Evolutionary Applications. https://doi.org/10.1111/eva.12293

2. Aitken SN, Yeaman S, Holliday JA et al. (2008) Adaptation, migration or extirpation: climate change outcomes for tree populations. Evolutionary Applications 1(1) 95-111. https://doi.org/10.1111/j.1752-4571.2007.00013.x

3. Arnell NW, Gosling SN (2016) The impacts of climate change on river flood risk at the global scale. Climatic Change 134(3) 387401. https://doi.org/10.1007/s10584-014-1084-5 
4. Bebber DP (2015) Range-Expanding Pests and Pathogens in a Warming World. Annual Review of Phytopathology 53(1) 335-356. https://doi.org/10.1146/annurev-phyto-080614-120207

5. Bergot M, Cloppet E, Pérarnaud V et al. (2004) Simulation of potential range expansion of oak disease caused by Phytophthora cinnamomi under climate change. Global Change Biology 10(9) 1539-1552. https://doi.org/10.1111/j.1365-2486.2004.00824.X

6. Blöschl G, Hall J, Viglione A et al. (2019, September 5) Changing climate both increases and decreases European river floods. Nature. https://doi.org/10.1038/s41586-019-1495-6

7. Dottori F, Szewczyk W, Ciscar JC et al. (2018) Increased human and economic losses from river flooding with anthropogenic warming. Nature Climate Change. https://doi.org/10.1038/s41558-018-0257-z

8. Dubrovský M, Hayes M, Duce P, Trnka M, Svoboda M, Zara P (2014) Multi-GCM projections of future drought and climate variability indicators for the Mediterranean region. Regional Environmental Change 14(5) 1907-1919

https://doi.org/10.1007/s10113-013-0562-z

9. Dyderski MK, Paź S, Frelich LE, Jagodziński AM (2018) How much does climate change threaten European forest tree species distributions? Global Change Biology 24(3) 1150-1163. https://doi.org/10.1111/gcb.13925

10. Frank A, Howe GT, Sperisen C et al. (2017) Risk of genetic maladaptation due to climate change in three major European tree species. Global Change Biology. https://doi.org/10.1111/gcb.13802

11. Hanel M, Rakovec O, Markonis Y et al. (2018) Revisiting the recent European droughts from a long-term perspective. Scientific Reports. https://doi.org/10.1038/s41598-018-27464-4

12. Jump AS, Peñuelas J (2005) Running to stand still: Adaptation and the response of plants to rapid climate change. Ecology Letters 8(9) 1010-1020. https://doi.org/10.1111/j.1461-0248.2005.00796x x

13. Kautz M, Meddens AJH, Hall RJ, Arneth A (2017) Biotic disturbances in Northern Hemisphere forests - a synthesis of recent data, uncertainties and implications for forest monitoring and modelling. Global Ecology and Biogeography. https://doi.org/10.1111/geb.12558

14. Nadal-Sala D, Hartig F, Gracia CA, Sabaté S (2019) Global warming likely to enhance black locust (Robinia pseudoacacia L.) growth in a Mediterranean riparian forest. Forest Ecology and Management 449 117448. https://doi.org/10.1016/j.foreco.2019.117448

15. Pureswaran DS, Roques A, Battisti A (2018) Forest Insects and Climate Change. Curr Forestry Rep 4 35-50. https://doi.org/10.1007/s40725-018-0075-6

16. Rehfeldt GE, Tchebakova NM, Parfenova YI et al. (2002) Intraspecific responses to climate in Pinus sylvestris. Global Change Biology. https://doi.org/10.1046/i.1365-2486.2002.00516.x

17. Schueler S, Falk W, Koskela J et al. (2014) Vulnerability of dynamic genetic conservation units of forest trees in Europe to climate change. Global Change Biology 20(5) 1498-1511. https://doi.org/10.1111/gcb.12476

18. Seidl R, Thom D, Kautz M, et al. (2017) Forest disturbances under climate change. Nature Clim Change 7 395-402 (2017) https://doi.org/10.1038/nclimate3303

19. Sperisen C, Pluess A, Arend M et al. (2016) Erhaltung genetischer Ressourcen im Schweizer Wald — heutige Situation und Handlungsbedarf angesichts des Klimawandels (pp. 367-383)

20. Spinoni J, Naumann G, Vogt JV (2017) Pan-European seasonal trends and recent changes of drought frequency and severity. Global and Planetary Change 148 113-130. https://doi.org/10.1016/j.gloplacha.2016.11.013

21. Stagge JH, Kingston DG, Tallaksen LM et al. (2017) Observed drought indices show increasing divergence across Europe. Scientific Reports 7(1) 1-10. https://doi.org/10.1038/s41598-017-14283-2

22. Sturrock RN, Frankel SJ, Brown AV et al. (2011) Climate change and forest diseases. Plant Pathology. https://doi.org/10.1111/j.1365-3059.2010.02406.x

23. Takolander A, Hickler T, Meller L, (2019) Comparing future shifts in tree species distributions across Europe projected by statistical and dynamic process-based models. Regional Environmental Change 19(1) 251-266.

https://doi.org/10.1007/s10113-018-1403-X

24. Thompson I, Mackey B, McNulty S, Mosseler A (2009) Forest Resilience, Biodiversity, and Climate Change: a synthesis of the biodiversity/resilience/stability relationship in forest ecosystems. Technical Series no. 43. Secretariat of the Convention on Biological Diversity, Montreal

25. van Lierop P, Lindquist E, Sathyapala S, Franceschini G (2015) Global forest area disturbance from fire, insect pests, diseases and severe weather events. Forest Ecology and Management 352 78-88 https://doi.org/10.1016/i.foreco.2015.06.010 
26. Winsemius HC, Aerts JCJH, Van Beek LPH et al. (2016) Global drivers of future river flood risk. Nature Climate Change 6(4) 381-385. https://doi.org/10.1038/nclimate2893

\subsubsection{Naturverjüngung und Saat von Stieleichenbeständen}

1. Bodor L (1991) Hagyomány és korszerűség az ormánsági síkvidéki kocsányos tölgyesek felújításában [Tradition and modernity in the regeneration of pedunculate oaks in the Ormánság lowlands]. Erdészeti lapok 126(2) 48-50 (in Hungarian)

2. Kovács A, Lajtos J, Sipos S, Veszeli J (2018) Az intenzíven terjedő fafajok tömeges térfoglalása a Gemenc Zrt. kezelésében lévő hullámtéren [Mass space occupation of intensively spreading tree species in the floodplain managed by Gemenc Zrt.]. Erdészeti lapok 153(6) 181-185 (in Hungarian)

3. Sipos S, Fodermayer V, Veszeli J (2016) Ártéri erdők és természetes felújítás Gemencen [Riparian forests and natural renovation in Gemenc]. Erdészeti lapok 151(6) 187-190 (in Hungarian)

\subsubsection{Künstliche Verjüngung der Stieleiche als Maßnahme zum Aufbau von Eichenwäldern, als Ergänzungs- pflanzung und zur Wiederherstellung von Auwaldökosystemen}

1. Saha S, Kuehne C, Bauhus J (2013) Tree species richness and stand productivity in low-density cluster plantings with oaks (Quercus robur L. and Q. petraea (Mattuschka) Liebl.). Forests 4:650-665

2. Saha S, Kuehne C, Kohnle U, et al. (2012) Growth and quality of young oaks (Quercus robur and Q. petraea) grown in cluster plantings in central Europe: a weighted meta-analysis. For Ecol Manag 283:106-118

\subsubsection{Ziele des Biodiversitäts- und Naturschutzmanagements}

1. Bayrak MM, Marafa LM (2016) Ten years of REDD+: A critical review of the impact of REDD+ on forest-dependent communities. Sustainability $8(7) 620$.

2. CBD (2010) Strategic plan for biodiversity 2011-2020 and the Aichi targets. In Report of the Tenth Meeting of the Conference of the Parties to the Convention on Biological Diversity.

3. FOREST EUROPE (2015): State of Europe's Forests 2015. Status and Trends in Sustainable Forest Management in Europe.

4. Wagner M (2018) Transboundary Mura-Drava-Danube Action Plan.

\section{Literaturempfehlungen}

1. Chirici G et al. (2012) National forest inventory contributions to forest biodiversity monitoring. For. Sci. 58:257-268

2. Coote L et al. (2013) Testing indicators of biodiversity for plantation forests. Ecol. Indic. 32:107-115

3. Gao T, Hedblom M, Emilsson T, Nielsen AB (2014) The role of forest stand structure as biodiversity indicator. For. Ecol. Manage. 330:82-93

4. Gao T, Nielsen AB, Hedblom M(2015) Reviewing the strength of evidence of biodiversity indicators for forest ecosystems in Europe. Ecol. Indic. 57:420-434

5. Marchetti M (2004) Monitoring and Indicators of Forest Biodiversity in Europe - From Ideas to Operationality

6. Oettel J, Lapin K (under rev. 2020) Linking forest management and biodiversity indicators to strengthen sustainable forest management in Europe. Ecol. Indic.

7. Smith GF et al. (2008) Identifying practical indicators of biodiversity for stand-level management of plantation forests. Biodivers. Conserv. 17:991-1015

8. WWF Austria (2018) coopMDD - Guidelines for a dynamic river corridor. http://www.interreg-danube.eu/uploads/media/approved_project output/0001/24/c33bf56841c18e182014950ede42c8e58990d67d.pdf

9. WWF Austria (2019) LIFE14 NAT/HR/000115 - DRAVA LIFE Action A.5 Natura 2000 - Drava Management Strategy https://www.drava-life.hr/wp-content/uploads/2016/08/A.5-Drava-LIFE-Natura-2000-Drava-Management-Strategy-ENG-FINAL.pdf

10. WWF Austria (2019) LIFE14 NAT/HR/000115 -DRAVA LIFE / Action A.7 Action plan for river birds. http://www.drava-life.hr/wp-content/uploads/2016/08/20190606 A.7 Drava_LIFE Actionplan_riverbirds_EN_FINAL.pdf

\subsubsection{Potentiale in der Laubwertholzproduktion}

1. Wilhelm GJW, Rieger H (2013) Naturnahe Waldwirtschaft mit der QD-Strategie. Ulmer Verlag, Stuttgart [in German] 


\subsubsection{Herausforderungen im Klimawandel}

1. Alagador D, Cerdeira JO, Araújo MB (2014) Shifting protected areas: Scheduling spatial priorities under climate change. Journal of Applied Ecology 51(3) 703-713. https://doi.org/10.1111/1365-2664.12230

2. Alarcon D, Cavieres LA (2015) In the right place at the right time: Habitat representation in protected areas of South American Nothofagus-dominated plants after a dispersal constrained climate change scenario. PLoS ONE 10(3)

https://doi.org/10.1371/journal.pone.0119952

3. Araújo MB, Alagador D, Cabeza M et al. (2011) Climate change threatens European conservation areas. Ecology Letters 14(5) 484-492. https://doi.org/10.1111/j.1461-0248.2011.01610.x

4. Bolte A, Ammer C, Löf M et al. (2009) Adaptive forest management in central Europe: Climate change impacts, strategies and integrative concept. Scandinavian Journal of Forest Research. Taylor \& Francis Group. https://doi.org/10.1080/02827580903418224

5. $\quad \mathrm{CBD}$ (2014) Global Biodiversity Outlook 4. A mid-term assessment of progress towards the implementation of the Strategic Plan for Biodiversity 2011-2020. CBD; PNUMA; ONU Montreal, Canada

6. Coetzee BWT, Robertson MP, Erasmus BFN et al. (2009) Ensemble models predict important bird areas in southern Africa will become less effective for conserving endemic birds under climate change. Global Ecology and Biogeography 18(6) 701-710. https://doi.org/10.1111/j.1466-8238.2009.00485.x

7. D'Amen M, Bombi P, Pearman PB et al. (2011) Will climate change reduce the efficacy of protected areas for amphibian conservation in Italy? Biological Conservation 144(3) 989-997. https://doi.org/10.1016/i.biocon.2010.11.004

8. Dudley N, Stolton S, Belokurov A et al. (2010) Natural solutions: protected areas helping people cope with climate change. Natural solutions: protected areas helping people cope with climate change.

9. Dybala KE, Matzek V, Gardali T, Seavy NE (2019) Carbon sequestration in riparian forests: A global synthesis and meta-analysis. Global change biology 25(1):57-67

10. Dyderski MK, Paź S, Frelich LE, Jagodziński AM (2018) How much does climate change threaten European forest tree species distributions? Global Change Biology 24(3) 1150-1163.https://doi.org/10.1111/gcb.13925

11. EEA (2020) Climate change. European Environment Agency

12. FOREST EUROPE (2015) State of Europe's Forests 2015. (p. 314)

13. Hannah L (2008) Protected areas and climate change. Annals of the New York Academy of Sciences.

https://doi.org/10.1196/annals.1439.009

14. Hannah L, Midgley G, Andelman S et al. (2007) Protected area needs in a changing climate. Front Ecol Environ 5 131-138. https://doi.org/10.1890/1540-9295(2007)5[131:paniac]2.0.c0

15. Hewitson B, Janetos AC, Carter TR et al. (2014) In: Climate Change 2014: Impacts, Adaptation, and Vulnerability. Part B: Regional Aspects. Contribution of Working Group II to the Fifth Assessment Report of the Intergovernmental Panel on Climate Change 1133-1197. Europe, 1199, 1266.

16. Hole DG, Willis SG, Pain DJ et al. (2009) Projected impacts of climate change on a continent-wide protected area network. Ecology Letters 12(5) 420-431. https://doi.org/10.1111/j.1461-0248.2009.01297.x

17. Jactel H, Desprez-Loustau M-L, Battisti A et al. (2020) Pathologists and entomologists must join forces against forest pest and pathogen invasions. NeoBiota 58107

18. Jactel H, Poeydebat C, van Halder I, Castagneyrol B (2019) Interactive Effects of Tree Mixing and Drought on a Primary Forest Pest. Frontiers in Forests and Global Change https://doi.org/10.3389/ffgc.2019.00077

19. Johnston A, Ausden M, Dodd AM et al. (2013) Observed and predicted effects of climate change on species abundance in protected areas. Nature Climate Change 3(12) 1055-1061. https://doi.org/10.1038/nclimate2035

20. Osipova E, Shadie P, Zwahlen C et al. (2017) IUCN world heritage outlook 2: a conservation assessment of all natural world heritage sites. IUCN, Gland.

21. Pureswaran DS, Roques A, Battisti A (2018) Forest Insects and Climate Change. Curr Forestry Rep 4 35-50. https://doi.org/10.1007/s40725-018-0075-6

22. Rodrigues ASL, Andelman SJ, Bakarr MI et al. (2004) Effectiveness of the global protected area network in representing species diversity. Nature 428 9-12. https://doi.org/10.1038/nature02459.1.

23. Sallmannshofer M, Chakraborty D, Vacik H et al. (2021) Continent-wide tree species distribution models may mislead regional management decisions without implementation of local site conditions. Regional Environmental Change. 
24. Seavy NE, Gardali T, Golet GH et al. (2009). Why climate change makes riparian restoration more important than ever: recommendations for practice and research. Ecological Restoration 27(3):330-338

25. Simler-Williamson AB, Rizzo DM, Cobb RC (2019) Interacting effects of global change on forest pest and pathogen dynamics. Annual Review of Ecology, Evolution, and Systematics 50:381-403

26. Sutfin NA, Wohl E (2019) Elevational differences in hydrogeomorphic disturbance regime influence sediment residence times within mountain river corridors. Nature Communications 10(1):1-14 https://doi.org/10.1038/s41467-019-09864-W

27. Sutfin NA, Wohl EE, Dwire KA (2016) Banking carbon: a review of organic carbon storage and physical factors influencing retention in floodplains and riparian ecosystems. Earth Surface Processes and Landforms 41(1):38-60

28. Téllez-Valdés O, Dávila-Aranda P (2003) Protected areas and climate change: A case study of the cacti in the Tehuacán-Cuicatlán biosphere reserve, México. Conservation Biology 17(3) 846-853. https://doi.org/10.1046/j.1523-1739.2003.01622.x

\subsubsection{Wildeinfluss und Wildtiermanagement}

1. Forstner M, Reimoser F, Lexer W et al. (2006) Sustainable Hunting Principles, Criteria and Indicators. Umweltbundesamt GmbH, Vienna, http://wildlife.reimoser.info/document/2006_Forstner\%20et\%20al._Sustainable\%20Hunting\%20-\%20Principles,\%20Criteria,\%20Indicators.pdf

\subsubsection{Management von nicht-heimischen Pflanzen}

1. Ashton IW, Hyatt LA, Howe KM et al. (2005) Invasive species accelerate decomposition and litter nitrogen loss in a mixed deciduous forest. Ecological Applications 15(4) 1263-1272. https://doi.org/10.1890/04-0741

2. Biró M, Molnár Z, Öllerer K et al. (2020) Conservation and herding co-benefit from traditional extensive wetland grazing. Agriculture, Ecosystems and Environment 300 106983. https://doi.org/10.1016/.jagee.2020.106983

3. Brundu G, Richardson DM (2016) Planted forests and invasive alien trees in Europe: a code for managing existing and future plantings to mitigate the risk of negative impacts from invasions. NeoBiota 30 5-47.https://doi.org/10.3897/neobiota.30.7015

4. Clout MN, Williams PA (2009) Invasive species management: a handbook of principles and techniques. Oxford University Press

5. Csiszár Á, Korda M (2015) Practical experiences in invasive alien plant control. Budapest: Duna-Ipoly National Park Directorate. Rosalia Handbooks 3.

6. D'Antonio CM, Chambers JC (2006) Using ecological theory to manage or restore ecosystems affected by invasive plant species. In: Falk D, Palmer M, Zedler J (ed) Foundations of restoration ecology, Island Press, pp 260-279

7. Ducs A, Kazi A, Bilko A, Altbaecker V (2016) Milkweed control by food imprinted rabbits. Behavioural Processes 130 75-80. https://doi.org/10.1016/j.beproc.2016.07.012

8. Evans T, Kumschick S, Blackburn TM (2016) Application of the Environmental Impact Classification for Alien Taxa (EICAT) to a global assessment of alien bird impacts. Diversity and Distributions 22(9) 919-931

9. Foxcroft LC, Rouget M, Richardson DM (2007) Risk assessment of riparian plant invasions into protected areas. Conservation Biology 21(2) 412-421

10. Gaggini L, Rusterholz H-PP, Baur B (2018) The invasive plant Impatiens glandulifera affects soil fungal diversity and the bacterial community in forests. Applied Soil Ecology 124 335-343. https://doi.org/10.1016/iapsoil.2017.11.021

11. GISD (2018) Global Invasive Species Database (GISD)

12. Hawkins CL, Bacher S, Essl F et al. (2015) Framework and guidelines for implementing the proposed IUCN Environmental Impact Classification for Alien Taxa (EICAT). Diversity and Distributions 21(11) 1360-1363

13. Heger T, Trepl L (2003). Predicting biological invasions. Biological invasions 5(4) 313-321

14. Heywood VH, Brunel S (2009) Code of conduct on horticulture and invasive alien plants. Council of Europe Publ., Strasbourg

15. Howe HF, Smallwood J (1982) Ecology of seed dispersal. Annual review of ecology and systematics 13(1) 201-228

16. Interreg Danube REFOCuS. (2021) DanubeForestHealth. Retrieved January 302021 https://danubeforesthealth.eu/

17. IUCN (2020) EICAT - Environmental Impact Classification of Alien Taxa.

18. IUCN-IAS (2020) Management of IAS.

19. Joly M, Bertrand P, Gbangou RY et al. (2011) Paving the way for invasive species: Road type and the spread of Common ragweed (Ambrosia artemisiifolia). Environmental Management 48(3) 514-522. https://doi.org/10.1007/s00267-011-9711-7

20. Knapp LB, Canham CD (2000) Invasion of an old-growth forest in New York by Ailanthus altissima: sapling growth and recruitment in canopy gaps. Journal of the Torrey Botanical Society 127(4) 307-315. https://doi.org/10.2307/3088649 
21. Kowarik I (1992) Einführung und Ausbreitung nichteinheimischer Gehölzarten in Berlin und Brandenburg und ihre Folgen für Flora und Vegetation (p. 188). Verhandlungen des botanischen Vereins Berlin und Brandenburg.

22. Kumschick S, Measey GJ, Vimercati G et al. (2017) How repeatable is the Environmental Impact Classification of Alien Taxa (EICAT)? Comparing independent global impact assessments of amphibians. Ecology and evolution 7(8) 2661-2670

23. Langmaier M, Lapin K (2020) A Systematic Review of the Impact of Invasive Alien Plants on Forest Regeneration in European Temperate Forests. Front. Plant Sci. 11:524969. https://doi.org/10.3389/fpls.2020.524969

24. Lapin K (2017) Information on measures and related costs in relation to species included on the Union list: Asclepias syriaca. Technical note prepared by IUCN for the European Commission.

25. Lapin K, Oettel J, Steiner $\mathrm{H}$ et al. (2019) Invasive alien plant species in unmanaged forest reserves, Austria. NeoBiota 4871

26. Luigi Nimis P, Pittao E, Altobelli A et al. (2019) Mapping invasive plants with citizen science. A case study from Trieste (NE Italy). Plant Biosystems-An International Journal Dealing with all Aspects of Plant Biology 153(5) 700-709

27. Maschek O, Halmschlager E (2017) Natural distribution of Verticillium wilt on invasive Ailanthus altissima in eastern Austria and its potential for biocontrol. Forest Pathology 47(5) e12356.

28. Medvecká J, Jarolímek I, Hegedüšová K et al. (2018) Forest habitat invasions-Who with whom, where and why. Forest Ecology and Management 409 468-478

29. Muscolo A, Bagnato S, Sidari M, Mercurio R (2014) A review of the roles of forest canopy gaps. Journal of Forestry Research 25(4) 725-736. https://doi.org/10.1007/s11676-014-0521-7

30. Pagad S, Genovesi P, Carnevali L et al. (2015) IUCN SSC Invasive Species Specialist Group: invasive alien species information management supporting practitioners, policy makers and decision takers.

31. Petrášová M, Jarolímek I, Medvecká J (2013) Neophytes in Pannonian hardwood floodplain forests - History, present situation and trends. Forest Ecology and Management 308 31-39. https://doi.org/10.1016/i.foreco.2013.07.041

32. Potgieter LJ, Gaertner M, O’Farrell PJ, Richardson DM (2019) Perceptions of impact: Invasive alien plants in the urban environment. Journal of environmental management 229 76-87. https:// doi.org/10.1016/j.jenvman.2018.05.080

33. Pötzelsberger E, Lapin K, Brundu G et al. (2020) Mapping the patchy legislative landscape of non-native tree species in Europe. Forestry 93(4) 1-21. https://doi.org/10.1093/forestry/cpaa009

34. Pysek P, Prach K (1993) Plant Invasions and the Role of Riparian Habitats: A Comparison of Four Species Alien to Central Europe. Journal of Biogeography 20 413-420. https://doi.org/10.2307/2845589

35. Pyšek P, Richardson DM, Rejmánek M et al. (2004) Alien plants in checklists and floras: towards better communication between taxonomists and ecologists. Taxon 53(1) 131-143

36. Rahmonov O (2009) The chemical composition of plant litter of black locust (Robinia pseudoacacia L.) and its ecological role in sandy ecosystems. Acta Ecologica Sinica 29(4) 237-243. https://doi.org/10.1016/j.chnaes.2009.08.006

37. Regulation E. U. (2014). Regulation (EU) No 1143/2014 of the European Parliament and of the Council of 22 October 2014 on the prevention and management of the introduction and spread of invasive alien species. Official Journal of the European Union 57(317) 35

38. Richardson DM, Holmes PM, Esler KJ et al. (2007) Riparian vegetation: degradation, alien plant invasions, and restoration prospects. Diversity and Distributions 13(1) 126-139 https://doi.org/10.1111/j.1366-9516.2006.00314.x

39. Richardson DM, Pyšek P, Rejmánek M et al. (2000) Naturalization and invasion of alien plants: concepts and definitions. Diversity and distributions 6(2) 93-107

40. Rivers M, Beech E, Bazos I et al. (2019) European Red List of Trees. International Union for Conservation of Nature and Natural Resources (IUCN).

41. Roy H, Groom Q, Adriaens T et al. (2018) Increasing understanding of alien species through citizen science (Alien-CSI). Research Ideas and Outcomes 4 e31412

42. Roy HE, Bacher S, Essl F et al. (2019) Developing a list of invasive alien species likely to threaten biodiversity and ecosystems in the European Union. Global change biology 25(3) 1032-1048. https://doi.org/10.1111/gcb.14527

43. Roy HE, Rabitsch W, Scalera R et al. (2018) Developing a framework of minimum standards for the risk assessment of alien species. Journal of applied ecology 55(2) 526-538

44. Rusterholz H-P, Schneuwly J, Baur B (2018) Invasion of the alien shrub Prunus laurocerasus in suburban deciduous forests: Effects on native vegetation and soil properties. Acta Oecologica 92 44-51. https://doi.org/10.1016/iactao.2018.08.004 
45. Schmiedel D, Huth F, Wagner S (2013) Using data from seed-dispersal modelling to manage invasive tree species: The example of Fraxinus pennsylvanica Marshall in Europe. Environmental Management 52(4) 851-860. https://doi.org/10.1007/s00267-013-0135-4

46. Seebens H, Blackburn TM, Dyer EE et al. (2017) No saturation in the accumulation of alien species worldwide. Nature communications 8(1) 1-9

47. Shackleton RT, Biggs R, Richardson DM, Larson BMH (2018) Social-ecological drivers and impacts of invasion-related regime shifts: consequences for ecosystem services and human wellbeing. Environmental science \& policy 89 300-314 https://doi.org/10.1016/i.envsci.2018.08.005

48. Sitzia T, Campagnaro T, Kowarik I, Trentanovi G (2016) Using forest management to control invasive alien species: helping implement the new European regulation on invasive alien species. Biological invasions 18(1) 1-7

49. Szitár K, Török K (2008) Short-term effects of herbicide treatment on the vegetation of semiarid sandy oldfields invaded by Asclepias syriaca. L. In Extended abstract in the Proceedings of the 6th European Conference on Ecological Restoration 8-12

50. Tanner R (2017) Information on measures and related costs in relation to species included on the Union list: Impatiens glandulifera. Technical note prepared by IUCN for the European Commission.

51. Thomsen PF, Willerslev E (2015) Environmental DNA-An emerging tool in conservation for monitoring past and present biodiversity. Biological conservation 183 4-18

52. Vilà M, Espinar JL, Hejda M et al. (2011) Ecological impacts of invasive alien plants: a meta-analysis of their effects on species, communities and ecosystems. Ecology letters 14(7) 702-708

53. Villamagna AM, Murphy BR (2010) Ecological and socio-economic impacts of invasive water hyacinth (Eichhornia crassipes): a review. Freshwater biology 55(2) 282-298 https://doi.org/10.1111/j.1365-2427.2009.02294.X

54. Woziwoda B, Krzyżanowska A, Dyderski MK et al. (2018) Propagule pressure, presence of roads, and microsite variability influence dispersal of introduced Quercus rubra in temperate Pinus sylvestris forest. Forest ecology and management 428 35-45.

https://doi.org/10.1016/i.foreco.2018.06.033

\subsubsection{Integration von Totholz in die reguläre Waldbewirtschaftung}

1. BAFU (2015) Maßnahmenbereich 2: Förderung von Alt- und Totholz. In Biodiversität im Wald: Ziele und Maßnahmen 57-74

2. Bayerische Staatsforsten. Naturschutzkonzept der Bayerischen Staatsforsten. (2009).

3. Bouget C, Larrieu L, Brin A (2014) Key features for saproxylic beetle diversity derived from rapid habitat assessment in temperate forests. Ecol. Indic. 36 656-664

4. Bouget C, Larrieu L, Nusillard B, Parmain G (2013) In search of the best local habitat drivers for saproxylic beetle diversity in temperate deciduous forests. Biodivers. Conserv. 22 2111-2130

5. Brassard BW, Chen HYH (2008) Effects of forest type and disturbance on diversity of coarse woody debris in boreal forest. Ecosystems 11 1078-1090

6. Bütler R, Lachat T (2009) Wälder ohne Bewirtschaftung: eine Chance für die saproxylische Biodiversität | Forests without harvesting: an opportunity for the saproxylic biodiversity. Schweizerische Zeitschrift fur Forstwes. 160 324-333

7. Cálix M et al. (2018) European Red List of Saproxylic Beetles. IUCN. https://portals.iucn.org/library/node/47296. Accessed 11 August 2020

8. Christensen M et al. (2005) Dead wood in European beech (Fagus sylvatica) forest reserves. For. Ecol. Manage. 210 267-282

9. Della Rocca F, Stefanelli S, Pasquaretta C et al. (2014) Effect of deadwood management on saproxylic beetle richness in the floodplain forests of northern Italy: Some measures for deadwood sustainable use. J. Insect Conserv. 18 121-136

10. Dittrich S, Jacob M, Bade C et al. (2014) The significance of deadwood for total bryophyte, lichen, and vascular plant diversity in an old-growth spruce forest. Plant Ecol. 215 1123-1137

11. Doerfler I, Müller J, Gossner MM et al. (2017) Success of a deadwood enrichment strategy in production forests depends on stand type and management intensity. For. Ecol. Manage. 400, 607-620

12. FOREST EUROPE (2015) State of Europe's Forests 2015.

13. ForstBW (Hrsg.). (2010) Alt- und Totholzkonzept Landesbetrieb ForstBW, Stuttgart

14. Franklin JF, Shugart HH, Harmon ME (2006) Tree Death as an Ecological Process. Bioscience 37 550-556

15. Fridman J, Walheim M (2000) Amount, structure, and dynamics of dead wood on managed forestland in Sweden. For. Ecol. Manage. 131 23-36 
16. FSC (2018) International Generic Indicators

17. Gao T, Nielsen AB, Hedblom M (2015) Reviewing the strength of evidence of biodiversity indicators for forest ecosystems in Europe. Ecol. Indic. 57 420-434

18. Harmon ME. et al. (1986) Ecology of Coarse Woody Debris in Temperate Ecosystems. Adv. Ecol. Res. 15 133-263

19. Heinze B (2019) Progressive mortality of Fraxinus species in Austria caused by Ash-dieback, in the context of Europe. In BFW Praxisinfo 43 7-12

20. Helfenstein J, Kienast F (2014) Ecosystem service state and trends at the regional to national level: A rapid assessment. Ecol. Indic. 36 11-18

21. Horák J, Kout J, Vodka Š, Donato DC (2016) Dead wood dependent organisms in one of the oldest protected forests of Europe: Investigating the contrasting effects of within-stand variation in a highly diversified environment. For. Ecol. Manage. $363229-236$

22. Humphrey J, Bailey S (2012) Managing deadwood in forests and woodlands. Forestry Commission Practice Guide

23. Humphrey JW et al. (2004) Deadwood as an Indicator of Biodiversity in European Forests: From Theory to Operational Guidance. In: Marchetti M (ed) Monitoring and Indicators of Forest Biodiversity in Europe - From Ideas to Operationality. EFI Proceedings 51 193-206

24. Kunttu P, Junninen K, Kouki J (2015) Dead wood as an indicator of forest naturalness: A comparison of methods. For. Ecol. Manage. 353 30-40

25. Lassauce A, Paillet Y, Jactel H, Bouget C (2011) Deadwood as a surrogate for forest biodiversity: Meta-analysis of correlations between deadwood volume and species richness of saproxylic organisms. Ecol. Indic. 11 1027-1039.

26. Lindenmayer DB, Margules CR, Botkin DB (2000) Indicators of biodiversity for ecologically sustainable forest management. Conserv. Biol. 14 941-950

27. Lombardi F et al. (2010) Deadwood in Forest Stands Close To Old-Growthness Under Mediterranean Conditions in the Italian Peninsula. L'Italia For. e Mont. 65(5) 481 - 504 https://doi.org/10.4129/ifm.2010.5.02

28. Maser C, Trappe JM (1984) The Seen and Unseen World of the Fallen Tree the Seen and Unseen World of the Fallen Tree. General Technical Report PNW-164

29. Meyer P, Schmidt M (2011) Accumulation of dead wood in abandoned beech (Fagus sylvatica L.) forests in northwestern Germany. For. Ecol. Manage. $261342-352$

30. Miler AT, Dobroczyński M (2019) Results of floodplain forests protection in the Uroczysko Warta, the Wielkopolska region, Poland. Infrastruct. Ecol. Rural Areas II 7-24

31. Morrissey RC, Jenkins MA, Saunders MR (2014) Accumulation and connectivity of coarse woody debris in partial harvest and unmanaged relict forests. PLoS One 9

32. Müller J, Bütler R (2010) A review of habitat thresholds for dead wood: A baseline for management recommendations in European forests. Eur. J. For. Res. 129 981-992

33. Nagel TA et al. (2017) Evaluating the influence of integrative forest management on old-growth habitat structures in a temperate forest region. Biol. Conserv. 216 101-107

34. Oettel J et al. (2020) Patterns and drivers of deadwood volume and composition in different forest types of the Austrian natural forest reserves. For. Ecol. Manage. 463

35. Parisi F et al. (2015) Spatial patterns of saproxylic beetles in a relic silver fir forest (Central Italy), relationships with forest structure and biodiversity indicators. For. Ecol. Manage. 381 217-234

36. PEFC (2018) Sustainable forest management - Requirements. Sustainable forest management

37. Rimle A, Heiri C, Bugmann H (2017) Deadwood in Norway spruce dominated mountain forest reserves is characterized by large dimensions and advanced decomposition stages. For. Ecol. Manage. 404 174-183

38. Schuck A, Meyer P, Menke N et al. (2004) Forest Biodiversity Indicator: Dead Wood - A Proposed Approach towards Operationalising the MCPFE Indicator. In: Marchetti M (ed) Monitoring and Indicators of Forest Biodiversity in Europe - From Ideas to Operationality, pp 49-78

39. Seibold S et al. (2015) Association of extinction risk of saproxylic beetles with ecological degradation of forests in Europe. Conserv. Biol. 29382-390

40. Seibold S. et al. (2015) Experimental studies of dead-wood biodiversity — A review identifying global gaps in knowledge. Biol. Conserv. 191 139-149 
41. Shorohova E, Kapitsa E (2015) Stand and landscape scale variability in the amount and diversity of coarse woody debris in primeval European boreal forests. For. Ecol. Manage. 356

42. Siitonen J (2001) Forest management, coarse woody debris and saproxylic organisms: Fennoscandian boreal forests as example. Ecol. Bull. 49 11-41

43. Siitonen J, Martikainen P, Punttila P, Rauh J (2000) Coarse woody debris and stand characteristics in mature managed and oldgrowth boreal mesic forests in southern Finland. For. Ecol. Manage. 128 211-225

44. Stürzenbaum K (2013) Potential effects of box elder control measures and vertical stratification of xylobiontic beetles in floodplain forests of the Donau-Auen National Park, Lower Austria. Diploma thesis. University Vienna https://doi.org/10.25365/thesis.30147

45. Vandekerkhove K, De Keersmaeker L, Menke N et al. (2009) When nature takes over from man: Dead wood accumulation in previously managed oak and beech woodlands in North-western and Central Europe. For. Ecol. Manage. 258 425-435

46. Winter S (2012) Forest naturalness assessment as a component of biodiversity monitoring and conservation management. Forestry $85291-304$

47. Zielonka T (2006) Quantity and decay stages of coarse woody debris in old-growth subalpine spruce forests of the western Carpathians, Poland. Can. J. For. Res. 36 2614-2622

\subsubsection{Forstschädlinge und Krankheiten in einer sich verändernden Welt: Die Bedeutung der Früherkennung}

1. Faccoli M (2015) European Bark and Ambrosia Beetles: Types, Characteristics and Identification of Mating Systems. WBA Handbooks 5, Verona

2. Kunca A, Zúbrik M, Csóka G (ed) (2013). Insects and Diseases Damaging Trees and Shrubs of Europe: A Colour Atlas. N. A. P.

3. Roques A, Cleary M, Matsiakh I, Eschen R (2017) Field guide for the identification of damage on woody sentinel plants. CABI Book. https://doi.org/10.1079/9781786394415.0000

\subsubsection{Krankheiten der Pappel und Pappelhybriden unter besonderer Berücksichtigung von Management- Empfehlungen}

1. Cellerino GP (1999) Review of fungal diseases in poplar. Food and Agriculture Organization of the United Nations. Rome AC492/E

2. Guzina V, Herpka I, Marinković P et al. (ed) (1986) Poplars and willows in Yugoslavia. Poplar Research Institute, Novi Sad, Yugoslavia.

3. Tóth T, Lakatos T, Koltay A (2013) Lonsdalea quercina subsp. populi subsp. nov., isolated from bark canker of poplar trees. Int. J. Syst. Evol. Microbiol. 63 2309-2313

4. Zlatković M, Tenorio-Baigorria I, Lakatos T et al. (2020) Bacterial canker disease of Populus $\times$ euramericana caused by Lonsdalea populi in Serbia. Forests 11(10) 1080. https://doi.org/10.3390/f11101080

\subsubsection{Eichensterben - Beispiel für ein Krankheitsphänomen durch verschiedene interagierende kausale Fakto-} ren

1. Denman S, Brown N, Kirk S et al. (2014) A description of the symptoms of Acute Oak Decline in Britain and a comparative review on causes of similar disorders on oak in Europe. Forestry. Oxford University Press. https://doi.org/10.1093/forestry/cpu010

2. Denman S, Brown N, Kirk S et al. (2014). A description of the symptoms of Acute Oak Decline in Britain and a comparative review on causes of similar disorders on oak in Europe. Forestry 87 535-551. http://dx.doi.org/10.1093/forestry/cpu010

3. Forest Research UK (s. a.) Oak Decline. Tools and resources, Pest and disease resources, https://www.forestresearch.gov.uk/tools-and-resources/pest-and-disease-resources/oak-decline/ Accessed 16 Oct. 2020

\subsubsection{Eschen-Triebsterben - eine schwerwiegende Bedrohung der Biodiversität in Auwäldern}

1. Bartha B, Mayer A, Lenz HD (n.d.). Acceleration of Ash Petiole Decomposition to Reduce Hymenoscyphus fraxineus Apothecia Growth-a Feasible Method for the Deprivation of Fungal Substrate.

2. Enderle R, Bußkamp J, Metzler B (2017) Growth performance of dense natural regeneration of Fraxinus excelsior under attack of the ash dieback agent Hymenoscyphus fraxineus. Baltic Forestry, 23(1) 218-228 
3. Grosdidier M, Scordia T, Ioos R, Marçais B (2020) Landscape epidemiology of ash dieback. Journal of Ecology 108(5) 1789-1799. https://doi.org/10.1111/1365-2745.13383

4. Havrdová L, Zahradník D, Romportl D et al. (2017) Environmental and Silvicultural Characteristics Influencing the Extent of Ash Dieback in Forest Stands. Baltic Forestry (Vol. 23).

5. Skovsgaard JP, Wilhelm GJ, Thomsen IM et al. (2017) Silvicultural strategies for Fraxinus excelsior in response to dieback caused by Hymenoscyphus fraxineus. Forestry: An International Journal of Forest Research 90(4) 455-472. https://doi.org/10.1093/forestry/cpx012

6. Timmermann V, Nagy NE, Hietala AM et al. (2017) Progression of ash dieback in Norway related to tree age, disease history and regional aspects. Baltic Forestry 23(1) 150-158

\subsubsection{Maßnahmen gegen die Ausbreitung von Phytophthora in Fluss begleitenden Wäldern}

1. Dalio RJD, Fleischmann F, Humez M, Osswald W (2014) Phosphite Protects Fagus sylvatica Seedlings towards Phytophthora plurivora via Local Toxicity, Priming and Facilitation of Pathogen Recognition. PLoS ONE 9(1) e87860.

https://doi.org/10.1371/journal.pone.0087860

2. Jung T, Blaschke M (2004) Phytophthora root and collar rot of alders in Bavaria: Distribution, modes of spread and possible management strategies. Plant Pathology 53(2) 197-208. https://doi.org/10.1111/j.0032-0862.2004.00957.X

3. Jung T, Orlikowski L, Henricot B et al. (2016) Widespread Phytophthora infestations in European nurseries put forest, semi-natural and horticultural ecosystems at high risk of Phytophthora diseases. Forest Pathology 46(2) 134-163. https://doi.org/10.1111/ efp.12239

\subsection{Baumartenportraits}

1. Barsig, M. (2004) Literaturrecherche. Vergleichende Untersuchungen zur ökologischen Wertigkeit von Hybrid- und Schwarzpappeln. Literarturstudie TU Berlin. $32 \mathrm{~S}$,

http://www.tu-berlin.de/fileadmin/f12/Downloads/kubus/30 Pappelvgl Endfassung 1 .pdf accessed 17.08.2020

2. Beck, P., Caudullo, G., Tinner, W., de Rigo, D. (2016) Fraxinus excelsior in Europa: Verbreitung, Lebensraum, Nutzung und Bedrohungen. In: San-Miguel-Ayanz, J., de Rigo, D., Caudullo, G., Houston Durrant, T., Mauri, A. (Eds.), European Atlas of Forest Tree Species. Publ. Off. EU, Luxemburg, pp. e0181c0+

3. BFW (2019) Österreichs Baumarten Fächer für unterwegs. Bundesforschungs- und Ausbildungszentrum für Wald, Naturgefahren und Landschaft Österreich (BFW), Wien.

4. Binder, F. \& Hofmann, M. (2015) Hybridpappel (Populus x canadensis Mönch; Syn. Populus x euramericana Guinier). In: Vor, T.; Spellmann, H.; Bolte, A.; Ammer, C. (Hrsg.): Potenziale und Risiken eingeführter Baumarten. Baumartenportraits mit naturschutzfachlicher Bewertung. Göttinger Forstwissenschaften, Band 7, 155-166

5. Bohn, U., et al. (2000/2003) Karte der natürlichen Vegetation Europas / Map of the Natural Vegetation of Europe. Maßstab / Scale $1: 2500$ 000. Münster (Landwirtschaftsverlag)

6. CAB International (2020) Robinia pseudoacacia (Schwarzheuschrecke). Datasheet. Invasive Species Compendium. https://www.cabi.org/isc/datasheet/47698, Zugriff am 06.08.2020

7. Carl, Christin (2018): Kurzportrait Robinie (Robinia pseudoacacia). https://www.waldwissen.net/waldwirtschaft/waldbau/wuh_robinie/index_DE, Zugriff am 11.08 .2020

8. Caudullo, G. Houston Durrant, T. (2016) Fraxinus angustifolia in Europe: distribution, habitat, usage and threats. In: San-MiguelAyanz, J. de Rigo, D., Caudullo, G., Houston Durrant, T., Mauri, A. (Eds.), European Atlas of Forest Tree Species. Publ. Off. EU, Luxemburg, pp. e0101d2+

9. Caudullo, G., de Rigo, D. (2016) Ulmus - Ulmen in Europa: Verbreitung, Lebensraum, Nutzung und Bedrohungen. In: San-Miguel-Ayanz, J., de Rigo, D., Caudullo, G., Houston Durrant, T., Mauri, A. (Eds.), European Atlas of Forest Tree Species. Publ. Off. EU, Luxemburg, pp. e01bd40+

10. Caudullo, G., de Rigo, D. (2016) Populus alba in Europa: Verbreitung, Lebensraum, Nutzung und Bedrohungen. In: San-MiguelAyanz, J., de Rigo, D., Caudullo, G., Houston Durrant, T., Mauri, A. (Eds.), European Atlas of Forest Tree Species. Publ. Off. EU, Luxemburg, pp. e010368+ 
11. Collin, E. (2003) EUFORGEN Technical Guidelines for genetic conservation and use for European white elm (Ulmus laevis). International Plant Genetic Resources Institute, Rome, Italy. 6 pages

12. Cronk Q. Ruzzier E., Belyaeva I., Percy D. (2015) Salix transect of Europe: latitudinal patterns in willow diversity from Greece to arctic Norway. Biodiversity Data Journal 3: e6258. doi: 10.3897/BDJ.3.e6258

13. de Rigo, D., Enescu, C. M., Houston Durrant, T.,Caudullo, G. (2016) Populus nigra in Europe: distribution, habitat, use and threats. In: San-Miguel-Ayanz, J., de Rigo, D., Caudullo, G., Houston Durrant, T., Mauri, A. (Eds.), European Atlas of Forest Tree Species. Publ. Off. EU, Luxemburg, pp. e0182a4+

14. Duke, J. (1983) Handbook of Energy Crops. https://www.hort.purdue.edu/newcrop/duke_energy/Alnus glutinosa.html, Zugriff am 12.08.2020

15. Enescu, C. M., Houston Durrant, T., de Rigo, D., Caudullo, G. (2016) Salix caprea in Europe: distribution, habitat, use and threats. In: San-Miguel-Ayanz, J., de Rigo, D., Caudullo, G., Houston Durrant, T., Mauri, A. (Eds.), European Atlas of Forest Tree Species. Publ. Off. EU, Luxemburg, pp. e01322d+

16. FRAXIGEN. 2005. Eschenarten in Europa: biologische Merkmale und praktische Richtlinien für eine nachhaltige Nutzung. Oxford Forestry Institute, University of Oxford, UK. $128 \mathrm{pp}$

17. Glenz, C; chlaepfer, R; Iorgulescu, I; Kienast, F. (2006) Flooding tolerance of Central European tree and shrub species, Forest Ecology and Management, Volume 235, Issues 1-3, Pages 1-13, ISSN 0378-1127, https://doi.org/10.1016/j.foreco.2006.05.065.

18. Global Invasive Species Database http://issg.org/database/species/ecology.asp?si=1669\&fr=1\&sts=\&lang=EN) - Zugriff am 20.07.2020

19. Heinze, B. (2016) Wasser.Wald: Auwaldbewirtschaftung zwischen Holzproduktion, neuen Schädlingen und Krankheiten sowie Naturschutz. BFW-Praxisinformation 40: 6 - 8,

https://www.waldwissen.net/wald/naturschutz/gewaesser/bfw_auwaldbewirtschaftung/index_DE/printerfriendly? accessed 17.08.2020

20. Houston Durrant, T., de Rigo, D., Caudullo, G. (2016) Salix alba in Europe: distribution, habitat, usage and threats. In: San-MiguelAyanz, J., de Rigo, D., Caudullo, G., Houston Durrant, T., Mauri, A. (Eds.), European Atlas of Forest Tree Species. Publ. Off. EU, Luxemburg, pp. e01153e+

21. 21. Houston Durrant, T., de Rigo, D., Caudullo, G., (2016) Alnus glutinosa in Europe: distribution, habitat, use and threats. In: San-Miguel-Ayanz, J., de Rigo, D., Caudullo, G., Houston Durrant, T., Mauri, A. (Eds.), European Atlas of Forest Tree Species. Publ. Off. EU, Luxemburg, pp. e01f3c0+

22. http://www.energiewald.org/?Daten_\%26amp\%3B_Fakten:Standort_und_Baumartenwahl, Zugriff 17.08.2020

23. Jaeger, C. (2008) Ökophysiologische Untersuchungen zur Hochwassertoleranz der Gemeine Esche (Fraxinus excelsiorL.) - Einfluss der Wurzelzonenhypoxie auf zentrale Parameter des C-Stoffwechsels. Fakultät für Forst- und Umweltwissenschaften,AlbertLudwigs-Universit at Freiburg im Breisgau, Deutschland

24. Jaeger, C. (2009) Unterschiede im C-Stoffwechsel von Eschenarten und -provenienzen als Folge von Wurzelsauerstoffentzug durch Staunässe. Journal of Experimental Botany, Vol. 60, No. 15, pp. 4335-4345, 2009 doi:10.1093/jxb/erp268

25. Kajba D. und J. Gračan. (2003) EUFORGEN technical guidelines for genetic conservation and use for black alder (Alnus glutinosa). International Plant Genetic Resources Institute, Rome, Italy. 4 pages

26. Konrad, H. (Hrsg.) (2020) Esche in Not. http://www.esche-in-notat/index.php/problematik, 10.07.2020

27. Kremer, D. et al. (2008) Distribution and management of black walnut (Juglans nigra L.) in Croatia. Periodicum Biologorum. VOL. 110, Nr. 4, 317-321

28. Markus-Michalczyk, H. et al. (2014) Salt intrusion in tidal wetlands: Salt intrusion in tidal wetlands: European willow species tolerate oligohaline conditions. Estuarine, Coastal and Shelf Science, Band 136, S. 35-42. doi 10.1016/j.ecss.2013.11.008

29. Mühlethaler, U. (2010): Eine Baumart gibt zu diskutieren. Mit Robinie in die Zukunft - oder den Neophyten bekämpfen? Wald Holz 91, 6: 35-38. https://www.waldwissen.net/waldwirtschaft/waldbau/ws__robinie/index_DE, accessed 11.08.2020

30. Nicolescu, V., Rédei, K., Vor, T. et al. (2020) A review of black walnut (Juglans nigra L.) ecology and management in Europe. Trees. https://doi.org/10.1007/s00468-020-01988-7

31. Palancean, I., Alba, N., Sabatti, M. und de Vries, S.M.G. (2018) EUFORGEN technical guidelines for genetic conservation and use for white poplar (Populus alba), European Forest Institute. 6 pages.

32. Pliûra, A.; Heuertz, M. (2003) EUFORGEN technical guidelines for genetic conservation and use for common ash (Fraxinus excelsior), International Plant Genetic Resources Institute, Rome, Italy. 6 pages.

33. Rédei, K.; Keserü, ZS.; Csiha, I.; Rásó, J.; Honfy, V. (2017) Plantagen-Waldbau von Robinie (Robinia pseudoacacia L.) Kultivaren in Ungarn - Eine Übersicht. South-east Eur for 8 (2): 151-156. DOI: https://doi.org/10.15177/seefor.17-11 
34. Rédei, K.; Takács, M.; Kiss, T. \& Keserü, Z. (2019) Ecology and Management of Black Walnut (Juglans nigra L.) in Hungary. South-east Eur for 10 (2): 187-191. DOI: https://doi.org/10.15177/seefor:19-12

35. Russell, K. (2003) EUFORGEN technical Guidelines for genetic conservation and use for wild cherry (Prunus avium). International Plant Genetic Resources Institute, Rome, Italy. 6 pages.

36. Schütt, P., Weisgerber, H., Lang, U. M., Roloff, A., Stimm, B. (2006) Enzyklopädie der Holzgewächse - Handbuch und Atlas der Dendrologie. ecomed Medizin, Verlagsgruppe Hüthig Jehle Rehm GmbH, Landsberg am Lech.

37. Sitzia, T., Cierjacks, A., de Rigo, D., Caudullo, G. (2016) Robinia pseudoacacia in Europa: Verbreitung, Lebensraum, Nutzung und Bedrohungen. In: San-Miguel-Ayanz, J., de Rigo, D., Caudullo, G., Houston Durrant, T., Mauri, A. (Eds.), European Atlas of Forest Tree Species. Publ. Off. EU, Luxemburg, pp. e014e79+

38. Starfinger, U. \& Kowarik, I. (2011) Populus x canadensis. In: Arten-Handbuch - Portraits wichtiger invasiver und potenziell invasiver Pflanzen- und Tierarten. Bundesamt für Naturschutz. Neobiota.de.

https://neobiota.bfn.de/handbuch/gefaesspflanzen/populus-x-canadensis.html Accessed 17.08.2020

39. Valenta, V., Moser, D., Kapeller, S. \& Essl, F. (2016) Ein neuer Forstschädling in Europa: A review of Emerald ash borer (Agrilus planipennis) invasion. Journal of Applied Entomology. 10.1111/jen.12369.

40. Vanden Broeck, A. (2003) EUFORGEN technical guidelines for genetic conservation and use for European black poplar (Populus nigra). International Plant Genetic Resources Institute, Rome, Italy. 6 pages.

41. Vítková, M. et al. (2016) Black locust (Robinia pseudoacacia) beloved and despised: A story of an invasive tree in Central Europe. Forest Ecology and Management. 384 (2017) 287-302. http://dx.doi.org/10.1016/j.foreco.2016.10.057

42. Walentowski H., Falk W., Mette T., Kunz J., Bräuning A., Meinardus C., Zang Ch., Sutcliffe L., Leuschner Ch., (2017) Assessing future suitability of tree species under climate change by multiple methods: a case study in southern Germany. Ann. For. Res. 60(1): 101-126.

43. Ward, J.V. et al. (2002) Riverine landscape diversity. Freshwater Biology, Band 47, 4th edition. https://doi.org/10.1046/j.1365-2427.2002.00893.x

44. Welk, E., de Rigo, D., Caudullo, G. (2016) Prunus avium in Europe: distribution, habitat, usage and threats. In: San-Miguel-Ayanz, J., de Rigo, D., Caudullo, G., Houston Durrant, T., Mauri, A. (Eds.), European Atlas of Forest Tree Species. Publ. Off. EU, Luxemburg, pp. e01491d+

45. Williams, R.D. () Juglans nigra L. - Black Walnut. U.S. Department of Agriculture, Forest Service. https://www.srs.fs.usda.gov/pubs/misc/ag_654/volume 2/juglans/nigra.htm, Zugriff am 06.08.2020

46. Ziemiańska, M. \& Kalbarczyk, R. (2018) Biometrics of tree-ring widths of (Populus X canadensis Moench) and their dependence on precipitation and air temperature in south-western Poland. In: Holzforschung 63(1):2018(1)

\section{Glossar}

1. Finkeldey R (1993) Die Bedeutung allelischer Profile für die Konservierung genetischer Ressourcen bei Waldbäumen. Goett. Forstgenet. Bericht 14:176p.

2. FRAXIGEN (2005) Ash species in Europe: biological characteristics and practical guidelines for sustainable use. Oxford Forestry Institute, University of Oxford, UK

3. Rohmeder E (1972) Das Saatgut in der Forstwirtschaft. Parey Verlag, Berlin

4. Vidaković M (n.d.). Četinjače - morfologija i varijabilnost. Biblioteka znanstvenih radova, JAZU, Sveučilišna naklada Liber, Zagreb. 


